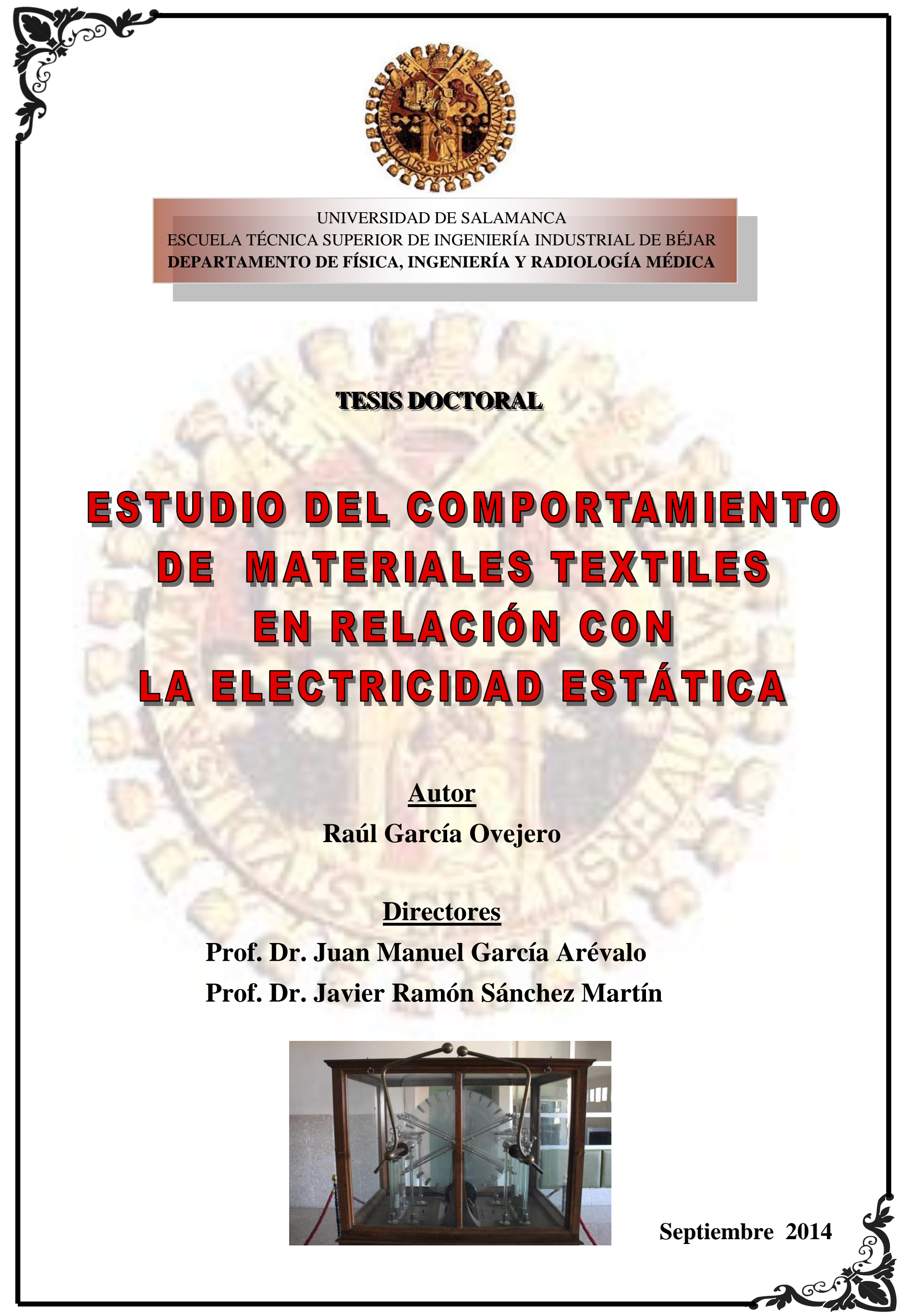




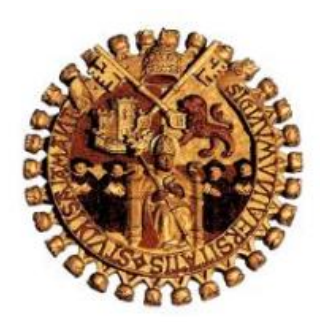

UNIVERSIDAD DE SALAMANCA

ESCUELA TÉCNICA SUPERIOR DE INGENIERÍA INDUSTRIAL DE BÉJAR DEPARTAMENTO DE FÍSICA, INGENIERÍA Y RADIOLOGÍA MÉDICA

\author{
TESIS DOCTORAL
}

\title{
ESTUDIO DEL COMPORTAMIENTO \\ DE MATERIALES TEXTILES \\ EN RELACIÓN CON LA \\ ELECTRICIDAD ESTÁTICA
}

\author{
$\underline{\text { Autor }}$ \\ Raúl García Ovejero \\ $\underline{\text { Directores }}$ \\ Prof. Dr. Juan Manuel García Arévalo \\ Prof. Dr. Javier Ramón Sánchez Martín
}

Béjar, Septiembre 2014 
El Prof. Dr. Juan Manuel García Arévalo, Profesor Titular de Universidad del Departamento de Física, Ingeniería y Radiología Médica de la Universidad de Salamanca y el Prof. Dr. Javier Ramón Sánchez Martín, Catedrático de Escuela Universitaria del Departamento de Ingeniería Química y Textil de la Universidad de Salamanca.

\section{CERTIFICAN:}

Que Raúl García Ovejero, Ingeniero Industrial, ha realizado bajo su dirección el trabajo de investigación titulado "Estudio del comportamiento de materiales textiles en relación con la electricidad estática", que presenta para optar al grado de Doctor.

Y para que conste, expide el presente certificado en Béjar a 18 de septiembre de 2014. 
A mi esposa Beatriz

y mis hijas Sofía y Lorena, para que perdonen mi falta de atención en estos años A mis padres $y$ hermanos 


\section{Agradecimientos}

"Es de importancia para quien desee alcanzar una certeza en su investigación, el saber dudar a tiempo" de Aristóteles. Esta cita refleja el desarrollo de la presente tesis doctoral. Son muchas las horas de trabajo dedicadas a ella y no pocas las dudas surgidas en su transcurso. Sin duda alguna, todas las personas que me han apoyado en estos cuatro años lo han hecho posible.

En primer lugar quisiera expresar mi mayor agradecimiento a los dos directores de esta tesis doctoral, los profesores Dr. Juan Manuel García Arévalo y Dr. Javier Ramón Sánchez Martín, por el apoyo incondicional mostrado en todo momento y principalmente por la amistad que me brindaron.

Al tratarse de un trabajo de índole interdisciplinar, han sido muchos los compañeros de la Escuela Técnica Superior de Ingeniería Industrial de Béjar que me han ayudado en la resolución de los problemas que me han surgiendo. Por lo que quisiera hacer extensible mi agradecimiento a todos los miembros de las distintas áreas que formamos parte de este campus de la Universidad de Salamanca.

La presente tesis doctoral se ha desarrollado en dos laboratorios de la ETSII de Béjar, uno del área de Electricidad y el otro del área Textil. A todas estas personas que trabajan en estas áreas quisiera agradecer su generosa ayuda y colaboración. En particular al Dr. Juan Ovejero Escudero, que me ha prestado una ayuda inestimable y que viene de lejos. Su gran experiencia científica, junto a la de los dos directores, ha contribuido a orientar la tesis por el camino correcto. En especial mi gratitud a todos los miembros del Área de Ingeniería Eléctrica de la Universidad de Salamanca, que me han permitido trabajar en un ambiente de tolerancia y armonía.

Esta gratitud se extiende también al departamento de Física, Ingeniería y Radiología Médica, del que el Área de Ingeniería Eléctrica forma parte, 
especialmente a su equipo directivo y a los servicios administrativos, en los que siempre he encontrado disposición de ayuda.

A las empresas que nos han facilitado los tejidos y el asesoramiento necesario para la realización de la tesis.

A la empresa suiza ROTHSCHILD, por la reparación del voltímetro estático. Sin este aparato no se hubiera podido realizar la tesis.

A la Fundación "En Memoria de D. Samuel Solórzano Barruso", por su contribución económica (proyectos de Ref. FS/20-2011 y Ref. FS/20-2012), sin la cual no hubiera sido posible la realización de la investigación que ha dado lugar a esta tesis.

Muchas gracias a todos. 


\section{$\underline{\text { ÍNDICE }}$}

\section{CAPÍTULO 1. Introducción y objetivos}

1.0. Resumen

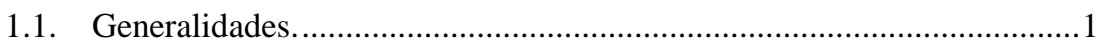

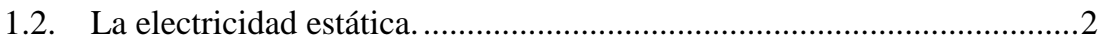

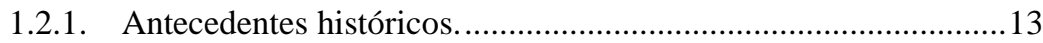

1.2.2. Factores que influyen en la electricidad eléctrica.....................21

1.2.3. Trastornos ocasionados por la electricidad estática...................29

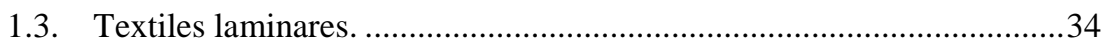

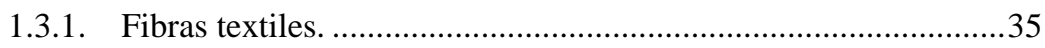

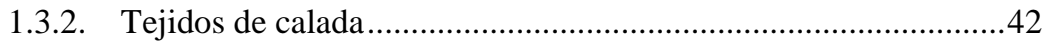

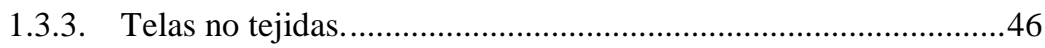

1.4. Evaluación de la electricidad estática en los materiales textiles ...........47

1.4.1. Evaluación de la generación de la electricidad estática en los materiales textiles.

1.4.2. Evaluación de la disipación de la electricidad estática en los materiales textiles.

1.5. Problemática de la evaluación de la electricidad estática......................52

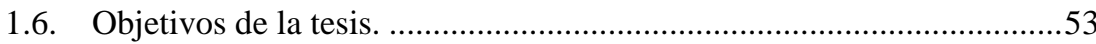

\section{CAPÍTULO 2. Fundamento teórico: Medida de laresistencia eléctrica de los materiales textiles}

2.0. Resumen

2.1. Clasificación de los materiales desde el punto de vista eléctrico .............55

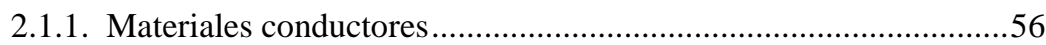

2.1.2. Materiales semiconductores. ...................................................57

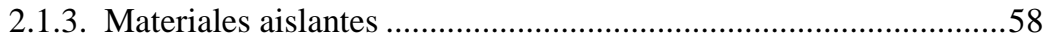

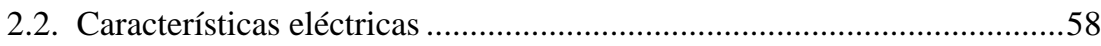


2.3. Métodos de ensayo para el cálculo de la resistencia eléctrica .................63

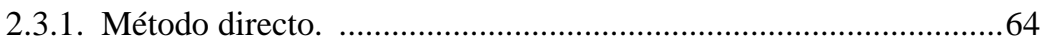

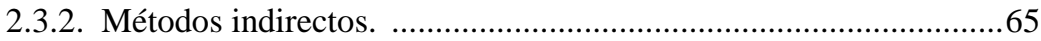

2.3.2.1. Procedimiento voltiamperimétrico ..........................................66

2.3.2.2. Procedimiento por desviación directa. ......................................68

2.3.2.3. Procedimiento por voltímetro estático. .....................................70

2.3.2.3.1. Procedimiento por comparación de corriente. .....................70

2.3.2.3.2. Procedimiento por descarga de condensador. ...................72

\section{CAPÍTULO 3. Procedimiento experimental}

3.0. Resumen

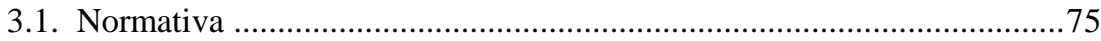

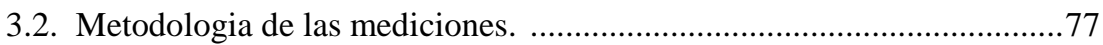

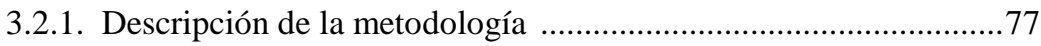

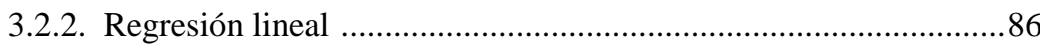

3.2.3. Coeficiente de correlación................................................................8 88

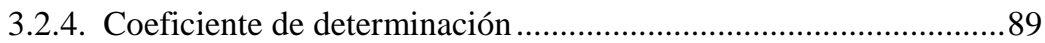

3.3. Análisis de los materiales textiles. ...........................................................90

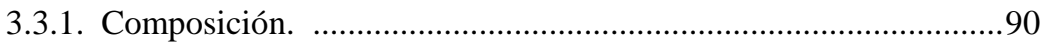

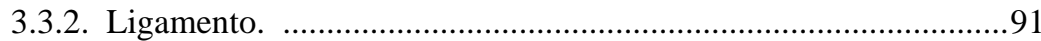

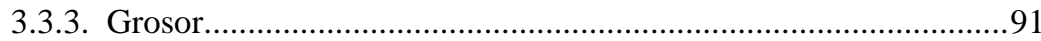

3.3.4. Título o masa lineal de los hilos (de urdimbre o trama) ...............92

3.3.5. Masa laminar o peso por unidad de superficie ...............................93

3.3.6. Densidad (de urdimbre o trama)...................................................94

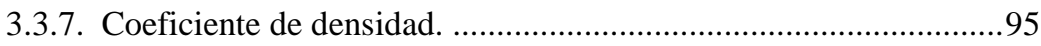

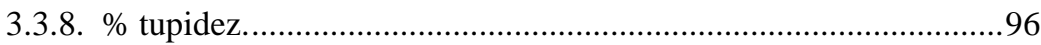

3.4. Diseño y construcción del equipo de ensayo y procesamiento de datos .97

3.4.1. Equipo de medición y funcionamiento. ........................................98

3.4.2. Equipo de acondicionamiento ambiental. .................................. 102

3.4.3. Equipo de captación de datos. ................................................. 108 
3.4.4. Procesamiento de datos: LabVIEW.

3.4.5. Problemática surgida en la construcción y conexionado de las partes del equipo. Funcionamiento general.

\section{CAPÍTULO 4 . Resultados y discusión}

4.0. Resumen

4.1. Introducción.

4.1.1. Tejido sin tratamiento previo de lavado

4.1.2. Tejido con tratamiento previo de lavado

4.2. Análisis de las características eléctricas a través de variables externas a los tejidos.

4.3. Análisis de las características eléctricas según la naturaleza del material.

4.3.1. Tejido de algodón. 161

4.3.2. Tejido de lana. 167

4.3.3. Tejido compuesto por Nomex-Kevlar-fibra antiestática. 176

4.34.4. Comparativa según su composición.

CAPÍTULO 5. Conclusiones generales y líneas de investigación futura ..193

5.1. Conclusiones 193

5.2. Líneas de investigación futuras. 195

CAPÍTULO 6. Bibliografía

Anexo 1

Anexo 2

Anexo 3

Anexo 4

Glosario 


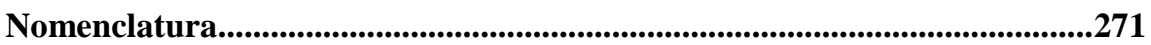

Relación de figuras .......................................................................................................2275

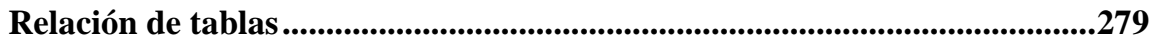




\section{CAPÍTULO 1 \\ INTRODUCCIÓN Y OBJETIVOS}

\section{Índice}

1.0. Resumen

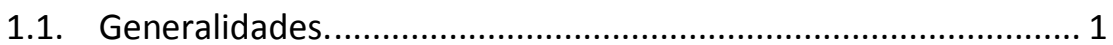

1.2. La electricidad estática............................................................ 2

1.2.1. Antecedentes históricos............................................... 13

1.2.2. Factores que influyen en la electricidad eléctrica.............. 21

1.2.3. Trastornos ocasionados por la electricidad estática......... 29

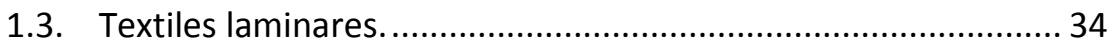

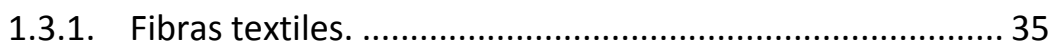

1.3.2. Tejidos de calada .......................................................... 42

1.3.3. Telas no tejidas............................................................... 46

1.4. Evaluación de la electricidad estática en los materiales textiles 47

1.4.1. Evaluación de la generación de la electricidad estática en los materiales textiles.

1.4.2. Evaluación de la disipación de la electricidad estática en los materiales textiles.

1.5. Problemática de la evaluación de la electricidad estática...........52

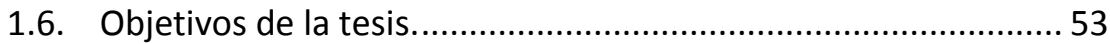




\section{CAPÍTULO 1 \\ INTRODUCCIÓN Y OBJETIVOS}

\subsection{Resumen.}

En este capítulo inicial se realiza un breve repaso histórico de la evolución del estudio de la electricidad estática, tema que en la actualidad despierta interés en distintos ámbitos de la industria, en especial en el textil. En efecto, desde la masiva difusión de las fibras sintéticas en la década de los sesenta del siglo pasado, se incrementaron mucho los problemas consecuencia de este fenómeno, producidos en los procesos de fabricación, en general como consecuencia de la fricción contra otros materiales, así como durante el uso de tejidos de estas fibras como vestimenta,

A continuación se realiza una descripción detallada de la constitución de los tejidos, con objeto de poder determinar los factores principales que pueden incidir en la producción, acumulación y descarga de la electricidad estática.

Por todo ello, consideramos relevante realizar el estudio y la evaluación de los materiales textiles en relación con la electricidad estática. Se pretende conocer los factores que determinan e influyen en este fenómeno y la forma en que lo hacen, con objeto de concretar su comportamiento.

Por último, este capítulo finaliza con la enumeración de los Objetivos de la tesis. 


\subsection{Generalidades.}

El comportamiento eléctrico de los textiles es un tema de gran interés para la industria textil, por las diversas consecuencias que puede tener, especialmente desde el punto de vista de la seguridad en la industria y de la comodidad en el uso de la vestimenta. Después de estudiar la bibliografía existente sobre este campo, consideramos que hay pocos estudios científicos al respecto y, por ello, decidimos realizar la investigación que ha dado lugar al trabajo que se presenta. Dada la naturaleza de este trabajo, que afecta tanto al sector eléctrico como al textil, en el equipo multidisciplinar que lo ha estudiado participan miembros de las áreas de conocimiento de Ingeniería Eléctrica y de Ingeniería Textil de la Universidad de Salamanca.

Entre los fenómenos eléctricos encontramos muchos que son útiles para el hombre, pero también los hay que presentan aspectos negativos. Existe una preocupación especial por las cuestiones relacionadas con la electricidad estática, tanto en las referentes a su generación como en su disipación, entendiendo por electricidad estática el desequilibrio de cargas eléctricas en un material, ya sea en su estructura interna o sobre su superficie [1]. Este desequilibrio de cargas se mantiene hasta que éstas son capaces de moverse, bien por medio de una corriente eléctrica o bien cuando se produce el fenómeno de descarga eléctrica. En el campo de la electricidad, la electricidad estática es nombrada así por contraste con la corriente eléctrica que discurre a través de cables u otros conductores [2]. Así pues, la "electrostática" estudiaría las fuerzas que actúan entre cargas eléctricas en reposo, en contraposición a la "electrodinámica" que estudia las cargas en movimiento [3].

Los problemas asociados a la electricidad estática en la industria textil son numerosos y este fenómeno se observa en los materiales textiles tanto en su procesamiento como en su uso. Hay, por tanto, dos tipos de problemas asociados a 
los materiales textiles: uno en la fase de producción de los hilos y las telas, y otro al usarlas. Por eso, a lo largo del tiempo, el personal científico textil ha estado preocupado por la necesidad de controlar tanto la generación como la descarga de la electricidad estática durante la fabricación de los productos textiles modernos y así acelerar los procesos textiles [4]. Los problemas se han agudizado en los últimos años debido a la introducción de nuevas fibras sintéticas y al empleo de máquinas cada vez más rápidas [5]. En cuanto al consumidor, es conocido que especialmente las fibras sintéticas se cargan de electricidad estática por frotamiento, descargándose a través de un material conductor cuando lo toca una persona que viste una prenda confeccionada con ellas, con el consiguiente sobresalto.

A pesar de estos aspectos negativos, la electricidad estática puede ser beneficiosa y es aprovechada actualmente en ciertas circunstancias como, por ejemplo, en algunos procesos de fabricación textiles tales como en el flocado o en los procesos de separación de polvo de una corriente de aire mediante filtros electrostáticos.

Por todo ello y dada la creciente importancia de la electricidad estática en el mundo textil, una mejor comprensión de esta propiedad y sus efectos es importante para el desarrollo de dicha industria.

\subsection{La electricidad estática.}

La electricidad estática es la primera forma de electricidad producida por el hombre y ya fue descrita por Tales de Mileto hacia el año 600 a.C., que la definió como una carga estacionaria.

La investigación científica sobre este fenómeno comenzó cuando se pudieron construir máquinas capaces de generar electricidad estática, como el 
generador electrostático construido por Otto von Guericke en el siglo XVII. La figura 1.1 muestra una de estas máquinas, que data de 1907 y es obra de D. Eugenio Cuadrado, sacerdote y profesor de física, química y matemáticas del seminario de Zamora. Está expuesta en la primera planta de la ETSII de Béjar.

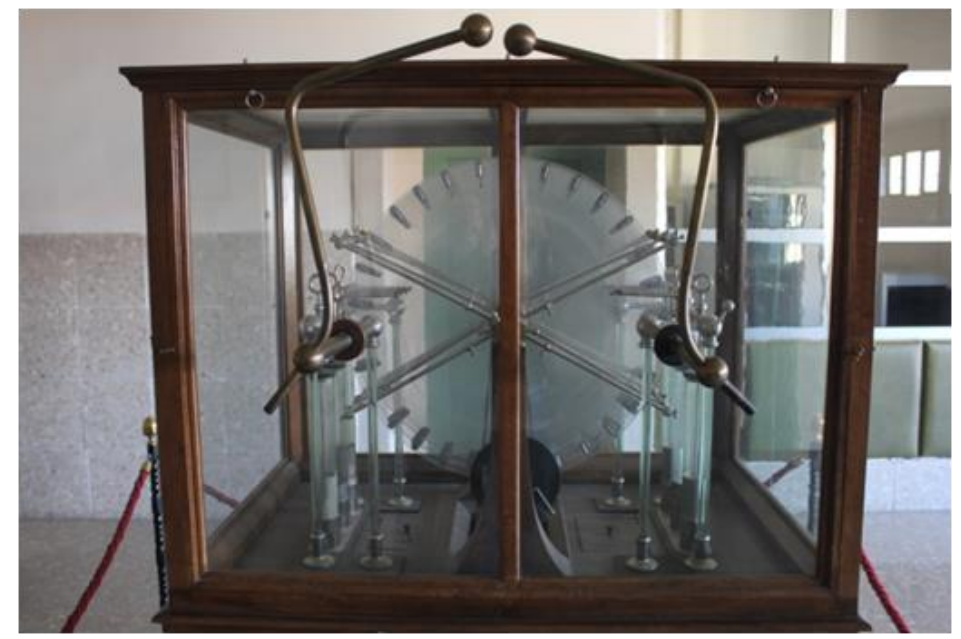

Figura 1. 1. Generador electrostático.

El desarrollo de estas máquinas electrostáticas había comenzado en el siglo XVIII, cuando se convirtieron en instrumentos fundamentales en los estudios acerca de la entonces nueva ciencia de la electricidad. Los generadores electrostáticos funcionan mediante el uso de energía manual para transformar trabajo mecánico en energía eléctrica. Estos dispositivos, al mover la manivela provocan la generación de cargas electrostáticas de signos opuestos y su acumulación en los dos conductores que posee la máquina; trabajando en base a placas en movimiento, tambores o cintas se eleva la carga eléctrica del electrodo para obtener un mayor potencial [6].

Hasta este siglo se trataba este tipo de formación de cargas de manera diferente, ya que se creía que estas cargas eran distintas a las originadas por otros 
métodos. Sin embargo, Michael Faraday demostró con sus experimentos, a partir de 1832, que la naturaleza de lo que hasta entonces se pensaba que eran diferentes tipos de electricidad, es decir, la electricidad inducida a través de un imán, la producida por una batería eléctrica y la generada por las cargas electrostáticas, eran del mismo tipo. A partir de este momento el estudio de la electricidad estática quedó dentro del de la electricidad en general y, como es conocido, la electricidad estudia el movimiento de las cargas y éstas forman parte de la estructura de la materia. Esta materia está formada por átomos, que es la parte más pequeña que puede existir de un cuerpo simple o elemento, y estos átomos están formados por el núcleo (protones y neutrones) y la corteza (electrones) [7]. En la materia, el número de protones de un átomo es igual al número de electrones, siendo éste neutro en conjunto; pero un átomo puede ganar o perder electrones, que es la única partícula que tiene a la vez carga y movimiento, y quedar cargado eléctricamente. Este exceso o defecto de electrones es lo que se denomina carga eléctrica del cuerpo, y se mide en culombios (C). La "electrización" es el fenómeno por el cual los cuerpos adquieren carga eléctrica. Pero en este proceso hay trasferencia de electrones y los que gana un cuerpo son porque los pierde otro, pero no se crean electrones nuevos. Es decir, la carga eléctrica total del proceso es constante y por tanto se conserva [8].

Todo cuerpo tiende al equilibrio electrostático, es decir, al estado neutro. La electricidad estática engloba el periodo desde la ganancia de las cargas que adquiere un material hasta que éste las pierde, definiéndose estas cargas como electrostáticas, ya que permanecen un determinado tiempo en el cuerpo debido a su no movilidad o movilidad lenta [9]. El proceso se puede estructurar en tres fases:

- Fase primera, o de generación de cargas electrostáticas.

- Fase segunda, o de acumulación de cargas electrostáticas.

- Fase tercera, o de disipación de cargas electrostáticas. 
La primera fase, la generación de cargas electrostáticas, se produce por aproximación, contacto o fricción de dos materiales y posterior separación de ambos. Esto da origen al traspaso de cargas negativas (electrones de los átomos de los elementos químicos) o/y positivas (protones del núcleo atómico privados de los electrones de la última capa) entre los materiales. Si esto se produce, estamos ante el inicio de la electricidad estática y su duración depende del tiempo en que exista transferencia de carga eléctrica. Este origen puede ser debido a tres causas distintas [10], que se revisan a continuación.

La primera de ellas, y la más común, se produce cuando dos materiales diferentes entran en contacto y se frotan. La carga originada de esta forma se llama carga triboeléctrica, y se pueden formar en situaciones como las mostradas en la figura 1.2.
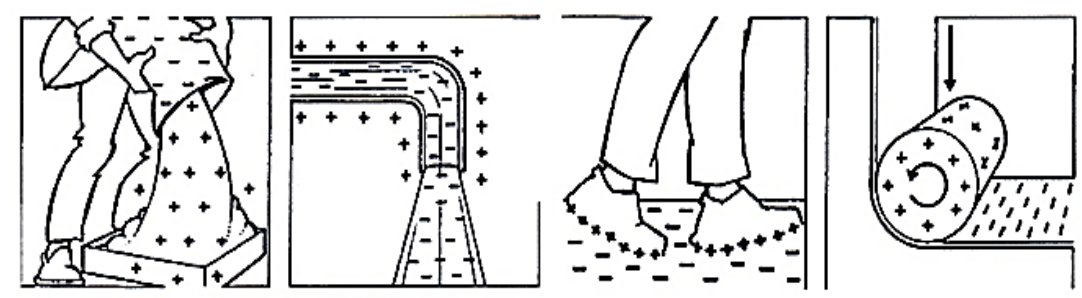

Figura 1. 2. Distintas formas de formación de las cargas por triboelectricidad [11].

En todas las situaciones que se indican en la figura 1.2. se observa la creación de cargas de polaridades opuestas. Para determinar la tendencia a ganar o ceder electrones de los materiales y la magnitud o cantidad de carga originada en ellos se establecieron las denominadas "series triboeléctricas".

La primera serie triboeléctrica fue desarrollada en 1757 por Wilcke [12], y a ésta le han seguido varias más, de otros autores. A pesar de sus más de 255 años de existencia, siguen sujetas a modificaciones y a veces existen variaciones según la 
fuente bibliográfica consultada, por lo que siguen siendo objeto de continua investigación [13].

En la tabla 1.1, se exponen varias series triboeléctricas que han sido realizadas por diferentes autores.

\begin{tabular}{|c|c|c|c|}
\hline \multirow{18}{*}{ Positivo (+) } & Lana & Vidrio & Lana \\
\hline & Lana Hercosett & Nailon 6.6 & Nailon \\
\hline & Nailon 6.6 & Nailon 6 & Viscosa \\
\hline & Nailon 6 & Lana & Algodón \\
\hline & Seda & Seda & Seda \\
\hline & Celulosa regenerada & Vis cosa & Acetato \\
\hline & Algodón & Vinylon (PVAlc) & Lucite (PMMA) \\
\hline & Poly (vinyl alcohol) (PVAlc) & Acrilan (Acrílico) & PVAlc \\
\hline & Lana clorada & Acero & Dacron (Poliester) \\
\hline & Triacetato de celulosa & Algodón & Orlon (Acrílico) \\
\hline & Alginato de calcio & Orlon (Acrílico) & PVC \\
\hline & Acrílico & Acetato & Dynel (VC/AN) \\
\hline & Acetato de celulosa & Dynel (VC/AN) & Velon (VDC/VC) \\
\hline & Polytetrafluoroethylene (PTFE) & Saran (PVDC) & Polietileno \\
\hline & Polietileno & Rhovyl (PVC) & Teflón (PTFE) \\
\hline & Polipropileno & Caucho & \\
\hline & Poly (ethylene terephthalate) & & \\
\hline & Poly (1,4-butyleneterephthalate) & & \\
\hline \multirow{2}{*}{ Negativo (-) } & Modacrílico & & \\
\hline & Clorofibra & & \\
\hline
\end{tabular}

Tabla 1. 1. Series triboeléctricas de acuerdo con la bibliografía $[14,15,16]$.

La magnitud de la carga electrostática está relacionada con la posición o distancia relativa entre sí de los materiales en la serie, y su signo está determinado por la propensión de un material a ceder o ganar electrones, que es lo que en realidad indica tal serie. Así, por ejemplo, atendiendo a la serie triboeléctrica de Wilcke (tercera columna), el frotamiento de una pieza de teflón con un trozo de lana y su posterior separación dará lugar a una carga electrostática negativa sobre la pieza de teflón y otra de igual magnitud pero positiva sobre la de lana. La misma experiencia con materiales de algodón y PVC daría cargas positivas y negativas 
respectivamente, pero con magnitud inferior al experimento anterior, es decir, hay menos cantidad de carga eléctrica.

Esta forma de generación de electricidad estática es la más corriente, pero otra forma posible para que comience se daría al aproximarse o entrar en contacto dos materiales, uno de los cuales posee carga eléctrica. Esta forma de generación de carga en un cuerpo se denomina "generación electrostática inductiva" y se produce cuando un objeto cargado repele o atrae los electrones de la superficie de un segundo objeto. Esto crea una región en uno de los objetos que está con una mayor carga positiva, produciéndose una fuerza atractiva entre ambos objetos [17]. Para una mejor comprensión de esta forma de generación electrostática se incluye la figura 1.3, en donde puede observarse la secuencia de una situación en la que existe generación electrostática por inducción.

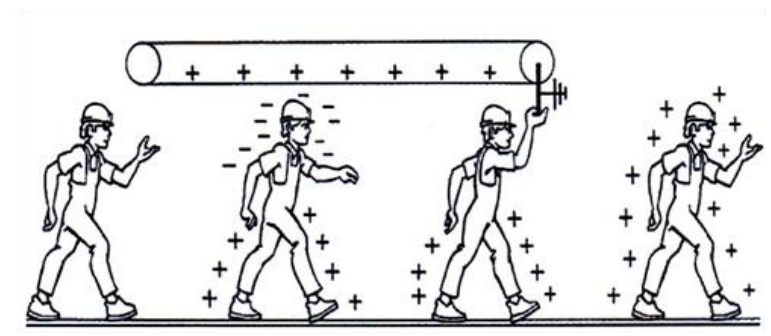

Figura 1. 3. Generación de cargas electrostáticas por inducción [18].

La tercera causa posible para originar la electricidad estática se refiere a la carga almacenada por el efecto de la capacidad. La ecuación $Q=C \cdot V$ nos indica que en un cuerpo con capacidad constante, al aumentar la carga la tensión también se incrementa [19]. Esto es de especial importancia en el sector electrónico, ya que si un componente queda cargado bajo la influencia de un campo eléctrico producido por un cuerpo cercano y éste se aleja respecto al otro objeto, la tensión electrostática aumenta, pudiendo producir daños en dicho objeto a causa de esta carga electrostática. En el campo de la electricidad y la electrónica existen dispositivos, 
los condensadores, que aprovechan este efecto para almacenar energía. El condensador es un componente pasivo y está formado por un par de superficies conductoras en situación de influencia total, esto es, que todas las líneas de campo eléctrico que parten de una van a parar a la otra. Generalmente las superficies conductoras tienen la forma de esferas o placas, y están separadas por un material dieléctrico cuya misión es disminuir el campo eléctrico, ya que actúa como aislante [20]. Cuando se someten las placas de un condensador a una diferencia de potencial (d.d.p.) adquieren una determinada carga eléctrica, positiva en una de las placas y negativa en la otra, siendo de valor nulo la carga total almacenada. La carga almacenada en una de las placas es proporcional a la diferencia de potencial entre esta placa y la otra, siendo esta constante de proporcionalidad la denominada "capacidad o capacitancia" que se mide en faradios (F). Un faradio es la capacidad de un condensador en el que, sometidas sus armaduras a una diferencia de potencial de un voltio $(\mathrm{V})$, éstas adquieren una carga eléctrica de un culombio [21]. El condensador almacena energía eléctrica cuando aumenta la diferencia de potencial en sus terminales, debido a la presencia de un campo eléctrico en su interior, devolviéndola cuando ésta disminuye [22]. La energía almacenada en un cierto instante por un condensador de capacidad "C" cuya tensión es "V" es la mitad del producto de la capacidad por el cuadrado de la tensión, es decir, se calcula a través de la fórmula:

$$
W=\frac{C \cdot V^{2}}{2}
$$

La fase siguiente a la generación de electricidad estática en los materiales es la denominada "acumulación de las cargas electrostáticas" y se produce en materiales no conductores o conductores aislados. Esta acumulación puede ocurrir en productos, equipos de proceso, tramos de tubería aislados, recipientes, personas con calzado aislante o sobre suelos que no disipan las cargas, entre otras 
circunstancias. A mayor cantidad de cargas electrostáticas corresponde mayor diferencia de potencial respecto a tierra [23]. Como se ha indicado anteriormente se produce en materiales no conductores o conductores aislados, término fundamental dentro del campo de la electricidad. Para poder definir si un cuerpo es conductor o no existe un término identificador, la conductividad eléctrica, que nos indica la mayor o menor capacidad para conducir la corriente eléctrica del material, es decir, la dificultad que encuentra la carga para desplazarse por ese material. Esta capacidad es propia del material y depende fundamentalmente de su estructura; se mide en Siemens por metro $(\mathrm{S} / \mathrm{m})$ o en Siemens por centímetro $(\mathrm{S} / \mathrm{cm})$. Desde el punto de vista eléctrico los materiales se pueden clasificar en tres grandes grupos en función del valor de la conductividad: materiales conductores (conductividad superior a $10^{3} \mathrm{~S} / \mathrm{cm}$ ), materiales semiconductores (conductividad entre $10^{3}$ y $10^{-9}$ $\mathrm{S} / \mathrm{cm}$ ) y materiales aislantes (conductividad inferior a $10^{-9} \mathrm{~S} / \mathrm{cm}$ ) [24].

Se define como conductor eléctrico el medio que posee partículas con carga eléctrica, libres de moverse si se les aplica una fuerza [25]. La característica común de estos materiales es la tenencia de electrones alejados del núcleo y por tanto éstos adquieren una gran libertad de movimiento dentro de sus átomos, en definitiva, convirtiéndose en verdaderos vehículos de transporte de carga eléctrica. A estas partículas se les denomina portadores y dentro de este tipo de materiales están los metales, que son excelentes conductores de electricidad.

Los materiales semiconductores son aquellos que poseen partículas con carga libre, electrones (carga negativa) y huecos (carga positiva), pero con menos cantidad de portadores que los conductores. Los semiconductores más conocidos son el silicio y el germanio.

Por último se define como material aislante a los que tienen muy pocas cargas libres, es decir, con la mayoría de las partículas que son fijas y por tanto no 
pueden moverse a través del volumen del cuerpo que las contiene [26]. A estos materiales también se les puede denominar dieléctricos. La estructura atómica de los materiales aislantes no permite a los electrones el grado de movilidad que tienen en los conductores, ya que se encuentran firmemente unidos a sus correspondientes átomos, estando muy limitado el desplazamiento de cargas. Pertenecen a esta categoría materiales de uso tan frecuente como el vidrio, el plástico, la madera, etc. La diferencia en el comportamiento de las sustancias respecto del desplazamiento de las cargas en su seno depende del tipo de átomos que forman su estructura atómica y de ahí su clasificación.

La duración de esta fase de acumulación de cargas en un objeto está condicionada en primer lugar por la tendencia a la generación de cargas electrostáticas del cuerpo y, en segundo lugar, por la tendencia a eliminarlas. La eliminación es función de su conexión a tierra o a otros materiales de menor potencial, por lo tanto esta fase de la electricidad estática se puede producir en cualquier material, ya que si no hay conexión directa a tierra el objeto tiene la capacidad de adquirir y retener carga eléctrica [27].

La tercera y última fase es la denominada "disipación de las cargas electrostáticas" y consiste en la desaparición de las cargas eléctricas en los materiales, al pasar a tierra o a otros objetos de menor potencial. El tiempo que trascurre hasta la ausencia de carga electrostática depende del material y de las características del medio que une el cuerpo cargado con tierra. En ese momento se produce el equilibrio electrostático. Si un material tiene mayor conductividad disipará mejor las cargas y por tanto esta fase tendrá una menor duración.

En ciertas situaciones la generación y acumulación de cargas es continua, ya sea porque el material está aislado y no disipa carga electrostática o porque se disipa más lentamente que se genera; en ese caso puede llegarse a una situación en 
la que es inevitable la denominada "descarga electrostática". Este fenómeno se produce cuando en el material se ha acumulado una cantidad de carga elevada, que se descargará rápidamente al ponerse en contacto a tierra o con un material conductor. En estos casos se genera una chispa visible e incluso audible, pudiendo ocasionarse situaciones de peligro, tales como incendios, explosiones en atmósferas inflamables, roturas en materiales de producción, choques eléctricos dolorosos o molestos, tamices obstruidos, etc. El rayo es un ejemplo natural de descargas estáticas fácilmente visible. Aunque los detalles no son claros y siguen siendo un tema de debate, se cree que la separación inicial de carga se asocia al contacto entre las partículas de hielo dentro de las nubes de tormenta [28].

La electricidad estática en la industria textil careció prácticamente de importancia hasta que comenzaron a utilizarse las fibras sintéticas; con ellas, el concepto de "electricidad estática" se ha ido difundiendo entre los profesionales de este sector industrial [29]. En todas las operaciones de transformación textil se produce carga electrostática y habitualmente se manifiesta de forma perjudicial, pudiendo producirse atracción entre materiales (por ejemplo, durante el cardado de fibras cortadas), repulsión entre ellos (por ejemplo, durante el bobinado con bobinas que son blandas e irregulares), o atracción de partículas sin carga (por ejemplo, la atracción de polvo e impurezas en el acabado) [30].

Pero hay que citar también a los llamados tejidos electrónicos (e-textiles), en los que se produce la unión de la microelectrónica y el textil, que tienen múltiples aplicaciones en electromedicina, dispositivos para móviles, militar,... [31]. Es decir, en ellos se trata de dotar al tejido de propiedades conductoras que hagan factible la transmisión de señales eléctricas, permitiendo integrar elementos electrónicos que formen parte de la propia prenda. Estos tejidos se pueden calificar como "tejidos inteligentes" o "Smart Textiles", que son aquellos que reaccionan de forma activa ante la incidencia de un agente o estímulo externo [32], [33]. 


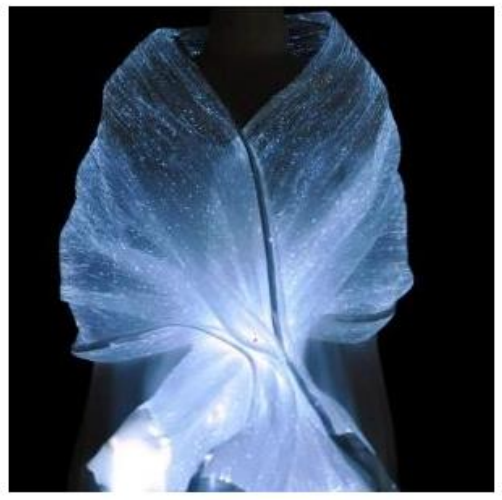

Figura 1. 4. Tejido "Smart textil".

En el ámbito de la vestimenta, el uso de prendas de vestir en las que se ha acumulado carga estática provoca incomodidad. Esto depende de la capacidad de generación y de descarga del tejido, variando en función de la combinación de materiales que se utilicen. Las cargas pueden llegar a un nivel que al tocar un objeto metálico se produce un "golpe" perceptible como consecuencia del intercambio de cargas [34].

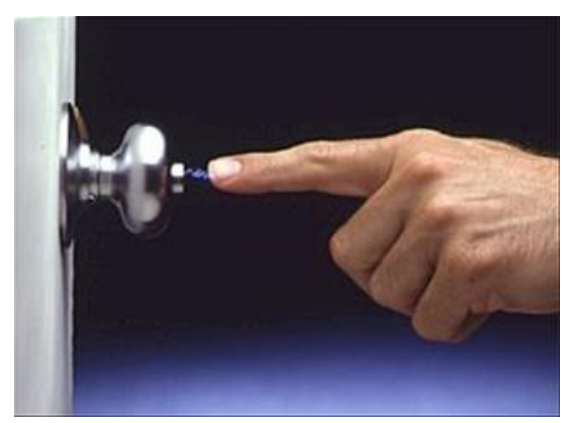

Figura 1. 5. Descarga electrostática.

Es por ello que se comenzaron a introducir hilos conductores en algunos tejidos que, según algunos autores, pueden proporcionar a las prendas textiles ciertas propiedades antiestrés, debido precisamente a que no acumulan electricidad estática, si no que la descargan [35]. 


\subsubsection{Antecedentes históricos.}

Al menos desde el siglo VI antes de Cristo se había observado que trozos de ámbar frotados con lana atraen pequeños cuerpos y motas de polvo, atribuyéndose a Tales de Mileto la primera información sobre este fenómeno. Esta propiedad se llamó después propiedad del ámbar o electricidad, por la palabra griega " $\eta \lambda \varepsilon \kappa \tau \rho o v "(e l e c t r o ́ n)$, que significa ámbar. Sería otro griego, Teofrasto (310 a. C.), quien realizó un estudio de los diferentes materiales que eran capaces de producir fenómenos eléctricos y escribió el primer tratado sobre la electricidad [36]. Más tarde se fue observando que otros cuerpos adquirían por frotamiento la propiedad de atraer o repeler. Pero hasta 1600 d.C. no se tiene constancia de estos avances, pues fue en ese año cuando el físico y médico inglés William Gilbert publicó en Londres que, además del ámbar, otros cuerpos después de frotados adquirían la propiedad de atracción. En ellas se empleó por primera vez la palabra electricidad y clasificó los materiales en dos grupos: conductores y no conductores.

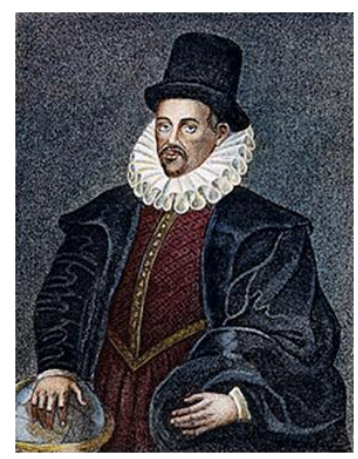

Figura 1. 6. Imagen de William Gilbert [37].

Este físico inventó el electroscopio, instrumento que se utiliza para saber si un cuerpo está cargado eléctricamente. El electroscopio consiste en una varilla metálica vertical que tiene una esfera en la parte superior y, en el extremo opuesto, dos láminas de aluminio muy delgado. La varilla está sostenida en la parte superior 
de una caja de vidrio transparente con un armazón de cobre en contacto con tierra. El esquema del electroscopio es el mostrado en la figura 1.7 [38].

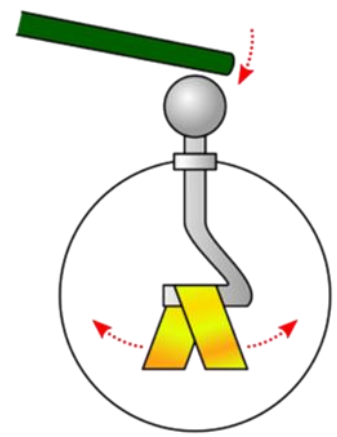

Figura 1. 7. Esquema de funcionamiento del electroscopio.

$\mathrm{Al}$ acercar un objeto electrizado a la esfera, la varilla se electriza y las laminillas cargadas con igual signo de eléctrico se repelen, separándose, siendo su divergencia una medida de la cantidad de carga que han recibido. La fuerza de repulsión electrostática se equilibra con el peso de las hojas. Si se aleja el objeto de la esfera, las láminas, al perder la polarización, vuelven a su posición normal. Un electroscopio pierde gradualmente su carga debido a la conductividad eléctrica del aire producida por su contenido en iones. Por ello, la velocidad con la que se carga o se descarga un electroscopio en presencia de un campo eléctrico puede ser utilizada para medir la densidad de iones en el aire del ambiente.

El jesuita italiano Niccolo Cabeo analizó sus experimentos y fue el primero en comentar que había fuerzas de atracción entre ciertos cuerpos y de repulsión entre otros. También experimentó con imanes, y opinó que sus atracciones eran diferentes de la fuerza del ámbar frotado, a la que dio el nombre de "fuerza eléctrica". Sobre el año 1660 Otto von Guericke fue capaz de construir máquinas capaces de generar electricidad estática, como la mostrada en la figura 1.8 que es utilizada en clases de ciencia [39]. 


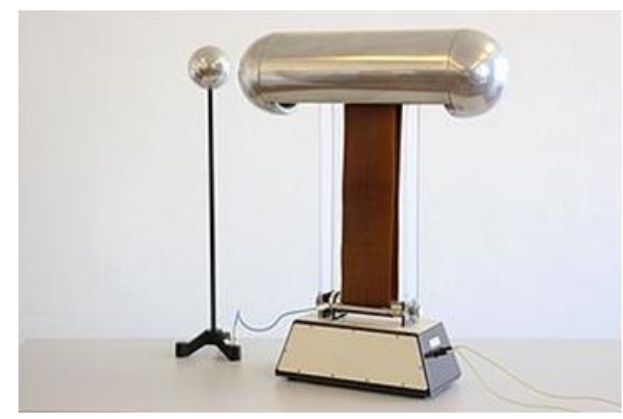

Figura 1. 8. Generador de electricidad electroestática.

Esto fue todo el conocimiento sobre la electricidad hasta el siglo XVIII, cuando Benjamin Franklin propuso la teoría de un único fluido, que llamó fluido eléctrico, para explicar esas atracciones y repulsiones. Según esa teoría, todos los cuerpos admitirían un nivel o carga normal de ese fluido. Pero, por frotamiento, puede conseguirse que ese fluido pase entre cuerpos. Entonces, unos quedan con mayor nivel (o carga de fluido) que el normal, y los otros con menor nivel o carga de fluido que el normal. Del cuerpo con más nivel que el normal se dice que tiene carga positiva de fluido, o que está cargado positivamente, y del cuerpo con menor nivel que el normal se dice que tiene carga negativa de fluido, o que está cargado negativamente. Del cuerpo que tiene nivel normal de fluido eléctrico se dice que está en estado neutro. Si dos cuerpos tienen nivel de fluido eléctrico superior al normal, o inferior al normal, se repelen. Si uno tiene nivel superior al normal, y otro inferior, se atraen. Dos cuerpos neutros, o sea, con su nivel normal de fluido, ni se atraen ni se repelen. Por último, según esa teoría, si se tocan dos cuerpos, el fluido eléctrico pasa del cuerpo de nivel superior al de nivel inferior. Sus experimentos sobre electricidad condujeron también a explicar las tormentas como fenómenos causados por la electricidad de las nubes, y al invento del pararrayos.

En el mismo siglo XVIII, concretamente en 1733, Du Fay propuso que las atracciones y repulsiones eléctricas pueden explicarse si se supone que hay dos 
clases de propiedades, es decir, dos clases de electricidad: una, la que adquiere el vidrio frotado con lana y la de todos los cuerpos a los que repele después de haber sido frotados con lana, que se llamó electricidad vítrea, y otra, la del ámbar frotado con lana y la de todos los cuerpos a los que repele después de frotados con lana, que se llamó electricidad resinosa. Con esta hipótesis, los cuerpos con la misma clase de electricidad se repelen y los que la tienen distinta se atraen. De los cuerpos que tienen electricidad se dice que están cargados de electricidad o que tienen carga eléctrica. De los cuerpos que no tienen electricidad se dice que están en estado neutro.

Ambas hipótesis, la del fluido eléctrico y la de las dos clases de electricidad, podían explicar las atracciones y repulsiones eléctricas, por lo que convivieron algún tiempo, hasta que el aumento del conocimiento fue dirigiendo las preferencias hacia la teoría de las dos clases de electricidad, que es la que se acepta hoy. Du Fay y Stephen Gray fueron dos de los primeros "físicos eléctricos" en frecuentar plazas y salones para popularizar y entretener con la electricidad. Por ejemplo, si se electriza a las personas se producen descargas eléctricas desde ellas, como en el llamado beso eléctrico: se electrificaba a una mujer y luego ella daba un beso a una persona no electrificada [40]. En 1745 se construyeron los primeros elementos de acumulación de cargas, denominados "condensadores", llamados incorrectamente en diversa bibliografía "capacitores" por el anglicismo implantado en nuestro idioma. Fueron desarrollados en la Universidad de Leyden (hoy Leiden) por Ewald Jürgen Von Kleist y Pieter Van Musschenbroeck. Estos instrumentos, inicialmente denominados botellas de Leyden, fueron utilizados como curiosidad científica durante gran parte del siglo XVIII. En esta época se construyeron diferentes instrumentos para acumular cargas eléctricas, en general variantes de la botella de Leyden, y otros para manifestar sus propiedades, como los electroscopios. 


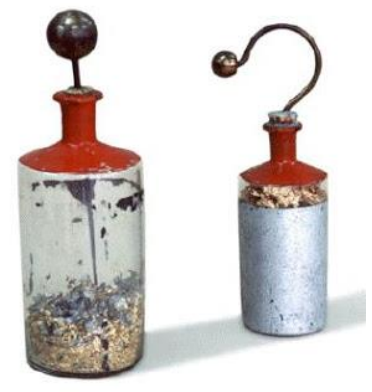

Figura 1. 9. Botellas de Leyden [41].

En el mismo siglo XVIII, Coulomb, con una balanza de torsión, comparó fuerzas entre dos esferillas cargadas. Las fuerzas parecían ser inversamente proporcionales al cuadrado de la distancia " $d$ " entre los centros de las esferas. Por eso, en 1785, propuso para el módulo de la fuerza entre dos de ellas la fórmula:

$$
F=k \cdot \frac{q_{1} \cdot q_{2}}{d^{2}}
$$

Donde:

$F$, fuerza de atracción/repulsión entre las cargas $(\mathrm{N})$.

$k$, constante de Coulomb $\left(\mathrm{N} \cdot \mathrm{m}^{2} / \mathrm{C}^{2}\right)$.

$d$, distancia entre las cargas (m).

$q_{1}$, valor de la carga puntual $1(\mathrm{C})$.

$q_{2}$, valor de la carga puntual $2(\mathrm{C})$.

Para completar esta fórmula hay que añadir que la fuerza $F$ es de repulsión si las dos cargas son de la misma clase, y de atracción si son de clase distinta. En ella, la fuerza es proporcional al producto de las cantidades de electricidad de las esferas. Estos enunciados se conocen como ley de Coulomb, y su concordancia con la realidad hacen que esta ley siga en vigor hasta la actualidad. La fórmula proporciona, además, un modo de medir cargas eléctricas y permitió definir la 
unidad electrostática (de carga eléctrica o de cantidad de electricidad), que es "la carga eléctrica de una esfera de radio despreciable que, separada un centímetro de otra igual y con la misma carga, ambas situadas en el vacío, es repelida por ella con una fuerza de una dina".

Las pruebas de que hoy día pueden realizarse con aparatos modernos indican que la electricidad es una propiedad de la materia, no un fluido ajeno a ella. Y se definen dos clases de electricidad, conocidas como electricidad positiva y electricidad negativa. La referencia es la carga del electrón, a la que se asigna signo negativo. Los protones tienen electricidad positiva y se les asigna signo positivo. No hay ninguna razón para haber asignado de esta forma los adjetivos positivo y negativo, por lo que la elección fue convencional. Actualmente se sabe que el electrón y el protón son las dos únicas partículas estables en electricidad con carga eléctrica. Por eso, la mejor definición de electricidad es "la propiedad del protón y del electrón que consiste en que dos protones se repelen, dos electrones se repelen, y un protón y un electrón se atraen, con fuerzas que cumplen la ley de Coulomb". La electricidad del protón se llama electricidad positiva y la del electrón electricidad negativa [42]. Si dos cuerpos que no son protones o electrones se atraen o repelen según la ley de Coulomb, también se dice de ellos que tienen electricidad, o que tiene carga eléctrica. Pero esa carga se debe a que cada uno tiene más protones que electrones, en cuyo caso se dice que tiene carga positiva, o a que tiene más electrones que protones, en cuyo caso se dice que tiene carga negativa. De hecho la forma más frecuente de cargar cuerpos sigue siendo frotar unos con otros. Así, electrones de la última capa de los átomos de un cuerpo pasan al otro. El cuerpo que queda con menos electrones que protones queda con electricidad positiva, y el que queda con más electrones que protones con electricidad negativa. Las cantidades de electricidad positiva se expresan hoy por medio de números reales positivos. 
A lo largo de los siglos han sido múltiples los intentos de explicar científicamente la procedencia de la electricidad estática. Pero, como ya se ha indicado, hasta la llegada de Michael Faraday y sus estudios, publicados en 1832, no se avanzó significativamente, quedando integrada la electricidad estática dentro de la electricidad en general.

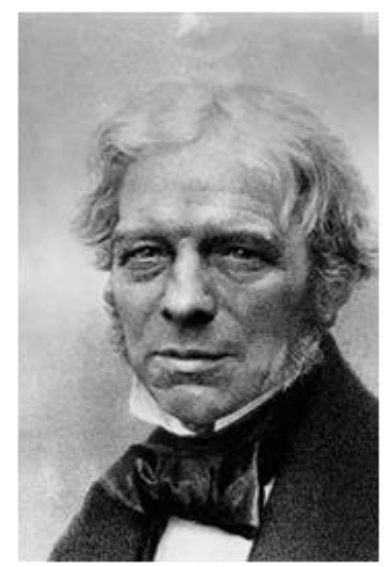

Figura 1. 10. Michael Faraday [43].

Otro paso importante en el mundo eléctrico se dió en 1864, cuando el físico escocés James Clerk Maxwell unificó las leyes de la electricidad y el magnetismo en un conjunto reducido de leyes matemáticas, que dieron origen al electromagnetismo. Muchos físicos lo consideran el científico del siglo XIX que más influencia tuvo sobre la física del siglo XX, habiendo realizado contribuciones fundamentales a la comprensión de la naturaleza. Incluso hay quien considera que sus contribuciones a la ciencia son de la misma magnitud que las de Isaac Newton y Albert Einstein [44].

En 1879 , la "teoría de la doble capa eléctrica" fue descrita por Helmholtz. Según este modelo, al poner en contacto dos cuerpos de distintos materiales tiene lugar una migración de electrones del material con menor energía de emisión al otro material [45]. 
A finales del siglo XIX se descubrió que un campo eléctrico en movimiento, producido por una corriente eléctrica que varía, genera un campo magnético, y que un campo magnético de por sí implica la presencia de un campo eléctrico. Así se llegó a la unión de las dos fuerzas anteriores en lo que hoy se conoce como la fuerza de Lorentz. En 1831 la ley de Ampère generalizada relacionó un campo magnético estático con la causa que la produce, es decir, una corriente eléctrica estacionaria. Entre 1890 y 1900 Liénard y Wiechert calcularon el campo electromagnético asociado a cargas en movimiento arbitrario, resultado que se conoce como potenciales de Liénard-Wiechert. Por otro lado, para generar una corriente eléctrica en un circuito cerrado debe existir una diferencia de potencial entre dos puntos del circuito, a ésta diferencia de potencial se la conoce como fuerza electromotriz y es proporcional a la rapidez con que el flujo magnético varía con el tiempo.

En el mundo textil, durante mucho tiempo la electricidad estática no era un factor a tener en cuenta, ya que el sistema de producción de los materiales textiles no ocasionaba problemas o éstos se podían solucionar con remedios fácilmente aplicables. Pero la aparición de las fibras sintéticas y de nuevas máquinas de producción mucho más veloces, hizo que los remedios utilizados hasta entonces no fueran suficientes, aumentando los problemas. Desde entonces el conocimiento del concepto de "electricidad estática" se ha venido extendiendo en este tipo de industria [46].

Por último, con la aparición de la nanotecnología ${ }^{1}$ en el mundo industrial, es muy importante para el sector textil conocer las características eléctricas de los hilos, ya que con la nanotecnología se consigue la integración definitiva de la

\footnotetext{
${ }^{1}$ Se define como al conjunto de ciencias y técnicas aplicables a nivel de "nanoescala", de manera que a este tamaño "nano" es posible trabajar y manipular estructuras moleculares y átomos.
} 
conductividad como propiedad característica del tejido inteligente. Actualmente se está trabajando ya con hilos conductores, baños con partículas metálicas, impresión digital de circuitos electrónicos, etc.

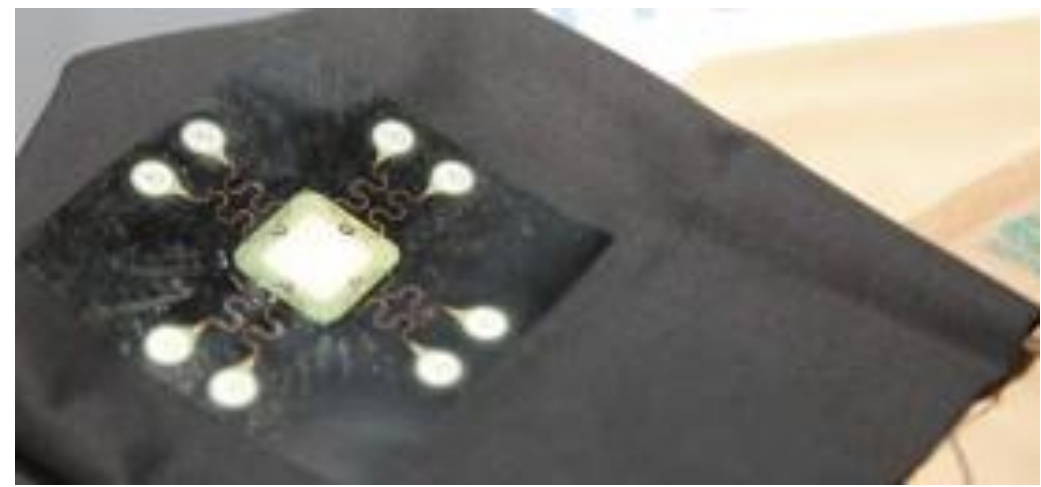

Figura 1. 11. Aplicación de un circuito conductor textil [47].

\subsubsection{Factores que influyen en la electricidad estática.}

Cada tipo de material posee una estructura molecular interna diferente y es por ello que cada uno tiene un comportamiento distinto frente a la electricidad estática, ya sea como conductor, semiconductor o aislante. Además, este comportamiento no sólo depende del tipo de material, sino que existen otros factores externos a su estructura que también influyen, siendo los principales los referentes a las condiciones ambientales existentes en el momento de producirse este fenómeno. El análisis de los factores que afectan en alguna de las etapas debe hacerse en función de la estructura interna, es decir, el estudio de los tipos de materiales es distinto según sean conductores, semiconductores o aislantes. Pero en todos los casos se realiza en función de una de sus características eléctricas, la resistividad, magnitud inversa a la conductividad. 
En los materiales conductores la variable o factor externo que más influye en el valor de la conductividad es la temperatura. Así, está comprobado que cuando aumenta la temperatura disminuye la conductividad o, lo que es equivalente, aumenta la resistividad [48]. El incremento relativo de la resistividad por cada grado que aumenta la temperatura se conoce como coeficiente de temperatura de la resistividad y viene determinado por la ecuación 1.3.

$$
\alpha=\frac{d \rho}{\rho \cdot d T}
$$

Donde:

$$
\begin{aligned}
& \alpha, \text { coeficiente de temperatura de la resistividad del material }\left({ }^{\circ} \mathrm{C}^{-1}\right) . \\
& \rho, \operatorname{resistividad}(\Omega \cdot \mathrm{m}) . \\
& T, \quad \text { temperatura }(\mathrm{K}) .
\end{aligned}
$$

Analizando esta ecuación, se deduce que este coeficiente varía en función de la variación de temperatura, aunque puede considerarse constante para pequeñas variaciones. Si se parte de esta premisa se puede desarrollar la ecuación 1.3 para calcular la resistividad del material conductor, obteniéndose la ecuación 1.4.

$$
\rho=\rho_{0} \cdot e^{\alpha \cdot t}
$$

Donde:

$$
\begin{array}{ll}
\rho, & \text { resistividad del material a la temperatura } \mathrm{t}(\Omega \cdot \mathrm{m}) . \\
\rho_{0}, & \text { resistividad del material a la temperatura de } 0^{\circ} \mathrm{C}(\Omega \cdot \mathrm{m}) . \\
\alpha, & \text { coeficiente de temperatura de la resistividad del material }\left({ }^{\circ} \mathrm{C}^{-1}\right) . \\
\mathrm{t}, & \text { temperatura del material }\left({ }^{\circ} \mathrm{C}\right) .
\end{array}
$$

Habitualmente, en vez de utilizar directamente esta fórmula se aplica la que se obtiene en su desarrollo en serie de Taylor, aproximada por sus dos primeros términos, es decir, la ecuación 1.5. 


$$
\rho=\rho_{1} \cdot\left(1+\alpha \cdot\left(\mathrm{t}-\mathrm{t}_{1}\right)\right)
$$

Donde:

$\rho, \quad$ resistividad del material a la temperatura $\mathrm{t}(\Omega \cdot \mathrm{m})$.

$\rho_{1}$, resistividad a una temperatura de referencia $\mathrm{t}_{1}(\Omega \cdot \mathrm{m})$.

$\alpha$, coeficiente de temperatura $\left({ }^{\circ} \mathrm{C}^{-1}\right)$.

$\mathrm{t}, \quad$ temperatura $\left({ }^{\circ} \mathrm{C}\right)$.

$\mathrm{t}_{1}$, temperatura de referencia $\left({ }^{\circ} \mathrm{C}\right)$.

En la tabla 1.2 se proporciona valores indicativos de la resistividad $(\rho)$ y del coeficiente de temperatura $(\alpha)$ de algunos materiales a la temperatura de $20^{\circ} \mathrm{C}$ [49].

\begin{tabular}{||l|c|c||}
\hline Material & $\begin{array}{c}\text { Resistividad } \\
\boldsymbol{\rho} \text { en } \mathbf{\Omega} \cdot \mathbf{m}\end{array}$ & $\begin{array}{c}\text { Coeficiente de } \\
\text { temperatura } \\
\boldsymbol{\alpha} \text { en }{ }^{\circ} \mathbf{C}^{-1}\end{array}$ \\
\hline \hline Aluminio & $2,70 \times 10^{-8}$ & 0,004 \\
\hline Cobre & $1,72 \times 10^{-8}$ & 0,004 \\
\hline $\begin{array}{l}\text { Constatán } \\
(\text { Cu 60\%, Ni 40\%) }\end{array}$ & $49,00 \times 10^{-8}$ & 0,000002 \\
\hline Gemanio puro & $0,046 \times 10^{-8}$ & $-0,048$ \\
\hline Hierro & $9,70 \times 10^{-8}$ & 0,006 \\
\hline Mercurio & $96,00 \times 10^{-8}$ & 0,001 \\
\hline Nicrom & $100,00 \times 10^{-8}$ & 0,0004 \\
\hline Níquel & $6,80 \times 10^{-8}$ & 0,007 \\
\hline Oro & $2,30 \times 10^{-8}$ & 0,004 \\
\hline Plata & $1,60 \times 10^{-8}$ & 0,004 \\
\hline Plomo & $21,00 \times 10^{-8}$ & 0,004 \\
\hline Wolframio & $5,50 \times 10^{-8}$ & 0,005 \\
\hline \hline
\end{tabular}

Tabla 1. 2. Tabla de valores de $\rho$ y $\alpha$ de algunos materiales conductores. 
La resistividad de los semiconductores depende también de la temperatura. Concretamente, el aumento de temperatura lleva a la producción de más electrones libres, con lo que aumentaría la conductividad.

A temperatura ambiente estos materiales son un término intermedio entre conductores y dieléctricos, con una densidad de electrones libres, o de conducción, intermedia y muy dependiente de la temperatura, aumentando o disminuyendo con ella. Esta estructura de los semiconductores, cuyo carácter se mantiene con firmeza a temperaturas próximas al cero absoluto, impide la existencia de electrones libres para originar corrientes a la citada temperatura. A temperaturas superiores al cero absoluto, la energía térmica de los átomos origina el salto de algún electrón de valencia, que queda libre en la red. Los electrones libres así originados, darán lugar a una corriente eléctrica si se aplica al cristal un campo eléctrico exterior. Por lo tanto, cuanto mayor sea la temperatura, mayor es la densidad de estos electrones libres, y mayor también su conductividad [50], al contrario de lo que sucede con los conductores.

El comportamiento eléctrico de los aislantes frente a la temperatura es similar al de los semiconductores, pero en estos materiales existen más parámetros que tienen influencia en la formación y descarga de la electricidad estática. En concreto, en los materiales textiles, la mayor parte de los cuales son aislantes, los investigadores $[51,52,53]$ han encontrado que las características eléctricas de las fibras textiles son influenciadas por aspectos de su morfología interna, tales como su estructura fina, grado de cristalización y orientación, o el estado de la superficie de los materiales. Pero también por condiciones externas, tales como las condiciones ambientales y el método de electrificación [54].

El parámetro estructural más importante es la composición de los tejidos, es decir, la influencia de las diferentes fibras, o de su proporción en el caso de mezclas 
[55]. En la figura 1.12 se puede comprobar que el tiempo de descarga de varios materiales textiles es distinto para condiciones externas fijas (mismo método de electrificación, $30^{\circ} \mathrm{C}$ de temperatura y humedad relativa del aire del $15 \%$ ); este tiempo de descarga está relacionado con la resistividad del elemento textil, que es una característica propia del material [56]. En la figura 1.12 puede observarse que, en igualdad de condiciones, el algodón da el mínimo tiempo de descarga, siendo bastante mayor el de la lana, aunque el máximo lo dan las fibras sintéticas, en general, y el poliéster en particular.

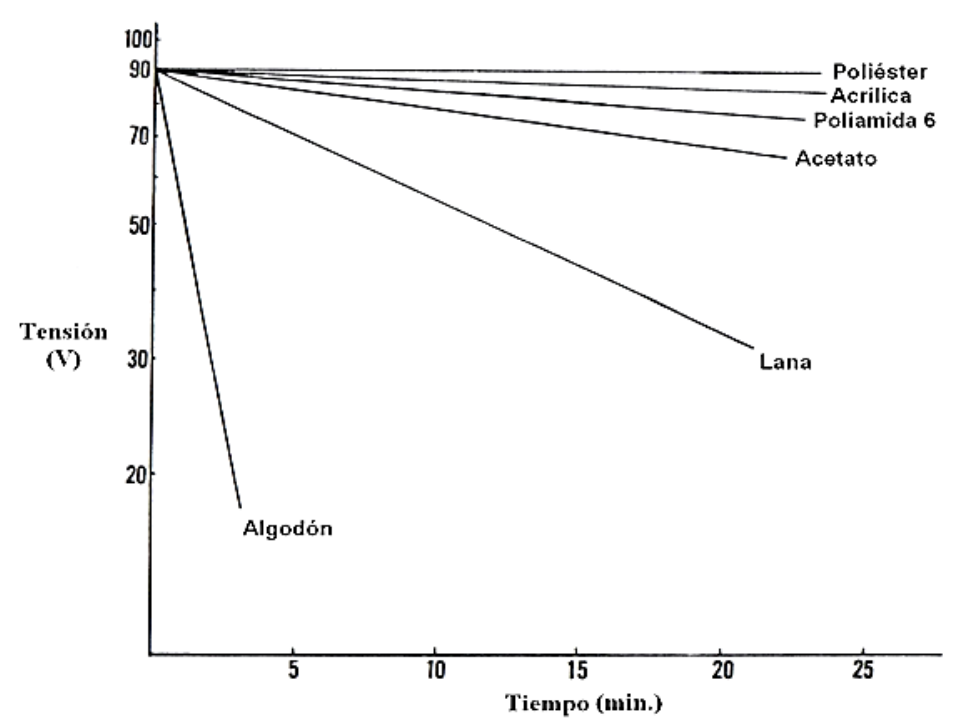

Figura 1. 12. Tiempos de descarga de varios materiales textiles a $30^{\circ} \mathrm{C}$ de temperatura y $15 \%$ de humedad relativa.

En cuanto a las condiciones externas las principales variables que determinan la conductividad son la temperatura y la humedad relativa del aire. El parámetro principal es la humedad del ambiente, ya que determina en mayor medida la resistividad y, por consiguiente, también la duración de las cargas electrostáticas en el material. En los materiales textiles el contenido en humedad del material está relacionado con la humedad relativa del ambiente y, por tanto, afecta a 
la estructura interna y tiene una gran influencia en el valor de la resistividad del textil. Pero, a su vez, depende en parte del propio material, ya que algunos materiales poseen mayor capacidad de absorción de humedad que otros. Por tanto, es importante controlar la humedad relativa ambiental para poder saber la duración del proceso de descarga eléctrica de los materiales textiles.

Conceptualmente, la humedad relativa del aire es el contenido de vapor de agua del aire en relación con su contenido en condiciones de saturación, a la misma temperatura, y se expresa en tanto por ciento. Otra definición más técnica de humedad relativa sería la relación de la fracción molar del vapor de agua presente en el aire, con la fracción molar del vapor de agua presente en el aire saturado, a la misma presión y temperatura [57]. Ya que el término correspondiente a la saturación es función de la presión, y especialmente de la temperatura, la humedad relativa es un indicativo ambiental importante y refleja algo más que el contenido en agua [58]. Se calcula por la siguiente ecuación:

$$
\text { H.R. }(\%)=\frac{r_{0}}{r_{s}} \cdot 100
$$

Donde:

H.R.(\%), humedad relativa en términos porcentuales.

$r_{0}, \quad$ contenido de agua.

$r_{s}, \quad$ contenido de agua en condiciones de saturación.

Todas las fibras textiles absorben humedad del ambiente y, por tanto, ésta pasa a formar parte de su estructura interna. Y lo hará en una cantidad que depende de las condiciones ambientales, de forma que cuanto mayor sea la H.R. mayor es la cantidad de humedad absorbida por el material, hasta el límite marcado por cada fibra [59]. 
La capacidad de las fibras para absorber humedad depende en gran medida de la naturaleza química del polímero que la constituye. Las fibras naturales se caracterizan porque son hidrofílicas, es decir, manifiestan gran tendencia a absorber la humedad, debido a que tienen grupos químicos capaces de interaccionar con ella, reteniéndola. Así, por ejemplo, la hidrofilidad de las fibras celulósicas es debida a los grupos hidroxilo que posee la celulosa, mientras que en el caso de la lana a los diferentes grupos polares que posee en su estructura. La cantidad de zonas amorfas de las fibras también tiene influencia en la absorción de agua, ya que es en éstas donde se produce principalmente la absorción. Por esta razón, fibras de la misma naturaleza química pueden absorber agua en proporción diferente; por ejemplo la viscosa absorbe más humedad que el algodón, debido a que la proporción de zonas amorfas es mayor en el caso de la viscosa. Para cuantificar este parámetro se utiliza la tasa de humedad, que es el porcentaje de agua que retiene una muestra textil en función de su peso seco. La tabla 1.3. proporciona los valores de absorción de humedad de diversas fibras; puede comprobarse que las fibras naturales son las que absorben mayor cantidad de humedad.

\begin{tabular}{||l|c||}
\hline \multicolumn{1}{|c|}{ Fibra } & Porcentaje de humedad (\%) \\
\hline \hline Lana peinada & $13-18$ \\
\hline Lana cardada & $13-18$ \\
\hline Viscosa y cupro & $11-13$ \\
\hline Algodón & $7-11$ \\
\hline Acetato & 6 \\
\hline Poliamida fibra / filamento & $4-4,5$ \\
\hline Acrílica & $1,3-2,5$ \\
\hline Poliéster & $0,1-0,4$ \\
\hline
\end{tabular}

Tabla 1. 3. Porcentaje de absorción de humedad de algunas fibras en relación a su peso seco.

Antiguamente, además de la derivación a tierra, la elevación de la humedad relativa constituía el remedio universal para eliminar la electricidad estática que se 
producía en los procesos textiles. Sin embargo, la absorción de humedad tiene un límite y la fibra ha de ser suficientemente hidrófila para no tener problemas con la electricidad estática. Por otra parte, la humedad no debe causar problemas de corrosión en la maquinaria y el clima de trabajo ha de ser soportable. Estas limitaciones, junto a la incorporación de fibras sintéticas al mercado, ha originado que la elevación de la humedad del ambiente ya no sea suficiente para disipar la carga electrostática del tejido, produciéndose en algunos casos problemas relacionados con la electricidad estática.

Para una mejor visión de la diferencia que existe en las características de los diversos materiales textiles con respecto a la humedad, en la tabla 1.4. se muestran los valores aproximados de absorción de humedad de varias fibras cuando la humedad relativa del aire es del $65 \%$ y, por otra parte, el valor de la humedad relativa del aire necesario para que todas las fibras tuvieran la misma resistividad eléctrica [60].

\begin{tabular}{|rl|}
\hline \multicolumn{1}{|c|}{$\begin{array}{c}\text { Absorción de humedad } \\
\text { a 65\% H.R. }\end{array}$} \\
\hline \hline $7,0 \%$ & Algodón \\
\hline $13,0 \%$ & Rayón viscosa \\
\hline $21,9 \%$ & Lana \\
\hline $15,0 \%$ & Ardil \\
\hline $4,0 \%$ & Nylon \\
\hline aprox. & Rayón acetato \\
\hline $1,7 \%$ & Acrilan \\
\hline $1,5 \%$ & Orlon \\
\hline $0,5 \%$ & Terylene \\
\hline
\end{tabular}

Tabla 1. 4. Comparación de los valores de absorción de humedad de diferentes materiales textiles. 
Como ya se ha indicado, el otro factor más influyente en la resistividad eléctrica de los aislantes, aunque en menor grado, es la temperatura. Se ha comprobado que estos materiales tienen un comportamiento similar al de los semiconductores [61].

\subsubsection{Trastornos ocasionados por la electricidad estática.}

¿Quién no ha sentido en algún momento de su vida los efectos y manifestaciones físicas de la electricidad estática? ¿Quién no ha realizado con fascinación la experiencia de frotar la carcasa de plástico de un bolígrafo con su manga para observar, con curiosidad, cómo atrae trocitos de papel?

Hay numerosos ejemplos cotidianos de manifestación de la electricidad estática, como la repulsión que sufre el cabello cuando lo cepillamos, la descarga que se produce si tocamos la ropa de otra persona cuando el suelo es de moqueta, o la pequeña sacudida que en ocasiones se recibe al bajar del automóvil y acercar la mano a la puerta. Normalmente, en situaciones comunes, los efectos fisiológicos de las descargas electrostáticas se limitan a una molesta sensación de picazón o escozor en la piel que suele llevar asociado un acto reflejo instintivo con sacudida muscular más o menos violenta [62]. Aunque no suele provocar lesiones, se trata de una situación ciertamente molesta que si se repite con frecuencia debe ser tratada correctamente, sobre todo si se repite en el lugar de trabajo. Según los expertos, estas descargas electrostáticas producidas de forma continuada son la causa principal de la enfermedad llamada "lipoatrofia semicircular", que apareció por primera vez en España en 2007, afectando a edificios emblemáticos de sedes de grandes empresas en Barcelona, y se ha generalizado en multitud de edificios de nuestro territorio nacional [63]. Los trastornos ocasionados se pueden convertir en un verdadero problema de seguridad si afectan a trabajadores que realizan otras operaciones de riesgo. 
Los efectos descritos en los ejemplos anteriores, que pueden ser más o menos anecdóticos e inofensivos en la mayor parte de los casos, pueden resultar mucho más peligrosos cuando las descargas electrostáticas se producen en el ámbito laboral, por ejemplo en ambientes donde existe presencia de sustancias con propiedades inflamables y/o explosivas, donde las consecuencias de la electricidad estática pueden incluso ser dramáticas. Así actividades tan cotidianas en la industria como el trasvase de líquidos inflamables entre otros recipientes de almacenamiento, la carga y descarga de cisternas de abastecimiento de combustibles en las estaciones de servicio, o el almacenamiento de polvos potencialmente explosivos en silos, como la harina, pueden generar, y de hecho han provocado, incendios y explosiones de extrema gravedad que han tenido su origen en descargas electrostáticas accidentales [64].

En una situación intermedia entre las propiedades más o menos curiosas de la electricidad estática, y los riesgos potenciales de incendio y explosión que se ha mencionado anteriormente asociados a este fenómeno, pero de una gran importancia económica para las empresas, se encuentran también los problemas que pueden afectar a la productividad de las líneas de fabricación y a la calidad de los productos terminados. En efecto, la generación de electricidad estática suele provocar la acumulación de partículas de polvo en superficies con carga estática, causando atracción de partículas sólidas, con los consiguientes problemas de acumulación de suciedad en productos terminados, aumento de atranque de líneas, colmatación de filtros, tamices obstruidos, tuberías de conducción bloqueadas, pintura y recubrimientos superficiales no distribuidos homogéneamente, etc.. Por lo tanto, las cargas electrostáticas pueden ser el origen de trastornos de tal magnitud que causen problemas en el desarrollo de los procesos de fabricación y produzcan descargas desagradables durante la manipulación del material producido [65]. 
El sector de la Electrónica está especialmente sensibilizado con este problema, pues los tipos de daños ocasionados por la electricidad estática son muchos y diversos, aunque se pueden clasificar en tres categorías [66]:

1/ Destrucción. Las altas tensiones y el flujo de corriente instantáneo producen la fusión de los óxidos metálicos y otros componentes.

2/ Degradación de la vida útil. Un flujo de corriente imprevisto que no sea lo suficientemente fuerte para destruir puede, sin embargo, dar lugar a fallos precoces del dispositivo.

3/ Funcionamiento impreciso. Las corrientes transitorias inducidas y la polarización pueden afectar a los parámetros de régimen de un dispositivo haciendo que funcione en una secuencia imprevista, o que no lo haga dentro de las tolerancias del proyecto.

Con lo mencionado anteriormente se pueden definir como los trastornos más significativos provocados por la electricidad electrostática los siguientes [67]:

- Atracción de polvo y suciedad.

- Menor calidad y mayor porcentaje de producto rechazado.

- Choques eléctricos dolorosos o molestos.

- Roturas y atascos del material de producción.

- Compresión, apilamiento o empaquetado incorrectos.

- Enganchado de hojas y películas

- Tuberías de conducción bloqueadas.

- Tamices obstruidos. 
- Ritmos de producción bajos para evitar paradas.

- Pinturas y recubrimientos no distribuidos uniformemente.

Pero el peligro más destacable en una industria es el de incendio o explosión si existen atmósferas potencialmente explosivas, como son las mezclas de aire con vapores, nieblas, gases o polvos combustibles. Este peligro puede dar lugar a accidentes en las operaciones o procesos con esas materias cuando la cantidad de cargas electrostáticas origina un potencial eléctrico elevado que puede ocasionar la producción de una energía de cierta magnitud en la descarga electrostática [68]. Ésta se produce si se genera una chispa, denominada técnicamente descarga disruptiva. El parámetro fundamental determinante de la peligrosidad de una chispa es la cantidad de energía liberada en el instante de producirse. Esta energía se manifiesta en forma de radiaciones (que hacen visible la chispa), de ionización y de calor y es la desencadenante de la reacción de combustión. Cuando tales descargas con chispa se producen en una atmósfera inflamable es relativamente fácil que se inicie un incendio, dado que la energía de activación que aportan suele ser superior a la que se precisa para la combustión de gases y vapores, que es del orden de 0,25 mJ. Un valor tan pequeño como $0,2 \mathrm{~mJ}$ pueden representar un riesgo de incendio, a pesar de ser tan baja que está a menudo por debajo del umbral de la percepción visual y auditiva humana [69]. Habitualmente el peligro de inflamación existe cuando la chispa es generada por una diferencia de potencial superior a los $1.000 \mathrm{~V}$. A menor distancia disminuye la tensión necesaria para que se produzca la chispa. En definitiva, para que se produzcan incendios o explosiones deberán cumplirse conjuntamente las tres condiciones siguientes:

- Existencia de una mezcla combustible y comburente susceptible de explosión o incendio por encontrarse dentro de su rango de inflamabilidad.

- Acumulación de una carga electrostática lo suficientemente alta para crear una diferencia de potencial generadora de chispa. 
- Producción de la descarga electrostática (chispa) iniciadora, de energía suficiente para inflamar una mezcla peligrosa.

Lógicamente en estas situaciones sería imperdonable desde el punto de vista preventivo que las instalaciones, locales, equipos de trabajo, sistemas de almacenamiento, vehículos, e incluso las personas, no dispusieran de los recursos técnicos necesarios para evitar la generación, acumulación y descarga violenta de cargas electrostáticas que pudieran provocar un auténtico desastre.

La energía liberada en una descarga de electricidad estática puede variar en un amplio rango. La energía disipada tiene un valor que está en función de la capacidad del condensador eléctrico formado por los dos conductores, su diferencia de potencial y la cantidad de carga eléctrica que acumula y que puede calcularse según la ecuación 1.7 [70]:

$$
W=C \cdot \frac{V^{2}}{2}=Q \cdot \frac{V}{2}=\frac{Q^{2}}{2 C}
$$

Donde:

$$
\begin{aligned}
& W, \text { energía desprendida en la descarga }(\mathrm{J}) . \\
& C, \text { capacidad }(\mathrm{F}) . \\
& V, \quad \text { diferencia de potencial }(\mathrm{V}) . \\
& Q, \quad \text { cantidad de carga }(\mathrm{C}) .
\end{aligned}
$$

El cuerpo humano es un buen conductor y, en ambientes de humedad relativa baja, acumula cargas electrostáticas que dan lugar a un potencial de varios miles de voltios. Existe normativa que establece máximos para que no existan riesgos para la salud humana. Por ejemplo, la norma IEC 479 -2:1987 afirma que una descarga de energía superior a $5 \mathrm{~J}$ conlleva un grave riesgo directo para la salud 
humana, y la IEC 60065 establece que los productos de consumo no pueden sobrepasar más de $350 \mathrm{~mJ}$ en una persona. El potencial generado normalmente en el cuerpo humano puede llegar hasta los $10 \mathrm{kV}$, aunque en condiciones óptimas de generación y acumulación de cargas puede llegar hasta los $25 \mathrm{kV}$. Si se generan potenciales por debajo de $3 \mathrm{kV}$ no suelen ser detectables por los seres humanos. Las cargas pueden generarse por contacto del calzado con suelos aislantes o en las propias operaciones de fabricación. Aparte del calzado, se deben incluir las prendas de vestir, las cuales son propensas a generar electricidad estática al despojarse de ellas, por frote. Esta situación es particularmente peligrosa en quirófanos, instalaciones de fabricación de explosivos y ocupaciones similares.

Pongamos algunos ejemplos. Se puede realizar un cálculo aproximado de la energía de una persona al tocar un automóvil: si la capacidad del cuerpo humano se estipula en $200 \mathrm{pF}$ y tiene un potencial de $10^{4} \mathrm{~V}$, se crea una chispa de energía de $10 \mathrm{~mJ}$ [71]. La diferencia de potencial con respecto a tierra alcanzada por el cuerpo humano en condiciones ambientales normales está comprendida entre 1-10 kV, aunque en condiciones óptimas de generación y acumulación se pueden alcanzar valores de hasta $20-25 \mathrm{kV}$. La baja humedad relativa aumenta la acumulación de las cargas. Por ejemplo, al caminar una persona $6,1 \mathrm{~m}$ en un piso de vinilo a $15 \%$ de humedad relativa puede provocar la acumulación de un potencial de hasta $12 \mathrm{kV}$, mientras que al $80 \%$ de humedad el potencial no supera los $1,5 \mathrm{kV}$ [72].

\subsection{Textiles laminares.}

Se trata de una estructura laminar flexible cuya elaboración obedece a un proceso textil, ya sea partiendo de fibras o de hilos, y que posee una serie de propiedades que la hace apta para vestir o para aplicaciones técnicas. 
Dependiendo del tipo de fibras de que esté compuesto y de cómo se ha realizado el entrelazado de dichas fibras, las estructuras textiles obtenidas proporcionan características diferentes.

El Textile Institute, de Manchester, considera tres tipos de textiles laminares: a) tejidos (de calada, de malla -punto-, y especiales, b) telas no tejidas (obtenidas por vía seca, húmeda o de fusión), y c) otros sistemas (cosido-tricotado, "tufting", recubrimientos, materiales compuestos,...) [73].

En los siguientes apartados se realiza un breve estudio de las principales fibras textiles existentes en el mercado, incluyendo algunos datos sobre fibras conductoras. Con las fibras pueden fabricarse hilos y con los hilos tejidos. Después nos centraremos en los tejidos de calada, aunque también se describirán brevemente las telas no tejidas (en inglés, "nonwoven fabrics").

\subsubsection{Fibras textiles.}

Se entiende por fibra textil toda materia o producto fibroso que es posible convertir en hilo o en tejido, con las consiguientes propiedades de resistencia, elasticidad y flexibilidad. Las fibras son largas, estrechas y flexibles, siendo estas características las más importantes. Existe un gran número de fibras textiles, que para su estudio se pueden agrupar en dos grandes grupos: fibras naturales y fibras químicas.

\section{- Fibras de origen Natural.}

Las fibras naturales son las que se presentan como tales en la naturaleza; a su vez se clasifican, según su procedencia, en fibras vegetales, fibras animales y fibras minerales. De estos tres grupos las fibras vegetales son, con diferencia, las 
que más se utilizan. Y, en cuanto a consumo, las minerales juegan un papel secundario en cuanto a utilización dentro de la industria textil [74].

Las fibras vegetales se obtienen de las plantas y están constituidas básicamente por celulosa, aunque suele estar acompañada por otras sustancias, en cantidad mayor o menor según la fibra de que se trate. La celulosa es un polisacárido, es decir, un azúcar de alto tamaño molecular. Por su propia naturaleza, las fibras vegetales se pueden considerar como una materia prima renovable. Según la parte de la planta de donde se obtienen, las fibras vegetales se dividen en los siguientes grupos: fibras de semilla, fibras de tallo, fibras de hoja y fibras de fruto.

Las fibras de semilla crecen en las semillas de algunas plantas; la más conocida es el algodón (fibra que procede de las semillas de la planta Gossypium). Las fibras de tallo se extraen del tallo de algunas plantas y se caracterizan porque son duras y bastas, debido a ciertas impurezas; son largas y están formadas por numerosas fibras elementales pegadas entre sí. La más conocida es la de lino (fibra que procede del tallo del lino Linum Usitatissimum). Las fibras de hoja se extraen de las hojas de algunas plantas; unas son grandes y carnosas y poseen en su interior una especie de nervios que las recorren en sentido longitudinal y que, una vez extraídos, se pueden utilizar como fibras. Son fibras muy duras, bastas y poco flexibles, por lo que no se utilizan en la industria textil; se usan en la industria de cordelería, de zapatillas, etc. La más conocida es la de esparto (fibra que procede de la hoja de la Stipa Tenacissima). Las fibras de fruto se extraen del fruto de algunas plantas. La más conocida es la de coco (fibra que procede del fruto de Cocos Nucifera).

Las fibras que se obtienen de los animales son químicamente proteínas, y éstas a su vez están constituidas por aminoácidos. Como fibras naturales que son, 
las fibras animales se pueden considerar materias primas renovables y se pueden clasificar en dos grupos: fibras de bulbo y fibras de glándula.

Las fibras de bulbo se obtienen del pelo que recubre a los animales mamíferos. Este pelo tiene en su extremo inferior un bulbo que está insertado en la epidermis de la piel, y es por donde se alimenta y crece. Estos pelos, aunque químicamente idénticos, son diferentes entre sí según su longitud, finura, color y rigidez. Los pelos más apropiados para ser utilizados como materia prima textil son los más finos, siempre que tengan una longitud suficiente, sean blancos y flexibles. Existen numerosas fibras animales de bulbo y para su estudio se pueden agrupar según el tipo de animal del que proceden, siendo la más utilizada la lana. El resto de las fibras se utiliza en mucha menor proporción y su producción es muy limitada, ya que los animales que las producen sólo se crían en algunas regiones del mundo. Hay otras fibras, denominadas pelo o crin, que se obtienen de animales comunes como el caballo, vaca, conejo, cabra, etc.

El otro grupo de fibras animales son las de glándulas; las producen algunos gusanos por medio de una glándula que poseen debajo de la cabeza, segregando un líquido viscoso que se solidifica en contacto con el aire y se transforma en filamentos. La más utilizada es la seda natural.

Las fibras minerales son aquellas que se obtienen de la naturaleza. El amianto es la única fibra natural que tiene alguna aplicación textil; está constituida por silicatos.

\section{- Fibras Químicas.}

Las fibras químicas se obtienen artificialmente mediante algún proceso de transformación o manipulación química. Se pueden clasificar en tres grandes grupos: fibras artificiales, sintéticas e inorgánicas. Un esquema simplificado del 
proceso general de obtención de las fibras químicas artificiales y sintéticas se muestra en la figura 1.13 [75].

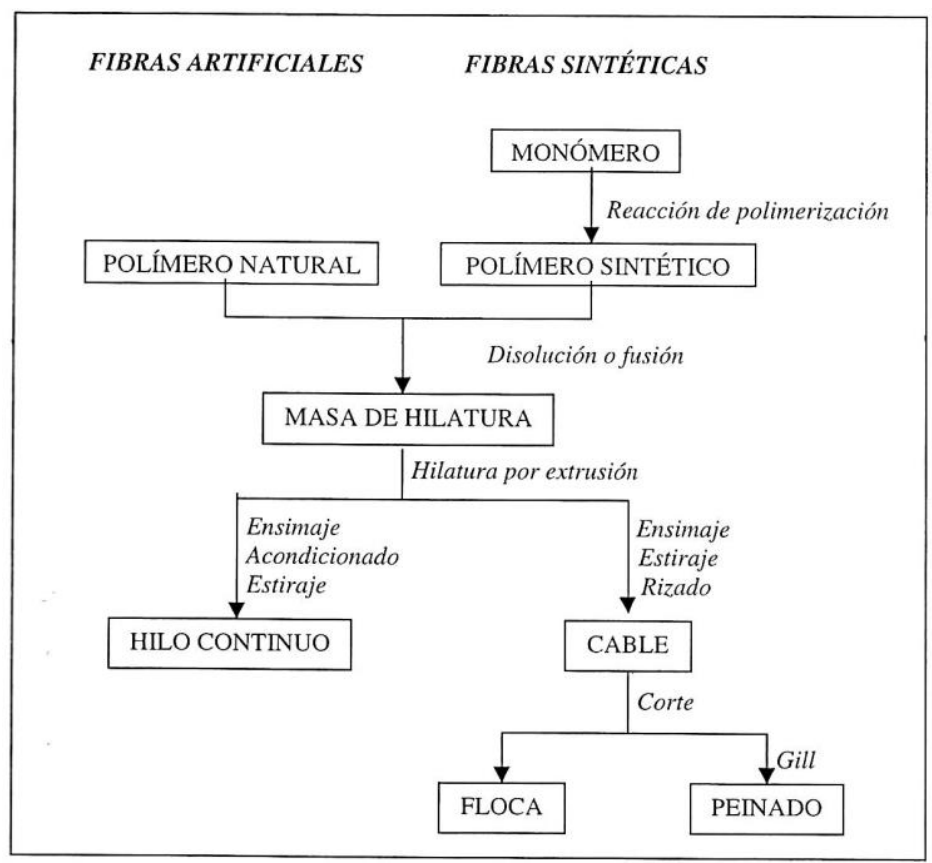

Figura 1. 13. Proceso general de obtención de las fibras químicas más importantes.

Las artificiales se obtienen mediante la transformación de polímeros obtenidos de la naturaleza, como la celulosa y las proteínas; por esta razón, estas fibras se deben considerar como una materia prima renovable.

En la mayor parte de los casos, las fibras químicas se fabrican procediendo a la extrusión del fluido viscoso de hilatura a través de los pequeños agujeros de una hilera [76]. Para ello, primero se obtiene la masa de hilatura, por disolución o fusión del polímero, y después esta masa es impulsada por una bomba que la hace salir a través de la hilera de extrusión, que es una placa que tiene pequeños agujeros; por cada uno de ellos sale un pequeño chorro de polímero que, al solidificarse, se transforma en un filamento sólido que luego se somete a estiraje. Los filamentos se 
pueden recoger como un hilo continuo o se puede recoger como un cable para luego cortarlo y obtener la fibra cortada.

Las fibras de celulosa industrial son de varios tipos y se diferencian entre sí en el procedimiento de obtención, aunque todas ellas se engloban bajo la denominación de celulosa regenerada, queriendo indicar con este nombre que su obtención se lleva a cabo disolviendo la celulosa y luego regenerándola con forma de filamento. También reciben la denominación de rayones. Otras fibras de este grupo son los acetatos de celulosa, que se obtienen también a partir de la celulosa, aunque en este caso es modificada químicamente por la acetilación de sus grupos hidroxilo, de forma que no se pueden considerar propiamente como polímeros de celulosa; de hecho los acetatos tienen propiedades completamente distintas del resto de las fibras celulósicas.

Las fibras sintéticas se fabrican a partir de polímeros sintéticos, que se obtienen por síntesis química a partir de productos derivados del petróleo; por esta razón, estas fibras deben considerarse como una materia prima no renovable. La fabricación de estas fibras comienza por la obtención del polímero, que es una molécula de gran tamaño molecular, a partir de un monómero, que es un producto químico de pequeño tamaño molecular, mediante una reacción de polimerización. A continuación el proceso es similar al utilizado para las fibras artificiales, es decir, se obtiene la masa de hilatura, por disolución o fusión del polímero, y luego se realiza la hilatura por extrusión para obtener los filamentos, que se pueden recoger como un hilo continuo o como un cable que posteriormente se corta para obtener la fibra cortada.

Una de las fibras sintéticas más importantes es la de poliéster, que está formada por macromoléculas lineales cuyas cadenas contienen numerosos grupos éster (-COOR-), y que contiene un mínimo del $85 \%$ de un éster de un diol con el 
ácido tereftálico. Otra es la de poliamida, formada por macromoléculas lineales cuya cadena contiene numerosos grupos amida (-CONH-) y que contiene un mínimo del $85 \%$ de agrupaciones alifáticas o cicloalifáticas. También están las acrílicas, formadas por macromoléculas lineales cuya cadena contiene al menos el $85 \%$ de acrilonitrilo.

Las fibras inorgánicas se caracterizan por la naturaleza inorgánica de su composición. Aunque tienen mucha importancia para algunas aplicaciones industriales, se utilizan poco en la industria textil, aunque con tendencia al alza. Entre las fibras inorgánicas puede citarse las de fibra de carbono, constituida al menos por un $90 \%$ de carbono y que generalmente se obtiene por carbonización de fibras orgánicas; o las de fibra metálica, constituidas por metales puros o aleaciones, etc [77].

Hay que precisar que la inmensa mayoría de las fibras textiles son aislantes, es decir, no conducen la electricidad. Por ello, un apartado especial en la industria de los textiles técnicos lo constituyen las fibras conductoras de la electricidad, que dan origen a textiles capaces de transmitir una señal eléctrica a través del propio material. Tiene aplicaciones en vestimenta antiestática, de importancia para determinada ropa laboral, como barrera para interferencias electromagnéticas, barrera para radiofrecuencia, etc.

El comportamiento antiestático de ciertos cuerpos, consecuencia de la electroconductividad, es especialmente apreciado en determinadas fibras de uso muy extendido, como la poliamida o el poliéster, que son muy propensas al desarrollo de electricidad estática. En el mercado existen desde hace mucho tiempo fibras de poliamida de comportamiento antiestático, consecuencia de la dispersión de un polímero hidrofílico (poli(óxido de etileno), por ejemplo) en un fundido de la poliamida 6.6 o 6 . El efecto antiestático de estas poliamidas ha sido considerado 
suficiente para evitar, por ej., las molestias que las prendas interiores de poliamida producen al pegarse o adherirse al cuerpo humano. Pero, a veces son mayores las exigencias y se necesitan fibras altamente antiestáticas, que posean un material electroconductor localizado en la periferia o en el interior de la fibra. En el caso de un recubrimiento, el agente electroconductor corresponde a carbono o a un metal como plata, solos o incorporados a una resina. El agente conductor presente como núcleo suele consistir en una mezcla carbono/polietileno, o en gránulos de carbono ocluidos en el interior de la fibra formando un núcleo discontinuo. Estas fibras pueden utilizarse en proporción $100 \%$ o mezclarse con otras de la misma familia pero de comportamiento no antiestático [78].

Los conductores eléctricos son relativamente fáciles de manejar en procesos de fabricación de textiles. Pero hay que tener en cuenta que las fibras o hilos de metal, carbono o polímeros conductores son también materiales en cierto modo rígidos y quebradizos, algo más pesados que la mayoría de las fibras textiles, con lo que a veces es difícil producir mezclas homogéneas [79].

En el caso de utilizar hilos conductores metálicos como elemento transmisor de conductividad eléctrica con alta resistividad, la distribución de los hilos en la estructura, así como el ligamento escogido, determinarán en buena medida el resultado final obtenido.

Un apartado interesante lo constituyen los recubrimientos de plata (ión $\mathrm{Ag}^{+}$) sobre fibras textiles, y que se puede utilizar no sólo en fibras sino también en hilos y en tejidos. Este es el caso, por ejemplo, del ProTex $\mathrm{Ag}{ }^{\circledR}$, que es un producto textil que tiene una capa de plata pura permanentemente unida a su superficie. El proceso permite a la fibra, hilo o tejido, retener sus inherentes propiedades textiles y, por tanto, ser utilizados en los procesos textiles normales, Proporciona, entre otros, conductividad térmica y conductividad eléctrica a los textiles fabricados con ellos. 
El fabricante dice que resiste como mínimo 150 lavados de la materia que soporta este recubrimiento [80].

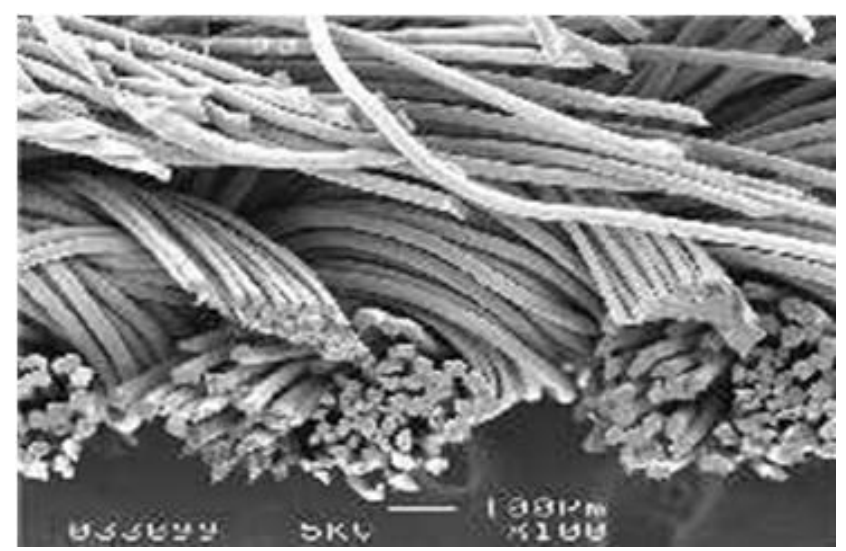

Figura 1. 14. Fibras con recubrimiento de ión Ag+ (ProTex Ag®).

\subsubsection{Tejidos de calada.}

Bajo el punto de vista técnico, con este nombre generalmente se conoce el género obtenido en forma de lámina más o menos resistente, elástica y flexible, mediante el cruzamiento y enlace de dos series de hilos: una longitudinal y la otra transversal [81]. A la serie de hilos longitudinales se les llama hilos de urdimbre y a la serie de hilos transversales se les llama hilos de trama.

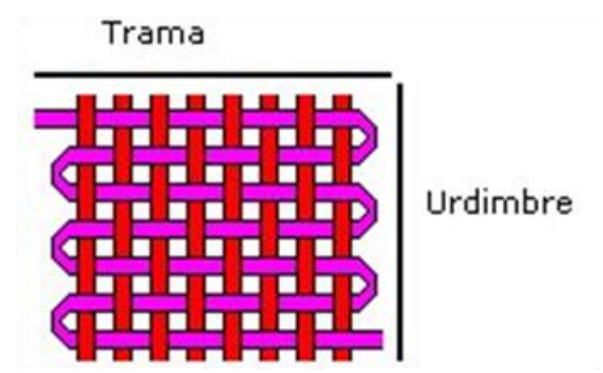

Figura 1. 15. Trama y urdimbre de un tejido. 
Estos hilos se cruzan y entrelazan según una disposición previamente establecida denominada "ligamento", formando una estructura tejida. El ligamento se representa en un papel cuadriculado donde cada columna es un hilo (urdimbre) y cada fila una pasada (trama). El número mínimo de hilos y pasadas necesario para representar el ligamento se denomina curso del ligamento, y se repite en el tejido en dirección longitudinal y trasversal. Atendiendo a la manera en que están constituidos, los ligamentos pueden clasificarse en simples (tafetán, sarga, raso o sus derivados) o compuestos. La representación de los ligamentos simples se muestra en la figura 1.16 .

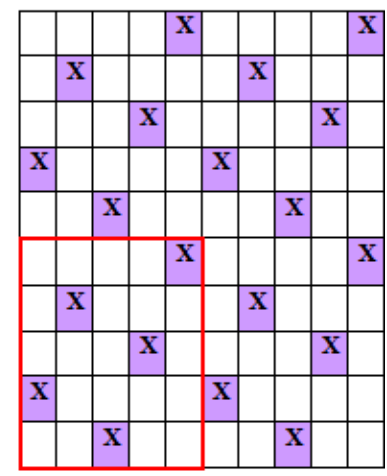

Figura 1. 16. Representación de un ligamento.

El proceso habitual de producción de tejidos implica una serie de etapas que son las siguientes [82]:

1) Obtención de fibras naturales o producción de sintéticas.

2) Procesado de las fibras.

3) Fabricación de hilos a partir de las fibras (hilado).

4) Fabricación de los textiles con los hilos de la etapa anterior (tejido).

5) Acabado. De acuerdo a la variedad de las telas y materias primas, el tipo y número de procesos varía. 
La manipulación de ciertas fibras, como poliéster, poliamida, etc., puede causar que se carguen excesivamente de electricidad estática, perturbando el proceso. Por ello, se procede a dotar a estas fibras de productos antiestáticos llamados ensimajes y suele realizarse previamente a la operación de mezclado de fibras [83].

Además de la fabricación, un apartado importante en el estudio de los tejidos -con aplicación en este trabajo-, es su identificación cuando ya se dispone de un tejido pero no se conocen sus características. Como los tejidos están formados por fibras, las pruebas de identificación de éstas pueden dividirse en dos grandes grupos: el que se funda en las propiedades físicas de las fibras, como longitud, finura, brillo, aspecto microscópico, etc., y el que se orienta a las propiedades químicas de las mismas, es decir, a las reacciones y comportamientos de cada clase de fibra al arder, en presencia de determinados reactivos, en el color que toman al ser tratados con líquidos colorantes, etc. [84].

Pero, además de la composición del tejido, es decir, de las fibras de que se compone y en qué porcentajes, hay otras características que es necesario determinar para caracterizarlo, como son el grosor del hilo utilizado, los hilos utilizados en cada dirección, etc. Estas características vienen recogidas en diversos conceptos, de los cuales los principales son los siguientes [85]:

- Composición. Todos los productos textiles que se comercializan están obligados a llevar una etiqueta de composición, es decir, deben figurar las distintas fibras de que se componen y sus porcentajes.

- Masa laminar. Es la masa por unidad de superficie del tejido.

- Densidad. La densidad de un tejido nos indica el número de hilos por unidad de longitud y se determina tanto en urdimbre como en trama. Siendo la densidad por urdimbre el número de hilos por centímetro 
(hilos/cm). Por trama se da como el número de pasadas por centímetro (pasadas $/ \mathrm{cm}$ ).

- Ligamento. Es la ley según la cual los hilos se cruzan y enlazan con las pasadas para formar el tejido. Su representación en superficie cuadriculada tiene también ese nombre.

- Título o masa lineal de los hilos. Es su peso por unidad de longitud. Existen dos sistemas de numeración: directos e inversos. El directo nos proporciona el peso de una determinada longitud, mientras que el inverso la longitud contenida en un determinado peso. En fibras de sección circular (o asimilable) este término se relaciona con el diámetro mediante la siguiente ecuación:

$$
\phi=\sqrt{(4 \cdot N \cdot 100) /(\pi \cdot \gamma)}
$$

Donde:

$\phi$, diámetro del hilo $(\mu \mathrm{m})$.

$\mathrm{N}$, título del hilo (dtex).

$\gamma$, peso específico de la fibra que lo compone.

- Coeficiente de densidad. El coeficiente de densidad (Kdtex) es un parámetro que relaciona el título de los hilos con la densidad del tejido. Se puede expresar también en métrico inverso. Se calcula por la siguiente fórmula:

$$
\mathrm{K}_{\mathrm{d}}=\frac{\text { Kdtex }}{31,62}
$$

\% Tupidez. Este porcentaje representa el coeficiente de densidad calculado en relación con su valor máximo posible y, por tanto, proporciona una idea de lo apretados que están los hilos. 


\subsubsection{Telas no tejidas.}

Las telas no tejidas o, simplemente, "no tejidos" (en inglés, nonwoven fabrics), están formadas por fibras entrelazadas entre sí formando una especie de velo o manta, a la que se le da consistencia por procedimientos mecánicos, térmicos o químicos, pero sin que sea necesario convertir las fibras en hilo [86] ni, claro está, ser tejidas en un telar.

La fabricación de no tejidos pasa por las etapas intermedias de formación del "velo" y de la "napa". El velo es la estructura textil laminar intermedia obtenida por deposición uniforme de fibras o filamentos (con eventual presencia de otros materiales, como absorbentes, etc.), y se suele realizar en una carda, aunque hay otras posibilidades. Con frecuencia, para formar el no tejido es conveniente superponer varios velos, obteniéndose lo que se llama una "napa", que es a la que se da consistencia. La consolidación de la napa, o directamente del velo, se realiza inmediatamente después de su formación, obteniéndose el producto final, la tela no tejida que, eventualmente, puede recibir aún tratamientos de acabado, como tintura, chamuscado, etc. [87].

Las telas no tejidas se pueden consolidar por vía seca (punzonado), por vía húmeda (ligado químico o ligado térmico) y por vía fusión (hilatura directa). La más corriente es la de punzonado.

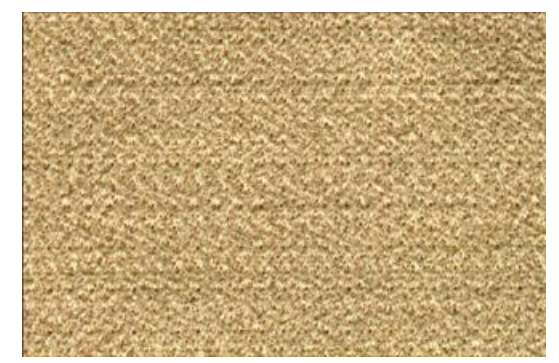

Figura 1. 17. Tela no tejida punzonada. 
Dentro de los no tejidos los hay desechables y los hay de larga duración. Por ejemplo, los productos para higiene (pañales, toallitas sanitarias, desmaquillantes, de manos,...) son desechables. En medicina se utilizan como batas de hospital y de cirugía, sábanas de quirófano, envoltorios de cirugía (la porosidad permite la esterilización de los instrumentos). Como geotextiles, como tela soporte para el asfalto de las carreteras, redes para impedir desprendimientos en trincheras en carreteras, geomembranas de protección, para la construcción de canales, sistemas de drenaje, control de erosión, etc. Como filtros, en la industria automovilística, en la extracción de minerales, filtración de gases contaminados con partículas o con productos químicos en cementeras, siderúrgicas, etc. Y así otras muchas aplicaciones.

\subsection{Evaluación de la electricidad estática en los materiales textiles.}

La cuantificación de la electricidad estática es una de las asignaturas pendientes, ya que presenta notables dificultades. Hasta la fecha resulta difícil obtener no solo valores absolutos, sino incluso lograr medidas relativas de algún parámetro que esté relacionado con la electricidad estática, con una buena reproducibilidad. Para una mejor comprensión se distingue la evaluación en sus dos fases principales: la generación y la disipación. Aunque se traten por separado, estas fases pueden coexistir e interrelacionar una con la otra.

\subsubsection{Evaluación de la generación de la electricidad estática en los materiales textiles.}

La medición de la formación de electricidad estática ha sido estudiada a partir de dos técnicas: en materiales conductores, a través de un voltímetro que 
capta la diferencia de potencial que hay entre la parte cargada del conductor y tierra, y en materiales no conductores mediante un método indirecto, a través de un medidor de intensidad de campo, ya que las cargas en el material generan un campo eléctrico que se puede determinar [88].

La formación de cargas electrostáticas se ha detectado en diversos sectores de la industria textil. Normalmente, su formación conlleva perjuicios económicos. Por ejemplo, en determinados trabajos con utilización de máquinas plegadoras. En la figura 1.18 se muestra la intensidad de campo generado en una máquina plegadora a lo largo de un ciclo de trabajo.

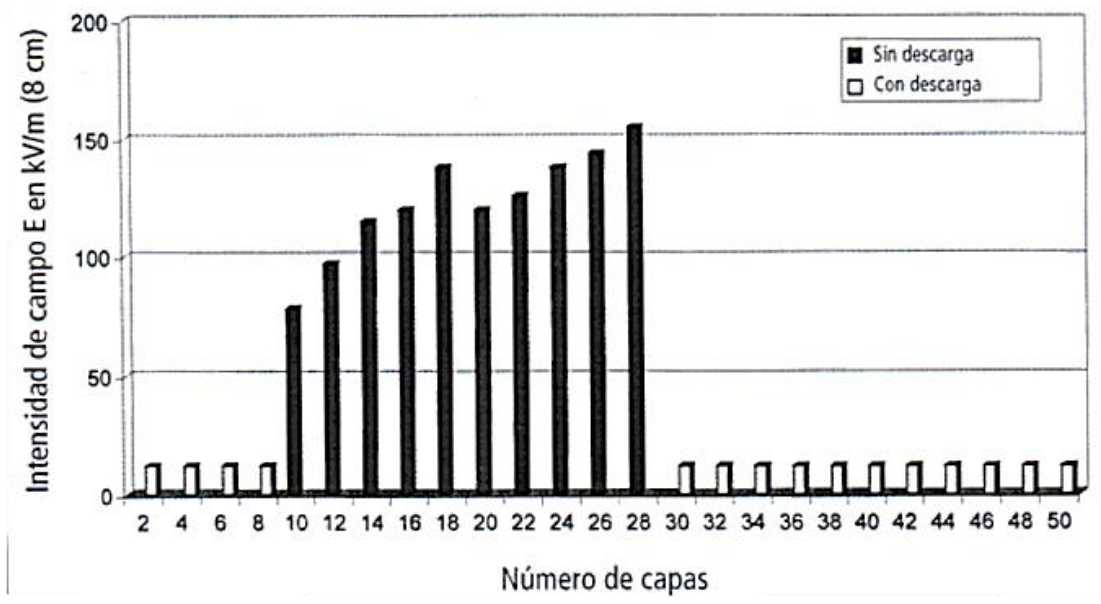

Figura 1. 18. Generación de cargas electrostáticas en una máquina plegadora.

En este experimento se situó en la máquina un dispositivo de descarga que se conectó y desconectó para comprobar su eficacia. Se observa cómo al tener conectado el dispositivo de descarga la intensidad del campo es constante a lo largo de su ciclo de trabajo, pero si se desconecta, a partir de la capa 10 hasta la 28 se ve como hay un incremento de intensidad de campo al aumentar el número de capas. Pero no solo en el ámbito industrial textil se generan cargas electrostáticas, en los ensayos realizados en el uso de ropa confirman la fuerte y variada tendencia de 
ciertos productos textiles a cargarse electrostáticamente en función de la combinación de materiales. Es más, la utilización de "ropa interior" influye drásticamente en la generación de carga, pudiéndose alcanzar el triple del nivel de carga en la ropa exterior que sin su utilización [89]. Además el comportamiento de un mismo artículo con acabados diferentes puede mostrar intensidades de campo muy variados, tal y como se muestra en la figura 1.19. En ella se ve como el tejido con color azul da una intensidad de campo mayor, aunque a lo largo del tiempo se disipe parte de su carga. En otros colores no ocurre esto y la carga permanece a lo largo del tiempo, como en los azules marinos.

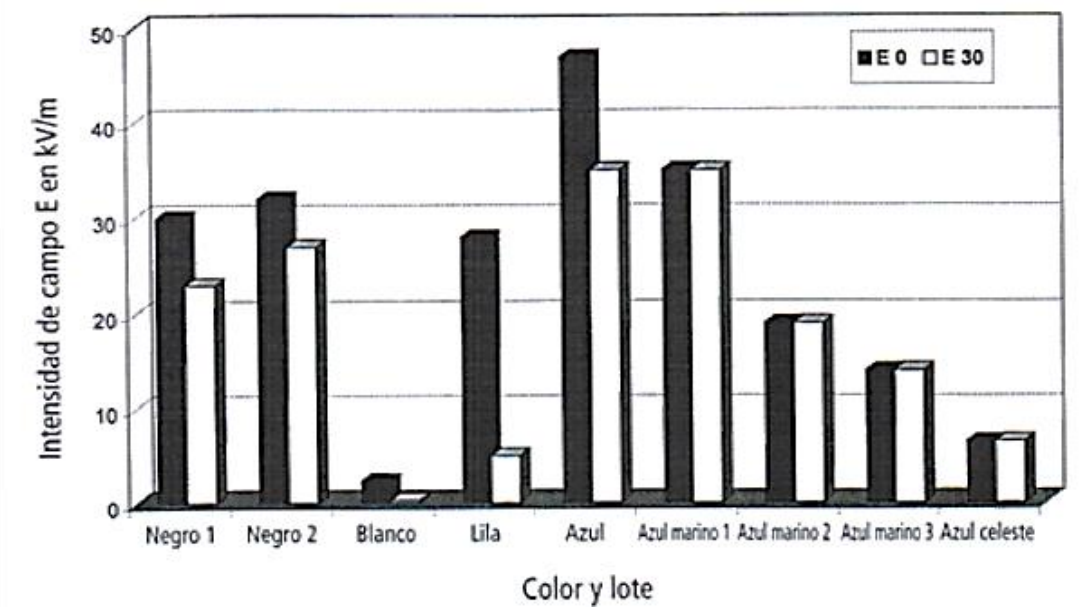

Figura 1. 19. Generación de cargas electrostáticas en una máquina plegadora en un mismo artículo textil con acabados diferentes. Para cada color, la columna oscura indica la carga generada, mientras que la clara a su lado, la que queda después de disiparse una parte.

\subsubsection{Evaluación de la disipación de la electricidad estática en los materiales textiles.}

Existen varios parámetros eléctricos que evalúan el comportamiento de la disipación de la electricidad estática en los materiales y, a su vez, varios medios 
para la obtención de sus medidas. De todos estos parámetros el más habitual y práctico es la obtención de la resistencia eléctrica de la materia (medido en ohmios, $\Omega$ ), es decir, conseguir el valor de oposición que ofrece un material al paso de la corriente entre sus dos extremos; esto va a depender del tipo de material y de su geometría [90]. Debido a la elevada resistencia eléctrica de los materiales textiles objeto de estudio, ya que se tratan de materiales aislantes, se tiene que utilizar un aparato de medida de sensibilidad elevada.

La resistencia eléctrica es específica de una muestra determinada, es decir, de un tipo de material con unas dimensiones concretas, pero no define la del tipo de material. Para ello, debe calcularse la resistividad eléctrica, que es un término propio del material, pero que está ligado con la resistencia eléctrica de una muestra de ese tipo de material.

Se sabe, por tanto, que la resistividad eléctrica es una importante característica de los materiales, y se define como la resistencia al paso de la corriente eléctrica que presenta una figura cúbica $\left(1 \mathrm{~m}^{3}\right.$ de material), entre dos caras opuestas de $1 \mathrm{~m}^{2}$ y con una distancia de $1 \mathrm{~m}$ entre ellas. Esta resistividad se expresa en Ohmios metro $(\Omega \cdot \mathrm{m})$ y es una constante del material [91]. Íntimamente vinculado a este concepto, en muchos materiales se define la conductividad eléctrica, que es la inversa de la resistividad eléctrica, término que nos indica la mayor o menor capacidad para conducir la corriente eléctrica del material [92]. Los materiales textiles, según los diferentes niveles de conductividad eléctrica (o de resistividad, que es la inversa), se pueden clasificar en cuatro grupos ya que ofrecen diferentes propiedades [93]. En la figura 1.20 se muestra esta clasificación atendiendo a su propiedad conductora. 


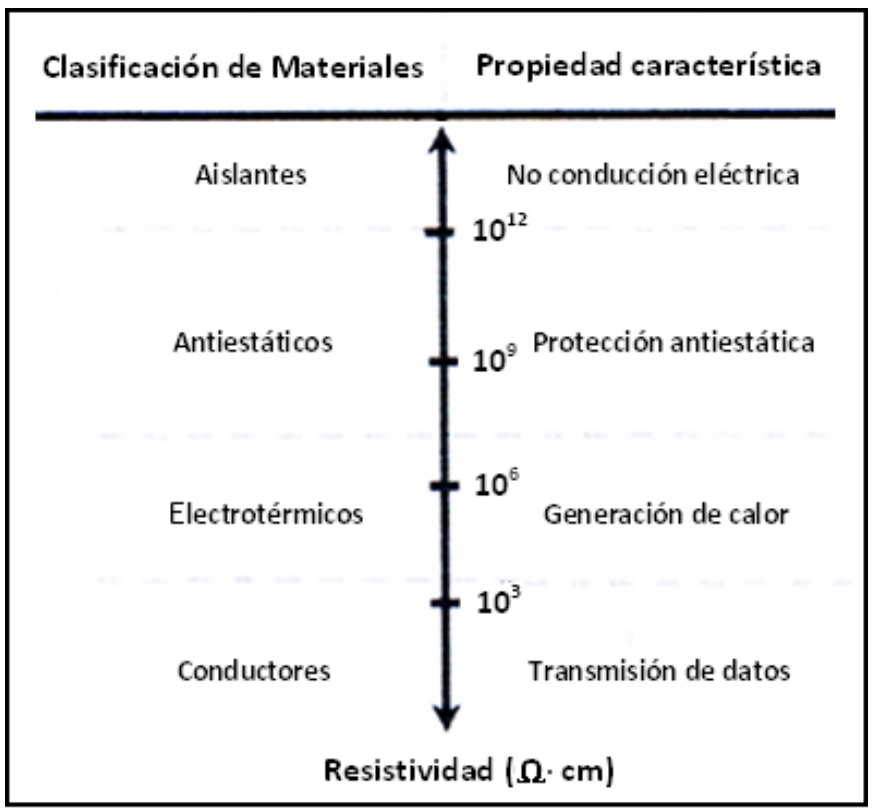

Figura 1. 20. Clasificación de los materiales textiles en función de su resistividad, en $\Omega \cdot \mathrm{cm}$.

Aclaremos los términos de la clasificación:

1. Aislantes. Son aquellos materiales que prácticamente no permiten el paso de una señal eléctrica a través del propio material textil, ya que poseen una conductividad muy pequeña.

2. Antiestáticos. Son tejidos con propiedades conductoras bajas pero suficientes como para ser utilizados como protección antiestática y, por ello, se denominan tejidos con disipación electrostática. Se trata de tejidos homogéneos, de forma que las propiedades eléctricas son constantes en toda la superficie del tejido. Estos tejidos se pueden considerar tejidos técnicos, ya que su función es en parte "pasiva".

3. Electrotérmicos. Son tejidos de resistencia no muy alta, que al aplicar una tensión elevada generan calor, y por eso se denominan tejidos electrotérmicos. Su 
conductividad no es muy buena, pero suficiente para que con una cierta tensión se pueda generar el efecto de calor. No obstante, la conductividad de este tipo de tejidos varía en un amplio rango y la disipación de calor dependerá de la tensión aplicada. Pueden ser tejidos homogéneos, es decir, con las mismas propiedades en toda la superficie del tejido, o heterogéneos, que tendrían una estructura conductora en el tejido en forma de circuito. Dentro de esta clasificación están los tejidos denominados de protección electromagnética o EMI. Son aquellos tejidos con las propiedades conductoras adecuadas para utilizarlos como aislamientos electromagnéticos. En función de su conductividad y estructura textil ofrecerán aislamiento a menores o mayores frecuencias. Por lo general se trata de tejidos homogéneos, buenos conductores y son considerados tejidos técnicos.

4. Conductores. Son aquellos tejidos denominados transmisores de datos, ya que se trata de tejidos altamente conductores que permiten la transmisión de datos en forma de pulsos eléctricos. Por lo general, se trata de tejidos heterogéneos, ya que se intenta crear un circuito tejido de transmisión de señales donde poder integrar sensores u otros dispositivos.

\subsection{Problemática de la evaluación de la electricidad estática.}

Existen diversos métodos para poder realizar la evaluación de cada una de las fases de las que se compone el fenómeno de la electricidad estática. Pero es en la última, la que se refiere a la disipación de las cargas electrostáticas, en la que determina la intensidad del campo eléctrico que se genera por la acción de las cargas electrostáticas y, por lo tanto, la mayor o menor atenuación de los problemas originados por este suceso. Por ello, en este documento se va a desarrollar un procedimiento basado en uno de los métodos que existen para la evaluación de la disipación de las cargas electrostáticas para estimar el comportamiento en esta fase de los materiales textiles, aplicándolo después a varias clases de tejidos. Hasta la 
fecha resulta difícil obtener valores absolutos, pero tampoco es nada fácil conseguir medidas relativas que tengan buena reproducibilidad. Por ello, los escasos datos experimentales publicados son difíciles de comparar entre sí, incluso si han sido obtenidos con técnicas similares pero por diferentes autores [94].

\subsection{Objetivos de la tesis.}

La finalidad de este trabajo de investigación es la elaboración y desarrollo de una metodología para determinar, en distintas condiciones ambientales, la resistencia eléctrica de los tejidos para así poder estimar el comportamiento de los diversos materiales textiles en relación con la electricidad estática. Como ya se ha indicado, esta medida no puede realizarse por métodos directos.

Para ello se realizará un estudio de las variables que modifican el valor de esta propiedad eléctrica en los materiales textiles, y se buscará la relación que existe entre la resistencia eléctrica y los parámetros que más influyen en ella, siendo necesario realizar los ensayos bajo unas condiciones de funcionamiento constantes e ir modificando cada una de las variables a estudio en las distintas series.

Podemos resumir los objetivos de este trabajo en los siguientes puntos:

1- Estudio de las propiedades eléctricas de los materiales, en especial los que poseen altas resistencias eléctricas, que es el caso de los textiles en general.

2- Estudio de la metodología más adecuada para la obtención de la característica eléctrica más importante de los materiales textiles, la resistividad.

3- Diseño, construcción y puesta en marcha de un equipo para determinar experimentalmente la resistividad de los materiales textiles, en función de las variables más influyentes. 
4- Adaptación de programas informáticos que controlan los parámetros de la experimentación y permiten procesar los resultados de las pruebas realizadas en función de los materiales textiles elegidos.

5- Estudio y discusión de los resultados obtenidos.

6- Buscar posibles relaciones entre las características eléctricas obtenidas y los parámetros que influyen en ella.

Entendemos que la determinación de la magnitud de las características eléctricas de materiales de alta resistividad y su relación con los parámetros fundamentales que lo determinan puede generar un amplio abanico de posibilidades en el mundo industrial. Y más en concreto en el sector textil, ya que la formación y acumulación de electricidad estática causa bastantes problemas, tanto en el proceso de fabricación de los tejidos (puede llegar a dar problemas de seguridad en ambientes inflamables), como en la comodidad de los usuarios en la utilización de las prendas textiles (descargas al aproximarse a tierra). 


\section{CAPÍTULO 2}

FUNDAMENTO TEÓRICO:

\section{MEDIDA DE LA RESISTENCIA ELECTRICA}

\section{DE LOS MATERIALES TEXTILES}

\section{Índice}

2.0. Resumen.

2.1. Clasificación de los materiales desde el punto de vista eléctrico. ...55

2.1.1. Materiales conductores. .......................................... 56

2.1.2. Materiales semiconductores. ...................................... 57

2.1.3. Materiales aislantes. ..................................................... 58

2.2. Características eléctricas. ............................................................. 58

2.3. Métodos de ensayo para el cálculo de la resistencia eléctrica. .......63 63

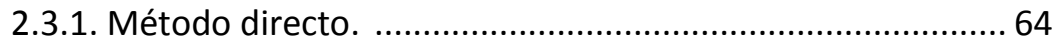

2.3.2. Métodos indirectos. .................................................... 65

2.3.2.1. Procedimiento voltiamperimétrico. .........................66 66

2.3.2.2. Procedimiento por desviación directa. ....................... 68

2.3.2.3. Procedimiento por voltímetro estático. .................... 70

2.3.2.3.1. Procedimiento por comparación de corriente. .. 70

2.3.2.3.2. Procedimiento por descarga de condensador. ... 72 


\section{CAPÍTULO 2}

\section{FUNDAMENTO TEÓRICO:}

\section{MEDIDA DE LA ELECTRICIDAD ESTÁTICA EN LOS MATERIALES TEXTILES}

\subsection{Resumen.}

En este capítulo se clasifican y describen los diferentes materiales existentes desde el punto de vista eléctrico.

Además se realiza un análisis de los parámetros eléctricos de los materiales para evaluar cuáles son los más adecuados para estimar el comportamiento frente a la electricidad estática.

Se describen, asimismo, de forma detallada los métodos de ensayo existentes para la obtención de la resistencia eléctrica de un material, ya que se trata del parámetro que nos determina la resistividad eléctrica, característica eléctrica más representativa del material. Como los materiales objeto de esta tesis son materiales textiles, es decir, dieléctricos, se hace un estudio más completo de los procedimientos indirectos, es decir:
A) Procedimiento voltiamperimétrico.
B) Procedimiento por desviación directa.
C) Procedimiento por voltímetro estático. 


\subsection{Clasificación de los materiales desde el punto de vista eléctrico.}

Existen numerosas clasificaciones posibles de los materiales atendiendo a sus distintas características. Pero, al estudiarlas desde el punto de vista eléctrico, la clasificación se realiza según la capacidad de movimiento de sus cargas. Por ello, antes de seguir adelante es conveniente caracterizar su estructura desde el punto de vista eléctrico.

Los materiales a estudio son sólidos y, por ello, suele decirse que cada átomo está fijo respecto a los otros átomos del mismo sólido. Pero esta afirmación es solo cierta en parte, pues los átomos pueden vibrar en torno a una hipotética posición de equilibrio, por lo que sería más acertado decir que están confinados en un pequeño volumen. No obstante, a pesar de su vibración, los átomos y las moléculas de los sólidos se consideran partículas fijas, mientras que las partículas que pueden moverse a través del volumen de todo el cuerpo se llaman partículas libres.

Si una cantidad de energía comunicada a una partícula no logra sacarla de un determinado volumen, se dice que esa partícula está confinada en ese volumen para esa energía. Es decir, es "fija" o "ligada" al volumen considerado, siempre que éste sea muy pequeño respecto al volumen total del sólido. Si la partícula fija tiene carga eléctrica se llama carga fija o carga ligada. Y, si no es fija, se llama partícula libre, y si además tiene carga eléctrica, se llama carga libre [95].

Entre los átomos de los cuerpos hay grandes espacios vacíos. Para una mejor comprensión supongamos el vacío entre las estrellas (es una buena imagen del vacío entre los átomos de los sólidos). Alrededor del núcleo de cada átomo giran sus electrones, de forma parecida a como alrededor del sol giran los planetas que le rodean. Pero, aumentándoles su energía, algunos electrones de la última capa 
pueden abandonar el átomo al que pertenecen y convertirse en electrones libres, que vagan en el vacío entre los átomos, como algunos cuerpos celestes se mueven por el espacio sin permanecer girando alrededor de ninguna estrella.

Los electrones libres se mueven en el espacio que existe entre las órbitas más externas de átomos contiguos, que en muchos casos es un espacio proporcionalmente enorme y vacío. Los electrones que giran en la última órbita se llaman electrones de valencia y son los primeros que se liberan.

Las moléculas de los líquidos y gases son partículas libres, pues se mueven por todo el volumen del fluido. Si algunas de esas partículas tienen carga eléctrica, son cargas libres. Por ejemplo, una disolución acuosa de una sal, de un ácido o de una base, consta de moléculas neutras y de iones positivos y negativos. Estos iones son cargas libres. En la atmósfera, junto a las moléculas neutras de oxígeno, nitrógeno, etc. hay iones de éstos u otros cuerpos originados por los rayos cósmicos (partículas subatómicas que proceden de fuera de la atmósfera, del espacio exterior y son una de las causas de ionización de las moléculas del aire), por tormentas o por otros motivos, que también son cargas libres.

Atendiendo a esta característica intrínseca de los materiales y, en función de las cargas libres que posea, desde el punto de vista eléctrico, los materiales se dividen en tres grandes grupos: conductores, semiconductores y aislantes [96].

\subsubsection{Materiales conductores.}

Se define material conductor a todo volumen con cargas libres y, por tanto, no importa el estado en que se encuentre ese material [97]. Los metales son los materiales conductores por excelencia, ya que poseen electrones libres sin necesidad de aporte de energía, conservándolos incluso en el cero absoluto de temperatura. 
Pero la existencia de cargas libres en un cuerpo no implica que esté cargado, pues la carga ligada puede ser opuesta a la libre. De hecho eso es lo que habitualmente ocurre en los metales: la carga total, suma de la libre y de la ligada, es cero, de forma que el conductor permanece en estado neutro.

\subsubsection{Materiales semiconductores.}

Se define material semiconductor a todo volumen que tiene algunas cargas libres, cuyo número está en función de condiciones externas [98]. Podría decirse que son un término medio entre los conductores y los aislantes. Cuando se obtienen cristales de Ge o Si de gran pureza (átomos extraños en proporción menor de 1 por cada $10^{10}$ ), se dice que son semiconductores intrínsecos. Estos elementos, que pertenecen al grupo IV del sistema periódico, tienen cuatro electrones en la última capa; cristalizan de forma que cada átomo está rodeado de otros cuatro, compartiendo un electrón de valencia con cada uno de los átomos vecinos, en enlace covalente.

A temperatura ambiente la energía térmica de los átomos origina el salto de algún electrón de valencia, que queda libre en la estructura del material. A la vez se origina un lugar vacío, denominado hueco. Estos huecos contribuyen junto a los electrones libres al fenómeno de la conducción en el semiconductor. A los electrones libres y a los huecos se les denominan portadores, pues transportan la carga que origina la corriente eléctrica cuando se aplica un campo eléctrico. Las propiedades de conducción de los semiconductores puros o intrínsecos se modifican añadiendo una pequeña proporción de determinadas impurezas, dando entonces lugar a los semiconductores extrínsecos. Dependiendo de la concentración de las impurezas añadidas el comportamiento es diferente, por lo que el fabricante debe definir las propiedades resultantes para poder incorporar estos materiales al circuito y que realicen la función encomendada de forma controlada. 


\subsubsection{Materiales aislantes.}

Se define como material aislante a todo volumen sin cargas libres [99]. Los cuerpos con enlaces químicos que mantengan todos los electrones ligados a sus átomos son aislantes. El vidrio, la mica y ciertos plásticos se encuentran entre los mejores materiales aislantes. Los cuerpos aislantes se llaman también dieléctricos. Pero en realidad, aunque a temperaturas próximas al cero absoluto los enlaces covalentes mantienen todos los electrones ligados a los átomos, a temperaturas más altas, algunos pocos electrones de las últimas capas pasan a ser electrones libres.

Los dieléctricos son un conjunto de moléculas, y cada molécula tiene cargas positivas y negativas que suman cero, pero que se pueden imaginar separadas por pequeñas distancias; por eso cada molécula puede describirse por un conjunto de dipolos. Esa será la hipótesis de partida para estudiar los dieléctricos. Además la suma vectorial de los momentos dipolares de todos los dipolos que describen una molécula se llama momento dipolar de esa molécula. Las moléculas cuyo momento dipolar no es cero se llaman moléculas polares, mientras que si es cero se conocen como moléculas apolares o no polares. Por ejemplo, las moléculas de agua son polares y las de dióxido de carbono apolares. Por tanto, desde el punto de vista electrostático, un dieléctrico puede describirse por un conjunto de dipolos puntuales situados en un volumen, lo que se llama una distribución volúmica de esos dipolos puntuales.

La mayoría de las fibras textiles son materias aislantes, al igual que los tejidos a que dan lugar.

\subsection{Características eléctricas.}

En los apartados anteriores se han definido los tipos de materiales en función de las cargas libres que posean. En la figura 2.1 se representa un corte por 
el plano del papel de una superficie de un material; si hay carga eléctrica neta que pasa hacia un lado de la superficie se dice que hay corriente eléctrica a través de dicha superficie y hacia ese lado. Por lo tanto se define corriente eléctrica como el paso neto de carga a través de una superficie $S$.

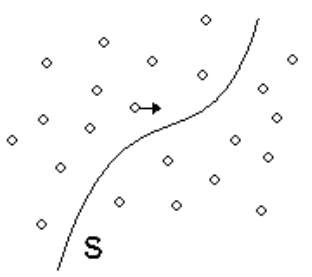

Figura 2. 1. Representación de carga que pasa a través de una superficie $\mathrm{S}$.

Para poder comparar corrientes una primera magnitud muy útil es la intensidad de la corriente a través de una superficie en un determinado sentido, que se define como la carga que ha pasado a través de dicha superficie en ese sentido en cada unidad de tiempo:

$$
i(t)=\frac{d q(t)}{d t}
$$

Donde:

$i(t), \quad$ intensidad de la corriente (A).

$q(t)$, carga que ha atravesado la superficie en el instante $t(\mathrm{C})$.

Como se ha mencionado, debe existir un movimiento neto de cargas y, para ello, debe haber una fuerza en un determinado sentido que permita su movimiento a una velocidad. Esta velocidad se conoce como velocidad de arrastre, v, y la fuerza que se aplica campo eléctrico, $\mathbf{E}$ (fuerza sobre cada unidad de carga positiva). 
Ambos están relacionados proporcionalmente a través de una constante, denominada movilidad de la partícula $(\mu)$, según la ecuación 2.2.

$$
\mathbf{v}=\mu \cdot \mathbf{E}
$$

Donde:
$\mathbf{v}$, velocidad de arrastre $(\mathrm{m} / \mathrm{s})$.
$\mu$, movilidad de la partícula $\left(\mathrm{m}^{2} / \mathrm{sV}\right)$.
E, campo eléctrico $(\mathrm{V} / \mathrm{m})$.

La figura 2.2 representa un cilindro en el interior de un material con una concentración de cargas libres "n", sometido a un campo eléctrico $\mathbf{E}$ que origina una velocidad de arrastre de las cargas y, por tanto, un paso neto de cargas en el sentido del campo.

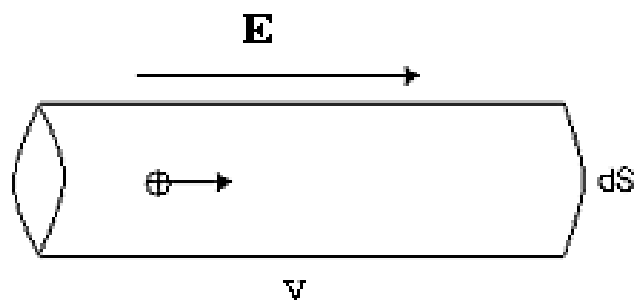

Figura 2. 2. Cilindro de generatriz igual a la velocidad de arrastre v.

La carga neta que cruza cada segundo es el resultado de la operación " $q \cdot n \cdot v \cdot d S$ ", donde " $q \cdot n \cdot v$ " representa la intensidad por unidad de superficie, y recibe el nombre de densidad de corriente. Su módulo vale en cada punto la intensidad que por cada unidad de superficie atraviesa una superficie perpendicular a la velocidad de arrastre.

La densidad de corriente está relacionada directamente con el campo aplicado a través de la ecuación: 


$$
\boldsymbol{j}=\mathrm{q} \cdot \mathrm{n} \cdot \mu \cdot \mathbf{E}
$$

Donde:

j, densidad de corriente $\left(\mathrm{A} / \mathrm{m}^{2}\right)$.

q, carga de la partícula (C).

$\mathrm{n}$, concentración de partículas (partículas $/ \mathrm{m}^{3}$ ).

$\mu$, movilidad de la partícula $\left(\mathrm{m}^{2} / \mathrm{sV}\right)$.

E, campo eléctrico $(\mathrm{V} / \mathrm{m})$.

A la relación entre densidad de corriente y campo eléctrico se le da el nombre de conductividad $(\sigma)$ y su unidad en el sistema internacional es el Siemens por metro, $\mathrm{S} / \mathrm{m}$ (es la equivalencia de $\Omega^{-1} \cdot \mathrm{m}^{-1}$ ). Este valor siempre es positivo ya que, si las cargas son negativas, $\mu$ y $q$ también lo serían y su producto es positivo. Por tanto, cualquiera que sea el signo de la carga de los portadores, la densidad de corriente a que dan lugar siempre tiene el sentido del campo. Esta conductividad puede ser o no uniforme, es decir, depende de si su valor varía o no según el campo aplicado. Si no varía se denominan "medios o materiales lineales" $(\mathbf{j}=\sigma \cdot \mathbf{E})$ y si lo hacen "medios o materiales no lineales" $(\mathbf{j}=\sigma(E) \cdot \mathbf{E})[49]$.

a)

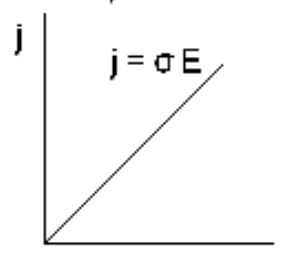

b)

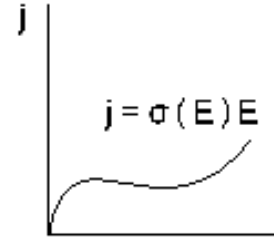

Figura 2. 3. a) Medio lineal b) Medio no lineal.

Un término también muy utilizado en ingeniería es la inversa de la conductividad, es decir, la resistividad $(\rho)$. Su unidad en el sistema internacional es el ohmio metro $(\Omega \cdot \mathrm{m})$.

$$
\rho=\frac{1}{\sigma}
$$


Cuando se tiene un volumen determinado de un material se obtiene un valor concreto de movilidad de las cargas libres a través de ese material, denominado conductancia $(\mathrm{G})$. Su unidad en el S.I. es el Siemens, $\mathrm{S}\left(\Omega^{-1}\right)$. Este término es menos utilizado que su inversa, la resistencia $(\mathrm{R})$, cuya unidad es el ohmio $(\Omega)$.

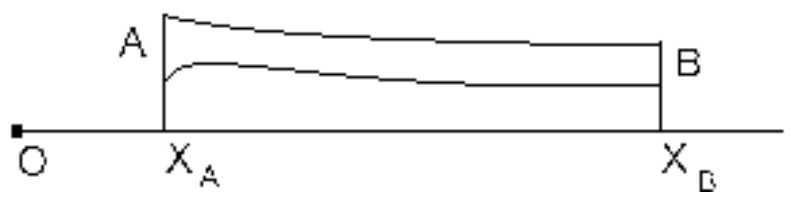

Figura 2. 4. Hilo conductor de sección dependiente de x.

Si tenemos un hilo conductor, como el mostrado en la figura 2.4, el cálculo de este término es:

$$
\boldsymbol{j}=\sigma \cdot \mathbf{E}=-\sigma \cdot \frac{d V}{d x}
$$

Desarrollando esta ecuación se obtiene la ecuación [100]:

$$
\mathrm{R}=\int_{A}^{B} \frac{\rho}{S} d x
$$

Si la resistividad y la superficie no dependen de x, por ejemplo en hilos de sección uniforme, entonces quedaría:

$$
\mathrm{R}=\rho \cdot \frac{l}{S}
$$

Donde:
$\mathrm{R}$, resistencia del material $(\Omega)$.
$\rho$, resistividad del material $(\Omega \cdot \mathrm{m})$.
l, longitud del material (m).
$\mathrm{S}$, superficie de la sección del material $\left(\mathrm{m}^{2}\right)$. 
En relación con los hilos de los tejidos podemos referirnos a varios conceptos de finura, la diametral, la seccional, la volumétrica y la gravimétrica. Para nuestro análisis interesa conocer la finura diametral y la seccional.

Se dice que un hilo tiene finura diametral si el hilo es de sección circular y constante. Está expresada por el valor del diámetro de la sección transversal del hilo y normalmente se mide en micras $\left(1 \mu \mathrm{m}=10^{-3} \mathrm{~mm}=10^{-6} \mathrm{~m}\right)$. Además, se dice que tiene finura seccional si la superficie media de la sección es constante en toda su longitud. Por tanto, si un hilo tiene finura diametral y seccional se caracteriza por el área del círculo correspondiente a su sección y el diámetro de esta sección respectivamente. Los hilos de los tejidos analizados van a tener tanto finura diametral como seccional, con los valores correspondientes a cada hilo.

\subsection{Métodos de ensayo para el cálculo de la resistencia eléctrica.}

De los conceptos desarrollados en el apartado anterior, el más práctico para evaluar el comportamiento de los materiales frente a la electricidad estática es "la resistencia eléctrica". A partir de ella se pueden ir calculando el resto de los parámetros eléctricos relacionados a través de las ecuaciones correspondientes.

Por tanto, el parámetro más importante a obtener es la resistencia eléctrica y, para ello, se pueden utilizar varios métodos, en función de la magnitud de su valor para el material a estudiar. Existen métodos sencillos, los directos, en las que se obtiene el valor de forma inmediata. Éstos se utilizan cuando los valores son pequeños y medibles por los aparatos de medida convencionales disponibles en el mercado. Sin embargo, cuando su magnitud impide la medida directa a través de los aparatos de medida, se utilizan otros métodos, los indirectos, en los que la obtención del valor de la resistencia eléctrica es a través de algún otro parámetro. 
Con él y utilizando las ecuaciones correspondientes, se relacionan las variables resultantes del análisis del circuito realizado y se calcula el valor de la resistencia eléctrica del material.

Los procedimientos para el cálculo de la resistencia eléctrica se exponen a continuación.

\subsubsection{Método directo.}

El valor de la resistencia eléctrica del material se obtiene a través de un aparato de medida. Son los denominados ohmímetros y existen diversos tipos en el mercado según el alcance de medición. En la figura 2.5 pueden verse algunos de ellos; el primero es un multímetro ya que puede mostrar los valores de varios parámetros, como la intensidad y la tensión de una parte de un circuito eléctrico; el segundo es un ohmímetro de precisión y se utiliza para medir únicamente la resistencia eléctrica.
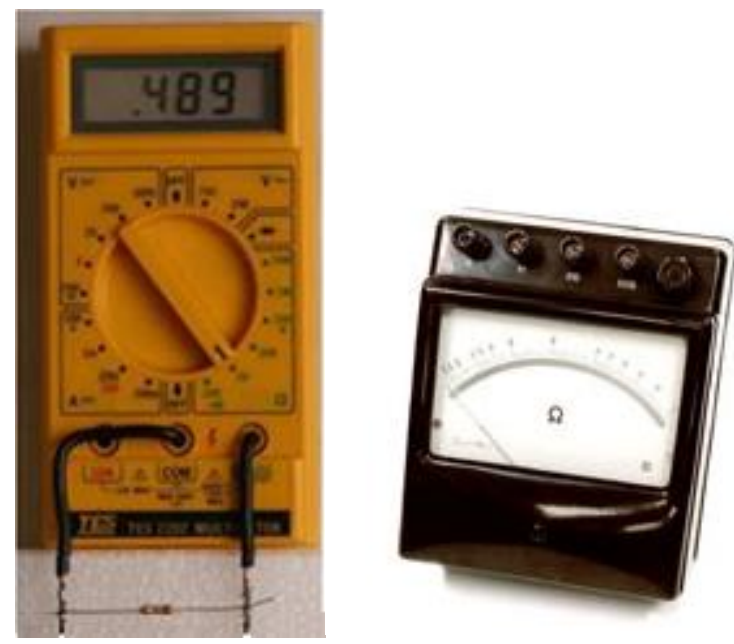

Figura 2. 5. Ohmímetros. 
En la práctica no se requiere montar ningún circuito externo y la conexión es muy sencilla, ya que simplemente hay que conectar los terminales del ohmímetro a los extremos del elemento (foto de la izquierda de la figura 2.5).

Un ohmímetro consta de una pequeña batería que aplica una tensión a la resistencia que trata de medirse, para luego, mediante un galvanómetro, medir la corriente que circula a través de la misma. La escala del galvanómetro está calibrada directamente en ohmios, ya que en aplicación de la ley de Ohm, al ser la tensión de la batería fija, la intensidad que circula a través del galvanómetro sólo va a depender del valor de la resistencia bajo medida, esto es, a menor resistencia mayor intensidad de corriente y viceversa. Existen otros tipos de ohmímetros más exactos y sofisticados, en los que la batería ha sido sustituida por un circuito que genera una corriente de intensidad constante, la cual se hace circular a través de la resistencia bajo prueba. Luego, mediante otro circuito se mide la tensión en los extremos de la resistencia y de acuerdo con la ley de Ohm se calcula el valor de su resistencia eléctrica $(\mathrm{R}=\mathrm{V} / \mathrm{I})$.

Para medidas de alta precisión la disposición indicada no es apropiada, por cuanto la lectura del medidor es la suma de la resistencia de los cables de medida y la de la resistencia bajo prueba. Para evitar este inconveniente, un ohmímetro de precisión tiene cuatro terminales, denominados contactos Kelvin. Dos terminales llevan la corriente constante desde el medidor a la resistencia, mientras que los otros dos permiten la medida de la tensión directamente entre terminales de la misma, con lo que la caída de tensión en los conductores que aplican dicha corriente constante a la resistencia bajo prueba no afecta a la exactitud de la medida.

\subsubsection{Métodos indirectos.}

Son aquellos métodos en los que no se obtiene el valor de la resistencia directamente del aparato de medida, sino que éste se calcula a través de una fórmula 
que relaciona directa o indirectamente la resistencia con otro parámetro obtenido a través del medidor.

La resistencia de los materiales textiles es generalmente elevada y en la actualidad no existen aparatos de medida que nos den su valor directamente, por lo que se usa algún método indirecto para ello. De hecho, va a ser necesaria la utilización de voltímetros electrostáticos o digitales de impedancia de entrada muy alta, ya que, de otra forma, los valores de tensión resultantes serían inmedibles [101].

Los procedimientos varían en función del valor de la resistencia a calcular y de la precisión que se quiere obtener, englobándose en tres grandes grupos que se exponen a continuación.

\subsubsection{Procedimiento voltiamperimétrico.}

Se trata de una generalización de este procedimiento que en general se utiliza para la medición de resistencias con valores no demasiados elevados, pero con algunas variantes que lo hacen apropiado para medir resistencias elevadas. El circuito eléctrico para obtener la resistencia de la muestra es el que se presenta en la figura $2.6[102]$.

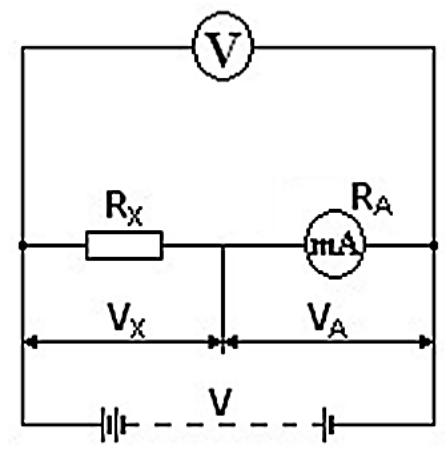

Figura 2. 6. Circuito eléctrico para el procedimiento voltiamperimétrico. 
La fuente de alimentación ha de tener una fuerza electromotriz lo más constante posible y generalmente se utiliza una batería de acumuladores de 100 a $200 \mathrm{~V}$. Por otra parte, se debe utilizar un miliamperímetro magnetoeléctrico de alta sensibilidad ya que la intensidad de corriente es muy pequeña.

Entonces la resistencia $R_{X}$ cuyo valor queremos medir, está expresada por:

$$
R_{X}=\frac{V}{I}-R_{A}
$$

La intensidad de corriente que pasa por el circuito es proporcional a la desviación de la aguja indicadora, “ $\alpha$ ”, o sea:

$$
I=k_{1} \cdot \alpha
$$

La resistencia del miliamperímetro, $\mathrm{R}_{\mathrm{A}}$, puede despreciarse, porque su valor es muy pequeño con respecto al valor de $R_{X}$; por lo tanto, queda:

$$
R_{X}=\frac{V}{I}=\frac{V}{\alpha \cdot k_{1}}
$$

Si la tensión V permanece constante, queda finalmente:

$$
R_{X}=\frac{k_{2}}{\alpha}
$$

Es decir, que la resistencia buscada, $R_{X}$, es inversamente proporcional al ángulo de desviación de la aguja del miliamperímetro.

Este procedimiento tiene el inconveniente de la sensibilidad del instrumento amperimétrico, ya que con resistencias muy elevadas se necesita de un 
miliamperímetro magnetoeléctrico de alta sensibilidad. Ello supone un equipo costoso para obtener datos fiables.

\subsubsection{Procedimiento por desviación directa.}

Se emplea, como en el caso anterior, una batería de acumuladores con fuerza electromotriz constante y un miliamperímetro magnetoeléctrico de alta sensibilidad.

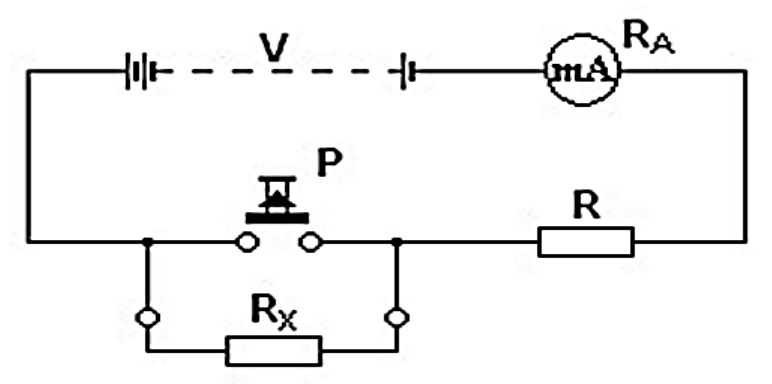

Figura 2.7. Circuito eléctrico para el procedimiento de la desviación directa.

Recuérdese que, en todos los casos, la intensidad de corriente que pasa por el circuito es proporcional al ángulo de desviación " $\alpha$ ", de la aguja indicadora. Cuando el pulsador $\mathrm{P}$ no está accionado, la resistencia a medir $\mathrm{R}_{\mathrm{X}}$ está insertada en el circuito. La resistencia total vale:

$$
R_{1}=R_{X}+R+R_{A}
$$

Y la intensidad de corriente que atraviesa este circuito es:

$$
I=k \cdot \alpha_{1}=\frac{V}{R_{1}}=\frac{V}{\left(R_{x}+R+R_{A}\right)}
$$


Cuando se acciona el pulsador, $\mathrm{P}$, la resistencia a medir $R_{X}$ queda cortocircuitada. En este caso, la resistencia total del circuito vale:

$$
R_{2}=R+R_{A}
$$

Y la intensidad de corriente que atraviesa este circuito:

$$
I_{2}=k \cdot \alpha_{2}=\frac{V}{R_{2}}=\frac{V}{\left(R+R_{A}\right)}
$$

De estas expresiones se puede deducir:

$$
\begin{aligned}
& \left(R_{X}+R+R_{A}\right)=\left(R+R_{A}\right) \cdot \frac{\alpha_{2}}{\alpha_{1}} \\
& R_{X}=\left(R+R_{A}\right) \cdot\left(\frac{\alpha_{2}}{\alpha_{1}}-1\right)
\end{aligned}
$$

En el caso en que la resistencia a medir, $R_{X}$, sea mucho más alta que la de la mayor resistencia, $R$, de que se dispone, el ángulo de desviación $\alpha_{1}$ resultará demasiado pequeño, o el ángulo de desviación $\alpha_{2}$ resultará excesivamente grande. En este caso, existen dos soluciones:

a) Medir con diferentes tensiones.

b) Conectar un shunt al miliamperímetro, cuando solamente esté en el circuito la resistencia $\mathrm{R}$.

Este método minimiza el problema de la fiabilidad de los resultados obtenidos del método anterior, aunque tiene el problema de necesitarse un equipo costoso y de la utilización de resistencias patrón de elevado valor. 


\subsubsection{Procedimiento por voltímetro estático.}

Este método es el más utilizado para la medida de resistencias elevadas y existen dos procedimientos diferentes que se detallan a continuación.

\subsection{Procedimiento por comparación de corriente.}

En este método se utiliza el voltímetro estático, por lo que se evitan varios problemas que tenían los anteriores métodos, consiguiendo poder operar con tensiones más pequeñas para obtener una buena medición. El esquema del método es el mostrado en la figura 2.8 .

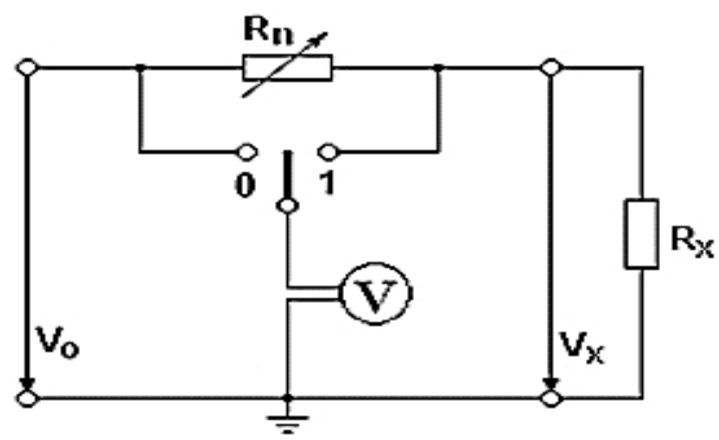

Figura 2.8. Circuito eléctrico del procedimiento por comparación de corriente.

Según se observa en la figura 2.8 , la resistencia desconocida $R_{X}$, está conectada en serie con una resistencia conocida $R_{n}$, bajo una tensión continua constante $V_{0}$ (por ejemplo, $1 \mathrm{kV}$ ). Con el voltímetro electrostático se controla primero la tensión $V_{0} \mathrm{y}$, después, se mide la tensión $V_{X}$ de la resistencia $R_{X}$. La fórmula que nos relaciona la resistencia a calcular con los valores de tensión del circuito se obtiene de la ecuación 2.19 , deducida a través de las siguientes ecuaciones. 


$$
\begin{aligned}
& V_{0}=I \cdot\left(R_{n}+R_{x}\right)=I \cdot R_{n}+I \cdot R_{x}=I \cdot R_{n}+V_{x} \\
& R_{X}=\frac{V_{x}}{I}=\frac{\left(R_{n}+R_{x}\right) \cdot V_{x}}{V_{0}} \\
& R_{X}=\frac{R_{n} \cdot V_{x}}{V_{0}-V_{x}}
\end{aligned}
$$

$\mathrm{Si} \mathrm{V}_{\mathrm{o}}$ se ajusta de forma que el voltímetro indique el valor final de la escala, ésta puede graduarse directamente en ohmios. La medición de $V_{0}$ se puede suprimir en el caso en que las tensiones estén estabilizadas en un valor exacto. Ajustando el valor de $\mathrm{Rn}$, se obtienen diferentes alcances de medida, resistencias comprendidas entre $1 \mathrm{M} \Omega$ y $10 \mathrm{~T} \Omega$. En la figura 2.9 se representa un teraohmímetro basado en este principio; según el fabricante este aparato tiene 28 alcances de medida que comprenden desde $0,6 \mathrm{M} \Omega$ hasta $5 \mathrm{~T} \Omega$, con tensiones de alimentación desde $10 \mathrm{~V}$ hasta $1000 \mathrm{~V}$, según el valor de la resistencia. Puede conectarse directamente a la red de corriente alterna de $220 \mathrm{~V}$ y $50 \mathrm{~Hz}$, ya que lleva incorporado el correspondiente equipo de rectificadores. El error de medida está comprendido entre $\pm 5 \%$, según los alcances de medida. La resistencia se obtiene directamente del aparato, aunque se debe incluir en el circuito una resistencia $R_{n}$ elevada, denominada resistencia patrón $(10 \mathrm{M} \Omega)$.

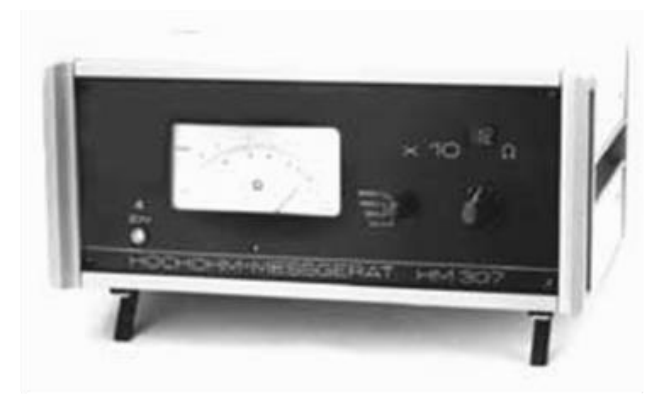

Figura 2.9. Teraohmímetro. 
Este método tiene el problema de la disposición de las resistencias patrón, de elevado valor. Para obtener rangos de medidas entre $1 \mathrm{M} \Omega$ y $1000 \mathrm{~T} \Omega$ se debe disponer de resistencias patrón de $10 \mathrm{M} \Omega$ y $1 \mathrm{~T} \Omega$.

\subsection{Procedimiento por descarga de condensador.}

Este método requiere de un generador de continua y un condensador de valor conocido, conectado como se muestra en la figura 2.10 [103].

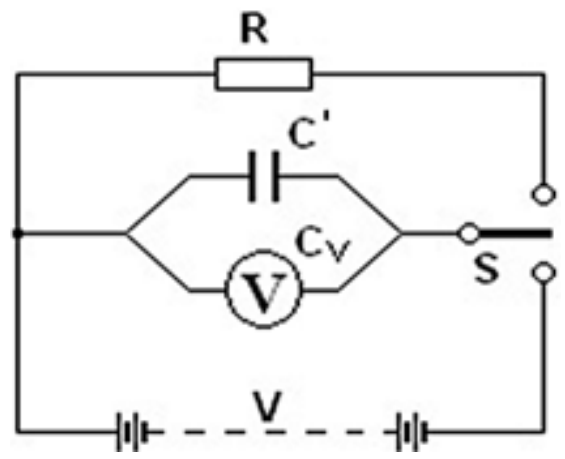

Figura 2.10. Circuito eléctrico del procedimiento por descarga de condensador.

En el esquema pueden diferenciarse tres partes básicas del circuito; fuente de alimentación constante, condensador y resistencia a medir. La fuente de alimentación del circuito debe suministrar una tensión elevada (entre $100 \mathrm{~V}$ y $5 \mathrm{kV}$ ) de corriente continua. Como fuente de tensión suele utilizarse un aparato de conexión a la red o un transformador de tensión, que genera la tensión de medida deseada a partir de la tensión de una batería con amplificador de transistores. El condensador tiene una capacidad, $\mathrm{C}^{\prime}$, y se carga a la tensión de la fuente de tensión, $\mathrm{V}$. El dispositivo de medida tiene una capacidad $\mathrm{C}_{\mathrm{V}}$ y la capacidad equivalente de este circuito, $\mathrm{C}$, es la suma de ambas capacidades $\left(\mathrm{C}^{\prime}+\mathrm{C}_{\mathrm{V}}\right)$. Por tanto, la carga de 
la capacidad equivalente es el producto de la capacidad equivalente por la tensión de la fuente de tensión $(\mathrm{Q}=\mathrm{C} \cdot \mathrm{V})$. La última parte incorpora la resistencia a medir, de valor R, en paralelo a la fuente de tensión.

Este procedimiento implica la medida de la tensión del condensador durante el proceso de su descarga sobre la resistencia incógnita en dos instantes diferentes separados por un tiempo conocido y medido. Por supuesto, las resistencias de aislamiento propias de los conductores y conmutadores en el circuito deben ser netamente superiores a la de la resistencia a medir. La ecuación de descarga es la que proporciona el valor de la resistencia, según la ecuación 2.20.

$$
R=\frac{t}{C \cdot \ln \left(V_{0} / V\right)}
$$




\title{
CAPÍTULO 3
}

\section{PROCEDIMIENTTO EXPERIMENTAL}

\author{
Índice
}

3.0. Resumen

3.1. Normativa....................................................................... 75

3.2. Metodologia de las mediciones. ........................................... 77

3.2.1. Descripcion de la metodología ....................................... 77

3.2.2. Regresión lineal .......................................................... 86

3.2.3. Coeficiente de correlación ................................................. 88

3.2.4. Coeficiente de determinación........................................... 89

3.3. Análisis de los materiales textiles. ....................................... 90

3.3.1. Composición. .......................................................... 90

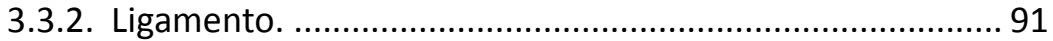

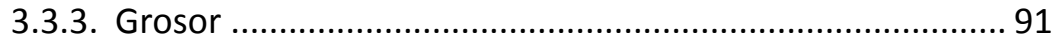

3.3.4. Título o masa lineal de los hilos (de urdimbre o trama) ..... 92

3.3.5. Masa laminar o peso por unidad de superficie.................. 93

3.3.6. Densidad (de urdimbre o trama). ................................... 94

3.3.7. Coeficiente de densidad............................................. 95

3.3.8. \% tupidez...................................................................... 96 
3.4. Diseño y construcción del equipo de ensayo y procesamiento de datos 97

3.4.1. Equipo de medición y funcionamiento. 98

3.4.2. Equipo de acondicionamiento ambiental. 102

3.4.3. Equipo de captación de datos. 108

3.4.4. Procesamiento de datos: LabVIEW. 110

3.4.5. Problemática surgida en la construcción y conexionado de las partes del equipo. Funcionamiento general. 120 


\section{CAPÍTULO 3}

\section{PROCEDIMIENTO EXPERIMENTAL}

\subsection{Resumen.}

Para elegir un método que permita el cálculo de la resistencia eléctrica de un material textil se debe hacer un estudio de las exigencias actuales a este respecto. En la norma aplicable, la EN-1149, se especifican las condiciones exigidas para poder asignar a un tejido el calificativo de antiestático, si bien no se dice nada acerca del comportamiento del tejido bajo otras condiciones que no sean las de las pruebas indicadas por la norma, que se indican de forma resumida.

En base a ello, en este capítulo se justifica la elección del procedimiento por voltímetro estático por descarga de condensador como la metodología más adecuada para el cálculo de la resistencia eléctrica de los tejidos. También se realiza un estudio detallado del procedimiento, explicando su funcionamiento y los problemas surgidos al montar el equipo. Como se verá, existen varios circuitos eléctricos/electrónicos para el funcionamiento óptimo del equipo, ya sea para el control de las variables ambientales, ya sea para obtener los resultados de los parámetros eléctricos. Éstos se calculan a través de las ecuaciones deducidas para cada tejido, que nos relaciona el tiempo de semidescarga, parámetro que se obtiene experimentalmente, con los parámetros eléctricos del tejido.

Se detalla además el análisis a realizar a los tejidos para obtener diversas características de su estructura, y así poder sacar relaciones de los resultados obtenidos. Se indica los métodos numéricos utilizados para el análisis de los resultados. 


\subsection{Normativa.}

Actualmente es la norma EN 1149 "Ropa de protección. Propiedades electrostáticas" la que regula los procedimientos de medición para el análisis de las propiedades electrostáticas en los tejidos textiles. Consta de cinco partes, a cuyo contenido principal nos referiremos por su interés para este trabajo:

- EN 1149-1:2006 [104]- Parte 1: Método de ensayo para la medición de la resistividad de la superficie. Este apartado nos describe el método de ensayo para determinar la resistividad superficial de un tejido bajo unas condiciones concretas, que vienen resumidas en el Anexo 1.

- EN 1149-2:1997 [105]- Parte 2: Método de ensayo para medir la resistencia eléctrica a través de un material (resistencia vertical). Este apartado describe el método de ensayo para determinar la resistencia vertical, $\mathrm{R}_{\mathrm{v}}$, de un tejido bajo unas condiciones concretas resumidas en el Anexo 1.

- EN 1149-3:2004 [106] - Parte 3: Métodos de ensayo para determinar la disipación de la carga. Existen dos métodos (para carga triboeléctrica y por inducción) que vienen reflejados en el Anexo 1.

- EN 1149-4: - Parte 4: Requisitos, incluyendo los requisitos de prestación y diseño. Esta norma no está en vigor, ya que ha sido sustituida por la norma EN $1149-5$.

- EN 1149-5:2008 [107]- Parte 5: Requisitos de comportamiento de material y diseño. Esta norma contiene los requisitos de resistividad y de diseño para las prendas de protección antiestática y su contenido está resumido en el Anexo 1. 
Para completar y mejorar la comprensión de los términos que se manejan en las normas existen las denominadas notas técnicas de protección (NTP). Las vinculadas a la norma 1149 son las NTP-567, NTP-887, NTP-225 y NTP-374 que nos indican las siguientes características:

- NTP-567: Protección frente a cargas electrostáticas.

- NTP-887: Calzado y ropa de protección "antiestáticos".

- NTP-225: Electricidad estática en el transvase de líquidos inflamables.

- NTP-374: Electricidad estática: carga y descarga de camiones cisterna (I).

La ropa de protección antiestática está diseñada para evitar la acumulación de cargas electrostáticas y su uso es exigido en determinadas situaciones de riesgo. Esta protección es también requisito adicional de protección para ropa diseñada con otros fines, como por ejemplo en ropa de protección contra sustancias químicas, ropa destinada al personal cuyo trabajo se desarrolla en lugares con atmósferas explosivas, ropa para personal de industrias químicas, ropa para personal que maneja materiales para artillería..., es decir, en aquellas situaciones donde una chispa es capaz de provocar incendios o explosiones.

Este tipo de ropa está identificada a través de una etiqueta con el siguiente símbolo, que nos indica que cumple la norma EN 1149.

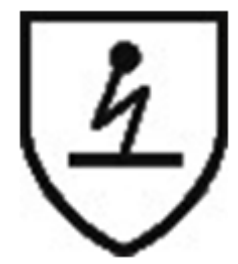

Figura 3. 1. Símbolo de identificación de tejido antiestático [108]. 


\subsection{Metodología de las mediciones}

\subsubsection{Descripción de la metodología}

La elección del procedimiento está condicionada por varios factores: conductancia límite, tensión de medida, aislamiento, blindaje y tiempo de medición. La conductancia límite es aquella cuya conexión en paralelo con el objeto de la medición produce una variación apenas perceptible en el dispositivo indicador del aparato de medida. La tensión de medida varía entre $100 \mathrm{~V}$ y $5 \mathrm{kV}$ en corriente continua, ya que en corriente alterna una eventual acción capacitiva puede determinar una corriente de carga mayor que la propia corriente utilizada en la medida, para conseguir una intensidad de medida suficientemente elevada. El aislamiento insuficiente puede provocar errores en la medición, por las corrientes de fuga, así como por las corrientes superficiales. El tiempo de medición viene determinado por la constante de tiempo $(\tau=R \cdot C)$ del circuito de medida, ya que durante la medición aparecen procesos de carga y descarga originados por los elementos capacitivos del circuito de medida; si el tiempo de medición es menor que la constante de tiempo del circuito de medida, las magnitudes de medida se convierten en funciones de tiempo y por tanto en una parte adicional [109].

Para la realización de este trabajo ha tenido que definirse una metodología que permita obtener la resistencia eléctrica del tejido controlando las condiciones ambientales del ensayo, con el fin de estimar el comportamiento de los materiales textiles con carga. Por ello ha sido necesario elegir en primer lugar un procedimiento de medida adecuado al trabajo a realizar, para después elaborar el organigrama de la metodología. Como ya se ha dicho, de los métodos analizados en el capítulo anterior se ha elegido el procedimiento por voltímetro estático por descarga de condensador, ya que el equipo de medición adquirido cumple con los requisitos definidos anteriormente. 
A continuación se realiza el análisis detallado de este procedimiento, con el fin de obtener una ecuación que relacione el parámetro que el aparato mide, es decir, el tiempo de descarga del condensador, con el parámetro eléctrico característico de este material, la resistencia eléctrica.

El circuito eléctrico equivalente del equipo de medición es el mostrado en la figura 3.2. Está regido por el conmutador y pueden identificarse dos partes diferenciadas, que funcionan de forma independiente una de la otra.

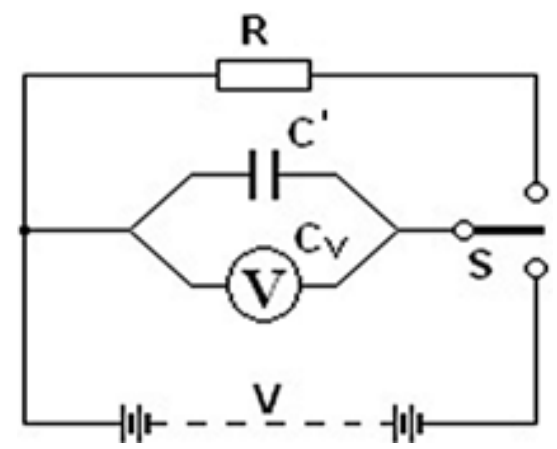

Figura 3. 2. Circuito del procedimiento por descarga de condensador.

Cuando el conmutador está en posición neutra no se conecta ninguna de las partes del circuito, por lo que está en posición de reposo. Para medir correctamente por este método, de la posición de reposo del conmutador se debe pasar a la posición inferior para que el circuito que entra en funcionamiento esté formado por la fuente de tensión y el condensador equivalente de la asociación en paralelo del condensador de capacidad $\mathrm{C}^{\prime}$ que contiene el aparato y la capacidad $\mathrm{Cv}$ del dispositivo de medida. En esta posición ambas partes se ponen en paralelo, quedando el circuito representado en la figura 3.3. 


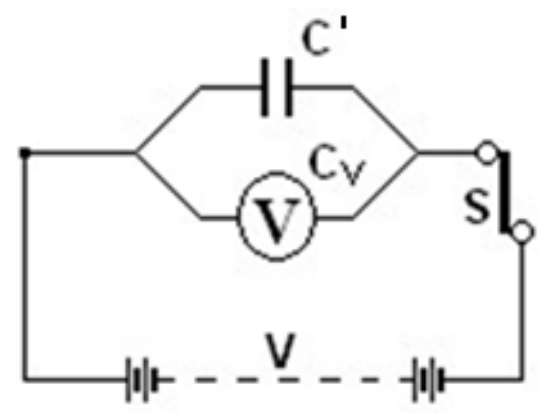

Figura 3. 3. Circuito equivalente en fase de carga del condensador.

El condensador se carga a la tensión que suministra la fuente $(\mathrm{V})$, lo que no se realiza de forma inmediata, por lo que hay que esperar el tiempo suficiente para ello. Este tiempo va a depender de la constante de tiempo del circuito, $\tau$, y cuanto mayor sea más tarda en alcanzarse su valor final, que se consigue en la práctica cuando pasa un tiempo superior a cinco veces la constante de tiempo [110]. En los conductores, la constante de tiempo es muy pequeña, casi instantánea, pero en los aislantes el tiempo puede ser elevado. En la realización práctica de los ensayos, el galvanómetro que incluye el equipo va indicando cual es la progresión y cuando se ha llegado al valor final. Esta progresión se realiza de forma exponencial, como se observa en figura 3.4 .

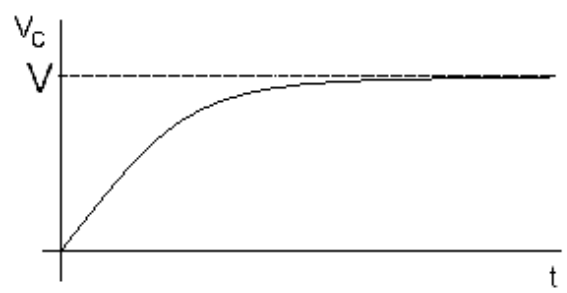

Figura 3. 4. Variación de la tensión en el condensador en fase de carga.

Una vez terminada esta fase, el conmutador ha de ser cambiado a la posición superior. En esta situación se ponen en paralelo la resistencia $R$ a calcular (la correspondiente a la muestra de tejido) y el condensador y, en ese instante, 
empieza la descarga del condensador a través de la resistencia $R$. El circuito equivalente de esta última fase del método es un circuito RC sin fuentes, mostrado en la figura 3.5.

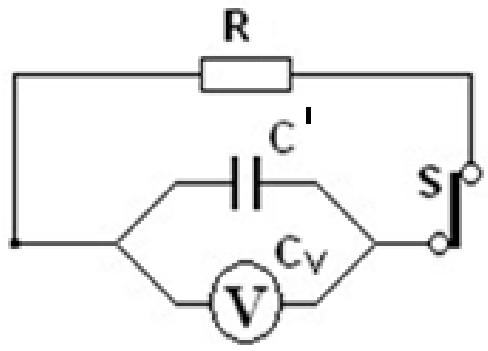

Figura 3. 5. Circuito equivalente en fase de descarga del condensador.

La tensión en un condensador es una función continua y, por tanto, la intensidad $i(t)$ que lo atraviesa está definida siempre, incluso cuando vale cero. Por otra parte, si $i(t)=C \cdot \frac{d_{V c(t)}}{d t}$ existe siempre, también existe $\frac{d_{V c(t)}}{d t}$, o su límite por la derecha o por la izquierda en cada punto; y para ello $\mathrm{v}_{\mathrm{C}}(\mathrm{t})$ debe ser una función continua. Este extremo es de especial importancia para fijar las condiciones iniciales en los circuitos que contienen condensadores. En este circuito por tanto la ecuación de la tensión en el condensador es [111]:

$$
v_{c}(t)=\frac{1}{C} \int i(t) d t=V \cdot e^{-t / R C}
$$

Y su gráfica representativa es la que muestra la figura 3.6.

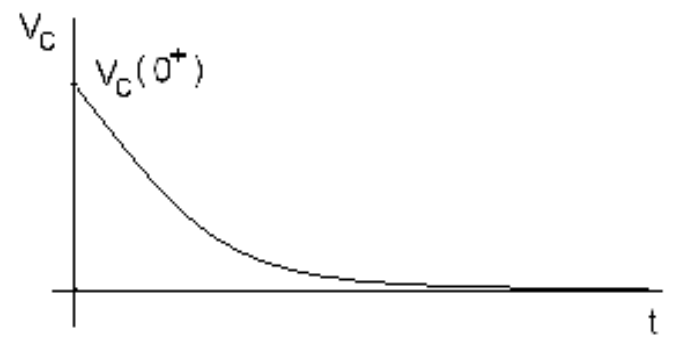

Figura 3. 6. Variación de la tensión en el condensador en fase de descarga. 
Desarrollando la ecuación 3.4 para despejar la variable R, se obtiene la ecuación final para el cálculo de la resistencia eléctrica del método:

$$
R=\frac{t}{C \cdot \ln \left(V_{0} / V\right)}(\Omega)
$$

Donde:

$$
\begin{aligned}
& R, \text { resistencia a medir }(\Omega) . \\
& \mathrm{t}, \quad \text { tiempo de descarga }(\mathrm{s}) . \\
& C, \text { capacidad del condensador equivalente }(\mathrm{F}) . \\
& V_{0}, \text { tensión inicial }(\mathrm{V}) . \\
& V, \text { tensión final }(\mathrm{V}) .
\end{aligned}
$$

Por tanto, el valor de la resistencia se obtiene en función del tiempo de descarga del condensador, de la variación de tensión en los terminales del condensador en los momentos inicial y final, y del valor de la capacidad del condensador equivalente del circuito. Estos valores dependen del circuito que se utilice, excepto el tiempo, que es el valor que hay que obtener para poder aplicar este procedimiento.

Elegido el procedimiento para la obtención de la resistencia del tejido, debe concretarse la metodología para la correcta toma de datos y la evaluación de los parámetros eléctricos que estimen el comportamiento de estos materiales frente a la electricidad estática. La metodología utilizada se muestra en la figura 3.7. 


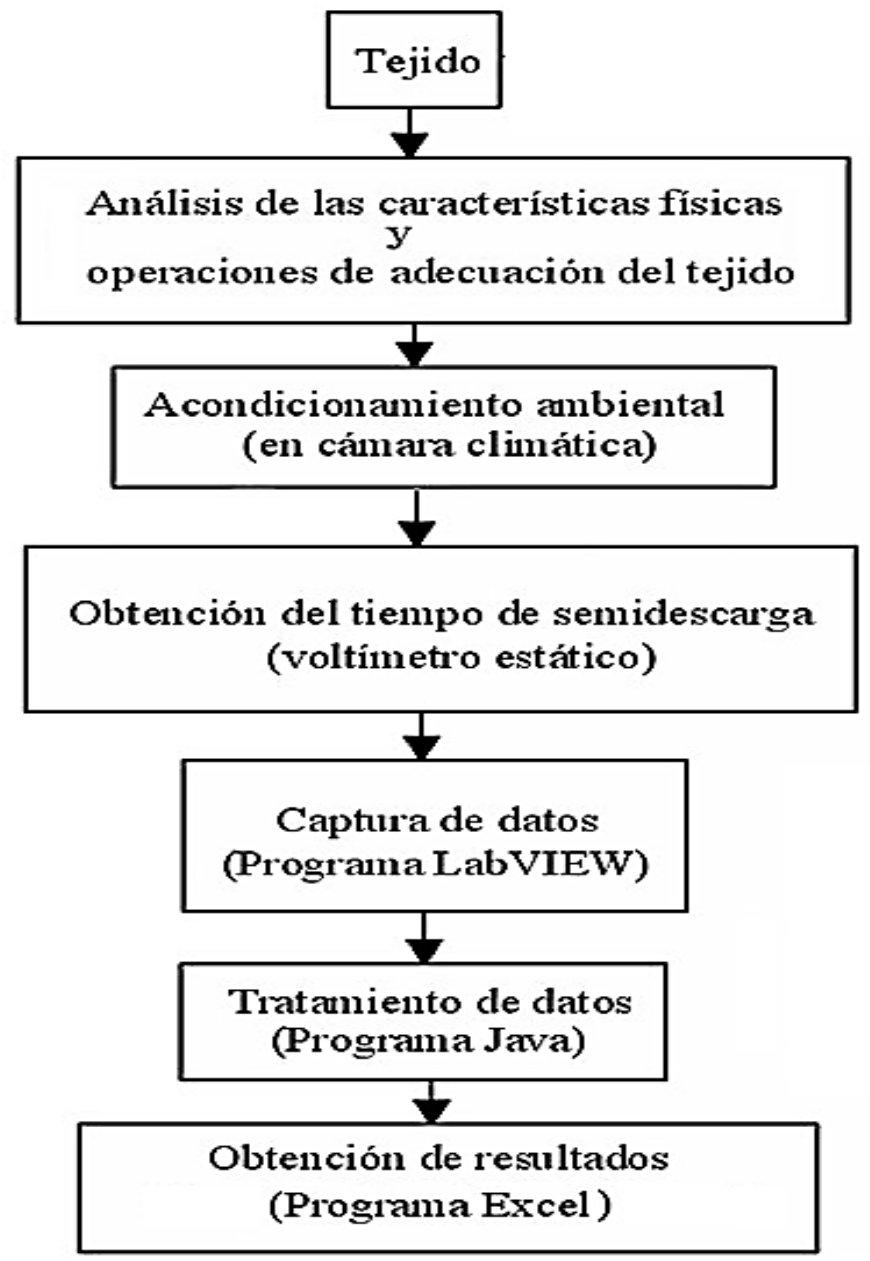

Figura 3. 7. Metodología: diagrama de flujo.

En ella se observa cómo, en primer lugar, se realiza un análisis de las características de los tejidos ensayados. Esto se hace para tratar de obtener relaciones entre el comportamiento eléctrico y la naturaleza de los tejidos. Para la realización del ensayo se debe situar una muestra del tejido en el protaprobetas que incorpora el voltímetro estático. Por ello se adecuó cada muestra a las dimensiones estipuladas por dicho portaprobetas. Además, se ha añadido al procedimiento una cámara climática para poder controlar las condiciones ambientales de la prueba 
durante el procedimiento experimental. Para ello se trasladó el portaprobetas desde el voltímetro estático a esta cámara y se conectaron los terminales de salida del voltímetro con los terminales del portaprobetas. También se modificó el procedimiento de toma de datos, ya que la toma manual que incluye el aparato era obsoleta y daba lugar a errores de medida. Para ello se ha desarrollado un programa informático que recopila toda la información requerida y se han realizado las conexiones correspondientes, que se detallarán a lo largo del capítulo siguiente. Para la obtención y tratamiento de los resultados obtenidos del procedimiento experimental se han utilizado e incluso elaborado diversos programas. El diagrama de flujo citado expresa las operaciones necesarias para la realización de los ensayos a las muestras textiles.

Una vez elegidos los tipos de tejidos a ensayar, en primer lugar se realizó un análisis de sus características. Después, una parte de los tejidos fue lavada con un detergente no iónico y dejados secar al aire. Así fue posible ensayar tejidos lavados y comparar su comportamiento eléctrico frente a los mismos tejidos sin lavado previo.

El siguiente paso fue colocar cada muestra en el portaprobetas del voltímetro estático, dentro de la cámara climática, controlando mediante el programa LabVIEW la temperatura y la humedad relativa existentes en la cámara climática, ya que son las variables externas que más influyen en la resistencia eléctrica del tejido. Se estabilizaron estos parámetros durante 24 horas para que la muestra se adaptara a las condiciones climáticas impuestas y, después, se realizaron cinco series de medidas. Cada serie fue tratada independientemente, registrando los resultados tiempo-tensión mediante el programa Java. Este programa, además de registrar los datos capturados por LabVIEW, realiza un tratamiento de dichos datos, que es gobernado por el usuario, ya que se pueden seleccionar los resultados más importantes a obtener. Además, el programa crea un archivo en Excel con los 
valores obtenidos y proporciona en sucesivas columnas los resultados de los siguientes parámetros: tiempo de descarga, tensión en los bornes del portaprobetas, humedad relativa y temperatura del aire de la cámara climática, resultados significativos del tiempo de descarga y de la tensión en los bornes del portaprobetas, y resultados máximo y mínimo de la temperatura y de la humedad relativa del aire de la cámara climática. Mediante el programa Excel se unifican en un solo archivo todos los resultados de las cinco series para un determinado material textil bajo las mismas condiciones ambientales, con objeto de obtener una hoja resumen de los resultados principales: tiempo medio de semidescarga, evolución gráfica de la tensión en los extremos de la muestra y resistencia eléctrica del tejido. Estos valores finales se incorporan en una nueva hoja Excel, junto a los obtenidos en los otros ensayos del mismo material, para obtener los resultados y las gráficas características del tejido.

La estadística descriptiva permite informar de forma concisa y rápida acerca de los aspectos fundamentales de un conjunto de datos. Esto supone el cálculo de medidas centrales, la cuantificación de la dispersión de los datos alrededor de las mismas, y la presentación de los resultados en forma de tablas y gráficos y tendencias. Las representaciones gráficas de los resultados facilitan información sobre aspectos fundamentales subyacentes en los mismos [112]. Los métodos estadísticos permiten reconocer si dos caracteres estudiados simultáneamente, dependen el uno del otro. En la mayor parte de las situaciones halladas en la práctica, el estudio estadístico no se efectúa sobre una sola variable, sino que intervienen simultáneamente varias [113].

Se realizaron 5 ensayos por cada una de las características a valorar de los tejidos en estudio. De los resultados obtenidos de cada una de las propiedades, se obtiene la media aritmética $(\bar{x})$, y el coeficiente de variación (C.V., en \%). 
La media aritmética es el promedio de los resultados obtenidos, es decir, el número que se obtiene al dividir la suma de todos los valores observados por el número de ellos [114].

$$
\bar{x}=\frac{\sum x_{i}}{n}
$$

Donde:

$\bar{x}, \quad$ media aritmética.

$\Sigma \mathrm{x}_{\mathrm{i}}$, suma de los valores de la variable, definido para $\mathrm{i}=1,2, . ., \mathrm{n}$.

$\mathrm{n}, \quad$ tamaño de la muestra.

Una medida de dispersión no debe ignorar ninguno de los datos de la distribución. La desviación estándar o cuasidesviación típica (s) es una medida de la dispersión de los valores respecto a la media y se calcula a través de la siguiente fórmula [115].

$$
s=\sqrt{\frac{\sum\left(x_{i}-\bar{x}\right)^{2}}{n-1}}
$$

Cuando se han de comparar dispersiones de dos o más distribuciones en las cuales las variables vienen expresadas en unidades diferentes, la desviación típica no es un estadígrafo adecuado puesto que se tendrían que comparar dos magnitudes expresadas en unidades distintas. El coeficiente de variación expresa la desviación típica como porcentaje de la media aritmética y es un parámetro adimensional que nos indica la dispersión relativa de las muestras. Se calcula a través de la siguiente fórmula [116]:

$$
\text { C. V. }=\frac{S}{\bar{x}} \cdot 100(\%)
$$


Su valor está comprendido entre el $0 \%$ y el $100 \%$. En poblaciones de datos normales no debe superar el $30 \%$ y si es superior al 50\% se trata de una población estadística no homogénea.

El estudio estadístico de los resultados obtenidos en este trabajo se realizó mediante regresión lineal simple, obteniendo su coeficiente de determinación y de correlación.

\subsubsection{Regresión lineal}

Cuando se tienen dos caracteres "x" e "y" y son apreciados en cada individuo, se puede representar el colectivo por un gráfico en el cual cada punto de abscisa "x" y de ordenada "y" corresponde a una observación. El conjunto constituye lo que se llama una nube de puntos [117].

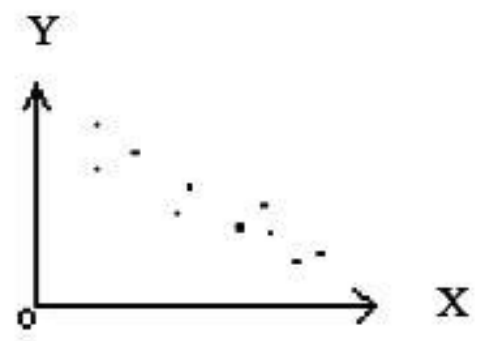

Figura 3. 8. Representación de la nube de puntos.

Una vez concluido que existe relación, la regresión lineal o no lineal permite definir la curva que mejor se ajusta a esta nube de puntos. Cuando se trata de una regresión no lineal, en este caso una función exponencial, el problema estadístico de ajustar a un modelo exponencial $\left(\mathrm{y}=\mathrm{A} \cdot \mathrm{B}^{\mathrm{X}}\right)$ se reduce al de la función lineal, con solo tomar logaritmos. Por tanto se reduce a una regresión lineal simple, es decir, a definir la recta que mejor se ajuste a la nube de puntos obtenidos. 
Una recta viene definida por la siguiente ecuación:

$$
y=a+b \cdot x
$$

Donde:
$\mathrm{x}$, variable independiente.
$\mathrm{y}$, variable dependiente, es decir, aquella que viene definida a partir de la variable $\mathrm{x}$.
a, ordenada en el origen.
b, pendiente de la recta.

En este caso "a" es el valor que toma la variable dependiente "y", cuando la variable independiente " $\mathrm{x}$ " vale cero, $\mathrm{y}$ es el punto donde la recta cruza al eje vertical. En el caso de "b" determina la pendiente de la recta, es decir, su grado de inclinación. Los parámetros "a" y "b" de la recta se calculan mediante las ecuaciones siguientes, en las que los sumatorios que incluyen estas ecuaciones están definidos para $\mathrm{i}=1,2, . ., \mathrm{n}$ :

$$
\begin{aligned}
& \mathrm{a}=\frac{\sum y \sum x^{2}-\sum x \cdot y \sum x}{n \sum x^{2}-\left(\sum x\right)^{2}} \\
& \mathrm{~b}=\frac{n \sum x y-\sum x \sum y}{n \sum x^{2}-\left(\sum x\right)^{2}}
\end{aligned}
$$

La recta será la que mejor se ajuste a la nube de puntos muestrales, según el criterio de mínimos. El valor así calculado puede ser tomado también como predicción individual del valor de la variable dependiente. 


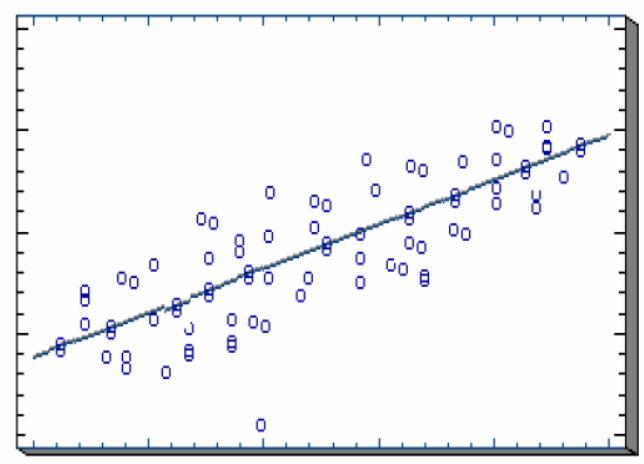

Figura 3. 9. Representación de la regresión lineal simple.

\subsubsection{Coeficiente de correlación}

Cuando dos variables se relacionan entre sí, se puede calcular el coeficiente de correlación (r), que es un parámetro que estima el impacto de la correlación entre las variables y puede tomar un valor entre - 1 y 1 , ya que indica la relación lineal de ambas variables y su forma conjunta de variar:

1. Si el coeficiente de correlación está cerca de 1, las variables están correlacionadas positivamente (relación directa).

2. Si el coeficiente está cerca de 0 , las variables no se correlacionan o se correlacionan poco.

3. Si el coeficiente está cerca de -1 , las variables se relacionan en sentido inverso, esto significa que el aumento en una variable se asocia con la disminución en la otra.

El grado de relación o dependencia entre ambas variables se obtiene mediante el denominado coeficiente de correlación (r) [118] y se obtiene aplicando la fórmula siguiente, en las que los sumatorios que incluye esta ecuación están definidos para $\mathrm{i}=1,2, . ., \mathrm{n}$ : 


$$
r=\sqrt{\frac{n_{\Sigma} x y-\sum_{\Sigma} x y}{\left[n_{\Sigma} x^{2}-\left(\sum x\right)^{2}\right] \cdot\left[n_{\Sigma} y^{2}-\left(\sum y\right)^{2}\right]}}
$$

\subsubsection{Coeficiente de determinación}

El coeficiente de determinación es la proporción de la varianza de una de las variables, que es función de la otra variable según un modelo lineal, y se calcula por la fórmula [119], en las que los sumatorios que incluye esta ecuación están definidos para $\mathrm{i}=1,2, . ., \mathrm{n}$ :

$$
\boldsymbol{R}^{2}=\frac{n \sum x y-\sum x \sum y}{\left[n \sum x^{2}-\left(\sum x\right)^{2}\right] \cdot\left[n \sum y^{2}-\left(\sum y\right)^{2}\right]}
$$

El resultado de esta operación, es decir, el valor del coeficiente de determinación es un número que puede tomar un valor entre 0 y 1 :

1. Si el coeficiente de determinación está cerca de 1 se trata de una dependencia casi exacta entre las variables.

2. Si el coeficiente está cerca de 0 , las variables son independientes o dependen poco una de otra.

Una propiedad sumamente importante es la relación existente entre estos dos coeficientes. El cuadrado del coeficiente de correlación coincide con el coeficiente de determinación, es decir:

$$
r^{2}=R^{2}
$$




\subsection{Análisis de los materiales textiles.}

Para poder establecer algún tipo de relación entre los resultados finales de la resistividad obtenida experimentalmente y la estructura de los tejidos, debe realizarse un análisis de las características más relevantes del tejido, que son: composición, ligamento, grosor, título o masa lineal de los hilos, densidad, coeficiente de densidad y tupidez. Los análisis se realizaron a tres tejidos diferentes.
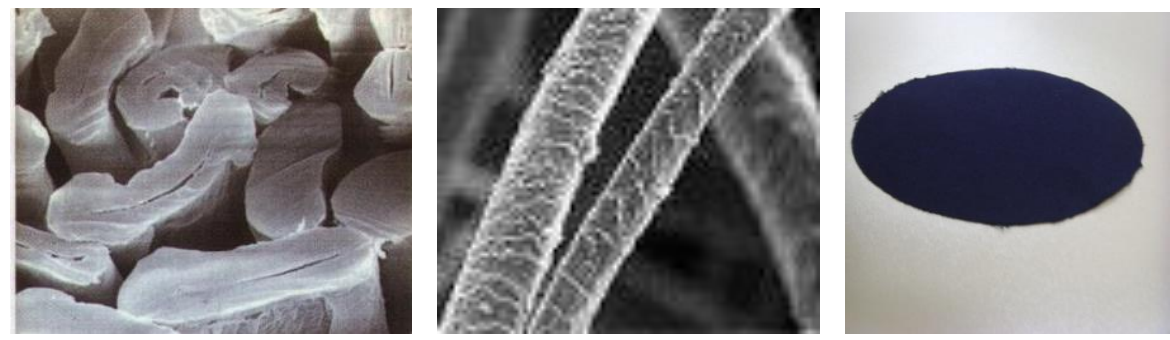

Figura 3. 10. Muestras de fibras de algodón (izquierda) y lana (centro) al microscopio, así como del tejido mixto de nómex, kevlar y fibra antiestática utilizado en las pruebas.

\subsubsection{Composición.}

El análisis de la composición del tejido consiste en identificar las fibras textiles que componen éste y en la determinación del porcentaje en que se encuentra cada una de ellas, es decir, se realiza tanto un análisis cualitativo como uno cuantitativo.

Los materiales textiles son de composición química diversa. Así, el algodón y las fibras celulósicas manufacturadas tienen como componente fundamental la celulosa, mientras que las fibras sintéticas son poliamidas, poliésteres, etc., y por ello su comportamiento frente a la combustión es muy variado. Para obtener los resultados hay que realizar las pruebas según vienen reflejadas en la norma UNE 40-110-94. 


\subsubsection{Ligamento.}

Es el parámetro que nos indica la forma en la que los hilos se cruzan con las pasadas para formar el tejido. Para determinar el ligamento hay que deshacer el tejido hilo por hilo, con ayuda de una lupa, hasta que se determina el curso y luego el enunciado del ligamento [120]. La norma para su determinación es la UNE- 40-084. Se representa normalmente en una superficie cuadriculada, en la que se supone que cada columna de cuadros es un hilo y cada fila de cuadros una pasada. Cuando un hilo pasa por encima de una pasada se marca este cuadrito con una $\mathrm{x}$, o se colorea en negro, y se dice que el hilo "toma". Mientras que si el cuadrito está en blanco es porque el hilo pasa por debajo de la pasada, y se dice que el hilo "deja". A continuación, en la figura 3.11, se expone la representación gráfica de un ligamento, en esto caso el denominado tafetán.

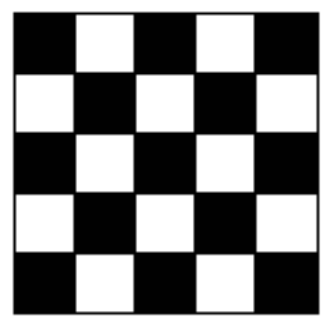

Figura 3. 11. Ejemplo de representación gráfica de un ligamento.

\subsubsection{Grosor.}

La norma UNE 40-224 indica un método para realizar esta medición. Consiste en medir el grosor en micrómetros especiales, en este caso mediante el mostrado en la figura 3.12. Están provistos de una platina fija y una móvil, que sube y baja de forma manual por medio de una palanca que se encuentra en su extremo derecho y un mecanismo de medición que permite observar la lectura en la pantalla. Se realizan cinco mediciones y se obtiene la media del grosor. 


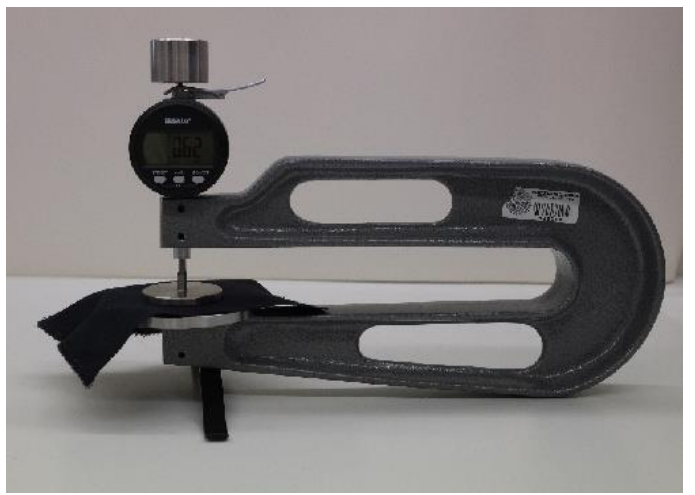

Figura 3. 12. Micrómetro de la casa Baxlo, modelo 40407.

\subsubsection{Título o número de los hilos de urdimbre y trama.}

Los hilos de que están formados los tejidos se caracterizan principalmente por su número o título, parámetro que sirve para valorar las propiedades de resistencia, elasticidad y regularidad de los mismos. Se trata de un parámetro muy relacionado con su grosor [121]. Existen varios sistemas de numeración para obtener el título; en este caso se utilizó el sistema directo para el cálculo del título, el cual se basa en medir el peso de una longitud constante del hilo (norma UNE 40078-80), de acuerdo con la fórmula.

$$
\mathrm{N}=\mathrm{k} \cdot \frac{P}{L}
$$

Donde:

N, Número o título del hilo (Tex).

k, constante dependiente del sistema de numeración $(1000 \mathrm{Tex} \cdot \mathrm{m} / \mathrm{g})$.

$\mathrm{P}$, peso (g).

L, longitud (m). 
Para la realización del análisis se cortan cinco muestras de diferentes longitudes de los hilos en cada dirección (trama y urdimbre). Cada una de ellas se mide y se pesa a través de la regla calibrada y de la báscula (figura 3.13).
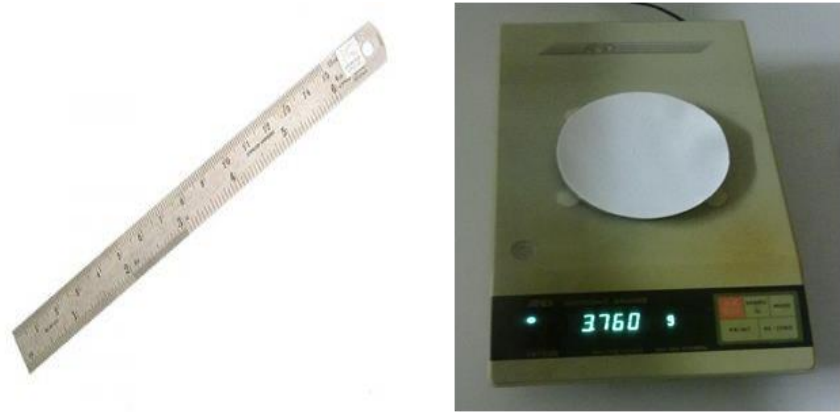

Figura 3. 13. Instrumentos de medida: metro calibrado y báscula.

\subsubsection{Masa laminar o peso por unidad de superficie.}

En el sistema internacional la masa laminar indica el peso por unidad de superficie del tejido. Para su determinación se corta una probeta cuadrada de 10x10 $\mathrm{cm}$, se miden sus lados y se pesa según se indica en la normativa UNE 40-260-75, siendo la unidad el g/ $\mathrm{m}^{2}$. Otra manera práctica de realizarlo es a través de un troquel o corta-probetas circular de $100 \mathrm{~cm}^{2}$ de superficie, como el mostrado en la figura 3.14. Una vez cortada la muestra se pesa en una báscula, como la de la figura 3.13. Este procedimiento se realiza para cinco muestras y se obtiene el valor medio.

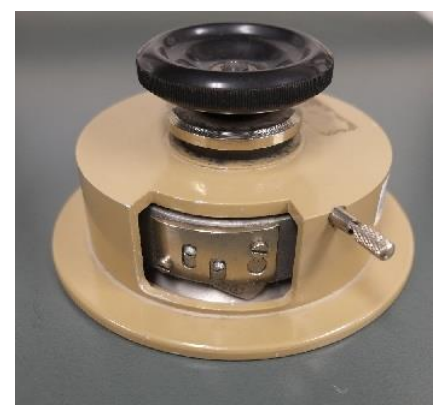

Figura 3. 14. Troquel o corta-probetas textil. 


\subsubsection{Densidad (de trama o urdimbre).}

La densidad es el número de hilos por unidad de longitud, bien en el sentido de la urdimbre o de la trama. Para determinar la densidad, se cuenta el número de hilos por centímetro del tejido según se precisa en la norma UNE 40-075-80. La unidad más frecuente para la dirección de urdimbre es de hilos/cm y para la trama de pasadas $/ \mathrm{cm}$.

El desarrollo de esta prueba se puede realizar de dos maneras: la primera con un cuenta hilos (figura 3.15), que consiste en observar el tejido a través de una lupa montada sobre una estructura cuadrada con una escala que corresponde a un centímetro cuadrado y después contar lo más exactamente posible el número de hilos y de pasadas que se encuentran en el área especificada, con la ayuda de un alfiler o aguja. En este caso se efectúan 10 recuentos por urdimbre y 10 por trama, siempre alejadas de los orillos en el momento de efectuar las mediciones. El otro método, consiste en cortar cuidadosamente muestras de un centímetro cuadrado de distintos lugares de la tela, y con un alfiler se va destejiendo con el fin de contar el número de hilos y pasadas. El utilizado en este procedimiento fue el cuenta hilos.

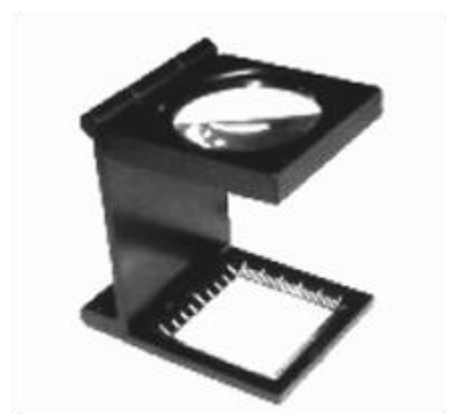

Figura 3. 15. Cuenta hilos. 


\subsubsection{Coeficiente de densidad.}

Como se explicó en el capítulo 1 , el coeficiente de densidad $\left(\mathrm{K}_{\mathrm{d}}\right)$ es un parámetro que relaciona el título de los hilos con la densidad del tejido y, por eso se realiza el cálculo de este coeficiente para urdimbre y para trama de forma separada. Existen tres formas de expresión diferentes de este coeficiente en función de la unidad de trabajo elegida:

a) Coeficiente de densidad (Tex). Se calcula mediante la siguiente ecuación:

$$
\mathrm{K}_{\mathrm{d}(\text { tex })}=\mathrm{D} \cdot \sqrt{N}
$$

Donde:

$$
\begin{array}{ll}
\mathrm{K}_{\mathrm{d}(\text { tex }),} & \text { coeficiente de densidad de urdimbre-trama. } \\
\mathrm{D}, \quad \begin{array}{l}
\text { densidad de urdimbre-trama } \\
\text { (hilos/cm - pasadas/cm). }
\end{array} \\
\mathrm{N}, \quad \text { título de urdimbre-trama (Tex). }
\end{array}
$$

b) Coeficiente de densidad en métrico inverso. Se calcula a través de la fórmula.

$$
\mathrm{K}_{\mathrm{d}}=\mathrm{K}_{\mathrm{d}(\mathrm{tex})} / 31,62
$$

Donde:

$$
\begin{aligned}
& \mathrm{K}_{\mathrm{d}}, \quad \begin{array}{l}
\text { coeficiente de densidad en métrico inverso } \\
\text { de urdimbre-trama. }
\end{array} \\
& \mathrm{K}_{\mathrm{d}(\text { tex })} \text {, coeficiente de densidad de urdimbre-trama. }
\end{aligned}
$$

c) Coeficiente de densidad máximo. Proporciona el valor teórico máximo que puede alcanzar el coeficiente de densidad en un determinado tipo de tejido; se calcula mediante: 


$$
\mathrm{K}_{d \max (u r d)}=\frac{Q}{1+0,73 K_{l(t r)}} \quad \mathrm{y} \quad \mathrm{K}_{d \max (t r)}=\frac{Q}{1+0,73 K_{l(u r d)}}
$$

Donde:

$$
\begin{aligned}
& \mathrm{K}_{\mathrm{dmax}(\mathrm{urd})}-\mathrm{K}_{\mathrm{dmax}(\mathrm{tr}), \quad \text { coeficiente de densidad máximo }} \\
& \text { urdimbre-trama. } \\
& \text { Q, } \quad \text { coeficiente que depende del tipo de } \\
& \text { materia }\left(\mathrm{Q}_{\mathrm{CO}}=9,8 ; \mathrm{Q}_{\mathrm{WO}}=10,8\right) \text {. } \\
& \text { Para el tejido con mezcla de fibras } \\
& \text { este parámetro se calcula a través } \\
& \text { de la expresión: } \\
& 0,93 \mathrm{Q}_{\text {NOMEX }}+0,05 \mathrm{Q}_{\text {KeVLAR }} \text {. } \\
& \mathrm{K}_{\mathrm{l}(\mathrm{urd})} \mathrm{K}_{\mathrm{l}(\mathrm{tr}), \quad \text { coeficiente de ligadura }} \\
& \text { de urdimbre-trama. }
\end{aligned}
$$

\subsection{8. \% tupidez.}

Este porcentaje representa el coeficiente de densidad encontrado, en relación con su valor máximo posible y, por tanto, nos proporciona una idea de lo apretados que están los hilos. Se puede calcular separadamente para trama y urdimbre o bien de forma conjunta, lo que se llama tupidez total, a través de la fórmula 3.10 .

$$
\% \text { tupidez }=\frac{K d(u r d-t r)}{K d_{\max }(u r d-t r)}
$$

Donde:

$$
\begin{array}{ll}
\text { Kd(urd-tr), } & \begin{array}{l}
\text { coeficiente de densidad } \\
\text { urdimbre-trama. }
\end{array} \\
\mathrm{K}_{\mathrm{dmax}(\text { urd-tr), }} & \begin{array}{l}
\text { coeficiente de densidad máximo } \\
\text { urdimbre-trama. }
\end{array}
\end{array}
$$




\subsection{Diseño y construcción del equipo de ensayo y procesamiento de datos.}

Para el desarrollo de este trabajo fue necesario construir un equipo capaz de medir adecuadamente y con buena reproducibilidad los parámetros a determinar. El equipo se construyó en base a cuatro partes diferenciadas:

- Equipo de medición. Es la parte que capta las señales a través del circuito eléctrico, del procedimiento experimental elegido y es capaz de proporcionar la información requerida para el cálculo de la resistencia eléctrica de la muestra. Todo ello sin influir en el comportamiento normal del circuito.

- Equipo de acondicionamiento ambiental. Se compone de una cámara climática y de todos los sistemas necesarios para proporcionar las condiciones de temperatura y humedad relativa del aire necesarias para los experimentos, y que son fijados por el usuario.

- Equipo de captación de datos. Compuesto de los programas necesarios para la adquisición, transcripción y almacenamiento de las señales que proporciona el equipo de medición.

- Equipo de procesamiento de datos. Los datos obtenidos se analizan a través de programas matemáticos para la obtención de los resultados, presentados de diferentes formas para la estimación del comportamiento electrostático del tejido textil.

La construcción de cada una de estas partes de las que se compone este equipo ha sido realizada a partir del dispositivo principal, el voltímetro estático R4021. Todo ello ha sido desarrollado y elaborado en el laboratorio de Medidas Eléctricas del área de Electricidad, perteneciente a la Escuela Técnica Superior de Ingeniería Industrial de Béjar (Universidad de Salamanca). 


\subsubsection{Equipo de medición y funcionamiento.}

El voltímetro estático R-4021, de la casa suiza Rothschild [122], es un equipo muy utilizado para la obtención de la resistencia eléctrica de diversos materiales, entre ellos los tejidos, y es adecuado para la investigación llevada a cabo en este trabajo. El aparato proporciona el circuito eléctrico necesario para los ensayos y la medición de la variación de la tensión en los extremos de las muestras, mediciones que no interfirieren en el funcionamiento del circuito.

Sin embargo, no indica directamente el valor de la resistencia eléctrica, sino que es necesario determinarla indirectamente a través de una ecuación que relaciona ésta con el resultado proporcionado por el voltímetro estático. Se realiza mediante un voltímetro, que es la parte de medición del equipo y nos indica la variación de la tensión entre los extremos del tejido a lo largo del tiempo.

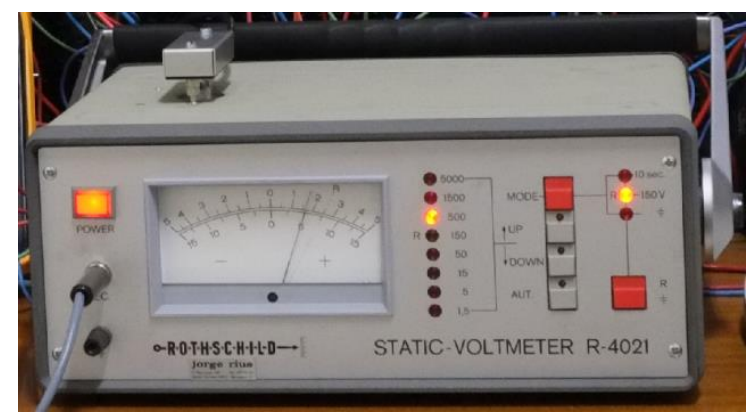

Figura 3. 16. Voltímetro estático R-4021(Rothschild).

En la fotografía de la figura 3.16 pueden observarse las distintas partes de las que consta el panel frontal, y en su parte superior se ve el portaprobetas utilizado. Existen diversos modelos de portaprobetas para materiales textiles en distintas formas de presentación. En la figura se ve que debajo del botón de encendido, situado a la parte izquierda del aparato, existe una conexión (cable incluido) para unir a un voltímetro externo, que es el que se ha utilizado para la 
obtención de la tensión del portaprobetas en cada instante. Para poder conectarlo a la tarjeta de adquisición de datos utilizada, sin riesgo de dañarla, el valor máximo de la tensión no debe superar $10 \mathrm{~V}$. Para ello hay que elegir en el panel frontal del voltímetro estático la posición 150 .

La metodología empleada para las medidas de los diversos tejidos es el denominado "método de integración", que es el utilizado por este aparato. A diferencia de otros instrumentos, el voltímetro estático utiliza un condensador para la medición, cuyo dieléctrico es el aire. Este aparato aplica una tensión continua a la muestra, y la diferencia de tensión que hay entre los extremos de ésta es la que indica el voltímetro que incorpora. Esta indicación es analógica, lo que no es útil para la captación de datos, pero el aparato incorpora además una conexión para un cable coaxial (proporcionado por el fabricante) que sí es válido para la recogida de valores y que fue la que se utilizó para ello.

El funcionamiento del voltímetro estático es el siguiente: cuando se presiona el pulsador rojo de la parte inferior derecha, el aparato carga su condensador interno con una tensión constante de $150 \mathrm{~V}$ (posición inferior del conmutador de la figura 3.2). La aguja del indicador del panel frontal se mueve a la derecha y cuando llega a la línea número 15 significa que el condensador ha adquirido los $150 \mathrm{~V}$. Al liberar el pulsador (posición superior del conmutador de la figura 3.2), se desconecta el generador del condensador y éste se conecta a los bornes del portaprobetas. El condensador se descarga a través de la resistencia del elemento situado en el portaprobetas, lo que se observa al descender la aguja del indicador a medida que la tensión del condensador disminuye. Cuando la aguja pasa por la línea punteada ( $\mathrm{R}$ de la figura 3.16) significa que la tensión ha descendido a la mitad de la inicial, es decir a $75 \mathrm{~V}$. El tiempo transcurrido desde que se soltó el pulsador hasta ese momento es el denominado "tiempo de semidescarga", $t_{50}$. Conocido este tiempo y la capacidad del condensador del circuito, se puede 
determinar la resistencia eléctrica del tejido situado en el portaprobetas, según la ecuación deducida previamente al explicar el procedimiento por descarga de condensador. En este equipo, las características del circuito eléctrico son:

- Tensión de la fuente: $\mathrm{V}_{\mathrm{O}}=150 \mathrm{~V}$.

- Valor medio de la tensión de la fuente: $\mathrm{V}=75 \mathrm{~V}$.

- Capacidad del condensador: $\mathrm{C}_{\mathrm{eq}}=8 \mathrm{pF}$.

El control de la variación de tensión en los extremos del portaprobetas se realiza a través de dos dispositivos, uno analógico (visual) y otro digital (captación de datos). El analógico lo hace a través del voltímetro que incorpora el aparato, y el digital a través de un voltímetro externo conectado a la salida que tiene el aparato para tal fin. El voltímetro del aparato se muestra en la figura 3.16 y el voltímetro externo conectado en la figura 3.17.

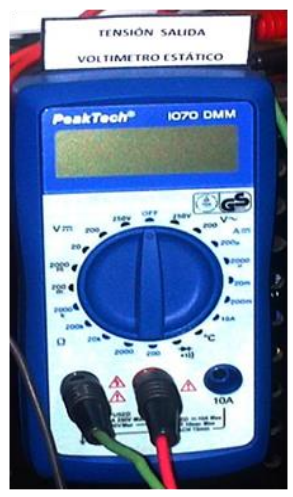

Figura 3. 17. Voltímetro de control de la tensión en la muestra.

Por tanto, si sustituimos los valores del circuito del equipo en la ecuación 3.5 deducida del procedimiento experimental (apartado 3.2), se obtiene la ecuación definitiva que se aplicará en el programa informático para la obtención de la resistencia eléctrica de un tejido textil.

$$
\mathrm{R}=0,866434 \cdot 10^{11} \cdot \mathrm{t}_{50}
$$


Siendo:

$\mathrm{t}_{50}$, tiempo de semidescarga (s).

Para controlar que la tensión proporcionada por la fuente es constante y la descarga del condensador es continua, se ha incluido un osciloscopio con objeto de visualizarlo (figura 3.18).

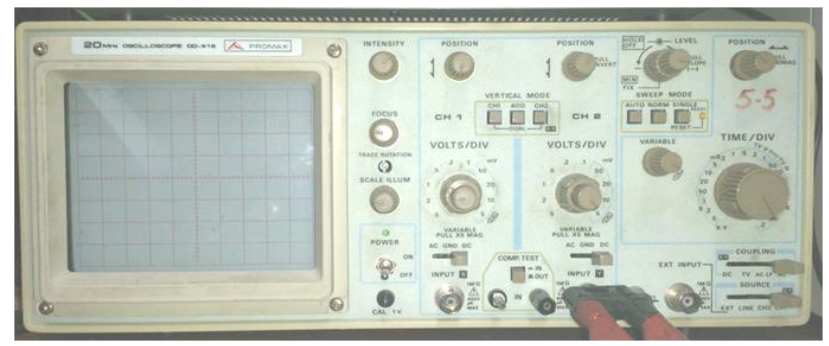

Figura 3. 18. Osciloscopio.

El portaprobetas está ubicado en la parte superior del equipo original, como se refleja en la figura 3.16. Pero, para la realización de las pruebas, hay que controlar las condiciones ambientales y, para ello, el portaprobetas del voltímetro estático se ha introducido dentro de una cámara climática. Esto ha exigido llevar los terminales de salida del voltímetro estático hasta la cámara climática a través de un cable apantallado, con objeto de evitar corrientes de fuga a través del cable, como sucedía en las pruebas iniciales. La siguiente fotografía muestra el portaprobetas en el interior de la cámara. 


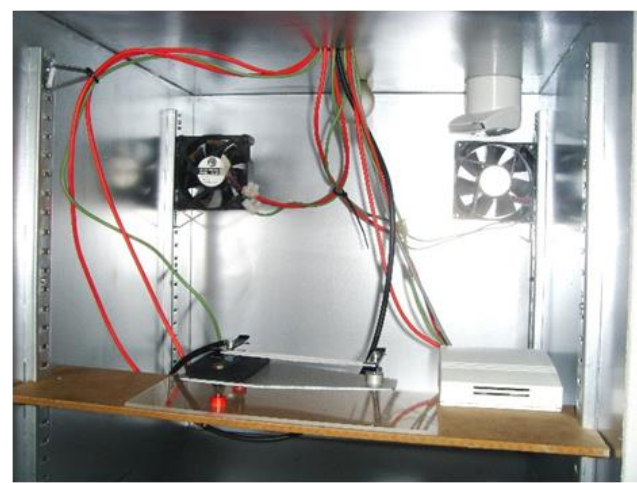

Figura 3. 19. Conexionado del portaprobetas en la cámara climática.

\subsubsection{Equipo de acondicionamiento ambiental.}

Para obtener resultados comparables entre diferentes muestras, los ensayos deben realizarse en las mismas condiciones ambientales. Para ello, se diseñó una cámara que mantuviera constantes en los valores fijados los dos parámetros que más interesa controlar, por su gran influencia en la generación y descarga de la electricidad estática, es decir, la temperatura y la humedad relativa. Con esta finalidad se adaptó una antigua estufa concebida originalmente para el acondicionamiento de muestras textiles (figura 3.20).

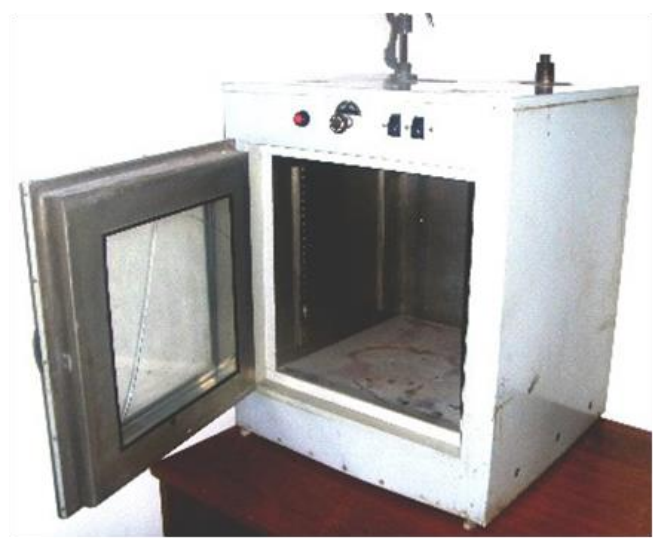

Figura 3. 20. Estufa de acondicionamiento de tejidos en su estado inicial, antes de adaptarla. 
Para ello fue necesario lijar y preparar la parte exterior e interior del aparato. La parte exterior se pintó con un esmalte de color gris medio para darle un aspecto adecuado y la interior con un esmalte especial de gran adherencia, elástico, que aporta un acabado liso y brillante ${ }^{2}$. Una vez realizado este acondicionamiento, el aspecto final de la cámara del equipo de medición se muestra en la fotografía de la figura 3.21 .

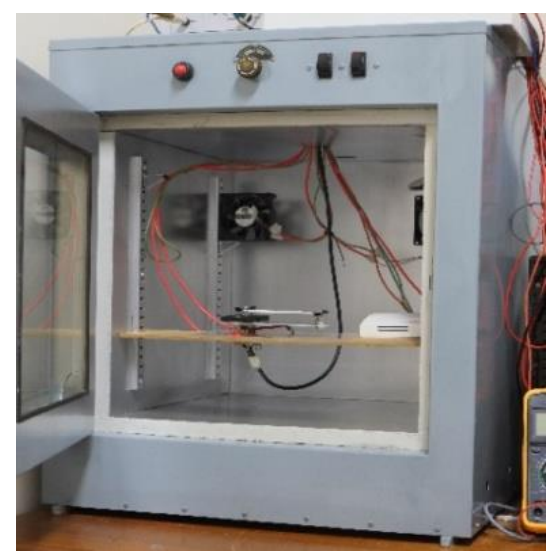

Figura 3. 21. Cámara climática ya reformada y adaptada.

Para realizar el acondicionamiento ambiental interno del aparato se dispusieron dos circuitos independientes, uno para la temperatura y otro para la humedad. Para controlar el aumento de la temperatura se modificó el sistema de calefacción inicial incorporando una nueva resistencia calefactora en la parte inferior y rehaciendo el cableado, para el correcto funcionamiento del circuito. Para poder aumentar la humedad relativa se incorporó un sistema de alimentación de aire húmedo en la parte superior de la cámara. Este aire proviene de un humidificador ultrasónico $^{3}$ (figura 3.22) con salida regulable de vapor frío, que utiliza un transductor ultrasónico de alta frecuencia para pulverizar el agua en diminutas

\footnotetext{
${ }^{2}$ Se trata del esmalte Titanlux 520 Plata de gran resistencia a la intemperie, ya que resiste temperaturas de $160{ }^{\circ} \mathrm{C}$ y todo tipo de humedad. Tiene larga duración y, por tanto, ideal para estufas, chimeneas,...

${ }^{3}$ Humificador ultrasónico Orbegozo HU 2060. Este dispositivo tiene una potencia de $40 \mathrm{~W}$ y una capacidad de tanque de 6 litros.
} 
partículas de diámetro 1-5 $\mu \mathrm{m}$. El sistema de ventilación libera vapor en el aire seco donde se evapora para alcanzar la humedad requerida.

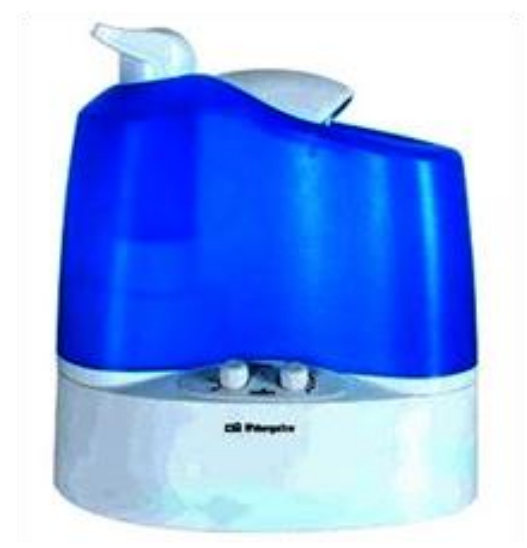

Figura 3. 22. Humidificador ultrasónico utilizado.

Con estas modificaciones ya es posible aumentar la temperatura y la humedad relativa, pero se necesita un sistema de control para estabilizar estos parámetros. Para ello, se incorporaron unos sensores de recogida de datos apropiados, así como una serie de mecanismos para detener los actuadores cuando se alcanzan las condiciones marcadas y reiniciarlos cuando no están en estas condiciones. El control de todo ello se realizó con un equipo informático dotado del programa LabVIEW. Este programa, para poder funcionar correctamente, necesita recoger la información de los parámetros a través de los sensores de temperatura y humedad relativa, y actuar a través de los mecanismos de control de los actuadores (resistencia calefactora y humidificador). Se ha utilizado el dispositivo LCNFTW04 (figura 3.23) que integra los sensores de temperatura y humedad relativa.

\footnotetext{
${ }^{4}$ Sensor LCN-FTW04 de la marca Thermokon. Este dispositivo necesita para el funcionamiento de los sensores una alimentación de $24 \mathrm{~V}$ en continua y tiene un margen de operación de 0-10 V (4-20 mA) para las salidas de los sensores.
} 


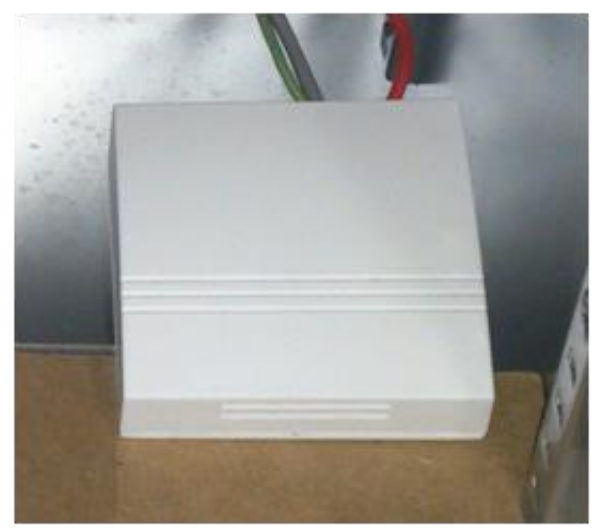

Figura 3. 23. Sensor LCN-FTW04.

El sensor tiene una tasa de error pequeño, asumible para esta metodología. Según indicación del fabricante sobre la precisión, el error máximo que puede alcanzar el aparato es del 3\%, tanto en la humedad relativa como en la temperatura.

Las señales de tensión de salida que nos proporcionan los sensores no pueden ser introducidas directamente al equipo informático. Para ello se necesita una tarjeta de adquisición de datos. La utilizada en nuestro trabajo es la tarjeta de National Instruments NI-USB6008 (figura 3.24), que se ajusta a las características requeridas [123]. Este tipo de tarjetas solo captan los valores de tensión que se le aplican a los bornes de sus canales. Ello significa que, para obtener el valor real de los parámetros, el programa LabVIEW necesita una trasformación, que es realizada mediante programación. Esta tarjeta admite valores de tensión de entre 0 y 10 voltios, por lo que es válida para las salidas de los sensores utilizados. Por lo tanto, la tarjeta de adquisición de datos y el programa informático de LabVIEW permiten realizar el control de la temperatura y humedad dentro de la cámara. 


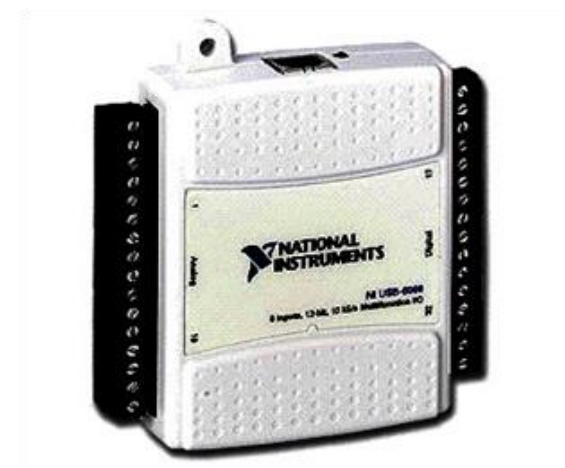

Figura 3. 24. Tarjeta de adquisición de datos NI USB6008.

La elección de esta tarjeta no se ha hecho únicamente en función de los canales de entrada hacia el equipo informático, sino también debido a que posee dos canales de salida analógicos, necesarios para el control de los actuadores a través del programa LabVIEW. Esta salida es limitada y no da las características requeridas por los relés de activación de los actuadores (temperatura y humedad relativa), por lo que fue necesario realizar una adaptación a los requerimientos del circuito y, para ello, se diseñó un circuito electrónico de control. Este circuito nos asegura la protección de la tarjeta por la separación de los dos circuitos, el de mando y el de potencia. El esquema utilizado es el que se muestra en la figura 3.25.

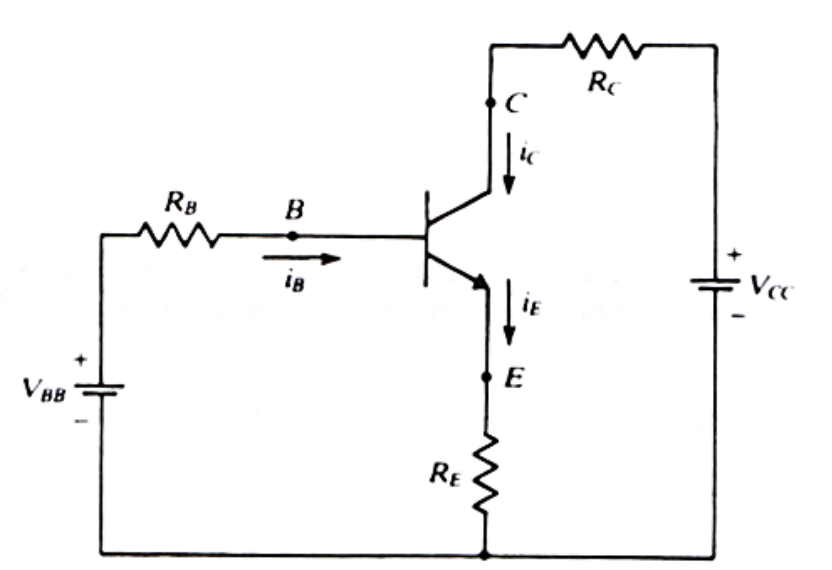

Figura 3. 25. Esquema electrónico de control de los actuadores. 
Como en este procedimiento hay dos actuadores, el de temperatura y el de humedad de la cámara, se construyeron dos circuitos idénticos. Para definir los componentes se utilizan las ecuaciones características del circuito representado:

$$
\begin{aligned}
& V_{B B}=R_{B} \cdot I_{B}+V_{B E}+R_{E}\left(I_{B}+I_{C}\right) \\
& V_{C C}=R_{C} \cdot I_{C}+V_{C E}+R_{E}\left(I_{B}+I_{C}\right)
\end{aligned}
$$

Donde:

$V_{B B}$, es la tensión en continua proporcionada por la salida de la tarjeta NI USB6008, obtenida a través del programa de LabVIEW. Tiene un valor de 0 o 3 voltios según su posición.

$V_{C C}$, es la tensión de polarización del circuito y tiene que dar un valor superior a la tensión de cambio del relé (4V en continua). El valor elegido para esta fuente es de $5 \mathrm{~V}$.

$R_{B}$, es la resistencia que debemos incluir en el terminal de la base del transistor para que el circuito funcione correctamente.

$R_{E}$, es la resistencia que debemos incluir en el terminal del emisor del transistor para que el circuito funcione correctamente.

$R_{C}$, es la resistencia de la bobina del relé, que es el encargado de conmutar el circuito de potencia del actuador.

$V_{C E}$ y $V_{B E} \quad$ son las tensiones en los terminales del transistor (colector/emisor y base/emisor) y están definidos por el propio transistor (547B).

Para realizar el cálculo de las resistencias, los datos necesarios son la tensión en el relé, es decir, la caída de tensión que tiene, que es el producto $R_{C} \cdot I_{C}$, en las dos situaciones que se desean. Con estos valores iniciales se obtienen las resistencias del circuito: $R_{E}=220 \Omega$ y $R_{B}=100 \mathrm{k} \Omega$. 
El circuito utilizado en el laboratorio puede observarse en la siguiente fotografía.

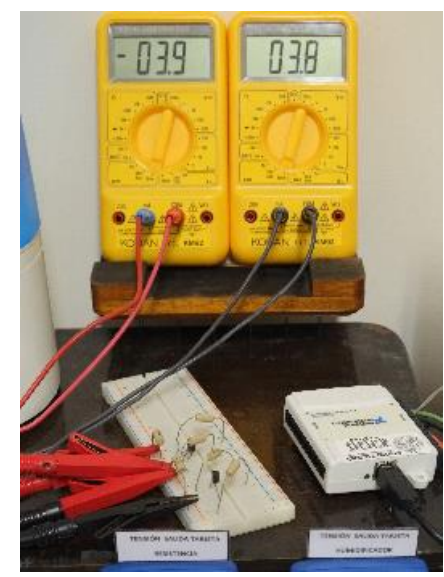

Figura 3. 26. Circuito electrónico utilizado.

\subsubsection{Equipo de captación de datos.}

La manipulación manual de instrumentos para realizar medidas prácticas sólo se utiliza en procesos de investigación o en entornos docentes. A nivel industrial, las medidas para el control de un determinado proceso, las pruebas funcionales sobre un equipo o el control de calidad de la producción se realizan de manera automática. El conjunto de instrumentos que hace posible la realización de la medida recibe el nombre de sistema de instrumentación. Todo sistema de instrumentación consta de unos dispositivos, un sistema de interconexión entre ellos y un controlador inteligente que gestiona el funcionamiento de todo el sistema y da las órdenes para que una medida se realice correctamente. La automatización de las medidas requiere que los instrumentos gocen de un cierto grado de "inteligencia" ,para que puedan ser gobernados por un controlador que se comunica con los instrumentos a través de un BUS de instrumentación. 


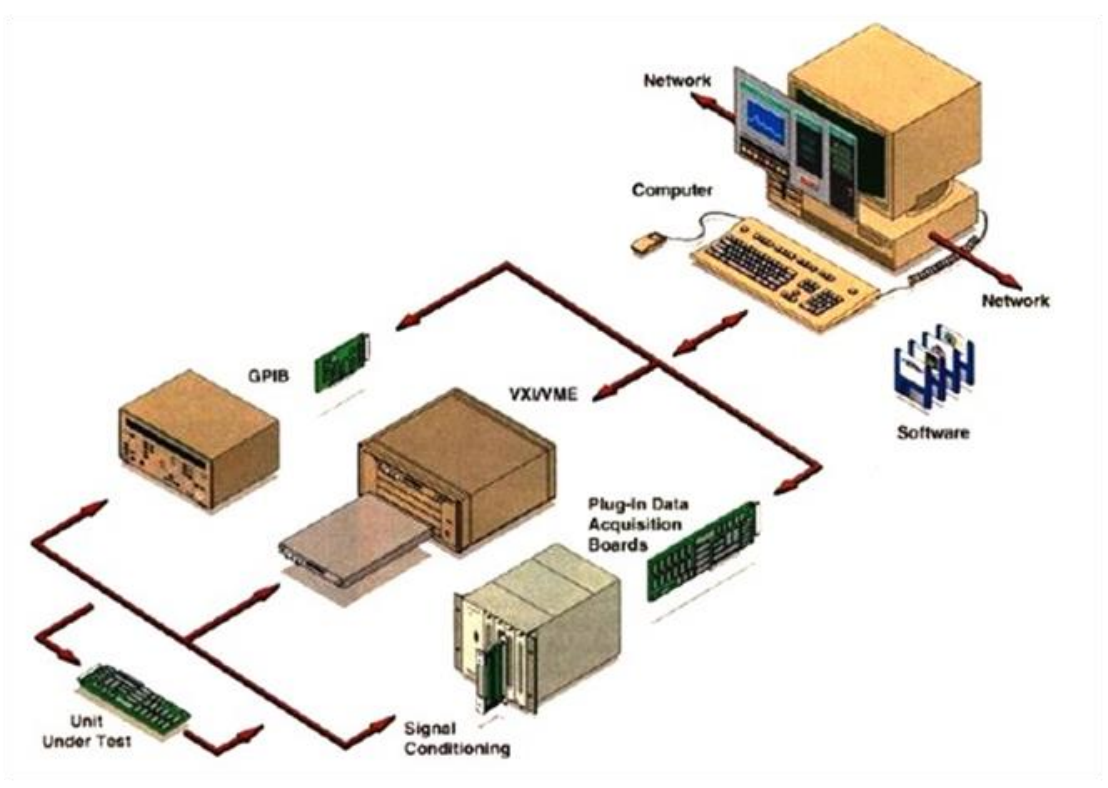

Figura 3. 27. Sistema de instrumentación virtual.

La figura 3.27 muestra un sistema de instrumentación virtual. Pero no es lo mismo hablar de instrumentación controlable por ordenador que de instrumentación virtual. De la primera a la segunda existe un salto importante, salto que ha sido posible gracias a los avances en el campo de la informática. Hablar de instrumentos virtuales es hablar de un software que se ejecuta sobre el controlador, que permite independencia de los instrumentos reales y de la forma de interconectarlos. En la mayor parte de los casos el usuario final del sistema de instrumentación sólo ve los instrumentos virtuales en la pantalla del ordenador.

La forma habitual de construir un sistema de instrumentación virtual, a partir de los instrumentos controlables disponibles y de tarjetas de adquisición conectadas directamente al bus del controlador, es utilizar un software comercial que facilite esta tarea. Existen varias posibilidades, aunque se pueden resumir en dos grandes grupos, los entornos de programación de tipo linguiístico y los entornos de programación gráficos. Además de este software se necesita una tarjeta de 
control dentro del ordenador, y los "drivers" de control de los instrumentos, que los suele facilitar el fabricante del entorno de programación. Para este trabajo se ha utilizado el programa LabVIEW, que utiliza funciones integradas para realizar la adquisición de datos, control de instrumentos y presentaciones de datos. El tratamiento de los datos recogidos por el LabVIEW se ha realizado mediante el programa Excel. Una dificultad añadida es que el paso de los datos de un programa a otro no es directo; para ello se ha tenido que realizar un programa en JAVA que, además, ha permitido depurar los datos Todos estos programas se explican en el apartado siguiente.

\subsubsection{Procesamiento de datos: LabVIEW.}

El programa del Laboratory Virtual Instrument Engineering Workbench, cuyas siglas son LabVIEW, es un lenguaje de programación gráfico para el diseño de sistemas de adquisición de datos, instrumentación y control. National Instruments es la empresa desarrolladora y propietaria de LabVIEW que se fundó en 1976 en Austin, Texas y sus primeros productos eran dispositivos para el bus de instrumentación GPIB. En abril de 1983 comenzó el desarrollo de lo que sería su producto estrella, LabVIEW y que salió a la venta en octubre de 1986, en su primera versión, LabVIEW 1.0 para Macintosh. Este programa permite diseñar interfaces de usuario mediante una consola interactiva basada en software, ya sea especificando su sistema funcional, su diagrama de bloques o una notación de diseño de ingeniería. Tiene un lenguaje de programación gráfico con funciones integradas para realizar la adquisición de datos, el control de instrumentos, y las presentaciones de datos. A diferencia de los lenguajes de propósito general, posee funcionalidad específica para que pueda acelerarse el desarrollo de aplicaciones de medición, control y automatización. 
Este programa es a la vez compatible con herramientas de desarrollo similares y puede trabajar con programas de otra área de aplicación, como por ejemplo Matlab. Tiene la ventaja de que permite una fácil integración con el hardware, específicamente con tarjetas de medición, adquisición y procesamiento de datos. Además, las necesidades de las aplicaciones van cambiando con el tiempo, pero este programa permite que los sistemas definidos y creados por el usuario puedan adecuarse sin necesidad de incorporar equipos nuevos [124]. Los programas desarrollados se denominan Instrumentos Virtuales (VIs), porque su apariencia y funcionamiento imitan los de un instrumento real. Sin embargo, son análogos a las funciones creadas con los lenguajes de programación convencionales. Los VIs tienen una parte interactiva con el usuario y otra parte de código fuente, y aceptan parámetros procedentes de otros VIs. Cada VI contiene dos partes principales:

- Panel frontal: nos indica cómo el usuario interacciona con el VI.

- Diagrama de bloques: son los medios para conectar un VI con otros VIs y se introduce el código que controla el programa.

\section{- Panel frontal.}

La parte del instrumento virtual que ve el usuario se muestra en la figura 3.28. Este interfaz recoge las entradas procedentes del usuario y representa las salidas proporcionadas por el programa. Está formado por una serie de pulsadores, potenciómetros, gráficos, etc. y cada uno de ellos puede estar definido como un control (a) o un indicador (b). Los primeros sirven para introducir parámetros al VI, mientras que los indicadores se emplean para mostrar los resultados producidos, ya sean datos adquiridos o resultados de alguna operación. 


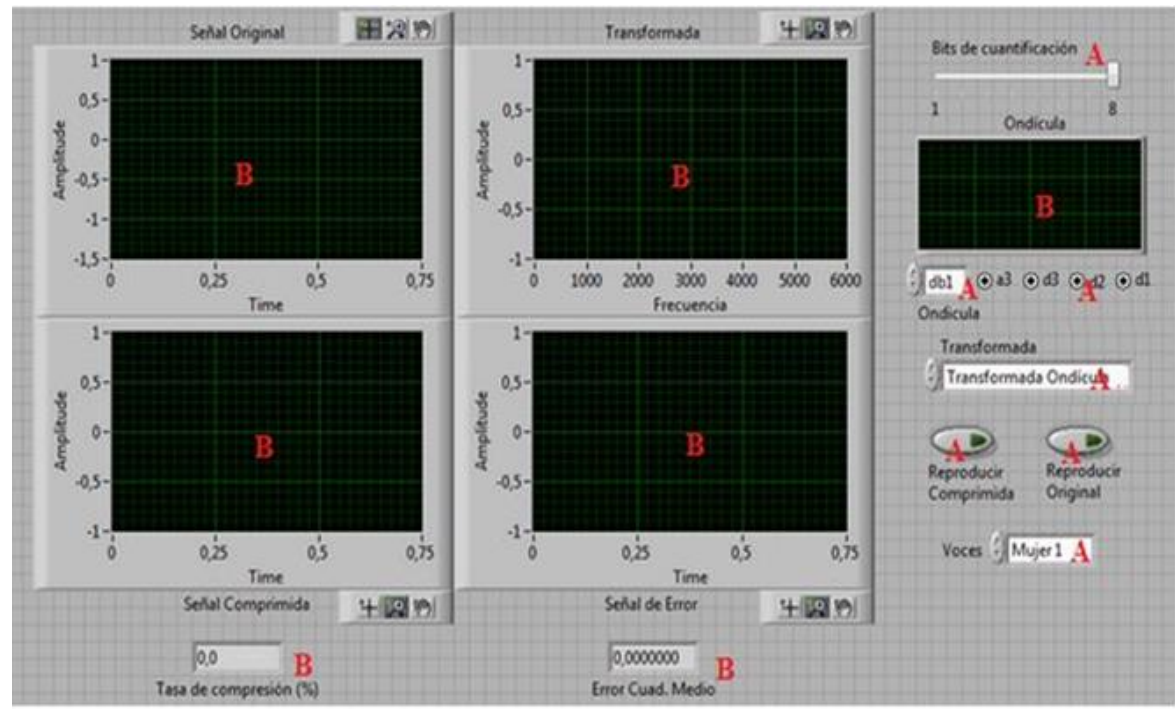

Figura 3. 28. Panel frontal con controles (A) e indicadores (B).

Los controles simulan instrumentos de entrada y entregan los respectivos datos al diagrama de bloques del VI, como los que se muestran en la figura 3.29.

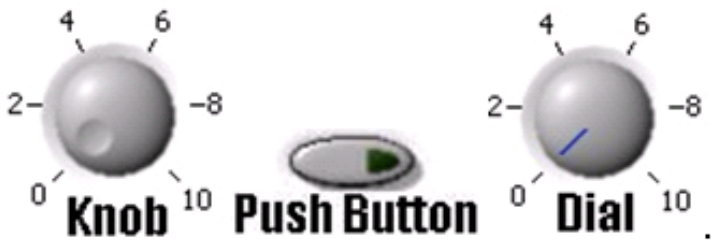

Figura 3. 29. Controles de entrada.

Los indicadores, figura 3.30, simulan instrumentos de salida y muestran los datos que el diagrama de bloques genera o adquiere y se puede visualizar en leds, gráficos y otros tipos de displays. 


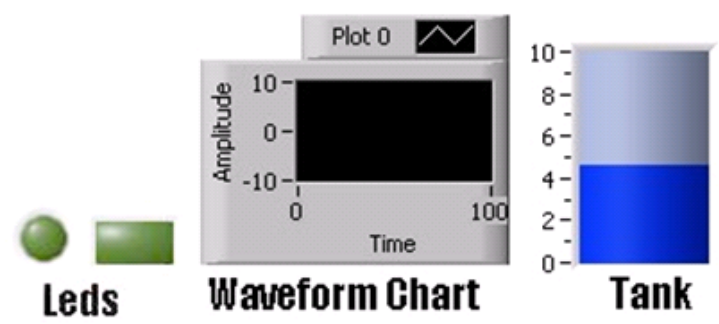

Figura 3. 30. Indicadores de salida.

\section{- Diagrama de bloques o de conexiones.}

El diagrama de bloques constituye el código fuente del VI y es donde se realiza la implementación del programa del VI para controlar o realizar cualquier procesado de las entradas y salidas que se crearon en el panel frontal. Si bien LabVIEW permite emplear el lenguaje de programación $\mathrm{C}$ para realizar cualquier tarea, lo más habitual es emplear los propios objetos integrados en el programa, dando como resultado una programación más rápida y fácil de revisar, aunque también más limitada, puesto que solo se puede disponer de las instrucciones incluidas en el programa. Si se necesitara realizar una acción que no tuviera su objeto gráfico equivalente en LabVIEW, sería necesario emplear C para crearlo [125]. En este lenguaje las funciones y las estructuras son nodos elementales, en donde los controles e indicadores que se colocaron previamente en el Panel Frontal, se materializan en el diagrama de bloques mediante los terminales. El diagrama de bloque contiene el código fuente gráfico y los objetos del panel frontal aparecen como terminales en el diagrama de bloques, tal y como se puede observar en la figura 3.31 . 


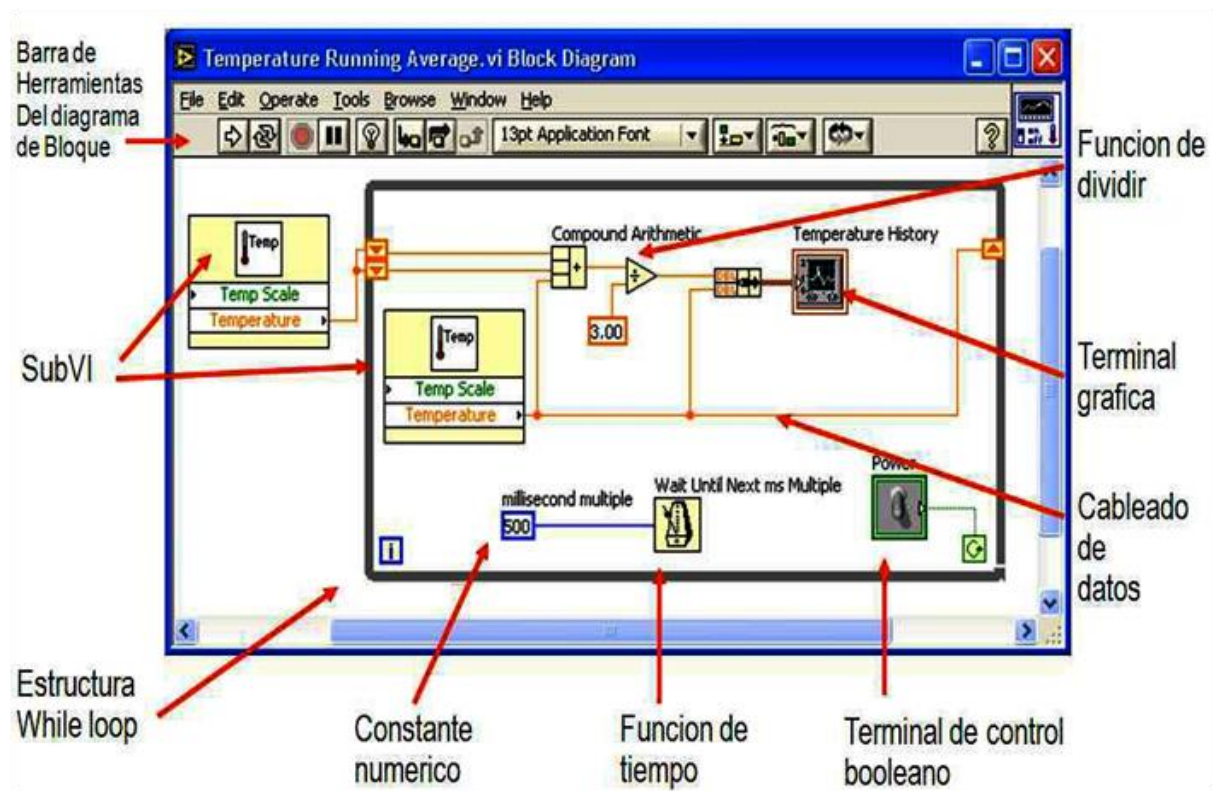

Figura 3. 31. Ejemplo de diagrama de bloques.

Adicionalmente, el diagrama de bloques contiene funciones y estructuras incorporadas en las bibliotecas de LabVIEW. Los cables conectan cada uno de los nodos en el diagrama de bloques, incluyendo controles e indicadores de terminal, funciones y estructuras. En este ejemplo de diagrama de bloque, el subVI Temp llama a la subrutina, la cual obtiene una temperatura desde una tarjeta de adquisición de datos (DAQ). La gráfica de la evolución de esta temperatura a lo largo del tiempo es mostrada junto con el valor medio de la temperatura por la instrucción "Temperature History". El interruptor de poder (Power) es un control booleano en el panel frontal, el cual va a detener la ejecución del programa "While Loop".

Para la realización de los programas son muy útiles las denominadas paletas de LabVIEW, que proporcionan las herramientas que se requieren para crear y modificar tanto el panel frontal como el diagrama de bloques. Existen las paletas de control, las de herramientas y las de funciones: 
- La paleta de control se usa para colocar los controles e indicadores en el panel frontal, como la entrada y visualización de valores booleanos, texto, cantidades numéricas, etc.

- La paleta de herramientas tiene como misión poder operar y modificar objetos en el panel frontal y en el diagrama de bloques, como el valor de los controles, las etiquetas, el color de fondo, de los objetos, etc.

- Se usa la paleta de funciones para construir un diagrama de bloques que nos proporciona los elementos de operación esenciales para programar en LabVIEW, como por ejemplo funciones lógicas, aritméticas, operar con ficheros, etc.

Los desplegables que se obtiene de cada una de las paletas son las que se muestran en los dibujos de la figura 3.32.
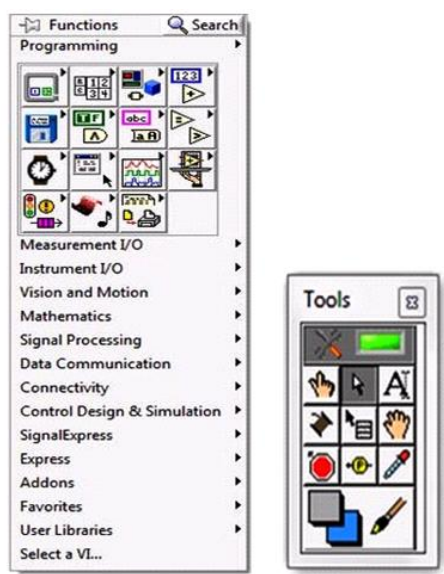

Figura 3. 32. Paletas de control, de herramientas y de funciones.

En la paleta de funciones la primera opción es la de las estructuras. Éstas controlan el flujo del programa, bien sea mediante la secuenciación de acciones, ejecución de bucles, etc. Las estructuras se comportan como cualquier otro nodo en el diagrama de bloques, ejecutando automáticamente lo que está programado en su 
interior, una vez que tiene disponibles los datos de entrada, y una vez ejecutadas las instrucciones requeridas. Como norma general, LabVIEW ejecuta en último lugar las instrucciones que requieren un dato que les proporcionará otra instrucción previa, de forma que parece que los datos fluyen del primer instrumento al último [126]. Cada estructura ejecuta su subdiagrama de acuerdo con las reglas específicas que rigen su comportamiento. Se define como subdiagrama a una colección de nodos, cables y terminales situados en el interior del rectángulo que constituye la estructura. La estructura es secuencial y ejecuta primero todos los instrumentos virtuales y operaciones que estén fuera de dicha estructura y, a continuación, comenzará a ejecutar los que estén dentro de ella, empezando por el primero, luego pasará al segundo y así sucesivamente hasta que acabe con todos los de la estructura.

Como se ha comentado anteriormente, la recogida de datos se realiza a través de "LabVIEW". Los datos recogidos son los referentes a las condiciones climáticas de la cámara (temperatura y humedad relativa) y la tensión de salida del voltímetro estático. Estos valores son introducidos en el equipo informático a través de la tarjeta de adquisición de datos. En esta tarjeta las entradas no pueden superar 10 voltios. Las tensiones de salida de los sensores no superan este valor, pero en el caso del voltímetro estático hay que tener la precaución de seleccionar el modo de salida adecuado, es decir, el valor de 150 en el panel frontal. Para controlar externamente estos valores, en cada instante se incorporaron al equipo una serie de voltímetros. Estos valores son trasmitidos a través de la tarjeta al programa informático, el cual debe mostrarlos en pantalla y guardarlos en un archivo. El programa principal realizado para ello es el mostrado en la figura 3.33. 


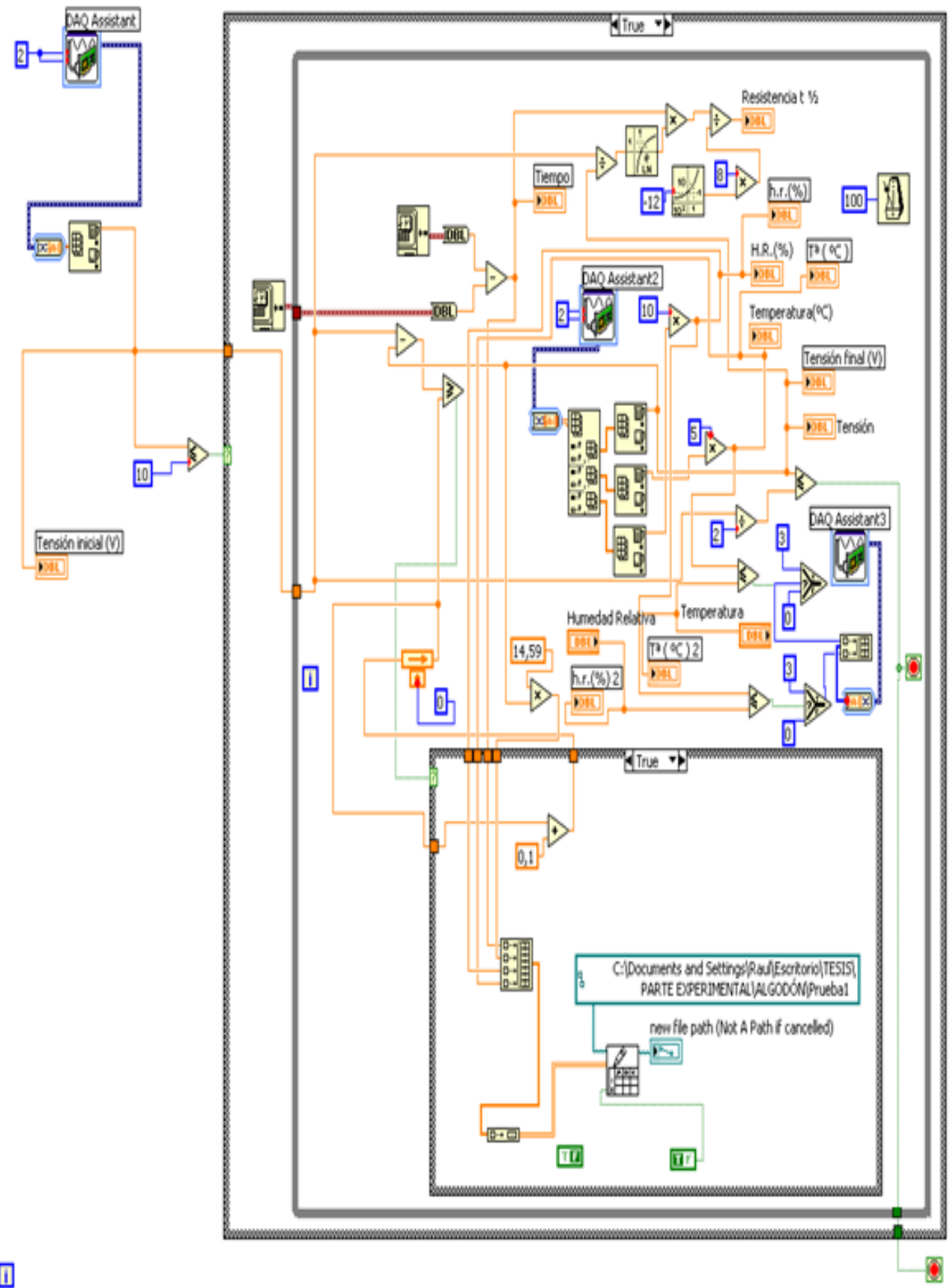

Figura 3. 33. Programa de captura de datos del equipo experimental. 
No obstante esta pantalla no es la que visualizará el usuario, si no la denominada pantalla principal, que es la que se observa en la figura 3.34.

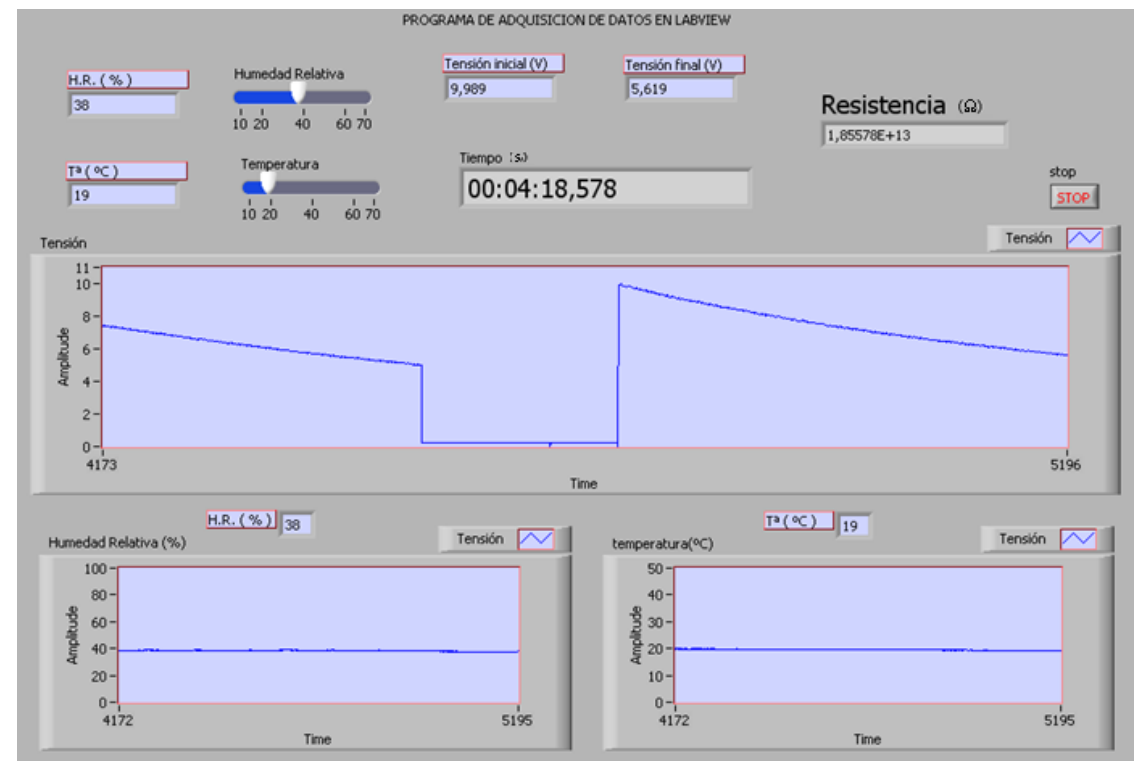

Figura 3. 34. Pantalla principal del programa realizado para la captura de datos en los ensayos.

El programa LabVIEW, además de los resultados mostrados en la pantalla del programa, genera un archivo con las medidas de tensión, humedad y temperatura para cada unidad de tiempo. Los datos del archivo han sido tratados mediante una aplicación JAVA que recoge los datos y, una vez filtrados en base a unos parámetros de entrada, genera un archivo Excel con estos datos y los más relevantes. A continuación, en la figura 3.35, se muestra la interface resultante de dicha aplicación en la que el usuario podrá configurar los parámetros de filtrado. El usuario puede indicar el número de datos que quiere obtener para la primera parte de la descarga que abarca desde el inicio de la prueba hasta la mitad del tiempo de semidescarga (primer intervalo) y para la segunda parte de la descarga que va desde la mitad del tiempo de semidescarga hasta el final del ensayo (segundo intervalo). 
Con ello se obtienen los pares de valores requeridos para la obtención de la gráfica, así como los valores máximos y mínimos de temperatura y humedad relativa de cada prueba para la comprobación de que están en el intervalo deseado, mostrado en la figura 3.36.

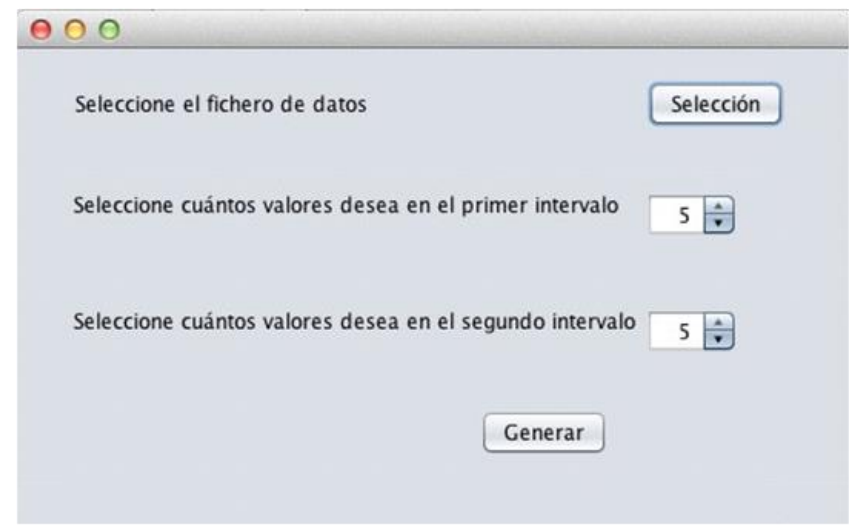

Figura 3. 35. Pantalla principal del programa JAVA.

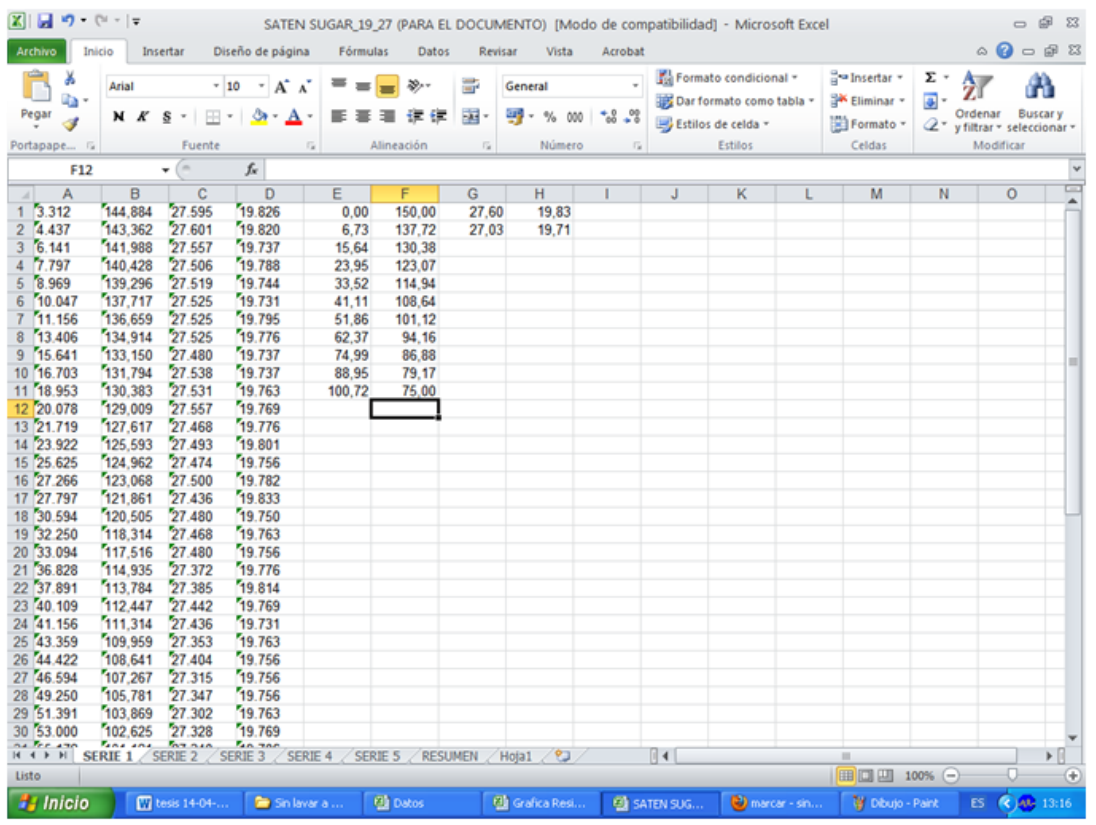

Figura 3. 36. Pantalla de datos de una de las series del programa Excel. 
Los resultados de los programas Excel generados para las pruebas realizadas bajo las mismas condiciones de realización son agrupadas en un mismo archivo. Además en la hoja resumen obtenida, mostrada en la figura 3.37, se indican los valores más relevantes de cada serie.

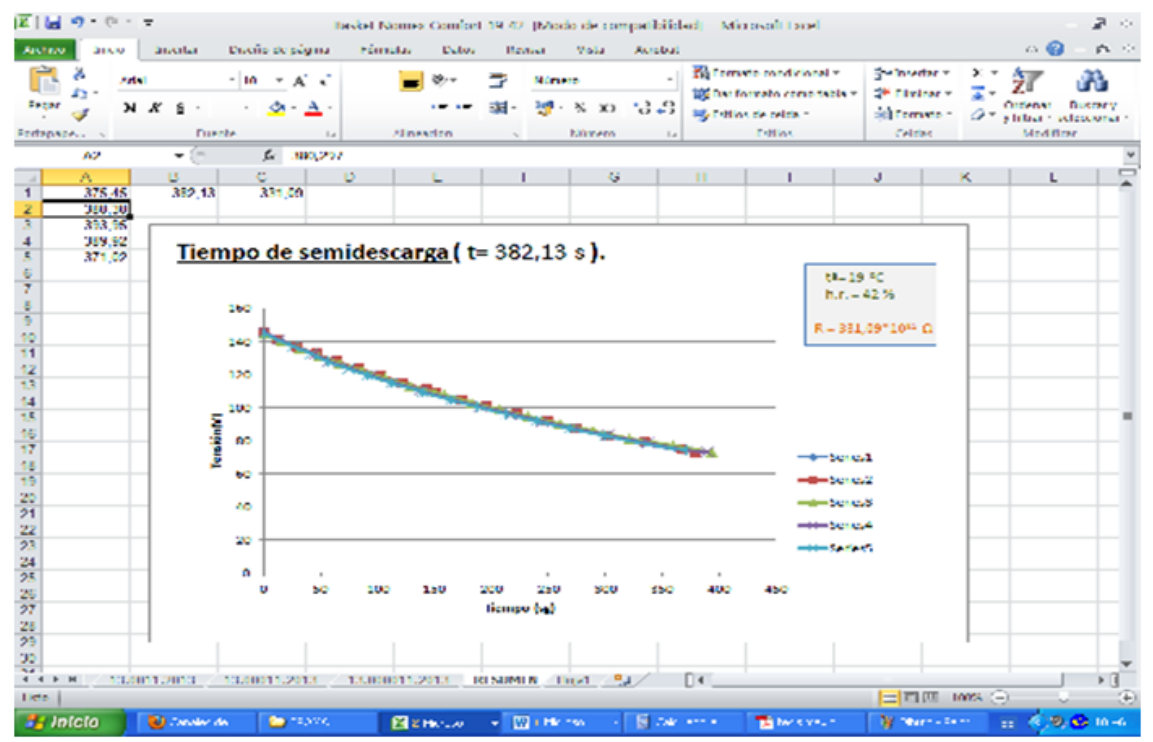

Figura 3. 37. Pantalla de resultados en la hoja resumen del programa Excel.

\subsubsection{Construcción y conexionado de las partes del equipo de ensayo. Funcionamiento general.}

Gran parte del tiempo dedicado a la realización de este trabajo lo ha sido al estudio, construcción y puesta a punto del equipo de ensayo.

La elección del procedimiento ha sido fundamental, ya que nos indicó el circuito a realizar. Como se ha indicado en los apartados anteriores, este circuito está incluido en el aparato elegido, el voltímetro estático R-4021 de la casa suiza 
Rothschild, que tiene incorporada la circuitería eléctrica necesaria para la realización de las pruebas a los textiles. Además, este modelo proporciona la tensión en los extremos de la muestra a través de un voltímetro incorporado, con la posibilidad de conexionar un voltímetro externo para obtener también su medida.

Tras múltiples ensayos para comprobar su funcionamiento y la reproducibilidad de las medidas realizadas, se definió la metodología a emplear. Sin embargo se comprobó que, a pesar de la corrección de la metodología, los resultados variaban debido a que había oscilaciones considerables en las condiciones ambientales, a pesar de estar situado el aparato en una sala aislada. Por ello se decidió completar el equipo con una cámara que mantuviera las condiciones ambientales estables y así poder obtener una buena reproducibilidad en las medidas. Para este fin, como ya se ha comentado anteriormente, se adaptó una antigua cámara de acondicionamiento textil, que demostró ser una buena solución para fijar las condiciones ambientales de cada ensayo, aunque dio bastantes problemas a la hora de montar el equipo.

Para poder modificar las características ambientales de la cámara climática se cambió la resistencia calefactora por una que permitiera obtener la temperatura deseada dentro de la cámara. Además, se adaptó un orificio que existía en la cámara para conectar un humidificador. Se conectaron el hueco de entrada a la cámara y la salida del humidificador mediante un tubo flexible de PVC. La conexión del tubo se realizó a través de diversos adaptadores. Una vez concluido y, a través de un programa informático, el usuario era ya capaz de controlar las condiciones ambientales y, por tanto, de controlar el funcionamiento tanto de la resistencia como del humidificador, denominados actuadores del equipo. Esto no pudo realizarse con conexión directa del ordenador a los actuadores, ya que necesitaba de un adaptador de señales. Para ello se utiliza la tarjeta NI USB6008. Aun así, nos encontramos con el problema de que los parámetros de funcionamiento de la tarjeta 
no eran los mismos que los requeridos por los actuadores y, para solucionarlo, se optó por diseñar un circuito electrónico que adaptara las características de la tarjeta a los de los actuadores. Este circuito electrónico incorpora los relés encargados de dar tensión al circuito principal de los actuadores en los momentos en los que éstos tienen que funcionar.

Debido a las múltiples incidencias surgidas a lo largo de la construcción del equipo se fueron incorporando al esquema diversos aparatos de medida para controlar las características de tensión e intensidad en diferentes ubicaciones del circuito y así realizar una supervisión instantánea de cada una de ellas.

Pero la dificultad más grande fue la incorporación del portaprobetas del voltímetro estático a la cámara climática. Esto se realizó a través de unos cables que conectan los terminales del portaprobetas, situado en el interior de la cámara climática, y los bornes de conexión del voltímetro estático. Pero se comprobó que la tensión en los extremos del portaprobetas sin muestra no era constante, disminuyendo con el paso del tiempo. Tras numerosos estudios y comprobaciones se obtuvo un resultado satisfactorio al sustituir los cables de conexión por cables apantallados 5 .

Después de las diversas pruebas realizadas y de comprobar que el funcionamiento era correcto, el esquema eléctrico final del equipo experimental quedó establecido como se muestra en la figura 3.38.

\footnotetext{
${ }^{5}$ Cable Datwyler altdorf RG-58 C/U, cuya Z es de 50 ohmios.
} 


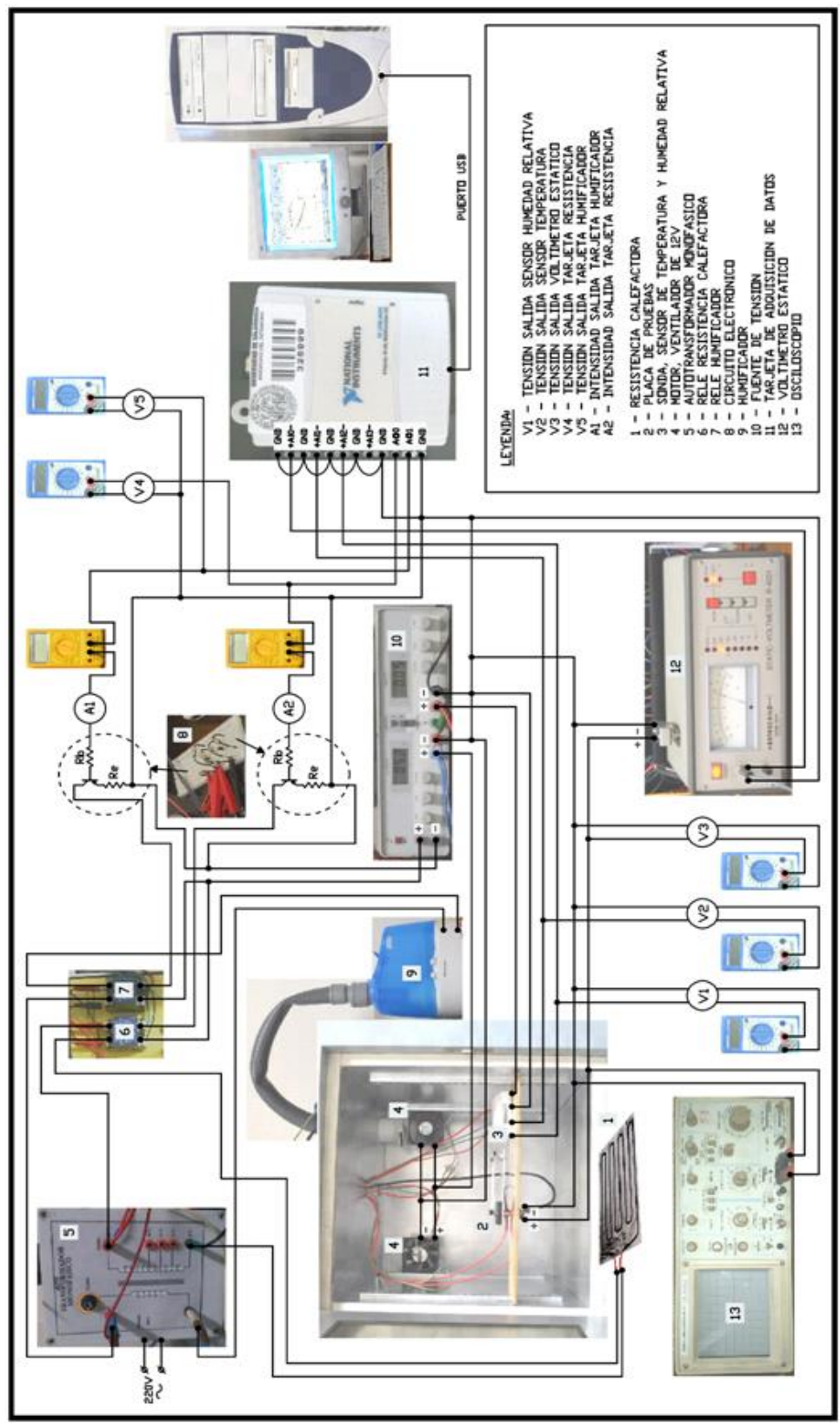

Figura 3. 38. Esquema eléctrico del equipo experimental. 
La realización de cada serie de pruebas lleva bastante tiempo, no tanto la realización de la prueba en sí, sino la preparación las muestras antes de realizar los ensayos. En primer lugar hay que lavar las muestras, adaptar sus dimensiones a las especificadas por el portaprobetas y finalmente, aclimatarlas durante 24 horas a las condiciones ambientales especificadas por el ensayo correspondiente. Transcurrido este tiempo se realizaba la prueba.

Una incidencia importante fue que, debido al gran número de ensayos llevados a cabo, el voltímetro estático sufrió una avería grave. Inicialmente se trató de reparar en los laboratorios de la Escuela, pero no fue posible. Para ello, se desmontó y se realizó un estudio de los diversos circuitos de los que consta este dispositivo, comprobando que la estructura interna es la mostrada en la figura 3.39.

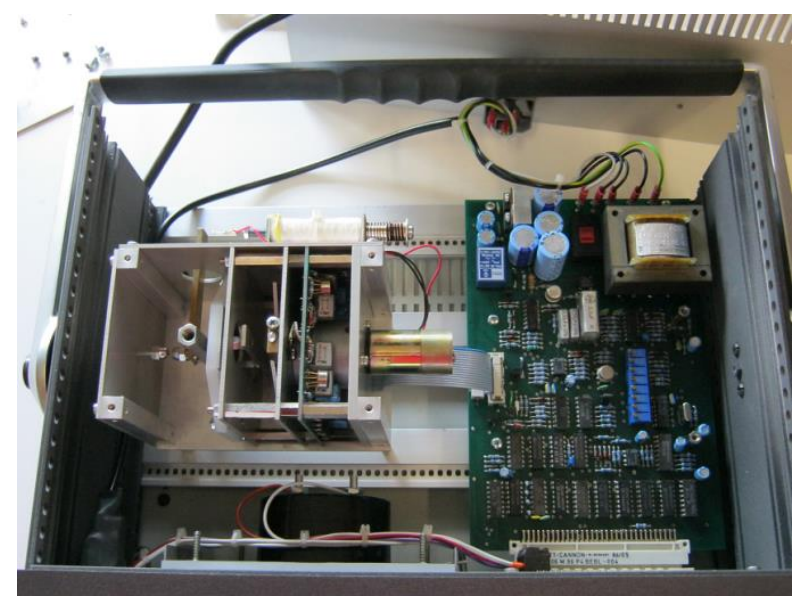

Figura 3. 39. Interior del voltímetro estático R-4021 Rothschild.

Después de cambiar diversos componentes no se pudo lograr la reparación total del dispositivo ya que, al probarlo, se comprobó los resultados de las pruebas y no eran fiables. Finalmente se pudo contactar con la empresa suiza Rothschild, fabricante del aparato, y tras múltiples conversaciones y reiteradas negativas, por 
fin aceptaron que se les enviara para su valoración, siendo al finalmente posible su reparación.

El equipo completo diseñado y montado para la realización de las pruebas a los tejidos textiles se muestra en la fotografía de la figura 3.40.

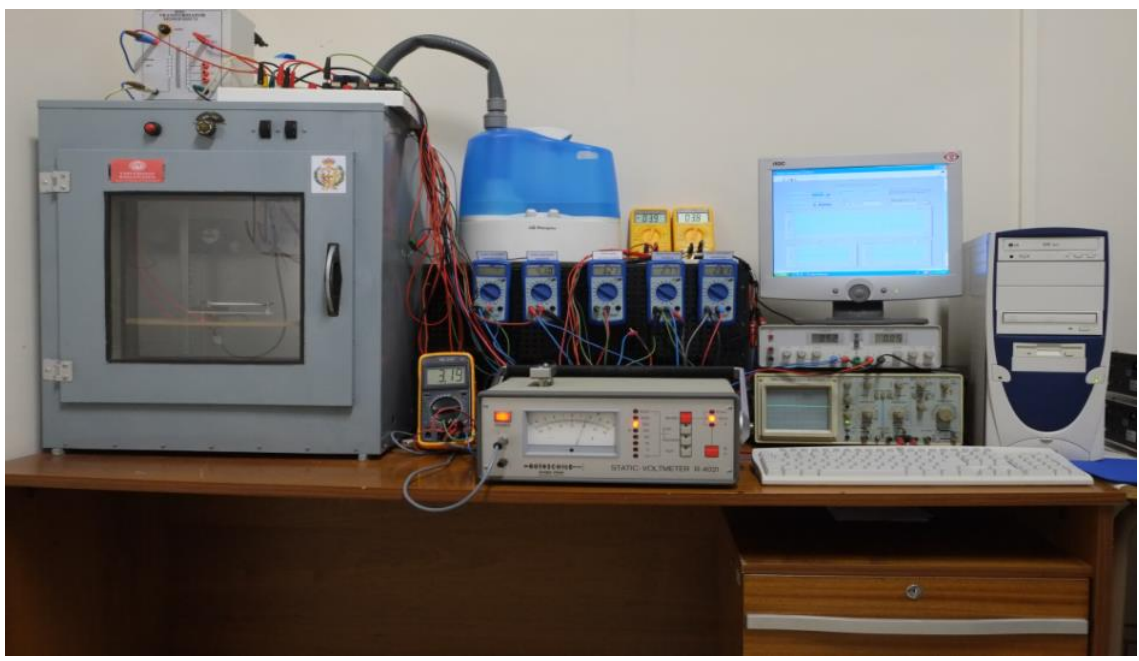

Figura 3. 40. Equipo completo para la realización de los ensayos.

Una vez finalizada la construcción del equipo se realizaron diversas pruebas de funcionamiento, comprobando la fiabilidad de las medidas obtenidas, tanto sin muestra en el portaprobetas como utilizando diversas clases de muestras.

Para la experimentación se eligieron tres tejidos de diferentes características, con objeto de verificar la diferencia de comportamiento eléctrico que existe entre ellos. La elección del tejido 100 \% algodón se realizó debido a que es el único tipo de fibra textil natural que se permite utilizar en prendas que vayan destinadas a trabajos donde haya riesgos derivados de la electricidad estática. La elección del tejido $100 \%$ lana fue motivada porque se trata de una fibra textil también de origen natural considerado no antiestática. Por último se eligió el tejido 
mezcla de fibras de nomex, kevlar y un $2 \%$ de una fibra antiestática, para ver el comportamiento de un tejido de mezcla de fibras con un comportamiento antiestático. Con ello se puede definir la tendencia de la resistividad de cada uno de estos tejidos.

Los ensayos se realizaron a cinco muestras de un mismo tejido que, previamente, habían sido acondicionadas a una temperatura de $19{ }^{\circ} \mathrm{C}$ y a una determinada humedad relativa, correspondiente a cada ensayo, durante 24 horas, en la cámara climática del equipo. Para los experimentos de este apartado se eligió el tejido de algodón, en la dirección de urdimbre, utilizando muestras de las dimensiones requeridas por el portaprobetas, es decir, muestras de $10 \mathrm{~cm}$ de largo por $1 \mathrm{~cm}$ de ancho. Las características del tejido fueron analizadas previamente en los laboratorios de Ingeniería Textil de la Escuela Técnica Superior de Ingeniería Industrial de Béjar (Universidad de Salamanca), tal y como se ha indicado anteriormente.

En los ensayos realizados se comprobó que los hilos están compuestos por fibras $100 \%$ algodón, formando un tejido cuyo ligamento es un "raso", y que posee un espesor de $0,70 \mathrm{~mm}$, una masa laminar de $376 \mathrm{~g} / \mathrm{m}^{2}$ y una densidad volumétrica de $0,54 \mathrm{~g} / \mathrm{cm}^{3}$.

La realización de cada prueba constó de las siguientes etapas:

1) Acondicionamiento de las muestras del tejido durante veinticuatro horas en la cámara climática.

2) Antes de la realización de las pruebas es necesario calibrar el voltímetro estático al inicio de cada serie. Ello consiste en la comprobación de la inexistencia de cargas electrostáticas al inicio de la prueba, a través del voltímetro del aparato, y la comprobación de que la tensión es constante entre los extremos de la muestra. Los resultados de la prueba proporcionan los tiempos de semidescarga y las 
condiciones ambientales a las que se ha realizado ésta. El programa LabVIEW muestra en su pantalla principal los valores de las variables de nuestro interés, tal y como puede comprobarse en la figura 3.41, además de almacenarlos en un archivo.

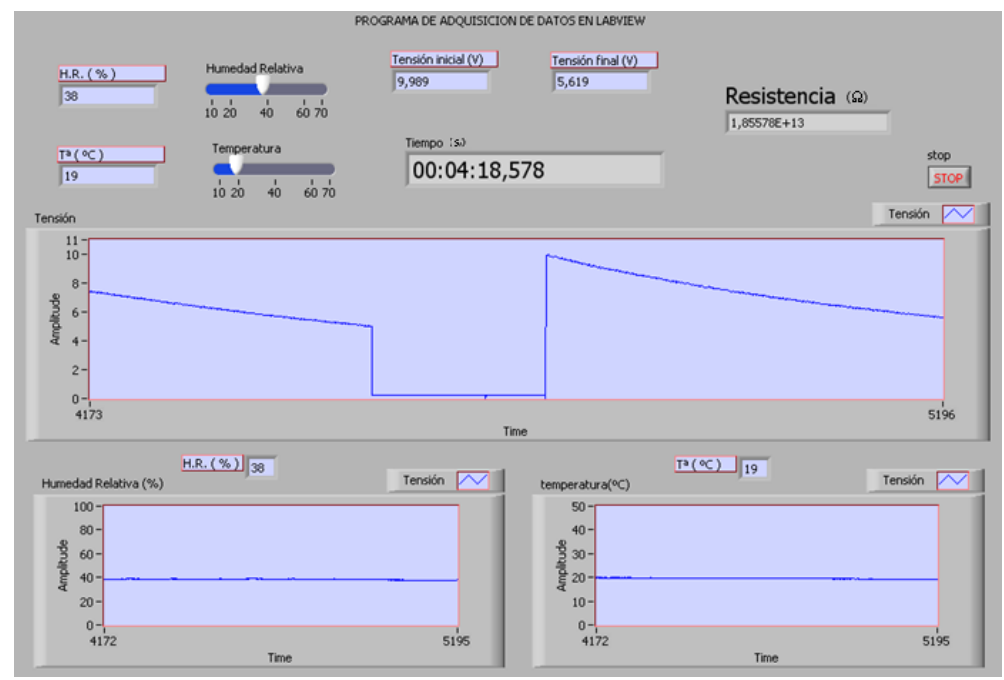

Figura 3. 11. Pantalla principal del programa LabVIEW.

Esta pantalla principal se divide en dos zonas, una donde se muestran los valores que el usuario ha marcado para la realización del ensayo (controladores situados en la parte superior izquierda) y otra que muestra los datos que va recibiendo en el transcurso de la prueba, quedando la pantalla con los siguientes controles e indicadores:

- HR(\%)-Humedad Relativa: se trata del controlador gráfico a través del cual el usuario introduce el parámetro de humedad relativa a la que se quiere realizar el ensayo. Su valor está expresado en tanto por ciento (\%). Al lado está situado otro controlador de este parámetro, en este caso numérico. El usuario puede actuar sobre este parámetro a través de cualquiera de los dos controladores. Lógicamente ambos están interconectados, por lo que los cambios de uno afectan al otro. 
- $T^{a}\left({ }^{\circ} \mathrm{C}\right)$-Temperatura: se trata del controlador gráfico en el que el usuario introduce el parámetro de temperatura a la que se quiere realizar el ensayo, en grados Celsius $\left({ }^{\circ} \mathrm{C}\right)$. Al lado existe otro controlador (numérico) de este parámetro y, como en el caso anterior, el usuario puede actuar sobre este parámetro a través de cualquiera de los dos controladores.

- Tiempo: se trata del indicador que muestra numéricamente el valor del tiempo que está transcurriendo desde el comienzo de la prueba. Este valor está expresado en segundos (s). Al finalizar el ensayo, el valor experimental obtenido es el tiempo de semidescarga, $\mathrm{t}_{50}$.

- Tensión inicial: se trata del indicador que muestra numéricamente el valor de la tensión entre los extremos de la muestra al inicio de la prueba. Este valor está expresado en voltios (V).

- Tensión final: se trata del indicador que muestra numéricamente el valor de la tensión en los extremos de la muestra en el transcurso de la prueba. Este valor está expresada en voltios (V). Al finalizar el ensayo, el valor indicado es la mitad del valor de la tensión inicial.

- Resistencia: se trata del indicador que muestra numéricamente el valor de la resistencia de la muestra textil, medido en ohmios $(\Omega)$, en el transcurso de la prueba. Al finalizar el ensayo, el valor indicado es el valor de la resistencia cuando ha transcurrido el tiempo de semidescarga.

- Tensión: se trata del indicador gráfico que muestra la tensión en los extremos de la muestra en el intervalo de tiempo que dura de la prueba. La unidad expresada en el eje de ordenadas es el voltio (V) y en el eje de abscisas es el segundo (s). 
- Humedad relativa: se trata del indicador gráfico que muestra la humedad relativa del aire de la cámara climática en el intervalo de tiempo que dura la prueba. La unidad expresada en el eje de ordenadas está en tanto por ciento (\%) y en el eje de abscisas la unidad es el segundo (s).

- H.R.(\%): se trata del indicador numérico que muestra el valor instantáneo de la humedad relativa del aire en la cámara climática. La unidad está expresada en tanto por ciento (\%).

- Temperatura: se trata del indicador gráfico que muestra la temperatura del aire de la cámara climática en el intervalo de tiempo que dura la prueba. La unidad del eje de ordenadas es el grado Celsius $\left({ }^{\circ} \mathrm{C}\right)$ y en el eje de abscisas la unidad es el segundo (s).

- $T^{a}\left({ }^{o} \mathrm{C}\right)$ : se trata del indicador numérico que muestra el valor instantáneo de la temperatura del aire en la cámara climática. La unidad está expresada en grados Celsius $\left({ }^{\circ} \mathrm{C}\right)$.

3) Tratamiento de los resultados de las distintas pruebas. Se ha utilizado un programa realizado en Excel, pero el archivo que guarda el programa LabVIEW tiene una extensión no compatible. Para solucionarlo se realizó un programa en JAVA, el cual recoge los resultados obtenidos del programa LabVIEW y los pasa al archivo Excel, proporcionando los resultados de la prueba en columnas, siendo las cuatro primeras columnas los valores originales del LabVIEW y las cuatro últimas los resultados más representativos. A modo de ejemplo, en la figura 3.42 se muestra una serie de datos obtenidos en el archivo Excel. 


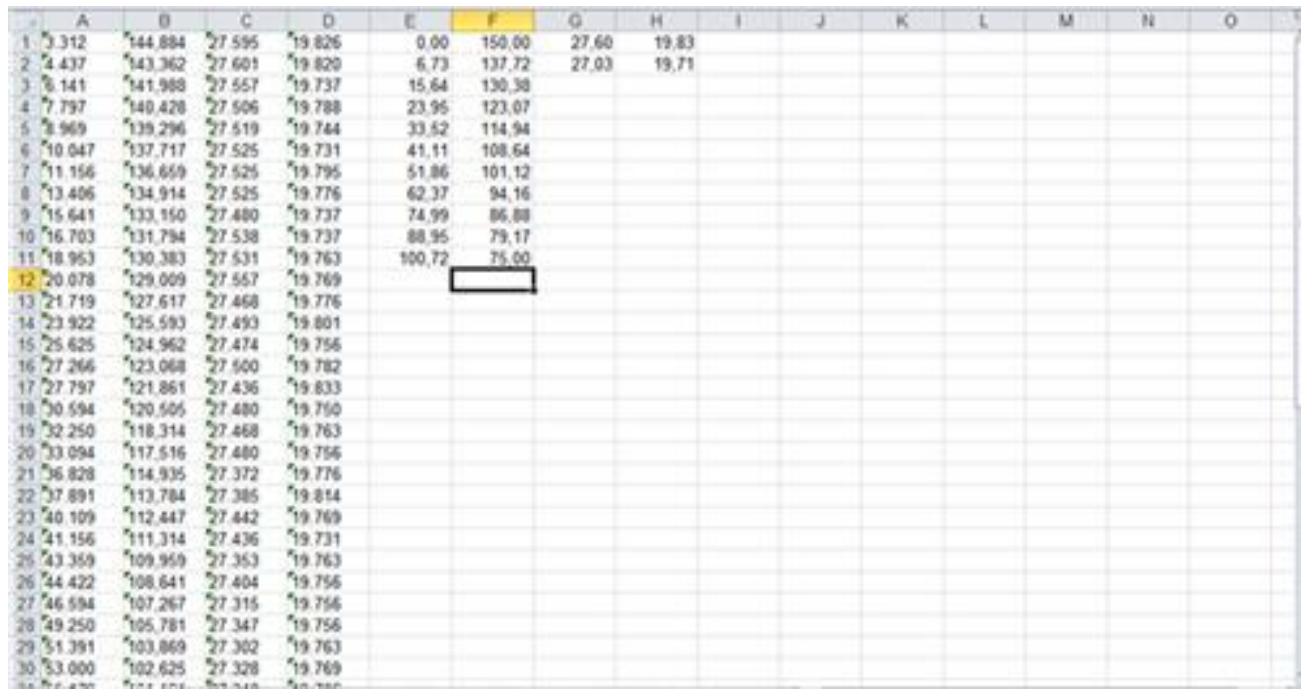

Figura 3. 42. Pantalla del programa Excel que muestra los resultados obtenidos de una de las pruebas realizadas.

Cada columna proporciona resultados de variables diferentes, es decir:

Primera columna: muestra los valores del tiempo trascurrido a lo largo de la prueba, recogidos por el programa LabVIEW.

Segunda columna: muestra los valores de la tensión en los extremos de la muestra en los instantes de tiempo definidos en la columna anterior.

Tercera columna: indican los valores de humedad relativa del aire en la cámara climática existente en cada instante de tiempo definido en la primera columna.

Cuarta columna: muestra los valores de temperatura en esta cámara en cada instante de tiempo definido en la primera columna.

Quinta columna: muestra los valores más significativos del tiempo del ensayo; el último valor de esta columna es el valor del tiempo de semidescarga que se utiliza para el cálculo de los parámetros eléctricos de la muestra. 
Sexta columna: muestra los valores de tensión en los extremos de la muestra recogidos en los instantes expresados en la anterior columna, donde el último valor ha de tener la mitad del valor inicial (primer valor).

Séptima columna: muestra los valores máximo y mínimo de la humedad relativa del aire del ensayo, donde el valor máximo y mínimo que se indican no deben superar el $\pm 1 \%$ de la humedad relativa fijada previamente.

Octava columna: muestra los valores máximo y mínimo de la temperatura del ensayo. Estos valores deben estar comprendidos en el intervalo de $\pm 1^{\circ} \mathrm{C}$ respecto a la temperatura establecida por el usuario.

Como puede verse, estas tres últimas columnas corresponden a valores de control para comprobar si la prueba realizada es válida. Si los valores correspondientes no están dentro de los límites marcados en los ensayos, las pruebas se descartan.

Las pruebas realizadas en las mismas condiciones de ensayo se almacenan en un mismo archivo Excel y se crea una hoja resumen para recopilar los datos significativos de cada serie. Este archivo consta de seis hojas distintas: las cinco primeras hojas son los resultados de cada una de las series (el contenido de cada una de ellas es el mostrado en la figura 3.42), y la sexta hoja (figura 3.43), muestra los resultados finales. En esta sexta hoja (RESUMEN) se reflejan los resultados obtenidos en cada prueba:

Primera columna: indica los valores obtenidos para los tiempos de semidescarga de cada serie (s).

Segunda columna: valor medio del tiempo de semidescarga de las cinco series (s).

Tercera columna: valor de la resistencia eléctrica de la muestra $(\Omega)$. 
Además, se incorpora en esta hoja una gráfica resumen de la evolución de la tensión en los extremos de la muestra de las cinco series y un cuadro resumen con los valores finales de la prueba, es decir, tiempo de semidescarga, resistencia eléctrica, humedad relativa y temperatura del ensayo.

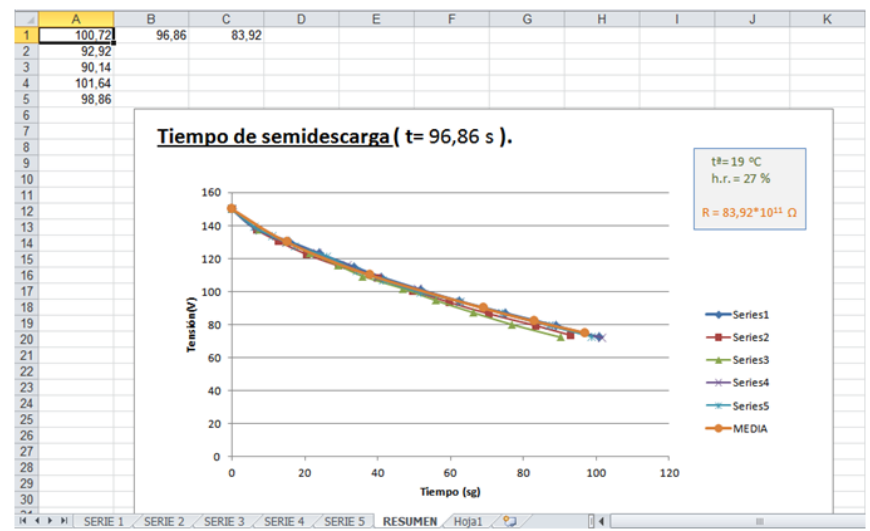

Figura 3.43. Pantalla del programa Excel que muestra la hoja resumen de los resultados obtenidos de un ensayo.

Una vez definida la forma de obtención de la resistencia de la muestra del tejido solo queda calcular la resistividad a través de la ecuación que las relaciona. 


\title{
CAPÍTULO 4 RESULTADOS Y DISCUSIÓN
}

\author{
Índice
}

4.0. Resumen

4.1. Introducción. 135

4.1.1. Tejido sin tratamiento previo de lavado 135

4.1.2. Tejido con tratamiento previo de lavado. 140

4.2. Análisis de las características eléctricas a través de variables externas a los tejidos. 149

4.3. Análisis de las características eléctricas según la naturaleza del material. 160

4.3.1. Tejido de algodón. 162

4.3.2. Tejido de lana. 167

4.3.3. Tejido compuesto por Nomex-Kevlar-fibra antiestática. . 176 4.3.4. Comparativa según su composición. 187 


\section{CAPÍTULO 4}

\section{RESULTADOS Y DISCUSIÓN}

\subsection{Resumen.}

En este capítulo se exponen y se discuten los resultados obtenidos, a partir de las cinco series realizadas para cada ensayo de una probeta. El parámetro medido experimentalmente es el tiempo de semidescarga $\mathrm{y}$, con sus valores, se calcula el valor de la resistencia eléctrica de las muestras de los tejidos para diferentes condiciones ambientales. Después, el tiempo de semidescarga se relaciona con la resistividad eléctrica, que es el parámetro eléctrico característico de cada material. Además, a través del coeficiente de variación se cuantifica el error de cada una de las series realizadas.

El objetivo es comprobar el comportamiento de la resistividad eléctrica de los tejidos estudiados a través de sus ecuaciones representativas. Así mismo, se realizó el estudio de la regresión lineal utilizando el método de los mínimos cuadrados, obteniendo los coeficientes de correlación y de determinación.

Una vez expuestos y discutidos los resultados, se sintetizan éstos en las conclusiones expuestas en el capítulo 5. 


\subsection{Introducción.}

En el capítulo anterior se ha definido la metodología a utilizar con el equipo montado, para el cálculo de la resistencia de los materiales textiles. Pero, lo primero que hay que comprobar es si los tejidos tal y como se nos han suministrado requieren de algún tratamiento previo antes de realizar las medidas. Para ello se realizará un análisis de los resultados obtenidos bajo dos condiciones de partida diferentes: una cuando el tejido está sin lavar y otra cuando el tejido se lava previamente.

La comprobación se realizó con el tejido de algodón, por urdimbre, y a una temperatura de $19^{\circ} \mathrm{C}$. Además se efectuaron ensayos a diferentes humedades relativas, comprendidas entre el $27 \%$ y el $70 \%$.

\subsubsection{Tejido sin tratamiento previo de lavado.}

Como se ha indicado anteriormente, los resultados obtenidos en el equipo de medición son los tiempos de descarga del circuito. De ellos el resultado final, el tiempo de semidescarga, es el utilizado para el cálculo de la resistencia eléctrica de la muestra textil analizada. Los resultados completos obtenidos en los ensayos realizados al tejido de algodón sin tratamiento de lavado se exponen en el anexo 4 de este documento, donde puede comprobarse la buena reproducibilidad de los resultados por la proximidad (casi coincidencia) de las cinco curvas correspondientes a las medidas realizadas para cada serie.

A través de los resultados medios de descarga de cada ensayo se obtiene la figura 4.1, que muestra gráficamente la evolución de la tensión (valor medio de los datos de cada ensayo) en los extremos de la muestra del tejido en función 
del tiempo, a distintas humedades relativas, y que resume todas las gráficas expuestas en el Anexo 4.

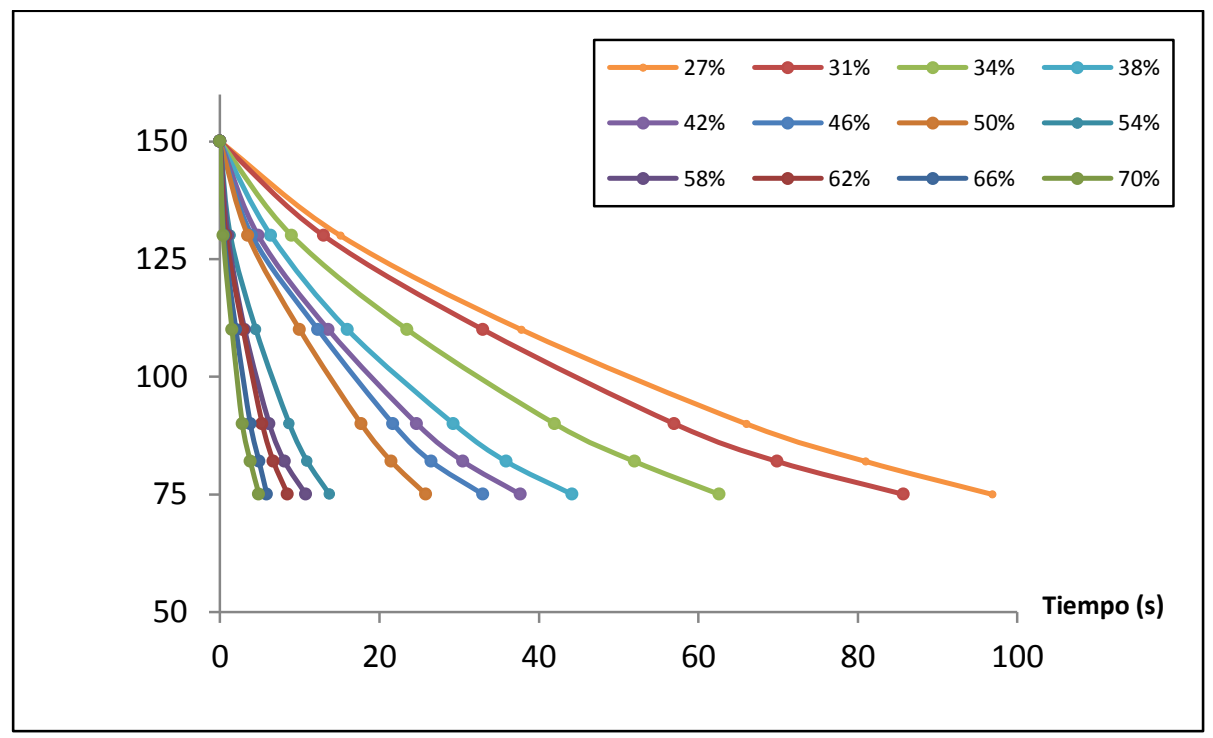

Figura 4. 1. Gráfica resumen de los resultados finales del tejido de algodón sin lavar, por urdimbre, a una temperatura de $19^{\circ} \mathrm{C}$ y diferentes H.R.

En esta figura se muestra la evolución de la descarga para cada humedad relativa utilizada en los ensayos y se visualiza la dependencia de esta variable. Pero esta dependencia no es uniforme, puesto que la disminución del tiempo de semidescarga con el aumento de la humedad relativa del aire es significativa hasta llegar al 54\%, disminuyendo en mucha menor proporción cuando se supera esa humedad. Ello es debido a que la diferencia entre la absorción de humedad de las fibras del tejido y la depositada en la superficie es menor debido a la saturación producida a humedades grandes. Merece pues la pena concluir el análisis a través del estudio de las características eléctricas, cuyo cálculo se realiza a través de los valores de los tiempos de semidescarga de 
las cinco series realizadas. Los valores medios obtenidos son los indicados en la tabla 4.1, incluyendo además el coeficiente de variación de cada ensayo.

\begin{tabular}{|c|c|c|c|c|c|c|c|}
\hline \multirow{3}{*}{$\begin{array}{c}\text { H.R. } \\
(\%)\end{array}$} & \multicolumn{7}{|c|}{$\mathbf{t}_{50}(\mathbf{s})$} \\
\hline & \multicolumn{5}{|c|}{ Ensayo } & \multirow{2}{*}{ Media } & \multirow{2}{*}{$\begin{array}{l}\text { C.V. } \\
(\%)\end{array}$} \\
\hline & 1 & 2 & 3 & 4 & 5 & & \\
\hline 27 & 100,72 & 92,92 & 90,14 & 101,64 & 98,86 & 96,86 & 5,22 \\
\hline 31 & 85,78 & 85,16 & 86,41 & 86,84 & 84,56 & 85,75 & 1,07 \\
\hline 34 & 62,16 & 65,17 & 61,61 & 61,36 & 62,91 & 62,64 & 2,45 \\
\hline 38 & 42,83 & 44,59 & 43,86 & 44,55 & 45,13 & 44,19 & 2,00 \\
\hline 42 & 36,59 & 37,59 & 38,08 & 37,94 & 38,19 & 37,68 & 1,71 \\
\hline 46 & 32,97 & 32,23 & 32,94 & 33,45 & 33,42 & 33,00 & 1,50 \\
\hline 50 & 25,67 & 25,89 & 25,72 & 25,72 & 26,17 & 25,83 & 0,80 \\
\hline 54 & 13,59 & 13,33 & 13,58 & 14,09 & 14,13 & 13,74 & 2,55 \\
\hline 58 & 10,89 & 10,86 & 10,89 & 10,89 & 10,33 & 10,77 & 2,31 \\
\hline 62 & 8,19 & 8,16 & 8,69 & 8,72 & 8,72 & 8,49 & 3,47 \\
\hline 66 & 5,98 & 6,02 & 5,98 & 5,47 & 5,97 & 5,88 & 3,96 \\
\hline 70 & 4,91 & 4,86 & 4,94 & 4,89 & 4,88 & 4,89 & 0,61 \\
\hline
\end{tabular}

Tabla 4. 1. Resultados y desviación típica del tiempo de semidescarga del tejido de algodón sin lavar, por urdimbre, a una temperatura de $19^{\circ} \mathrm{C}$ y diferentes H.R.

Los valores de tiempo de semidescarga obtenidos en cada ensayo muestran un coeficiente de variación pequeño. Como se ha indicado anteriormente, el valor de la resistencia eléctrica se obtiene en función del tiempo de semidescarga, a través de la ecuación 3.11. A partir de este valor obtenido se halla la resistividad eléctrica, que está en relación directa con la resistencia eléctrica a través de la ecuación 4.1 [127]: 


$$
\rho=\frac{E}{L} \cdot R \cdot A
$$

Donde:

$\rho, \quad$ resistividad eléctrica $(\Omega \cdot \mathrm{cm})$.

$R$, resistencia eléctrica $(\Omega)$.

A, ancho de la muestra (cm).

E, espesor de la muestra $(\mathrm{cm})$.

$\mathrm{L}$, longitud de la muestra (cm).

Sustituyendo los valores referentes a la muestra del tejido de algodón $(\mathrm{W}=1 \mathrm{~cm}, \mathrm{E}=0,07 \mathrm{~cm}, \mathrm{~L}=10 \mathrm{~cm})$ en la ecuación 4.1, se obtiene la ecuación particular utilizada para este tejido:

$$
\rho=0,007 \cdot R
$$

La conductividad, que es la inversa de la resistividad, se calcula a través de la siguiente ecuación:

$$
\sigma=\frac{1}{\rho}
$$

Donde:

$$
\begin{aligned}
& \sigma, \text { conductividad eléctrica }\left(S \cdot \mathrm{cm}^{-1}\right) \text {. } \\
& \rho, \text { resistividad eléctrica }(\Omega \cdot \mathrm{cm}) .
\end{aligned}
$$

Los resultados obtenidos aplicando las anteriores ecuaciones para todos los ensayos se recogen en la tabla 4.2. De esta tabla se obtiene la figura 4.2, representación de la resistividad frente a la H.R., comprobándose que la disminución de la resistividad con el aumento de la humedad relativa ha sido muy rápida hasta el 54\%, y disminuyendo de forma menos acusada cuando se sobrepasa ese valor. 


\begin{tabular}{|c|c|c|c|c|}
\hline H.R. $(\%)$ & $\mathrm{t}_{50}(\mathrm{~s})$ & $\mathrm{R}(\Omega)$ & $\rho(\Omega \cdot \mathrm{cm})$ & $\sigma(\mathrm{S} / \mathrm{cm})$ \\
\hline $\mathbf{2 7}$ & 96,86 & $83,92 \cdot 10^{11}$ & $5,87 \cdot 10^{10}$ & $0,17 \cdot 10^{-10}$ \\
\hline $\mathbf{3 1}$ & 85,75 & $74,30 \cdot 10^{11}$ & $5,20 \cdot 10^{10}$ & $0,19 \cdot 10^{-10}$ \\
\hline $\mathbf{3 4}$ & 62,64 & $54,27 \cdot 10^{11}$ & $3,80 \cdot 10^{10}$ & $0,26 \cdot 10^{-10}$ \\
\hline $\mathbf{3 8}$ & 44,19 & $38,29 \cdot 10^{11}$ & $2,68 \cdot 10^{10}$ & $0,37 \cdot 10^{-10}$ \\
\hline $\mathbf{4 2}$ & 37,68 & $32,65 \cdot 10^{11}$ & $2,29 \cdot 10^{10}$ & $0,44 \cdot 10^{-10}$ \\
\hline $\mathbf{4 6}$ & 33,00 & $28,59 \cdot 10^{11}$ & $2,00 \cdot 10^{10}$ & $0,50 \cdot 10^{-10}$ \\
\hline $\mathbf{5 0}$ & 25,83 & $22,38 \cdot 10^{11}$ & $1,57 \cdot 10^{10}$ & $0,64 \cdot 10^{-10}$ \\
\hline $\mathbf{5 4}$ & 13,74 & $11,91 \cdot 10^{11}$ & $0,83 \cdot 10^{10}$ & $1,20 \cdot 10^{-10}$ \\
\hline $\mathbf{5 8}$ & 10,77 & $9,33 \cdot 10^{11}$ & $0,65 \cdot 10^{10}$ & $1,53 \cdot 10^{-10}$ \\
\hline $\mathbf{6 2}$ & 8,49 & $7,36 \cdot 10^{11}$ & $0,52 \cdot 10^{10}$ & $1,94 \cdot 10^{-10}$ \\
\hline $\mathbf{6 6}$ & 5,88 & $5,10 \cdot 10^{11}$ & $0,36 \cdot 10^{10}$ & $2,80 \cdot 10^{-10}$ \\
\hline $\mathbf{7 0}$ & 4,89 & $4,24 \cdot 10^{11}$ & $0,30 \cdot 10^{10}$ & $3,37 \cdot 10^{-10}$ \\
\hline
\end{tabular}

Tabla 4. 2. Resultados de los parámetros eléctricos del tejido de algodón sin lavar, por urdimbre, a una temperatura de $19^{\circ} \mathrm{C}$ y diferentes H.R.

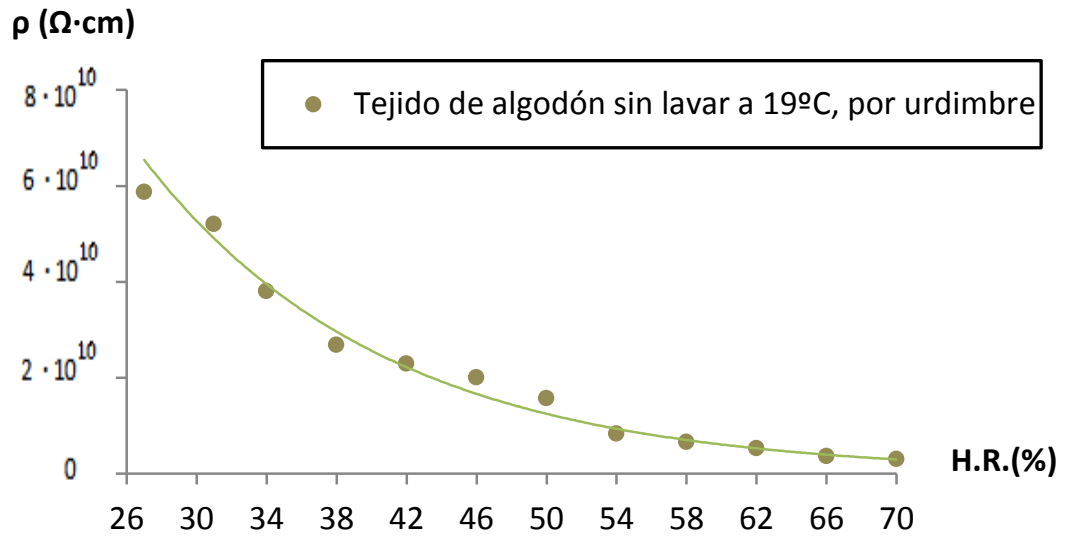

Figura 4. 2. Ajuste gráfico de la resistividad en función de la H.R. del tejido de algodón sin lavar, por urdimbre, a una temperatura de $19^{\circ} \mathrm{C}$. 
De dicha gráfica se obtiene, por ajuste de la curva, la ecuación que da la evolución de la resistividad en función de la humedad relativa del aire de cada ensayo, que es una exponencial. Esta ecuación es:

$$
\rho=5 \cdot 10^{11} \cdot \mathrm{e}^{-0,0721 \cdot \mathrm{H} \cdot \mathrm{R} .}
$$

El coeficiente de determinación de esta ecuación es $98,77 \%$, es decir, muy significativo, e indica que los resultados obtenidos en este estudio permiten predecir la resistividad de cualquier muestra de este tejido, en la dirección de urdimbre, y a cualquier humedad relativa ambiental, con un margen de error muy pequeño.

Así pues, a través de esta ecuación queda caracterizada la evolución de la resistividad del tejido de algodón sin lavar en la dirección de urdimbre a una temperatura de $19^{\circ} \mathrm{C}$ en función de la humedad relativa del ambiente.

\subsubsection{Tejido con tratamiento previo de lavado.}

Las pautas para la realización de las pruebas al tejido con tratamiento previo de lavado han sido las mismas que en el caso anterior. Pero, en este caso, la muestra textil ha sido sometida previamente a un proceso de lavado con un detergente no iónico, a fin de eliminar cualquier sustancia extraña al tejido. El lavado se realizó siguiendo las recomendaciones proporcionadas en otros trabajos para tejidos $[128,129,130]$, es decir, utilizando una concentración de 2 $\mathrm{ml} / 1$ de "Sandozina MRN" (Clariant) $)^{6}$, una relación de baño $1 / 50$, a $45{ }^{\circ} \mathrm{C}$ de

\footnotetext{
"La "Sandozina MRN" es un detergente no iónico que se utiliza como agente habitual de limpieza, no produce espuma y es soluble en agua (a partir de una relación 1:3) y estable a ácidos y álcalis (se trata de un derivado de un éter poliglicólico, con $90 \%$ de materia activa). Este producto es un líquido transparente, entre incoloro y ligeramente amarillento, dependiendo de
} 
temperatura y durante 30 minutos. El lavado se realiza en el aparato de laboratorio denominado Linitest (figura 4.3) ${ }^{7}$, el cual es programable y consta de seis recipientes para introducir las muestras y calentarlas al "baño maría". Después del lavado se realizan varios aclarados con agua tibia y las muestras se secan a temperatura ambiente.

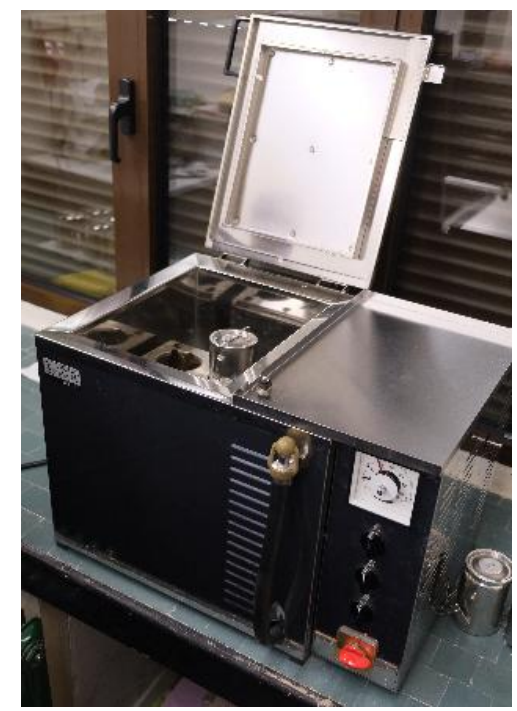

Figura 4. 3. Fotografía del Linitest del laboratorio Textil.

Como se indicó al principio de este apartado, las pruebas que se realizaron al tejido de algodón, por urdimbre, van a ser efectuadas a una temperatura de $19{ }^{\circ} \mathrm{C}$ y a diferentes humedades relativas, desde el $27 \%$ hasta el 70\%. Los resultados completos obtenidos en los ensayos para el tejido de algodón, previamente sometido al tratamiento de lavado indicado se exponen en el anexo 4.

su temperatura, y hace que el agua del lavado tenga un $\mathrm{pH}$ cercano al neutro (5-8). Además se trata de un detergente biodegradable y, por tanto, respetuoso con el medio ambiente.

${ }^{7}$ El Linitest es un aparato de lavado programable por temperatura y tiempo de lavado. Consta de seis recipientes para el lavado al baño maría de dichas muestras. 
A través de los resultados medios obtenidos en cada ensayo se construye la figura 4.4, que muestra gráficamente la evolución de la tensión (valor medio de los datos de cada ensayo) en los extremos de la muestra del tejido en función del tiempo.

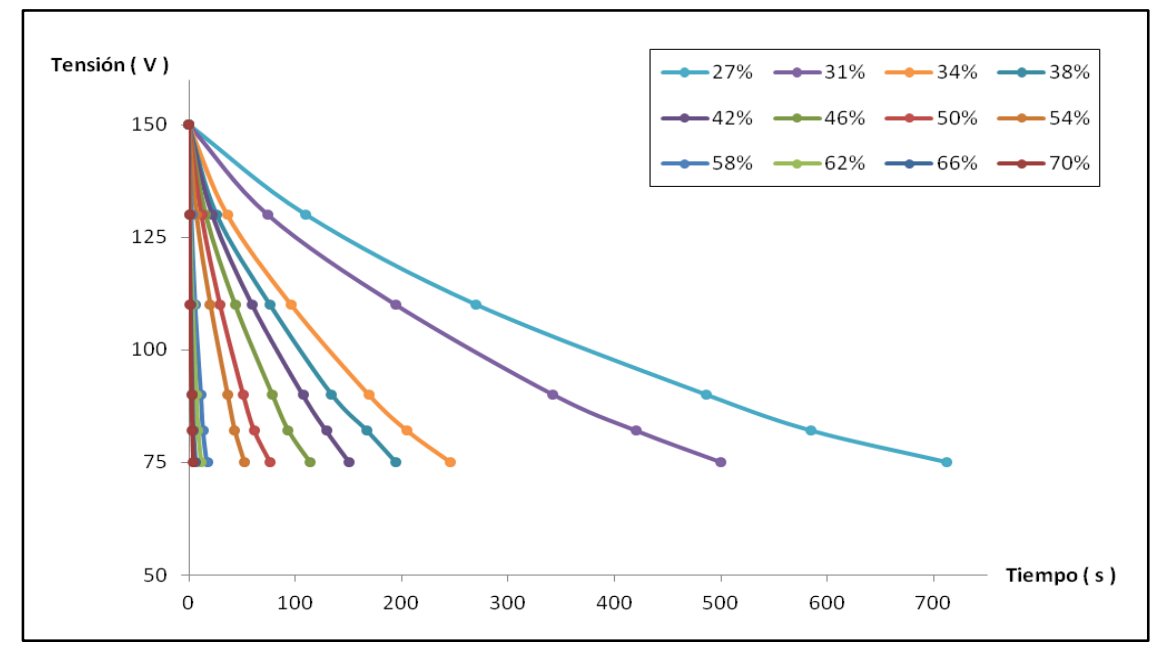

Figura 4. 4. Gráfica resumen de los resultados finales del tejido lavado de algodón, por urdimbre, a una temperatura de $19^{\circ} \mathrm{C}$ y diferentes H.R.

La disminución del tiempo de semidescarga con el aumento de la humedad relativa del aire es significativa hasta llegar al 58\%, disminuyendo en mucha menor proporción cuando se supera esta humedad relativa del aire. También se observa un salto importante, en este caso, al pasar del 31 al 34\% de H.R.

Para obtener la resistencia eléctrica del tejido debe obtenerse el tiempo de semidescarga. En la tabla 4.3 se han recogido los valores de los tiempos de semidescarga de las cinco series y su valor medio, incluyendo el coeficiente de variación de cada ensayo. 


\begin{tabular}{||c|c|c|c|c|c|c|c||}
\hline \multirow{2}{*}{$\begin{array}{c}\text { H.R. } \\
(\mathbf{\%})\end{array}$} & \multicolumn{7}{|c|}{$\mathbf{t}_{\mathbf{5 0}}(\mathbf{S})$} \\
\cline { 2 - 8 } & $\mathbf{1}$ & $\mathbf{2}$ & $\mathbf{3}$ & $\mathbf{4}$ & $\mathbf{5}$ & Media & $\begin{array}{c}\text { C.V. } \\
(\mathbf{\%})\end{array}$ \\
\hline $\mathbf{2 7}$ & 666,23 & 698,89 & 748,21 & 766,48 & 679,31 & 711,83 & 6,13 \\
\hline $\mathbf{3 1}$ & 496,19 & 497,34 & 484,72 & 486,73 & 532,81 & 499,56 & 3,89 \\
\hline $\mathbf{3 4}$ & 230,50 & 244,06 & 250,66 & 254,61 & 248,98 & 245,76 & 3,80 \\
\hline $\mathbf{3 8}$ & 182,34 & 190,47 & 201,84 & 196,80 & 198,61 & 194,01 & 3,98 \\
\hline $\mathbf{4 2}$ & 144,77 & 151,80 & 146,89 & 149,66 & 160,36 & 150,69 & 4,00 \\
\hline $\mathbf{4 6}$ & 109,34 & 110,23 & 115,28 & 114,27 & 117,30 & 113,28 & 2,99 \\
\hline $\mathbf{5 0}$ & 76,34 & 76,20 & 75,89 & 75,70 & 77,08 & 76,24 & 0,70 \\
\hline $\mathbf{5 4}$ & 51,52 & 49,73 & 50,95 & 53,63 & 52,14 & 51,59 & 2,79 \\
\hline $\mathbf{5 8}$ & 16,31 & 16,45 & 17,52 & 17,41 & 16,95 & 16,93 & 3,21 \\
\hline $\mathbf{6 2}$ & 11,42 & 10,91 & 10,89 & 11,44 & 10,94 & 11,12 & 2,56 \\
\hline $\mathbf{6 6}$ & 5,98 & 6,00 & 5,45 & 5,44 & 5,42 & 5,66 & 5,37 \\
\hline $\mathbf{7 0}$ & 4,33 & 4,36 & 4,34 & 4,38 & 4,36 & 4,35 & 0,41 \\
\hline \hline
\end{tabular}

Tabla 4. 3. Resultados y desviación típica del tejido lavado de algodón, por urdimbre, a una temperatura de $19^{\circ} \mathrm{C}$ y diferentes H.R.

Los valores de tiempo de semidescarga, $\mathrm{t}_{50}$, obtenidos en cada ensayo muestran un coeficiente de variación pequeño. Como se ha indicado, con los valores numéricos se comprueba que al aumentar la humedad relativa de la cámara climática, la disminución inicial del $\mathrm{t}_{50}$ es muy elevada hasta el $34 \%$ de H.R., pero posteriormente va disminuyendo más despacio y, a partir del $58 \%$, esta disminución es muy pequeña. La tendencia es muy parecida a la del caso anterior, aunque los valores obtenidos sean diferentes. Esto es debido a que las pruebas se realizan al mismo tejido textil, que es la variable que más afecta a la tendencia del comportamiento eléctrico. 
Los valores de los parámetros eléctricos se calculan a través de las ecuación 3.11, 4.2 y 4.3, y los resultados de estas operaciones se muestran en la tabla 4.4.

\begin{tabular}{|c|c|c|c|c|}
\hline H.R. (\%) & $\mathrm{t}_{50}(\mathrm{~s})$ & $\mathrm{R}(\Omega)$ & $\rho(\Omega \cdot \mathrm{cm})$ & $\sigma(\mathrm{S} / \mathrm{cm})$ \\
\hline $\mathbf{2 7}$ & 711,83 & $616,75 \cdot 10^{11}$ & $43,17 \cdot 10^{10}$ & $0,02 \cdot 10^{-10}$ \\
\hline $\mathbf{3 1}$ & 499,56 & $432,84 \cdot 10^{11}$ & $30,30 \cdot 10^{10}$ & $0,03 \cdot 10^{-10}$ \\
\hline $\mathbf{3 4}$ & 245,76 & $212,94 \cdot 10^{11}$ & $14,91 \cdot 10^{10}$ & $0,07 \cdot 10^{-10}$ \\
\hline $\mathbf{3 8}$ & 194,01 & $168,10 \cdot 10^{11}$ & $11,77 \cdot 10^{10}$ & $0,08 \cdot 10^{-10}$ \\
\hline $\mathbf{4 2}$ & 150,69 & $130,57 \cdot 10^{11}$ & $9,14 \cdot 10^{10}$ & $0,11 \cdot 10^{-10}$ \\
\hline $\mathbf{4 6}$ & 113,28 & $98,15 \cdot 10^{11}$ & $6,87 \cdot 10^{10}$ & $0,15 \cdot 10^{-10}$ \\
\hline $\mathbf{5 0}$ & 76,24 & $66,06 \cdot 10^{11}$ & $4,62 \cdot 10^{10}$ & $0,22 \cdot 10^{-10}$ \\
\hline $\mathbf{5 4}$ & 51,59 & $44,70 \cdot 10^{11}$ & $3,13 \cdot 10^{10}$ & $0,32 \cdot 10^{-10}$ \\
\hline $\mathbf{5 8}$ & 16,93 & $14,67 \cdot 10^{11}$ & $1,03 \cdot 10^{10}$ & $0,97 \cdot 10^{-10}$ \\
\hline $\mathbf{6 2}$ & 11,12 & $9,63 \cdot 10^{11}$ & $0,67 \cdot 10^{10}$ & $1,48 \cdot 10^{-10}$ \\
\hline $\mathbf{6 6}$ & 5,66 & $4,90 \cdot 10^{11}$ & $0,34 \cdot 10^{10}$ & $2,92 \cdot 10^{-10}$ \\
\hline $\mathbf{7 0}$ & 4,35 & $3,77 \cdot 10^{11}$ & $0,26 \cdot 10^{10}$ & $3,79 \cdot 10^{-10}$ \\
\hline
\end{tabular}

Tabla 4. 4. Resultados de los parámetros eléctricos del tejido lavado de algodón, por urdimbre, a una temperatura de $19^{\circ} \mathrm{C}$ y diferentes H.R.

A través de esta tabla se demuestra que los valores de los parámetros eléctricos del tejido sin tratamiento previo de lavado y con tratamiento son diferentes.

Al igual que en el caso anterior se representa la curva que refleja la evolución de la resistividad frente a la humedad relativa del ensayo se muestra en la figura 4.5, comprobándose que el ajuste a la nube de puntos es el mismo que en el tejido sin lavar, es decir, un ajuste exponencial. 
$\rho(\Omega \cdot \mathrm{cm})$

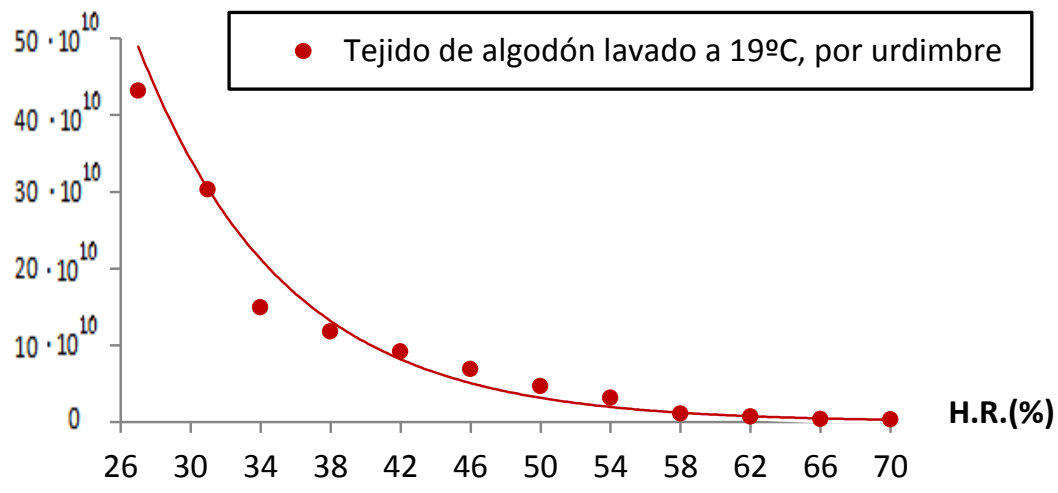

Figura 4. 5. Ajuste gráfico de la resistividad en función de la H.R. del tejido de algodón lavado, por urdimbre, a una temperatura de $19^{\circ} \mathrm{C}$ y diferentes H.R.

La ecuación que relaciona la resistividad con la humedad relativa de cada ensayo es de tipo exponencial, como en el tejido sin lavar, y es la siguiente:

$$
\rho=10^{13} \cdot e^{-0,1194 \cdot H R}
$$

El coeficiente de determinación es del 97,59\%, lo que indica que puede predecirse la resistividad de este material, con un margen de error pequeño.

En la tabla 4.5 se realiza una comparación entre los valores de resistividad $(\Omega \cdot \mathrm{cm})$ obtenidos cuando hay lavado inicial del tejido y cuando no lo hay. Con estos resultados se ha definido la metodología final a utilizar en los diversos ensayos que se realizarán a partir de ahora. 


\begin{tabular}{|c|c|c|c|}
\hline \multirow{2}{*}{$\begin{array}{l}\text { H.R. } \\
(\%)\end{array}$} & \multicolumn{2}{|c|}{$\rho(\Omega \cdot \mathrm{cm})$} & \multirow{2}{*}{$\begin{array}{c}\text { Relación } \\
\text { ( } \rho \text { lavado/ } \rho \text { sin lavar })\end{array}$} \\
\hline & Lavado & Sin lavar & \\
\hline 27 & $43,17 \cdot 10^{10}$ & $5,87 \cdot 10^{10}$ & 7,35 \\
\hline 31 & $30,30 \cdot 10^{10}$ & $5,20 \cdot 10^{10}$ & 5,83 \\
\hline 34 & $14,91 \cdot 10^{10}$ & $3,80 \cdot 10^{10}$ & 3,92 \\
\hline 38 & $11,77 \cdot 10^{10}$ & $2,68 \cdot 10^{10}$ & 4,39 \\
\hline 42 & $9,14 \cdot 10^{10}$ & $2,29 \cdot 10^{10}$ & 3,99 \\
\hline 46 & $6,87 \cdot 10^{10}$ & $2,00 \cdot 10^{10}$ & 3,44 \\
\hline 50 & $4,62 \cdot 10^{10}$ & $1,57 \cdot 10^{10}$ & 2,95 \\
\hline 54 & $3,13 \cdot 10^{10}$ & $0,83 \cdot 10^{10}$ & 3,77 \\
\hline 58 & $1,03 \cdot 10^{10}$ & $0,65 \cdot 10^{10}$ & 1,56 \\
\hline 62 & $0,67 \cdot 10^{10}$ & $0,52 \cdot 10^{10}$ & 1,30 \\
\hline 66 & $0,34 \cdot 10^{10}$ & $0,36 \cdot 10^{10}$ & 0,94 \\
\hline 70 & $0,26 \cdot 10^{10}$ & $0,30 \cdot 10^{10}$ & 0,88 \\
\hline
\end{tabular}

Tabla 4. 5. Influencia del lavado en la resistividad del tejido de algodón, por urdimbre, a una temperatura de $19^{\circ} \mathrm{C}$ y diferentes H.R.

Al analizar estos resultados de la resistividad del tejido para comprobar la influencia del tratamiento previo de lavado se deduce que, lo más probable es que el tejido ensayado puede llevar algún tipo de aditivo que hace que descargue más rápidamente cuando está sin lavar. Es decir, se verifica que los tejidos con algún tipo de tratamiento se comportan de forma diferente a los tejidos sin ese tratamiento, y que éste es un factor importante a la hora de evaluar el comportamiento eléctrico del material frente a la electricidad estática. Concretamente, y para facilitar la fase de preparación y de hilatura, previas a la obtención de este tipo de tejidos, se utilizan sustancias denominadas ensimajes, cuya composición principal son aceites de diversos tipos, pero que también suelen llevar una pequeña proporción de sustancias antiestáticas [131]. Estas sustancias o agentes antiestáticos pueden ser de dos tipos: temporales o 
permanentes. Y para la realización de las pruebas, los tejidos no deben llevar ningún tipo de agente antiestático permanente, ya que si es así se obtendrían resultados impropios de ese tejido, es decir, se falsearían las medidas. Por ello, es importante lavar las muestras antes de realizar las pruebas y así eliminar los agentes antiestáticos temporales o cualquier otra sustancia que altere el comportamiento eléctrico del tejido.

En la figura 4.6 se representa los datos de la tabla 4.5, con objeto de comparar más fácilmente las diferencias de resistividad entre el tejido lavado y sin lavar.

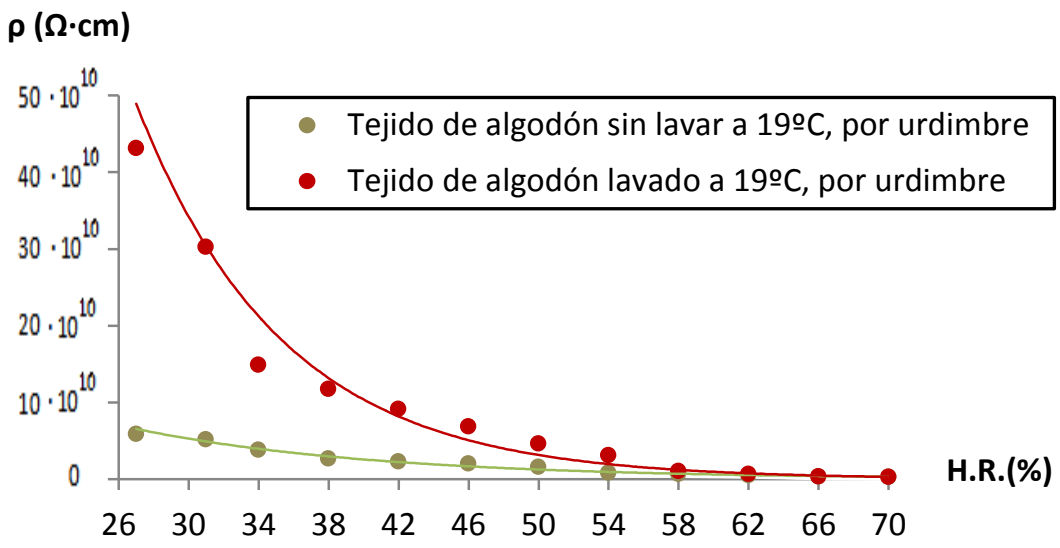

Figura 4. 6. Ajuste gráfico de la resistividad eléctrica en función de la H.R. del tejido de algodón lavado y sin lavar, por urdimbre, a una temperatura de $19{ }^{\circ} \mathrm{C}$.

Como la resistividad tiene valores muy altos en comparación con los de la humedad relativa, para poder realizar un mejor análisis comparativo de estas variables se trasformó la resistividad en su logaritmo. De este modo se realizó el ajuste lineal con el cambio de variable indicado, utilizando el método de los mínimos cuadrados, de forma que: 


$$
\ln \rho=a \cdot H R+b
$$

Donde:

$\rho, \quad$ resistividad $(\Omega \cdot \mathrm{cm})$.

HR, humedad relativa del aire (\%).

$\mathrm{a}, \mathrm{b}, \quad$ constantes que determinan el ajuste lineal.

\begin{tabular}{||c|c|c|c|c||}
\cline { 2 - 5 } \multicolumn{1}{c|}{} & \multicolumn{4}{c||}{ Ajuste lineal } \\
\hline Tejido & $\mathrm{a}$ & $\mathrm{b}$ & $\mathrm{r}$ & $\mathrm{R}^{2}$ \\
\hline Sin lavar & $-0,0721$ & 26,851 & $-0,9938$ & 0,9877 \\
\hline Lavado & $-0,1193$ & 30,139 & $-0,9879$ & 0,9759 \\
\hline
\end{tabular}

Tabla 4.6. Coeficientes del ajuste lineal y coeficiente de determinación del tejido de algodón lavado y sin lavar, por urdimbre, a una temperatura de $19{ }^{\circ} \mathrm{C}$ y diferentes H.R.

En esta tabla siguiente se muestra los valores de los parámetros obtenidos para los ajustes. La representación gráfica de estas rectas se exponen en la figura 4.13.

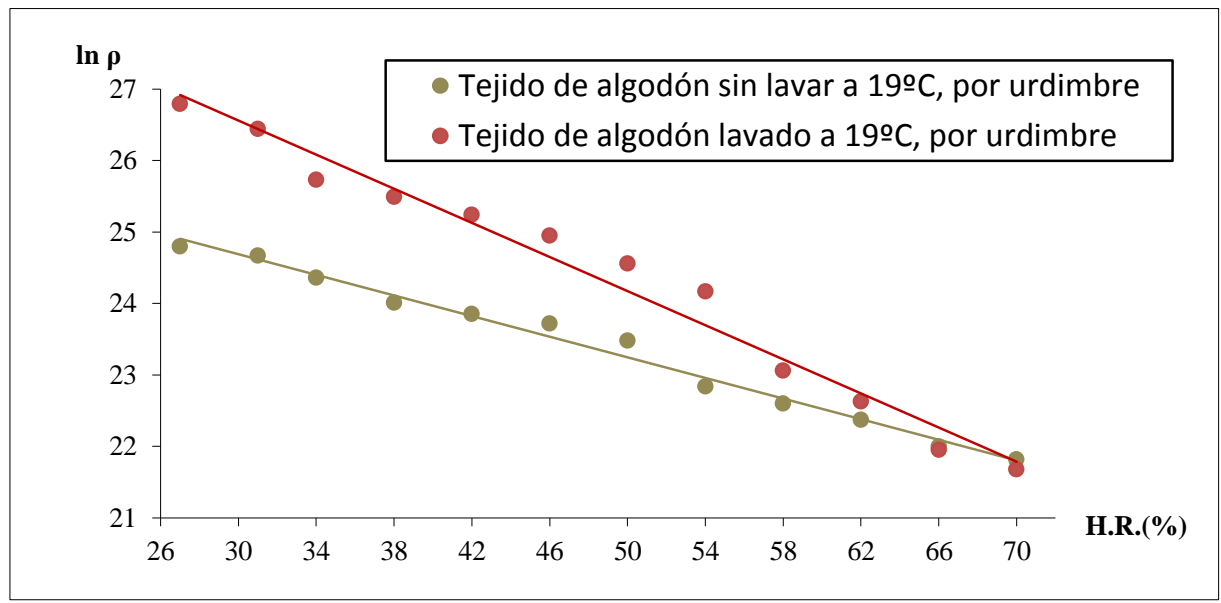

Figura 4.7. Recta del ajuste lineal del tejido de algodón lavado y sin lavar, por urdimbre, a una temperatura de $19^{\circ} \mathrm{C}$ y diferentes H.R. 
En la figura 4.7 se pone de manifiesto la lógica disminución de la resistividad eléctrica al aumentar la humedad relativa, a través del signo negativo de la pendiente de las rectas, a, y del coeficiente de correlación, r. Los modelos lineales estudiados son significativos al 97\%, pero el que tiene mayor coeficiente de determinación se obtiene cuando se realiza sin lavar, con un $98,77 \%$. Los ensayos que proporcionan mayor pendiente de la recta y por tanto mayor variación con la humedad, corresponden al tejido lavado. También se observa que no hay diferencias significativas entre los valor de la resistividad eléctrica del tejido lavado y sin lavar al sobrepasar una humedad relativa del ambiente del $58 \%$, lo que es debido a que la resistividad del tejido es función, principalmente, del agua absorbida por éste y de la retenida en su superficie. Así pues, en las pruebas realizadas, el tejido sin lavar presenta unos valores de resistividad eléctrica inferiores que cuando se lava previamente el tejido; ello significa que si al tejido se le incorpora algún tipo de ensimaje, normalmente tiene menor capacidad de generar cargas electrostáticas durante su fabricación y uso, provocando menos problemas en relación con la electricidad estática [132].

\subsection{Análisis de las características eléctricas a través de variables externas a los tejidos.}

El principal objetivo de este apartado del capítulo, es conocer la tendencia de la resistividad de los tejidos en función de parámetros no relacionados con la estructura del material textil. Las dos variables más influyentes en la determinación de esta propiedad son la temperatura y la humedad relativa. Ésta última influye notablemente en el valor de la resistividad, como se ha puesto de manifiesto en los ensayos realizados en el apartado anterior. En el caso de la temperatura, se han fijado como condiciones 
de realización del ensayo los siguientes: tejido de algodón por urdimbre bajo diferentes condiciones ambientales de temperatura $\left(19^{\circ} \mathrm{C}, 23^{\circ} \mathrm{C}\right.$ y $\left.27^{\circ} \mathrm{C}\right)$ y humedad relativa (entre $27 \%$ y $70 \%$ ). Todos los ensayos se realizan bajo las mismas pautas indicadas en el apartado anterior, realizando un lavado previo a todas las muestras utilizadas.

Los resultados completos obtenidos en las pruebas realizadas al tejido de algodón a las temperaturas de $19^{\circ} \mathrm{C}, 23^{\circ} \mathrm{C}$ y $29^{\circ} \mathrm{C}$ están reflejados en el anexo 4. En las tablas 4.3 y 4.4 se exponen los resultados finales de las pruebas a $19^{\circ} \mathrm{C}$, así como los valores de los parámetros eléctricos.

Para poder obtener los parámetros a $23^{\circ} \mathrm{C}$ se obtiene el tiempo medio de semidescarga para las distintas humedades relativas. La figura 4.8 muestra gráficamente la evolución de la tensión (valores medios) existente entre los extremos de la muestra del tejido en función del tiempo.

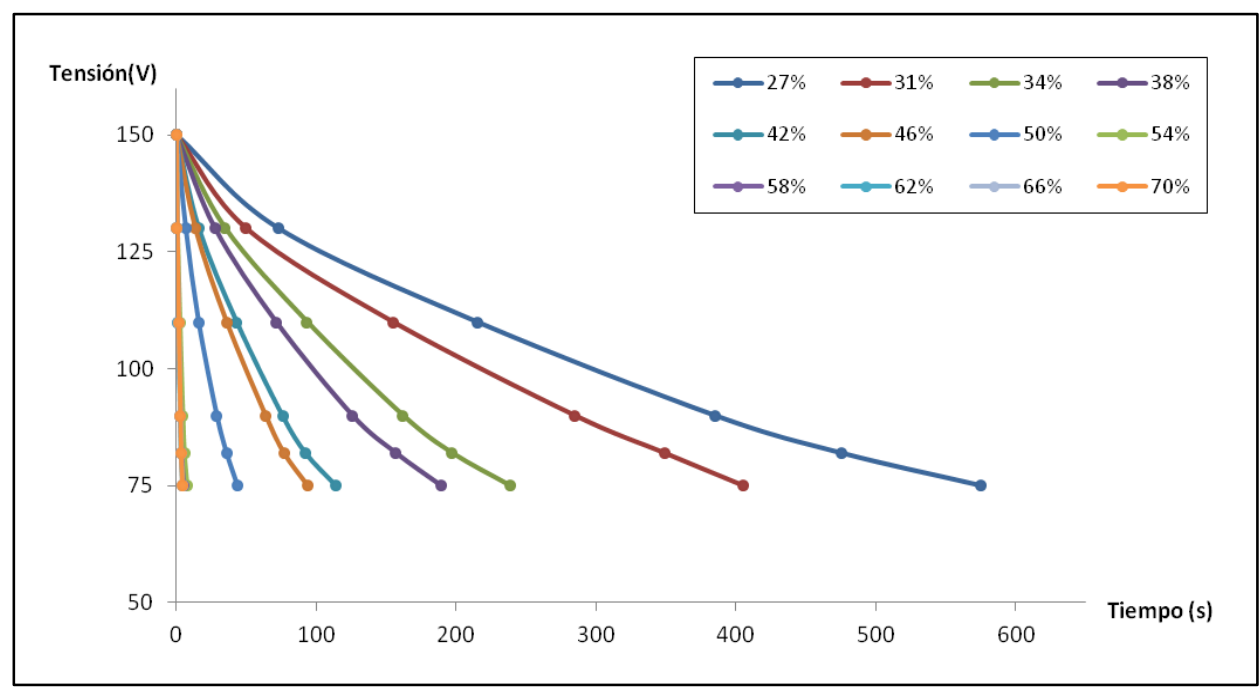

Figura 4. 8. Gráfica resumen de los resultados finales del tejido de algodón lavado, por urdimbre, a una temperatura de $23^{\circ} \mathrm{C}$ y diferentes H.R. 
La disminución del tiempo de semidescarga con el aumento de la humedad relativa del aire es significativa hasta llegar al 54\%. A partir de esa humedad su disminución es mucho menor, debido a que la diferencia entre la absorción de humedad de la fibra del tejido y la depositada en la superficie es menor debido a su saturación, de la misma forma que ocurría en los ensayos realizados a $19^{\circ} \mathrm{C}$.

En la tabla 4.7 se exponen los valores de los tiempos de semidescarga de las cinco series y su valor medio, incluyendo el coeficiente de variación de cada ensayo.

\begin{tabular}{|c|c|c|c|c|c|c|c|}
\hline \multirow{3}{*}{$\begin{array}{c}\text { H.R. } \\
(\%)\end{array}$} & \multicolumn{7}{|c|}{$\mathbf{t}_{50}(\mathrm{~s})$} \\
\hline & \multicolumn{5}{|c|}{ Ensayo } & \multirow{2}{*}{ Media } & \multirow{2}{*}{$\begin{array}{l}\text { C.V. } \\
(\%)\end{array}$} \\
\hline & 1 & 2 & 3 & 4 & 5 & & \\
\hline 27 & 544,34 & 565,47 & 581,30 & 583,86 & 600,36 & 575,07 & 3,68 \\
\hline 31 & 393,83 & 397,52 & 412,53 & 409,25 & 414,00 & 405,42 & 2,26 \\
\hline 34 & 241,69 & 231,83 & 240,45 & 234,84 & 243,25 & 238,41 & 2,04 \\
\hline 38 & 185,30 & 185,23 & 191,94 & 199,06 & 185,63 & 189,43 & 3,21 \\
\hline 42 & 119,14 & 112,69 & 111,08 & 112,94 & 116,33 & 114,43 & 2,84 \\
\hline 46 & 93,92 & 92,08 & 96,34 & 94,20 & 94,33 & 94,18 & 1,61 \\
\hline 50 & 45,00 & 41,73 & 45,78 & 44,27 & 42,53 & 43,86 & 3,86 \\
\hline 54 & 19,61 & 20,19 & 20,23 & 22,38 & 20,41 & 20,56 & 5,14 \\
\hline 58 & 10,22 & 9,69 & 9,67 & 9,66 & 10,23 & 9,89 & 3,07 \\
\hline 62 & 8,17 & 9,25 & 7,52 & 7,52 & 8,05 & 8,10 & 8,76 \\
\hline 66 & 4,91 & 4,86 & 4,94 & 4,89 & 4,88 & 4,89 & 0,61 \\
\hline 70 & 3,31 & 4,86 & 4,88 & 4,28 & 4,31 & 4,33 & 14,69 \\
\hline
\end{tabular}

Tabla 4. 7. Resultados y desviación típica del tejido de algodón lavado, por urdimbre, a una temperatura de $23^{\circ} \mathrm{C}$ y diferentes H.R. 
Los valores del tiempo de semidescarga obtenidos en cada ensayo muestran un coeficiente de variación pequeño, excepto para el valor del 70\% de humedad relativa del aire. Al aumentar la humedad relativa en la cámara climática, la disminución inicial del tiempo de semidescarga es muy elevada hasta el $34 \%$, posteriormente va disminuyendo más despacio y, a partir del $54 \%$ esta disminución es muy pequeña.

Los resultados de los parámetros eléctricos se muestran en la tabla 4.8.

\begin{tabular}{|c|c|c|c|c|}
\hline H.R. $(\%)$ & $\mathrm{t}_{50}(\mathrm{~s})$ & $\mathrm{R}(\Omega)$ & $\rho(\Omega \cdot \mathrm{cm})$ & $\sigma(\mathrm{S} / \mathrm{cm})$ \\
\hline $\mathbf{2 7}$ & 711,83 & $498,26 \cdot 10^{11}$ & $34,88 \cdot 10^{10}$ & $0,03 \cdot 10^{-10}$ \\
\hline $\mathbf{3 1}$ & 499,56 & $351,27 \cdot 10^{11}$ & $24,59 \cdot 10^{10}$ & $0,04 \cdot 10^{-10}$ \\
\hline $\mathbf{3 4}$ & 245,76 & $206,57 \cdot 10^{11}$ & $14,46 \cdot 10^{10}$ & $0,07 \cdot 10^{-10}$ \\
\hline $\mathbf{3 8}$ & 194,01 & $164,13 \cdot 10^{11}$ & $11,49 \cdot 10^{10}$ & $0,09 \cdot 10^{-10}$ \\
\hline $\mathbf{4 2}$ & 150,69 & $99,15 \cdot 10^{11}$ & $6,94 \cdot 10^{10}$ & $0,14 \cdot 10^{-10}$ \\
\hline $\mathbf{4 6}$ & 113,28 & $81,60 \cdot 10^{11}$ & $5,71 \cdot 10^{10}$ & $0,18 \cdot 10^{-10}$ \\
\hline $\mathbf{5 0}$ & 76,24 & $38,00 \cdot 10^{11}$ & $2,66 \cdot 10^{10}$ & $0,38 \cdot 10^{-10}$ \\
\hline $\mathbf{5 4}$ & 51,59 & $17,81 \cdot 10^{11}$ & $1,25 \cdot 10^{10}$ & $0,80 \cdot 10^{-10}$ \\
\hline $\mathbf{5 8}$ & 16,93 & $8,57 \cdot 10^{11}$ & $0,60 \cdot 10^{10}$ & $1,67 \cdot 10^{-10}$ \\
\hline $\mathbf{6 2}$ & 11,12 & $7,02 \cdot 10^{11}$ & $0,49 \cdot 10^{10}$ & $2,04 \cdot 10^{-10}$ \\
\hline $\mathbf{6 6}$ & 5,66 & $4,24 \cdot 10^{11}$ & $0,30 \cdot 10^{10}$ & $3,37 \cdot 10^{-10}$ \\
\hline $\mathbf{7 0}$ & 4,35 & $3,75 \cdot 10^{11}$ & $0,26 \cdot 10^{10}$ & $3,81 \cdot 10^{-10}$ \\
\hline
\end{tabular}

Tabla 4. 8. Resultados de los parámetros eléctricos del tejido de algodón lavado, por urdimbre, a una temperatura de $23{ }^{\circ} \mathrm{C}$ y diferentes H.R.

La curva que refleja la evolución de la resistividad eléctrica frente a la humedad relativa, se muestra en la figura 4.9. 


\section{$\rho(\Omega \cdot \mathrm{cm})$}

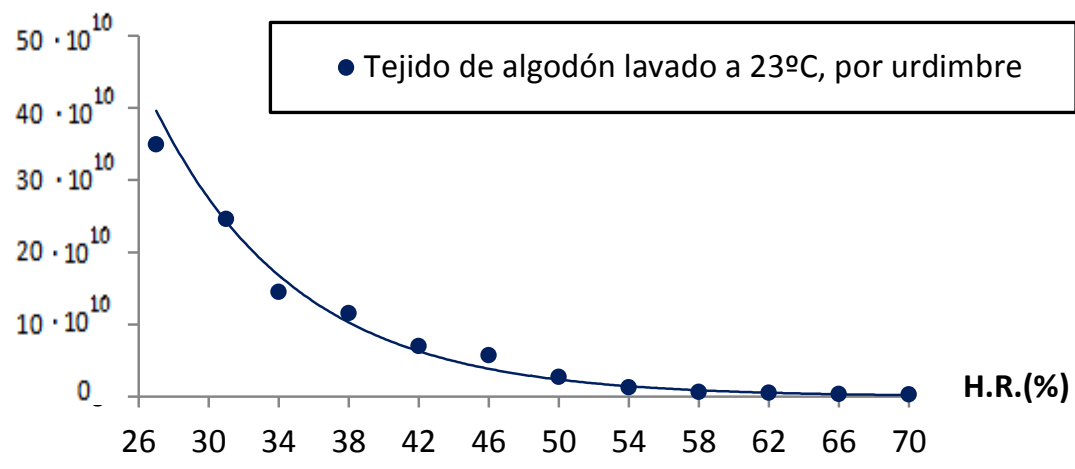

Figura 4.9. Ajuste gráfico de la resistividad en función de la H.R. del tejido de algodón lavado, por urdimbre, a una temperatura de $23^{\circ} \mathrm{C}$ y diferentes H.R.

La ecuación que las relaciona tiene un buen coeficiente de determinación, 98,57\%, y es la siguiente:

$$
\rho=10^{13} \cdot e^{-0,1227 \cdot \text { H.R. }}
$$

Los valores medios obtenidos de los resultados para una temperatura de $27^{\circ} \mathrm{C}$ están representados en la figura 4.10 .

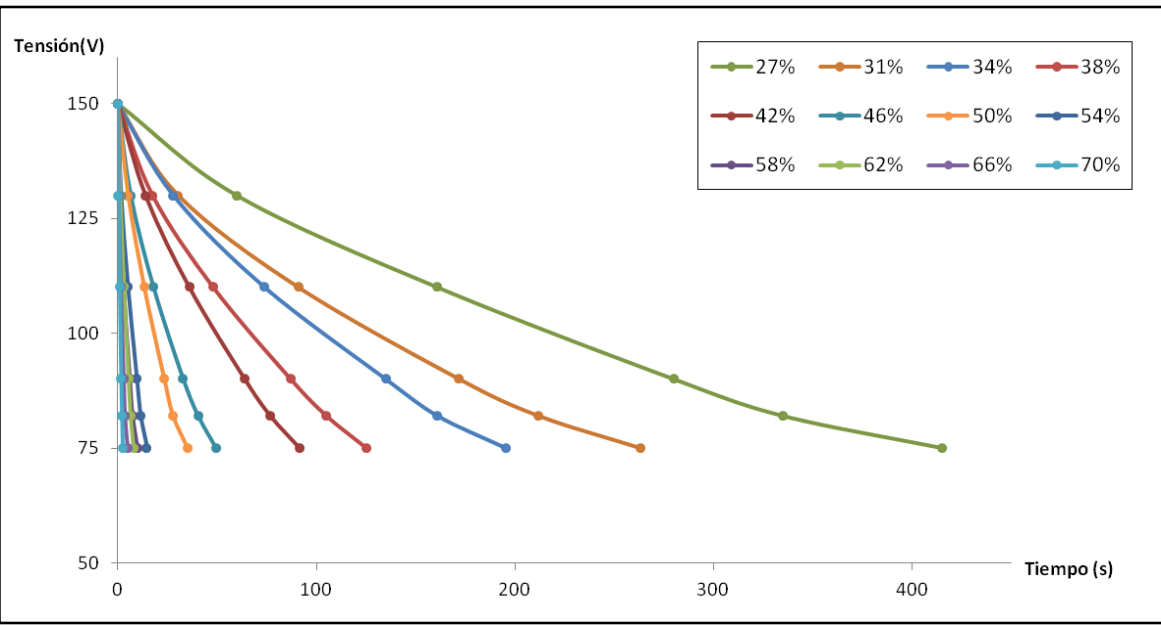

Figura 4. 10. Gráfica resumen de los resultados finales del tejido lavado de algodón, por urdimbre, a una temperatura de $27^{\circ} \mathrm{C}$ y diferentes H.R. 
En esta gráfica se observa como la disminución del tiempo de semidescarga con el aumento de la humedad relativa del aire es significativa hasta llegar al 54\% y que, a partir de esa humedad, su disminución es mucho menor. Con ello se puede deducir que la absorción de agua para un mismo tejido debe ser similar a diferentes temperaturas, en este caso entorno al 54$58 \%$, ya que su influencia en el tiempo de semidescarga es mínima con poca humedad relativa y grande con una humedad relativa del aire elevada.

En la tabla 4.9 se muestran los valores obtenidos de los ensayos, reflejando los resultados para cada serie realizada, su media y el coeficiente de variación.

\begin{tabular}{|c|c|c|c|c|c|c|c|}
\hline \multirow{3}{*}{$\begin{array}{c}\text { H.R. } \\
(\%)\end{array}$} & \multicolumn{7}{|c|}{$\mathbf{t}_{50}(\mathrm{~s})$} \\
\hline & \multicolumn{5}{|c|}{ Ensayo } & \multirow{2}{*}{ Media } & \multirow{2}{*}{$\begin{array}{l}\text { C.V. } \\
(\%)\end{array}$} \\
\hline & 1 & 2 & 3 & 4 & 5 & & \\
\hline 27 & 391,56 & 413,92 & 423,33 & 418,81 & 427,02 & 414,93 & 3,36 \\
\hline 31 & 246,11 & 264,48 & 268,11 & 274,17 & 262,91 & 263,16 & 3,98 \\
\hline 34 & 180,33 & 184,75 & 198,11 & 206,33 & 207,69 & 195,44 & 6,36 \\
\hline 38 & 129,03 & 129,95 & 116,72 & 128,41 & 121,33 & 125,09 & 4,63 \\
\hline 42 & 94,16 & 91,81 & 87,64 & 85,52 & 99,73 & 91,77 & 6,10 \\
\hline 46 & 50,95 & 47,13 & 48,27 & 50,98 & 50,41 & 49,55 & 3,54 \\
\hline 50 & 35,09 & 36,08 & 36,73 & 36,16 & 31,58 & 35,13 & 5,89 \\
\hline 54 & 14,20 & 13,98 & 14,53 & 15,05 & 15,58 & 14,67 & 4,41 \\
\hline 58 & 7,64 & 7,63 & 8,19 & 8,13 & 8,17 & 7,95 & 3,65 \\
\hline 62 & 5,45 & 5,44 & 5,47 & 5,45 & 5,97 & 5,56 & 4,16 \\
\hline 66 & 4,34 & 4,31 & 4,89 & 4,88 & 4,91 & 4,67 & 6,61 \\
\hline 70 & 2,72 & 2,73 & 2,73 & 2,69 & 2,72 & 2,72 & 0,71 \\
\hline
\end{tabular}

Tabla 4. 9. Resultados y desviación típica del tejido lavado de algodón, por urdimbre, a una temperatura de $27^{\circ} \mathrm{C}$ y diferentes H.R. 
Como en casos anteriores, el coeficiente de variación es pequeño en todos los casos, siempre por debajo del $10 \%$.

Los resultados de los parámetros eléctricos se muestran en la tabla 4.10.

\begin{tabular}{|c|c|c|c|c|}
\hline H.R. $(\%)$ & $\mathrm{t}_{50}(\mathrm{~s})$ & $\mathrm{R}(\Omega)$ & $\rho(\Omega \cdot \mathrm{cm})$ & $\sigma(\mathrm{S} / \mathrm{cm})$ \\
\hline $\mathbf{2 7}$ & 414,93 & $359,51 \cdot 10^{11}$ & $25,17 \cdot 10^{10}$ & $0,04 \cdot 10^{-10}$ \\
\hline $\mathbf{3 1}$ & 263,16 & $228,01 \cdot 10^{11}$ & $15,96 \cdot 10^{10}$ & $0,06 \cdot 10^{-10}$ \\
\hline $\mathbf{3 4}$ & 195,44 & $169,34 \cdot 10^{11}$ & $11,85 \cdot 10^{10}$ & $0,08 \cdot 10^{-10}$ \\
\hline $\mathbf{3 8}$ & 125,09 & $108,38 \cdot 10^{11}$ & $7,59 \cdot 10^{10}$ & $0,13 \cdot 10^{-10}$ \\
\hline $\mathbf{4 2}$ & 91,77 & $79,51 \cdot 10^{11}$ & $5,57 \cdot 10^{10}$ & $0,18 \cdot 10^{-10}$ \\
\hline $\mathbf{4 6}$ & 49,55 & $42,93 \cdot 10^{11}$ & $3,01 \cdot 10^{10}$ & $0,33 \cdot 10^{-10}$ \\
\hline $\mathbf{5 0}$ & 35,13 & $30,44 \cdot 10^{11}$ & $2,13 \cdot 10^{10}$ & $0,47 \cdot 10^{-10}$ \\
\hline $\mathbf{5 4}$ & 14,67 & $12,71 \cdot 10^{11}$ & $0,89 \cdot 10^{10}$ & $1,12 \cdot 10^{-10}$ \\
\hline $\mathbf{5 8}$ & 7,95 & $6,89 \cdot 10^{11}$ & $0,48 \cdot 10^{10}$ & $2,07 \cdot 10^{-10}$ \\
\hline $\mathbf{6 2}$ & 5,56 & $4,82 \cdot 10^{11}$ & $0,34 \cdot 10^{10}$ & $2,97 \cdot 10^{-10}$ \\
\hline $\mathbf{6 6}$ & 4,67 & $4,05 \cdot 10^{11}$ & $0,28 \cdot 10^{10}$ & $3,53 \cdot 10^{-10}$ \\
\hline $\mathbf{7 0}$ & 2,72 & $2,36 \cdot 10^{11}$ & $0,17 \cdot 10^{10}$ & $6,06 \cdot 10^{-10}$ \\
\hline
\end{tabular}

Tabla 4. 10. Resultados de los parámetros eléctricos del tejido lavado de algodón en urdimbre a una temperatura de $27^{\circ} \mathrm{C}$ y diferentes H.R.

En esta tabla se comprueba que la disminución de la resistividad en función de la humedad relativa del aire es considerable hasta alcanzar una humedad del 54\%, siendo a partir de entonces menos significativa. Como se ha reflejado en los anteriores ensayos, para el tejido de algodón, por encima del $60 \%$ de humedad relativa la variación de resistividad es pequeña. Por ello, en el entorno industrial, uno de los remedios para eliminar las cargas electrostáticas de los procesos es el aumento de humedad relativa en el aire [133]. El límite 
para procesos industriales con tejidos de algodón se ha comprobado que está en torno al $60 \%$.

La curva que refleja la evolución de la resistividad a una temperatura de $27^{\circ} \mathrm{C}$ frente a la humedad relativa del aire del ensayo se muestra a continuación, en la figura 4.11.

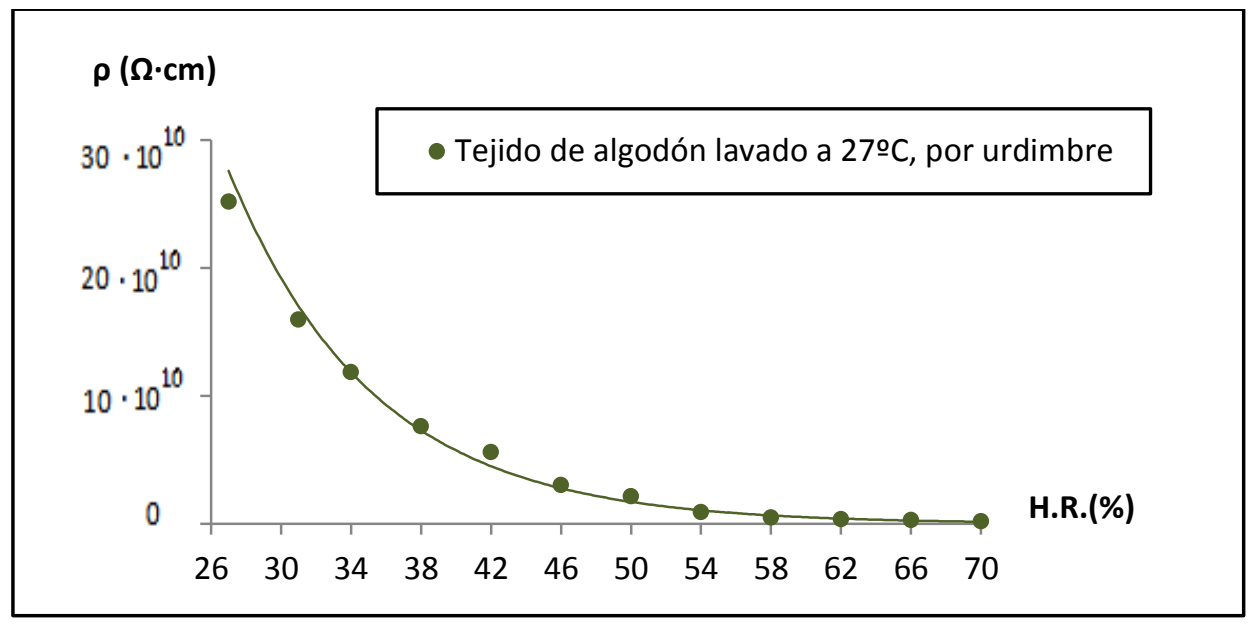

Figura 4. 11. Ajuste gráfico de la resistividad eléctrica en función de la H.R. del tejido de algodón lavado, por urdimbre, a una temperatura de $27^{\circ} \mathrm{C}$.

La gráfica muestra la evolución de la resistividad para en función de la humedad relativa de cada ensayo, y visualiza la dependencia de estas variables. La ecuación que las relaciona es:

$$
\rho=7 \cdot 10^{12} \cdot e^{-0,121 \cdot H . R .}
$$

El coeficiente de determinación es del $99,11 \%$, lo que indica que los resultados obtenidos en este estudio permiten predecir la resistividad eléctrica de cualquier muestra de este tejido a cualquier humedad relativa ambiental, con un margen de error pequeño. 
Una vez realizados los ensayos a diferentes temperaturas, los resultados obtenidos para la resistividad se reagrupan en la tabla 4.11. De esta manera se da una mejor la visión de los mismos, es decir, se ve como varía este parámetro frente a la humedad relativa del ambiente a las tres temperaturas estudiadas.

\begin{tabular}{|c|c|c|c|}
\hline \multirow{2}{*}{ H.R. (\%) } & \multicolumn{3}{|c|}{$\boldsymbol{(}(\mathbf{\Omega} \cdot \mathbf{c m})$} \\
\cline { 2 - 4 } & $\mathbf{1 9}$ & $\mathbf{2 3}$ & $\mathbf{2 7}$ \\
\hline $\mathbf{2 7}$ & $43,17 \cdot 10^{10}$ & $34,88 \cdot 10^{10}$ & $25,17 \cdot 10^{10}$ \\
\hline $\mathbf{3 1}$ & $30,30 \cdot 10^{10}$ & $24,59 \cdot 10^{10}$ & $15,96 \cdot 10^{10}$ \\
\hline $\mathbf{3 4}$ & $14,91 \cdot 10^{10}$ & $14,46 \cdot 10^{10}$ & $11,85 \cdot 10^{10}$ \\
\hline $\mathbf{3 8}$ & $11,77 \cdot 10^{10}$ & $11,49 \cdot 10^{10}$ & $7,59 \cdot 10^{10}$ \\
\hline $\mathbf{4 2}$ & $9,14 \cdot 10^{10}$ & $6,94 \cdot 10^{10}$ & $5,57 \cdot 10^{10}$ \\
\hline $\mathbf{4 6}$ & $6,87 \cdot 10^{10}$ & $5,71 \cdot 10^{10}$ & $3,01 \cdot 10^{10}$ \\
\hline $\mathbf{5 0}$ & $4,62 \cdot 10^{10}$ & $2,66 \cdot 10^{10}$ & $2,13 \cdot 10^{10}$ \\
\hline $\mathbf{5 4}$ & $3,13 \cdot 10^{10}$ & $1,25 \cdot 10^{10}$ & $0,89 \cdot 10^{10}$ \\
\hline $\mathbf{5 8}$ & $1,03 \cdot 10^{10}$ & $0,60 \cdot 10^{10}$ & $0,48 \cdot 10^{10}$ \\
\hline $\mathbf{6 2}$ & $0,67 \cdot 10^{10}$ & $0,49 \cdot 10^{10}$ & $0,34 \cdot 10^{10}$ \\
\hline $\mathbf{6 6}$ & $0,34 \cdot 10^{10}$ & $0,30 \cdot 10^{10}$ & $0,28 \cdot 10^{10}$ \\
\hline $\mathbf{7 0}$ & $0,26 \cdot 10^{10}$ & $0,26 \cdot 10^{10}$ & $0,17 \cdot 10^{10}$ \\
\hline
\end{tabular}

Tabla 4. 11. Resistividad del tejido lavado de algodón, por urdimbre, a cada temperatura y humedad relativa estudiada.

Para valorar el comportamiento de la resistividad frente a la temperatura nos fijamos en una humedad relativa, por ejemplo el $46 \%$, por tener un coeficiente de variación no superior al $4 \%$. Los resultados (expresados en $\Omega \cdot \mathrm{cm}$ ) fueron de $6,87 \cdot 10^{10}, 5,71 \cdot 10^{10}$ y $3,01 \cdot 10^{10}$ para $19^{\circ} \mathrm{C}, \quad 23^{\circ} \mathrm{C}$ y $27^{\circ} \mathrm{C}$, respectivamente, lo que pone de manifiesto que la resistividad es menor cuanto más elevada es la temperatura. Es decir, para un tiempo de descarga constante, 
la caída de tensión es mayor cuanta más alta sea la temperatura. Por lo tanto tiene la misma tendencia de comportamiento que el resto de los aislantes y el de los semiconductores, ya que en estos materiales la resistividad es mayor a temperaturas bajas que a temperaturas altas [134]. Por tanto, tienen mayor número de carga libre a mayor temperatura. Se trata de un comportamiento muy diferente al de los conductores metálicos, en los que aumenta su resistividad con la temperatura debido a la agitación térmica.

En el análisis gráfico, representado en la figura 4.12, se contempla la tendencia de la variación de la resistividad frente a la humedad relativa a las temperaturas estudiadas.

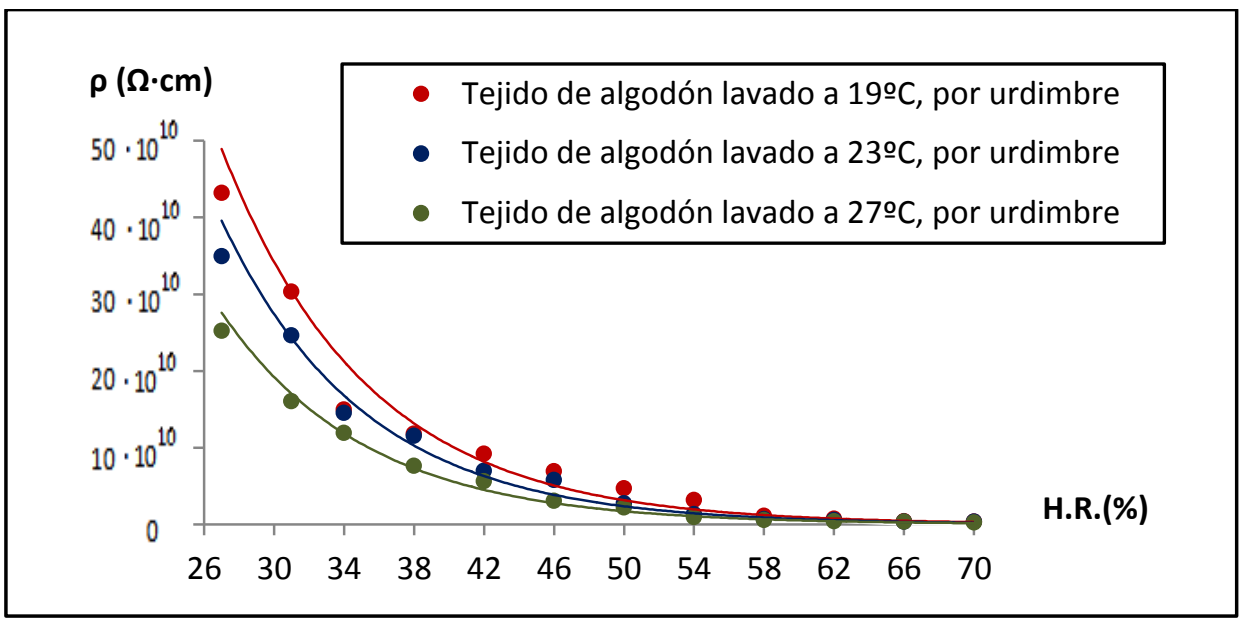

Figura 4. 12. Ajuste gráfico de la resistividad del tejido de algodón lavado, por urdimbre, para las temperaturas $19{ }^{\circ} \mathrm{C}, 23^{\circ} \mathrm{C}$ y $27{ }^{\circ} \mathrm{C}$ y diferentes H.R.

Los valores de los coeficientes del ajuste lineal de la resistividad a las distintas temperaturas estudiadas se reagrupan en la tabla 4.12. 


\begin{tabular}{||c|c|c|c|c||}
\cline { 2 - 5 } \multicolumn{1}{c||}{} & \multicolumn{4}{c|}{ Ajuste lineal } \\
\hline Tejido & $\mathrm{a}$ & $\mathrm{b}$ & $\mathrm{r}$ & $\mathrm{R}^{2}$ \\
\hline $19^{\circ} \mathrm{C}$ & $-0,1193$ & 30,139 & $-0,9879$ & 0,9759 \\
\hline $23^{\circ} \mathrm{C}$ & $-0,1228$ & 30,022 & $-0,9882$ & 0,9765 \\
\hline $27^{\circ} \mathrm{C}$ & $-0,121$ & 29,612 & $-0,9971$ & 0,9942 \\
\hline
\end{tabular}

Tabla 4. 12. Coeficientes del ajuste lineal y coeficientes de determinación del tejido de algodón lavado, por urdimbre, a las temperaturas $19^{\circ} \mathrm{C}, 23^{\circ} \mathrm{C}$ y $27^{\circ} \mathrm{C}$ y diferentes H.R.

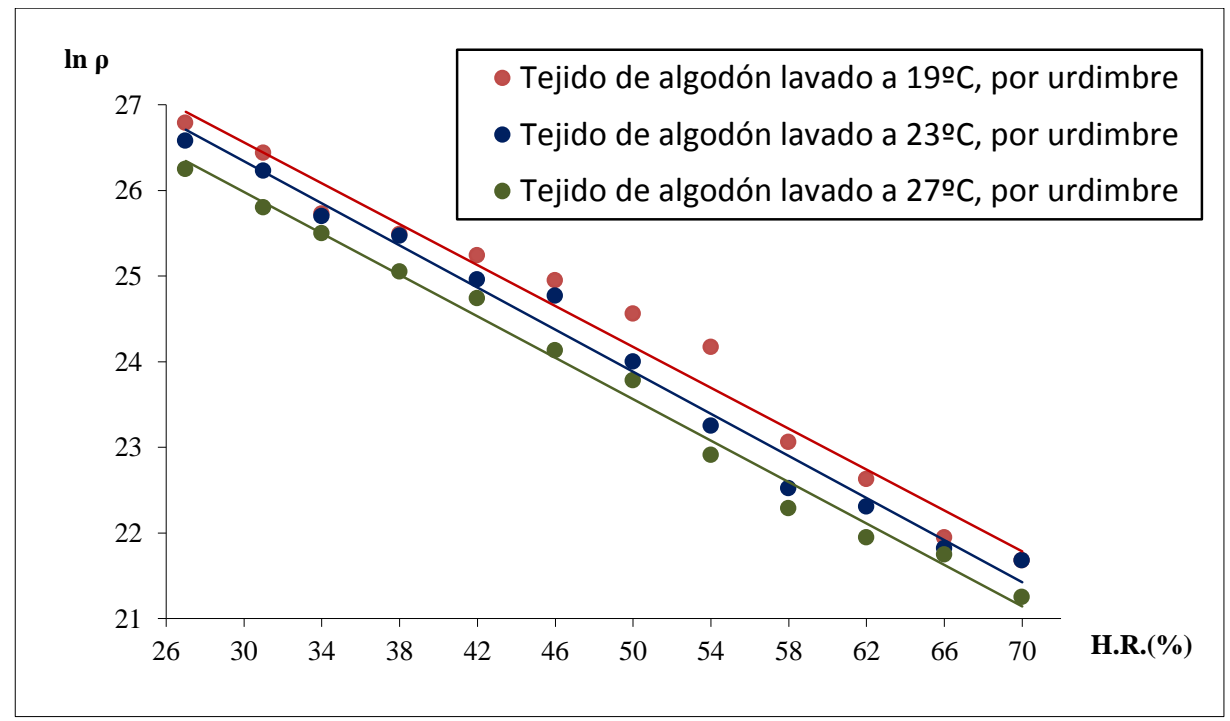

Figura 4. 13. Recta del ajuste lineal del tejido de algodón lavado, por urdimbre para unas temperaturas de $19^{\circ} \mathrm{C}, 23^{\circ} \mathrm{C}$ y $27^{\circ} \mathrm{C}$ y diferentes H.R.

En la figura 4.13 se pone de manifiesto la esperada disminución de la resistividad al aumentar la humedad relativa del ambiente a través del signo negativo de la pendiente, a, y del coeficiente de correlación, r. Los modelos lineales estudiados son significativos al $97 \%$, pero el que tiene mayor 
coeficiente de determinación se obtiene cuando se realiza a $27^{\circ} \mathrm{C}$, con un $99,42 \%$. Los ensayos proporcionan una pendiente muy parecida y por tanto la tendencia de la variación de la resistividad con la humedad relativa sería similar en los tres casos.

A igualdad de H.R., los valores de resistividad son más bajos a mayor temperatura, de entre las elegidas. Ello que significa que, a mayor temperatura, el tejido disipa mejor las cargas electrostáticas durante su fabricación y uso, provocando menos problemas en relación con la electricidad estática. Este cambio de resistividad es menos significativo que con el cambio de humedad relativa del ambiente y, por ello, en la industria textil utiliza más el control de la electricidad estática mediante la variación de la H.R. que con la temperatura.

\subsection{Análisis de las características eléctricas según la naturaleza del material textil.}

El objetivo de este apartado del capítulo, es conocer la tendencia de la resistividad de los tejidos en función de los parámetros relacionados con la naturaleza del material textil. Se van a utilizar tres tejidos distintos, uno de algodón, otro de lana y otro compuesto de nomex, kevlar y un pequeño porcentaje de fibra antiestática. En primer lugar se realiza el estudio para cada tipo de material textil y a continuación se realiza el análisis en función de la estructura propia del tejido. Por último se realiza una comparación entre los distintos tejidos estudiados. 


\subsubsection{Tejido de algodón.}

El tejido de algodón utilizado es un tejido compuesto por fibras $100 \%$ algodón cuyo ligamento es un "raso", y posee un espesor de $0,70 \mathrm{~mm}$. Tiene una masa laminar de $376 \mathrm{~g} / \mathrm{m}^{2}$ y una densidad volumétrica de $0,54 \mathrm{~g} / \mathrm{cm}^{3}$. Se realizará un estudio de los parámetros eléctricos en las dos direcciones del tejido, es decir, en trama y en urdimbre. La variación de características de un tejido en las dos direcciones hará que, presumiblemente, cambien los resultados de los ensayos realizados. Para poder asegurarlo, inicialmente se analizaron una serie de características en ambas direcciones, dando los resultados indicados en la tabla 4.13.

\begin{tabular}{||l|c|c||}
\cline { 2 - 3 } \multicolumn{1}{c|}{} & Urdimbre & Trama \\
\hline Densidad del tejido & $46(\mathrm{~h} / \mathrm{cm})$ & $26(\mathrm{p} / \mathrm{cm})$ \\
\hline Título del hilo (Tex) & 36 & 64 \\
\hline $\mathrm{K}_{\mathrm{d}}$ & 8,73 & 6,58 \\
\hline $\mathrm{K}_{\mathrm{dtex}}$ & 276 & 208 \\
\hline $\mathrm{K}_{\mathrm{dmax}}$ & 9,13 & 7,59 \\
\hline Tupidez $(\%)$ & 95,57 & 86,72 \\
\hline \hline
\end{tabular}

Tabla 4. 13. Principales características del tejido algodón.

Los resultados finales de las pruebas para el tejido de algodón, tanto de los obtenidos para la dirección urdimbre como los de trama, están reflejados en el anexo 4. Los valores de resistividad para las diferentes humedades relativas en la dirección de urdimbre ya fueron calculados y expuestos en la tabla 4.4. Los de la dirección de trama se obtienen a través del tiempo de semidescarga de los ensayos correspondientes y se muestran en la gráfica 4.14. en la que se refleja la evolución de la tensión en los extremos de la muestra textil en función del tiempo. Como ya se indicó, el tejido fue lavado previamente. 


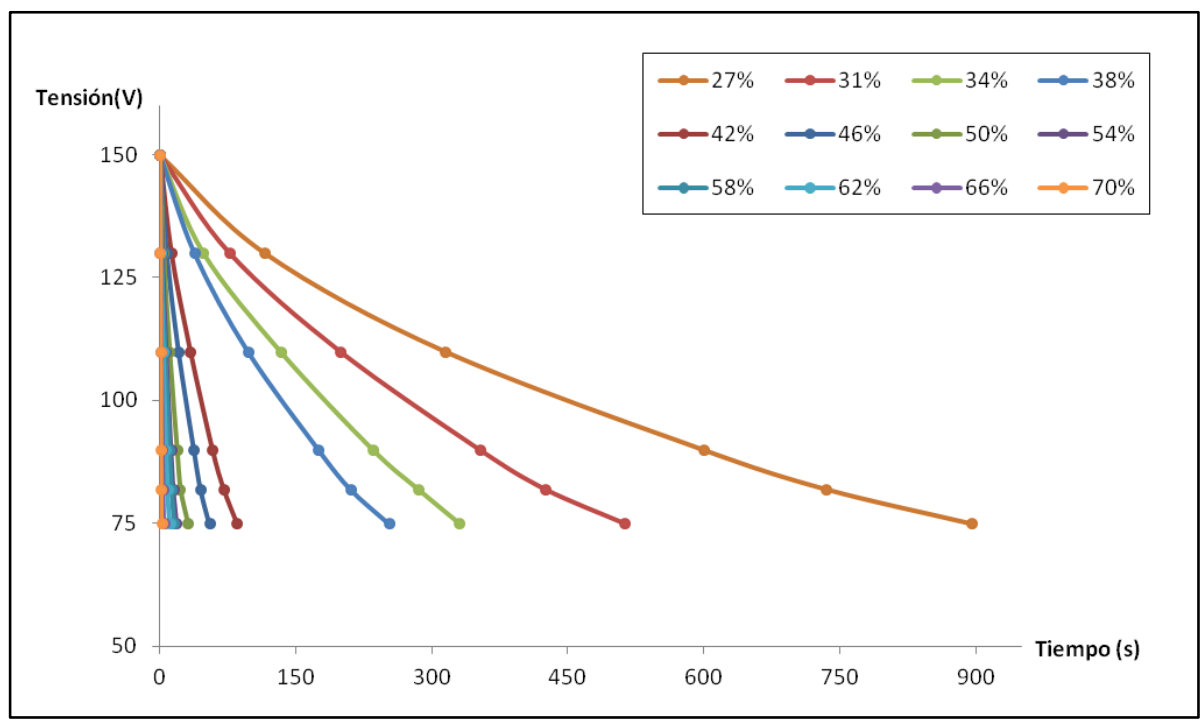

Figura 4. 14. Gráfica resumen de los resultados finales del tejido de algodón lavado, por trama, a una temperatura de $19^{\circ} \mathrm{C}$ y diferentes H.R.

En este caso, la disminución del tiempo de semidescarga en función de la humedad relativa del aire varía significativamente hasta una H.R. del 50\%, haciéndolo mínimamente a partir de esa humedad.

Los valores finales de estos tiempos de semidescarga se muestran en la tabla 4.14, en donde además se indica el coeficiente de variación. 


\begin{tabular}{||c|c|c|c|c|c|c|c||}
\hline \multirow{2}{*}{$\begin{array}{c}\text { H.R. } \\
(\mathbf{\%})\end{array}$} & \multicolumn{7}{|c|}{$\mathbf{t}_{\mathbf{5 0}}(\mathbf{s})$} \\
\cline { 2 - 7 } & $\mathbf{1}$ & $\mathbf{2}$ & $\mathbf{3}$ & $\mathbf{4}$ & $\mathbf{5}$ & Media & $\begin{array}{c}\text { C.V. } \\
(\%)\end{array}$ \\
\hline $\mathbf{2 7}$ & 904,34 & 984,38 & 866,20 & 849,27 & 870,88 & 895,01 & 6,01 \\
\hline $\mathbf{3 1}$ & 452,41 & 549,52 & 495,66 & 515,70 & 551,41 & 512,94 & 8,03 \\
\hline $\mathbf{3 4}$ & 350,28 & 337,91 & 312,81 & 315,63 & 336,75 & 330,68 & 4,83 \\
\hline $\mathbf{3 8}$ & 259,50 & 249,78 & 255,69 & 248,61 & 248,97 & 252,51 & 1,92 \\
\hline $\mathbf{4 2}$ & 82,23 & 81,94 & 85,03 & 88,19 & 86,38 & 84,75 & 3,16 \\
\hline $\mathbf{4 6}$ & 56,17 & 54,08 & 54,80 & 52,86 & 54,84 & 54,55 & 2,22 \\
\hline $\mathbf{5 0}$ & 27,80 & 30,52 & 28,84 & 33,95 & 32,69 & 30,76 & 8,36 \\
\hline $\mathbf{5 4}$ & 18,52 & 18,53 & 18,48 & 18,55 & 18,14 & 18,44 & 0,93 \\
\hline $\mathbf{5 8}$ & 15,22 & 15,27 & 15,23 & 16,34 & 16,88 & 15,79 & 4,90 \\
\hline $\mathbf{6 2}$ & 10,86 & 10,91 & 10,92 & 10,88 & 10,89 & 10,89 & 0,23 \\
\hline $\mathbf{6 6}$ & 4,89 & 4,89 & 4,36 & 4,38 & 4,91 & 4,68 & 6,19 \\
\hline $\mathbf{7 0}$ & 2,17 & 2,19 & 2,20 & 2,16 & 2,17 & 2,18 & 0,82 \\
\hline
\end{tabular}

Tabla 4. 14. Resultados y desviación típica de los tiempos de semidescarga del tejido lavado de algodón, por trama, a una temperatura de $19^{\circ} \mathrm{C}$ y diferentes H.R.

Todos los valores del coeficiente de variación para las distintas humedades relativas son inferiores al $10 \%$, por lo que nos indican su buena reproducibilidad.

De la misma forma que cuando se estudió por urdimbre, y a través de las mismas ecuaciones de cálculo, se hallan los valores de los parámetros eléctricos en la dirección de trama. Estos resultados se muestran en la tabla 4.15 . 


\begin{tabular}{||c|c|c|c|c||}
\hline H.R $(\%)$ & $\mathrm{t}_{50}(\mathrm{~s})$ & $\mathrm{R}(\Omega)$ & $\rho(\Omega \cdot \mathrm{cm})$ & $\sigma(\mathrm{S} / \mathrm{cm})$ \\
\hline $\mathbf{2 7}$ & 895,01 & $775,47 \cdot 10^{11}$ & $54,28 \cdot 10^{10}$ & $0,02 \cdot 10^{-10}$ \\
\hline $\mathbf{3 1}$ & 512,94 & $444,43 \cdot 10^{11}$ & $31,11 \cdot 10^{10}$ & $0,03 \cdot 10^{-10}$ \\
\hline $\mathbf{3 4}$ & 330,68 & $286,51 \cdot 10^{11}$ & $20,06 \cdot 10^{10}$ & $0,05 \cdot 10^{-10}$ \\
\hline $\mathbf{3 8}$ & 252,51 & $218,78 \cdot 10^{11}$ & $15,32 \cdot 10^{10}$ & $0,07 \cdot 10^{-10}$ \\
\hline $\mathbf{4 2}$ & 84,75 & $73,43 \cdot 10^{11}$ & $5,14 \cdot 10^{10}$ & $0,20 \cdot 10^{-10}$ \\
\hline $\mathbf{4 6}$ & 54,55 & $47,26 \cdot 10^{11}$ & $3,31 \cdot 10^{10}$ & $0,30 \cdot 10^{-10}$ \\
\hline $\mathbf{5 0}$ & 30,76 & $26,65 \cdot 10^{11}$ & $1,87 \cdot 10^{10}$ & $0,54 \cdot 10^{-10}$ \\
\hline $\mathbf{5 4}$ & 18,44 & $15,98 \cdot 10^{11}$ & $1,12 \cdot 10^{10}$ & $0,89 \cdot 10^{-10}$ \\
\hline $\mathbf{5 8}$ & 15,79 & $13,68 \cdot 10^{11}$ & $0,96 \cdot 10^{10}$ & $1,04 \cdot 10^{-10}$ \\
\hline $\mathbf{6 2}$ & 10,89 & $9,44 \cdot 10^{11}$ & $0,66 \cdot 10^{10}$ & $1,51 \cdot 10^{-10}$ \\
\hline $\mathbf{6 6}$ & 4,68 & $4,05 \cdot 10^{11}$ & $0,28 \cdot 10^{10}$ & $3,52 \cdot 10^{-10}$ \\
\hline $\mathbf{7 0}$ & 2,18 & $1,89 \cdot 10^{11}$ & $0,13 \cdot 10^{10}$ & $7,56 \cdot 10^{-10}$ \\
\hline
\end{tabular}

Tabla 4. 15. Resultados de los parámetros eléctricos del tejido de algodón lavado, por trama, a una temperatura de $19^{\circ} \mathrm{C}$ y diferentes H.R.

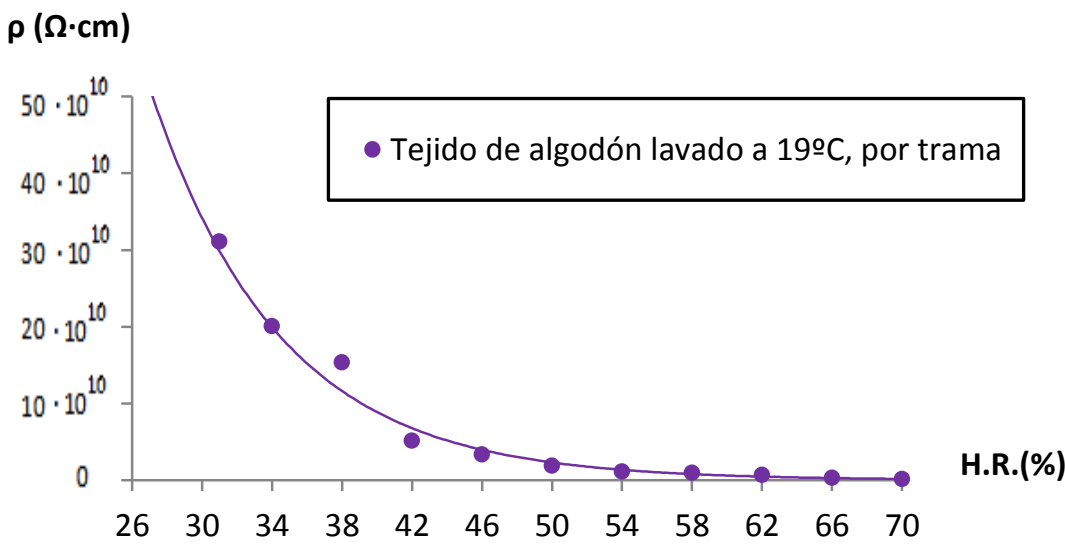

Figura 4. 15. Ajuste gráfico de la resistividad en función de la H.R. del tejido de algodón lavado, por trama, a una temperatura de $19^{\circ} \mathrm{C}$ y diferentes H.R. 


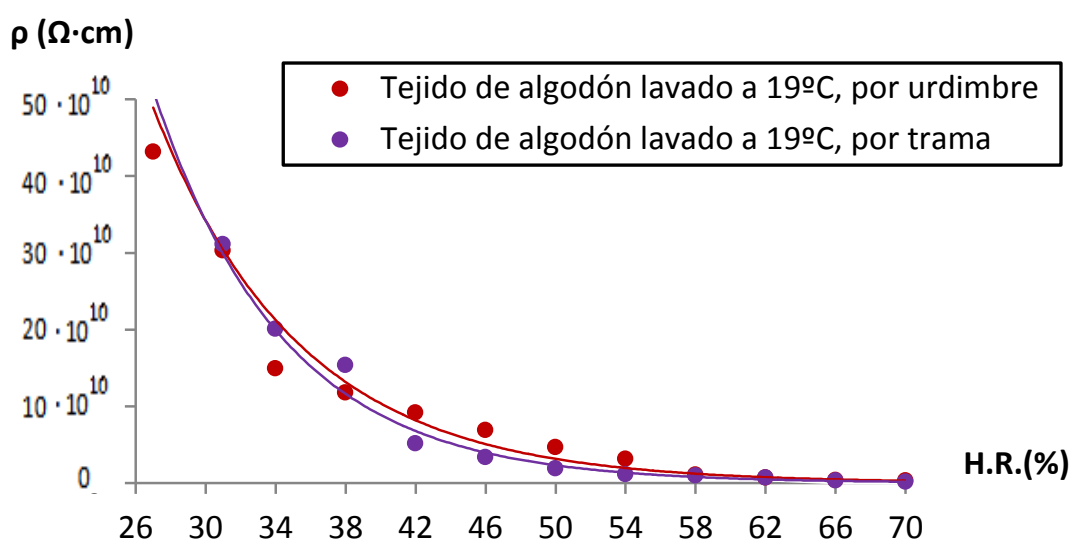

Figura 4. 16. Evolución de la resistividad en función de la humedad relativa del tejido de algodón lavado, por udimbre y trama, a una temperatura de $19^{\circ} \mathrm{C}$.

La tendencia de la resistividad en ambas direcciones es diferente, ya que a H.R. bajas tiene mayor resistividad el tejido en la dirección de urdimbre, mientras que a H.R. mayores es en la dirección de trama la que tiene mayor resistividad.

Como se ha indicado, el análisis se realiza mejor utilizando el procedimiento del método de los mínimos cuadrados, utilizado ya en los anteriores casos y se obtiene la ecuación siguiente, cuyo coeficiente de determinación es del 98,83\%:

$$
\rho=2 \cdot 10^{13} \cdot \mathrm{e}^{-0,1349 \cdot \text { H.R. }}
$$

Utilizando la misma metodología para el análisis, a través del ajuste lineal, se obtienen los coeficientes reflejados en la tabla 4.16. Para poder comparar, se han incluido también los que se obtienen para la dirección de urdimbre (tabla 4.6) y la representación de $\ln \rho$ frente a la H.R. en la figura 4.16 (se incluye también la de la dirección de urdimbre). 


\begin{tabular}{||c|c|c|c|c|}
\cline { 2 - 5 } \multicolumn{1}{c|}{} & \multicolumn{4}{c|}{ Ajuste lineal } \\
\hline \hline Tejido & $\mathrm{a}$ & $\mathrm{b}$ & $\mathrm{r}$ & $\mathrm{R}^{2}$ \\
\hline Urdimbre & $-0,1193$ & 30,139 & $-0,9879$ & 0,9759 \\
\hline Trama & $-0,1348$ & 30,599 & $-0,9941$ & 0,9883 \\
\hline
\end{tabular}

Tabla 4. 16. Coeficientes del ajuste lineal y coeficientes de determinación del tejido de algodón lavado por urdimbre y trama, a una temperatura de $19^{\circ} \mathrm{C}$ y diferentes H.R.

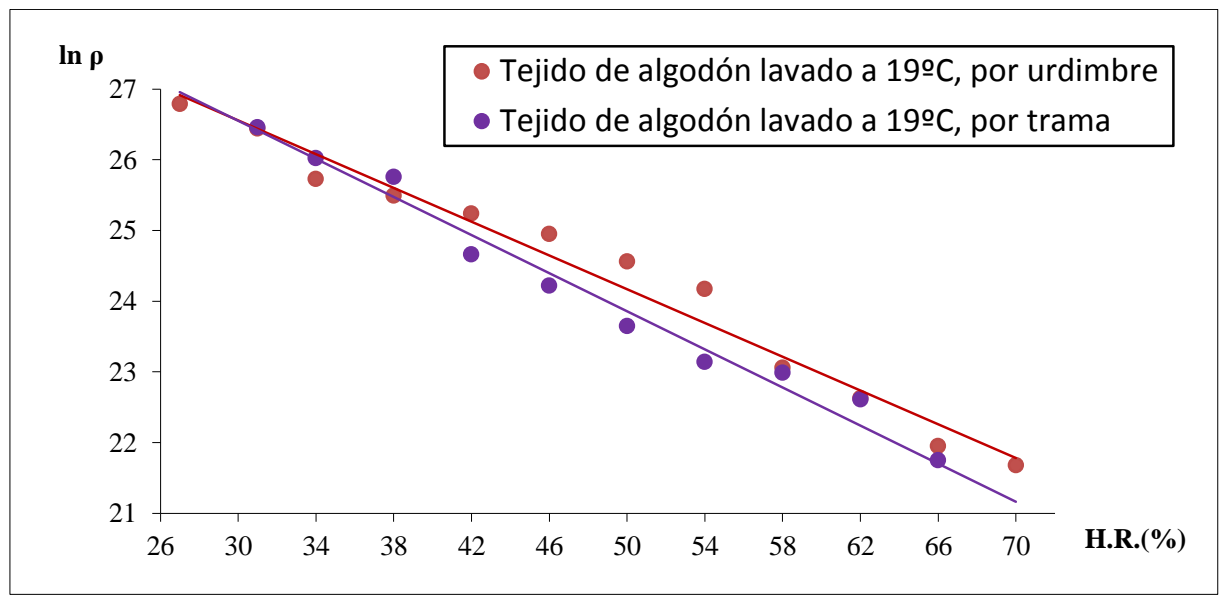

Figura 4. 17. Recta de ajuste lineal del tejido de algodón lavado, por urdimbre y trama, a una temperatura de $19^{\circ} \mathrm{C}$ y diferentes H.R.

Se pone de manifiesto la lógica disminución de la resistividad al aumentar la humedad, a través del signo negativo de la pendiente, a, y del coeficiente de correlación, r. Los modelos lineales estudiados son significativos al 97\%, pero el que tiene mayor coeficiente de determinación se obtiene cuando se realiza en la dirección de trama con un 98,83\%. Los ensayos que proporcionan mayor pendiente y por tanto mayor variación con la humedad se dan cuando la dirección es trama. A $19^{\circ} \mathrm{C}$, el tejido en trama presenta unos valores de resistividad superiores que en urdimbre desde el $27 \%$ de H.R. hasta el $38 \%$, cambiando la tendencia a partir de esa H.R. (valores dados en las tablas 4.11 y 4.15$)$. 
A través de estos resultados se puede deducir que la humedad del aire influye decisivamente en el valor de la resistividad según la dirección del tejido, ya que a distintas humedades relativas hay diferencias de valores entre trama y urdimbre. Es decir, la conductividad del tejido está en función del material y de la humedad (tanto de la absorbida por los hilos como de la que hay en la superficie y en los intersticios entre fibras) y, por tanto, varía si la carga acumulada se disipa en la dirección de trama o de urdimbre. Esto es debido a que la densidad y el título de los hilos tienen distintos valores en cada una de las direcciones, lo que afecta a la resistencia eléctrica. No obstante también entra en juego la tupidez del tejido, ya que a mayor humedad relativa del aire, mayor humedad existe entre los huecos de los hilos. Este hecho y el cambio de grosor en función de la humedad que absorba la fibra los que probablemente influyen más en el valor de la resistividad del tejido.

\subsubsection{Tejido de lana.}

El tejido utilizado está compuesto por fibras $100 \%$ de lana, con ligamento "tafetán", y posee un espesor de $0,39 \mathrm{~mm}$. El análisis de las características del tejido proporcionó los resultados indicados en la tabla 4.17.

\begin{tabular}{||c|c|c||}
\cline { 2 - 3 } \multicolumn{1}{c|}{} & Urdimbre & Trama \\
\hline Densidad del tejido & $22(\mathrm{~h} / \mathrm{cm})$ & $19(\mathrm{p} / \mathrm{cm})$ \\
\hline Título del hilo (Tex) & 34 & 34 \\
\hline $\mathrm{K}_{\mathrm{d}}$ & 4,12 & 3,50 \\
\hline $\mathrm{K}_{\mathrm{dtex}}$ & 130,15 & 110,79 \\
\hline $\mathrm{K}_{\text {dmax }}$ & 5,88 & 5,88 \\
\hline Tupidez $(\%)$ & 70,07 & 59,52 \\
\hline
\end{tabular}

Tabla 4. 17. Principales características del tejido lana. 
La metodología para el cálculo de las características eléctricas es la misma que la utilizada para el tejido de algodón. Por ello se exponen primero los resultados de las pruebas realizadas para la dirección de urdimbre y después la de trama.

A la hora de realizar las pruebas experimentales, la diferencia con el algodón es que la a H.R. bajas daba $t_{50}$ altísimos, y hubo que subir hasta H.R. del $62 \%$ para poder obtener medidas razonables. Este es el motivo de que las pruebas empiecen a H.R. del $62 \%$.

La figura 4.18 muestra la evolución de la tensión entre los extremos de la muestra del tejido en función del tiempo, observándose cómo la influencia de la humedad relativa del aire es mucho más acentuada que en el tejido de algodón, es decir, la variación de la resistividad en función de la humedad relativa es mayor. Aún a H.R. altas el tejido sigue teniendo dificultades para descargar la electricidad estática, debido a su mayor resistividad.

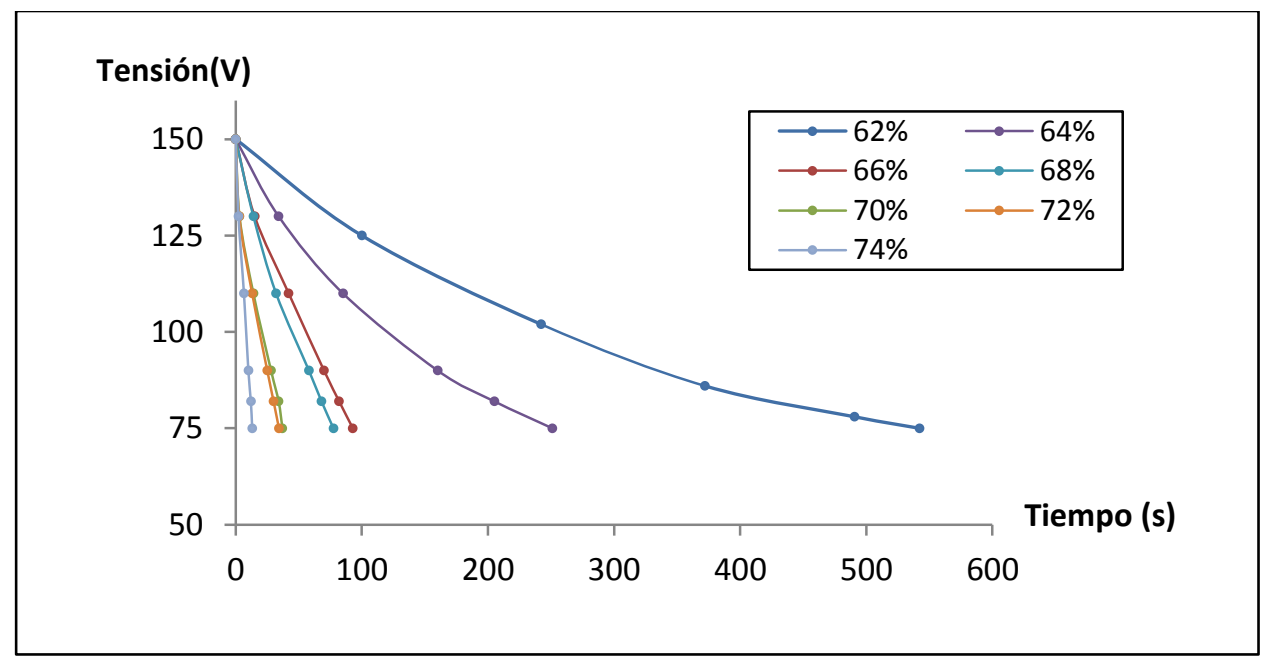

Figura 4. 18. Gráfica resumen de los resultados finales del tejido de lana lavado en urdimbre a una temperatura de $19^{\circ} \mathrm{C}$ y diferentes H.R. 
Los valores del tiempo medio de semidescarga para cada ensayo se indican en tabla 4.18 .

\begin{tabular}{||c|c|c|c|c|c|c|c||}
\hline \multirow{2}{*}{$\begin{array}{c}\text { H.R. } \\
(\%)\end{array}$} & \multicolumn{7}{|c||}{$\mathbf{t}_{\mathbf{5 0}}(\mathbf{s})$} \\
\cline { 2 - 8 } & $\mathbf{1}$ & $\mathbf{2}$ & $\mathbf{3}$ & $\mathbf{4}$ & $\mathbf{5}$ & Media & $\begin{array}{c}\text { C.V. } \\
(\%)\end{array}$ \\
\hline $\mathbf{6 2}$ & 476,84 & 564,20 & 539,78 & 541,28 & 590,00 & 895,01 & 7,74 \\
\hline $\mathbf{6 4}$ & 234,45 & 231,02 & 255,50 & 225,34 & 258,83 & 241,03 & 6,28 \\
\hline $\mathbf{6 6}$ & 96,95 & 91,70 & 95,20 & 91,97 & 88,50 & 92,87 & 3,55 \\
\hline $\mathbf{6 8}$ & 78,09 & 85,66 & 76,02 & 74,61 & 73,02 & 77,48 & 1,92 \\
\hline $\mathbf{7 0}$ & 32,73 & 35,50 & 31,69 & 39,47 & 45,88 & 37,05 & 15,59 \\
\hline $\mathbf{7 2}$ & 35,73 & 37,88 & 30,78 & 35,17 & 31,86 & 34,24 & 8,50 \\
\hline $\mathbf{7 4}$ & 11,94 & 13,05 & 14,19 & 12,45 & 13,56 & 13,04 & 6,81 \\
\hline
\end{tabular}

Tabla 4. 18. Resultados y desviación típica de los tiempos de semidescarga para el tejido de lana lavado, por urdimbre, a una temperatura de $19{ }^{\circ} \mathrm{C}$ y diferentes H.R.

Los valores de tiempo de semidescarga obtenidos en cada ensayo muestran un coeficiente de variación pequeño, excepto al $70 \%$ que llega a alcanzar el 15\%. De forma similar al algodón (aunque con valores más altos) al aumentar la humedad relativa de la cámara climática, la disminución inicial es muy elevada hasta el $66 \%$ y posteriormente va lentamente, siendo más pequeña a partir del $70 \%$.

Al tratarse del tejido de lana, el valor de los parámetros eléctricos se calcula a través de las ecuación 3.11, 4.3 y 4.5. y se muestran en la tabla 4.4. En la ecuación 4.1 el valor del espesor del tejido de lana $(0,39 \mathrm{~mm})$ varía con respecto al de algodón $(0,70 \mathrm{~mm})$, por lo que hay que recalcular la fórmula que relaciona la resistividad del tejido de lana con la resistencia de la muestra, 
quedando:

$$
\rho=\frac{E}{L} \cdot R \cdot A=0,0039 \cdot R
$$

Los resultados finales se incluyen en la tabla 4.19.

\begin{tabular}{|c|c|c|c|c|}
\hline H.R. (\%) & $\mathrm{t}_{50}(\mathrm{~s})$ & $\mathrm{R}(\Omega)$ & $\rho(\Omega \cdot \mathrm{cm})$ & $\sigma(\mathrm{S} / \mathrm{cm})$ \\
\hline $\mathbf{6 2}$ & 542,42 & $469,97 \cdot 10^{11}$ & $18,33 \cdot 10^{10}$ & $0,05 \cdot 10^{-10}$ \\
\hline $\mathbf{6 4}$ & 241,03 & $208,84 \cdot 10^{11}$ & $8,14 \cdot 10^{10}$ & $0,12 \cdot 10^{-10}$ \\
\hline $\mathbf{6 6}$ & 92,87 & $80,47 \cdot 10^{11}$ & $3,14 \cdot 10^{10}$ & $0,32 \cdot 10^{-10}$ \\
\hline $\mathbf{6 8}$ & 77,48 & $67,13 \cdot 10^{11}$ & $2,62 \cdot 10^{10}$ & $0,38 \cdot 10^{-10}$ \\
\hline $\mathbf{7 0}$ & 37,05 & $32,10 \cdot 10^{11}$ & $1,25 \cdot 10^{10}$ & $0,80 \cdot 10^{-10}$ \\
\hline $\mathbf{7 2}$ & 34,28 & $29,70 \cdot 10^{11}$ & $1,16 \cdot 10^{10}$ & $0,86 \cdot 10^{-10}$ \\
\hline $\mathbf{7 4}$ & 13,04 & $11,30 \cdot 10^{11}$ & $0,44 \cdot 10^{10}$ & $2,27 \cdot 10^{-10}$ \\
\hline
\end{tabular}

Tabla 4. 19. Resultados de los parámetros eléctricos del tejido lavado de lana en urdimbre a una temperatura de $19^{\circ} \mathrm{C}$ y diferentes H.R.

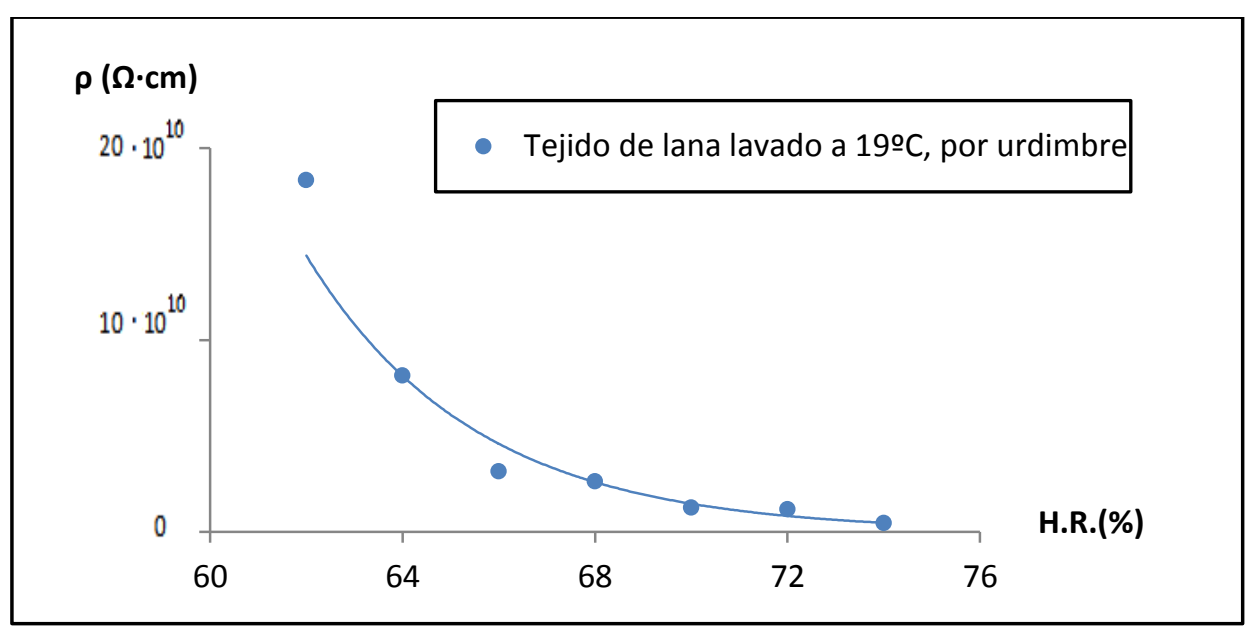

Figura 4. 19. Evolución de la resistividad en función de la H.R. del tejido de lana lavado, por urdimbre, a $19^{\circ} \mathrm{C}$ y diferentes H.R. 
La curva que refleja la evolución de la resistividad frente a la humedad relativa del ensayo obtenida de la tabla 4.19, se muestra en la figura 4.19. En esta gráfica se muestra la evolución de la resistividad eléctrica para cada humedad relativa del ensayo y visualiza la dependencia de estas variables.

La ecuación que las relaciona es:

$$
\rho=7 \cdot 10^{18} \cdot e^{-0,2859 \cdot \text { H.R. }}
$$

El coeficiente de determinación es del 96,36\%, es decir, muy significativo e indica que los resultados obtenidos en este estudio permiten predecir la resistividad eléctrica de cualquier muestra de este tejido a cualquier humedad relativa ambiental con bastante precisión.

Los resultados de los ensayos en la dirección de trama están representados en el anexo 4. A través de ellos se obtiene la figura 4.20, que muestra gráficamente la evolución de la tensión entre los extremos de la muestra del tejido en función del tiempo.

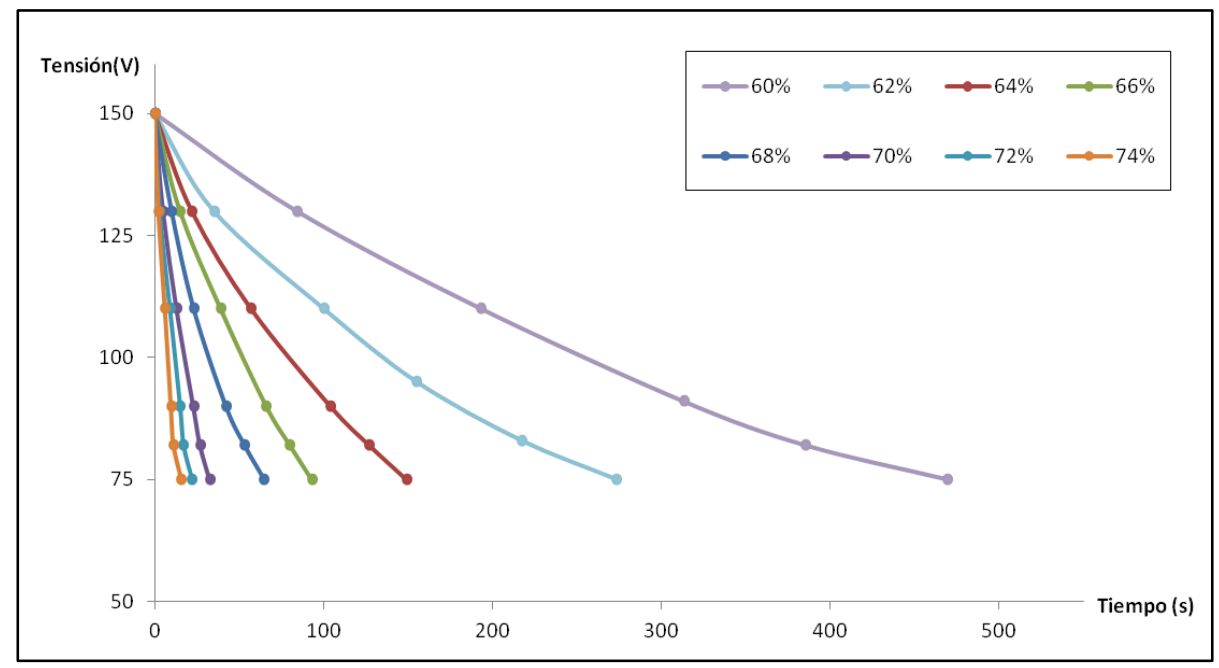

Figura 4. 20. Gráfica resumen de los resultados finales del tejido de lana lavado, por trama, a una temperatura de $19^{\circ} \mathrm{C}$ y diferentes H.R. 
En esta gráfica se muestra la evolución de la descarga para cada humedad relativa del ensayo y visualiza la dependencia de estas variables. La disminución del tiempo de semidescarga con el aumento de la humedad relativa del aire es significativa en todo el intervalo de humedad relativa estudiado.

Los valores del tiempo de semidescarga de cada prueba se indican en la tabla 4.20, recopilando valores de cada serie, media y coeficiente de variación.

\begin{tabular}{|c|c|c|c|c|c|c|c|}
\hline \multirow{3}{*}{$\begin{array}{r}\text { H.R. } \\
(\%)\end{array}$} & \multicolumn{7}{|c|}{$\mathbf{t}_{50}(\mathrm{~s})$} \\
\hline & \multicolumn{5}{|c|}{ Ensayo } & \multirow{2}{*}{ Media } & \multirow{2}{*}{$\begin{array}{l}\text { C.V. } \\
(\%)\end{array}$} \\
\hline & 1 & 2 & 3 & 4 & 5 & & \\
\hline 60 & 456,11 & 467,53 & 479,77 & 488,38 & 452,67 & 468,89 & 3,25 \\
\hline 62 & 249,09 & 264,41 & 296,03 & 265,17 & 292,44 & 273,43 & 7,35 \\
\hline 64 & 148,14 & 150,48 & 152,28 & 146,05 & 147,94 & 148,98 & 1,63 \\
\hline 66 & 96,95 & 91,70 & 95,20 & 91,97 & 88,50 & 92,87 & 3,55 \\
\hline 68 & 63,16 & 63,88 & 66,19 & 64,33 & 65,58 & 64,62 & 1,92 \\
\hline 70 & 33,27 & 30,56 & 29,70 & 33,75 & 31,03 & 31,66 & 5,56 \\
\hline 72 & 22,59 & 20,44 & 23,13 & 23,67 & 20,42 & 22,05 & 6,93 \\
\hline 74 & 15,70 & 16,16 & 15,73 & 15,84 & 15,23 & 15,73 & 2,11 \\
\hline
\end{tabular}

Tabla 4. 20. Resultados y desviación típica de los tiempos de semidescarga para el tejido lavado de lana por trama, a una temperatura de $19^{\circ} \mathrm{C}$ y diferentes H.R.

El coeficiente de variación es muy pequeño, inferior al 10\%. Al tratarse del tejido de lana, el valor de los parámetros eléctricos se calcula a través de las ecuaciones $3.11,4.3$ y 4.5 y se muestran en la tabla 4.21 . 


\begin{tabular}{|c|c|c|c|c|}
\hline H.R. $(\%)$ & $\mathrm{t}_{50}(\mathrm{~s})$ & $\mathrm{R}(\Omega)$ & $\rho(\Omega \cdot \mathrm{cm})$ & $\sigma(\mathrm{S} / \mathrm{cm})$ \\
\hline $\mathbf{6 0}$ & 468,89 & $406,26 \cdot 10^{11}$ & $15,84 \cdot 10^{10}$ & $0,06 \cdot 10^{-10}$ \\
\hline $\mathbf{6 2}$ & 273,43 & $236,91 \cdot 10^{11}$ & $9,24 \cdot 10^{10}$ & $0,11 \cdot 10^{-10}$ \\
\hline $\mathbf{6 4}$ & 148,98 & $129,08 \cdot 10^{11}$ & $5,03 \cdot 10^{10}$ & $0,20 \cdot 10^{-10}$ \\
\hline $\mathbf{6 6}$ & 92,87 & $80,46 \cdot 10^{11}$ & $3,14 \cdot 10^{10}$ & $0,32 \cdot 10^{-10}$ \\
\hline $\mathbf{6 8}$ & 64,62 & $55,99 \cdot 10^{11}$ & $2,18 \cdot 10^{10}$ & $0,46 \cdot 10^{-10}$ \\
\hline $\mathbf{7 0}$ & 31,66 & $27,43 \cdot 10^{11}$ & $1,07 \cdot 10^{10}$ & $0,93 \cdot 10^{-10}$ \\
\hline $\mathbf{7 2}$ & 22,05 & $19,10 \cdot 10^{11}$ & $0,74 \cdot 10^{10}$ & $1,34 \cdot 10^{-10}$ \\
\hline $\mathbf{7 4}$ & 15,73 & $13,63 \cdot 10^{11}$ & $0,53 \cdot 10^{10}$ & $1,88 \cdot 10^{-10}$ \\
\hline
\end{tabular}

Tabla 4. 21. Resultados de los parámetros eléctricos del tejido lavado de lana en trama a una temperatura de $19^{\circ} \mathrm{C}$ y diferentes H.R.

La curva que refleja la evolución de la resistividad frente a la humedad relativa del ensayo se observa en la figura 4.21.

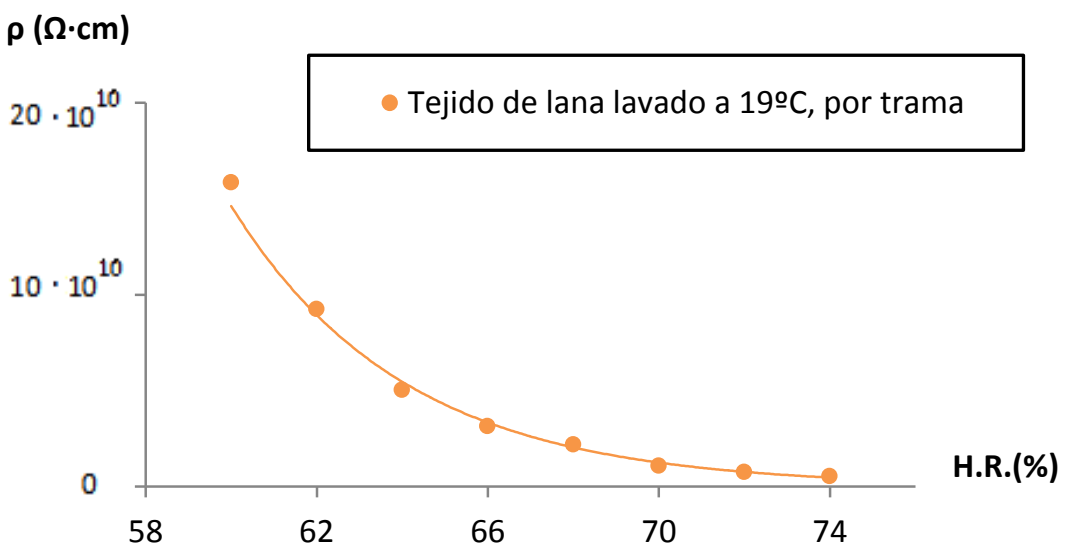

Figura 4. 21. Ajuste gráfico de la resistividad en función de la H.R. del tejido de lana lavado en urdimbre a una temperatura de $19^{\circ} \mathrm{C}$. 
En la siguiente figura se muestra la diferencia que existe entre la tendencia de resistividad eléctrica en las dos direcciones del tejido, urdimbre y trama. El valor de este parámetro en urdimbre siempre es mayor que en trama.

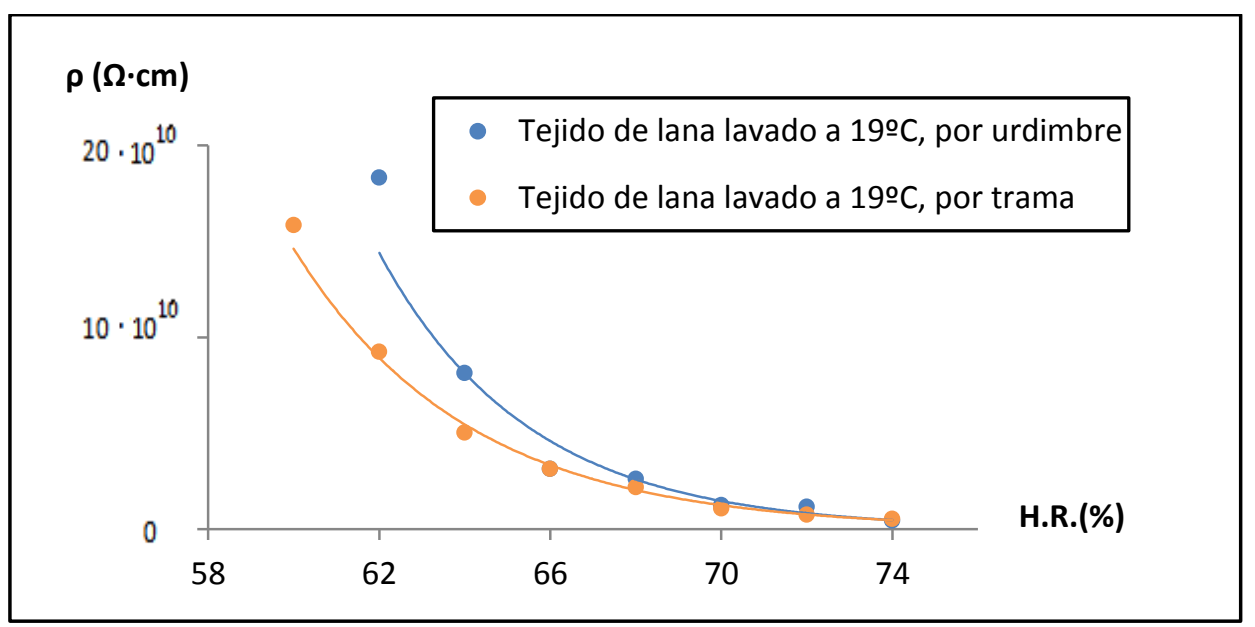

Figura 4. 22. Ajuste gráfico de la resistividad en función de la H.R. del tejido de lana lavado, por urdimbre, a una temperatura de $19^{\circ} \mathrm{C}$.

En esta gráfica se muestra la evolución de la resistividad eléctrica para cada humedad relativa del ensayo y visualiza la dependencia de estas variables. Realizando el ajuste correspondiente se obtiene la ecuación que las relaciona, obteniendo un coeficiente de determinación del 99,38\%.

$$
\rho=4 \cdot 10^{17} \cdot \mathrm{e}^{-0,2465 \cdot \text { H.R. }}
$$

Para el análisis se realiza el cálculo de los coeficientes del ajuste lineal para ambas direcciones, obteniéndose los valores mostrados en la tabla 4.16. Las rectas obtenidas del ajuste lineal del $\ln \rho$ frente a la H.R. para ambas direcciones se muestran en la figura 4.23. 


\begin{tabular}{||c|c|c|c|c||}
\cline { 2 - 5 } \multicolumn{1}{c||}{} & \multicolumn{4}{c||}{ Ajuste lineal } \\
\hline \hline Tejido & $\mathrm{a}$ & $\mathrm{b}$ & $\mathrm{r}$ & $\mathrm{R}^{2}$ \\
\hline Urdimbre & $-0,2859$ & 43,416 & $-0,9817$ & 0,9636 \\
\hline Trama & $-0,2468$ & 40,517 & $-0,9969$ & 0,9938 \\
\hline
\end{tabular}

Tabla 4. 22. Coeficientes del ajuste lineal y coeficientes de determinación del tejido de lana lavado, por trama y urdimbre, a una temperatura de $19^{\circ} \mathrm{C}$ y diferentes H.R.

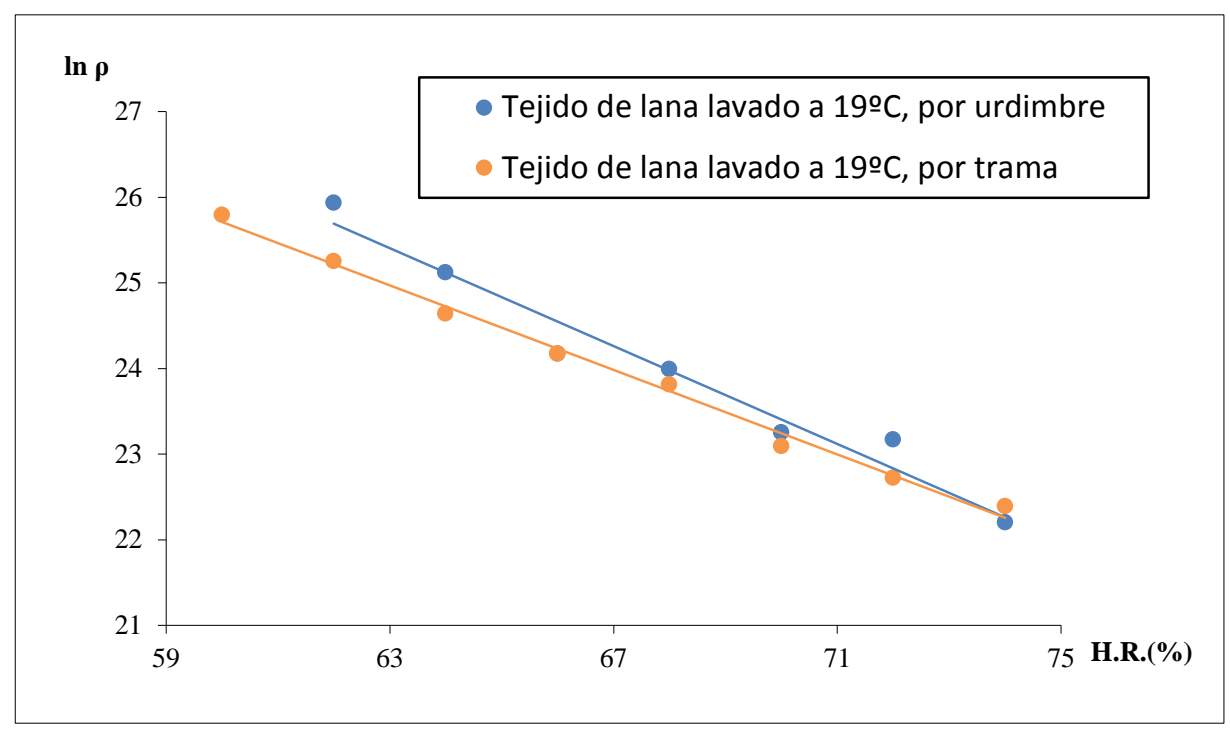

Figura 4. 23. Recta de ajuste lineal del tejido de lana lavado, por urdimbre y trama, a una temperatura de $19^{\circ} \mathrm{C}$ y diferentes H.R.

Como puede observarse, la resistividad es bastante más alta en el caso de la lana que en el del algodón, para los mismos valores de H.R., a pesar de que el tejido de lana utilizado era de un grosor muy inferior al del algodón. Los modelos lineales estudiados son significativos al 96\%. El signo negativo de la pendiente, a, y del coeficiente de correlación, $r$, pone de manifiesto la lógica disminución de la resistividad al aumentar la humedad. Las pruebas en las que 
la rectas tienen mayor pendiente y, por tanto, mayor variación con la humedad, es cuando el tejido se ensaya en la dirección de urdimbre. También se observa que no hay diferencias significativas en el valor de la resistividad al sobrepasar una humedad relativa del ambiente del $70 \%$ que, como se indicó en apartados anteriores, es debido a que la resistividad del tejido es función, en gran parte, del agua absorbida por éste y de la que se deposita en la superficie y en los intersticios. Además, en la dirección de trama el tejido presenta unos valores de resistividad menores que en urdimbre; esto es debido que es inferior la resistencia equivalente que existe en los extremos del tejido en la dirección de trama con respecto a la de urdimbre, que como se indicó en el tejido de algodón está en función de varias características del material textil.

\subsubsection{Tejido compuesto por Nomex-Kevlar-fibra antiestática.}

El tejido técnico utilizado está compuesto por fibras de Nomex al 93\% y por fibras de Kevlar al 5\%, así como un $2 \%$ de fibra antiestática. El ligamento es una "sarga" y posee un espesor de $0,51 \mathrm{~mm}$. Todas estas fibras son químicas, a diferencia de en los anteriores tejidos, que eran naturales. Se ha incluido este material para determinar si la tendencia del comportamiento eléctrico es similar a los tejidos naturales y compuestos por una sola fibra. Para poder realizar el análisis en función de la posición del tejido se realiza primero el cálculo de las diferentes características del tejido para cada dirección estudiada (urdimbre y trama), que son: 


\begin{tabular}{||c|c|c||}
\cline { 2 - 3 } \multicolumn{1}{l|}{} & Urdimbre & Trama \\
\hline Densidad del tejido & $28(\mathrm{~h} / \mathrm{cm})$ & $24(\mathrm{p} / \mathrm{cm})$ \\
\hline Título del hilo (Tex) & 40 & 55 \\
\hline $\mathrm{K}_{\mathrm{d}}$ & 5,60 & 5,63 \\
\hline $\mathrm{K}_{\mathrm{dtex}}$ & 177,09 & 177,99 \\
\hline $\mathrm{K}_{\mathrm{dmax}}$ & 7,49 & 7,49 \\
\hline Tupidez $(\%)$ & 74,80 & 75,18 \\
\hline
\end{tabular}

Tabla 4. 23. Características estructurales del tejido Nomex-Kevlarfibra antiestática.

Para el análisis de los ensayos se utilizó el mismo procedimiento que en los apartados anteriores. Los resultados finales de las pruebas para este tejido en urdimbre y trama se exponen en el anexo 4. A través de los resultados obtenidos en cada ensayo se obtiene la figura 4.24, que muestra gráficamente la evolución de la tensión (valor medio de los datos de cada ensayo) en los extremos de la muestra del tejido en función del tiempo.

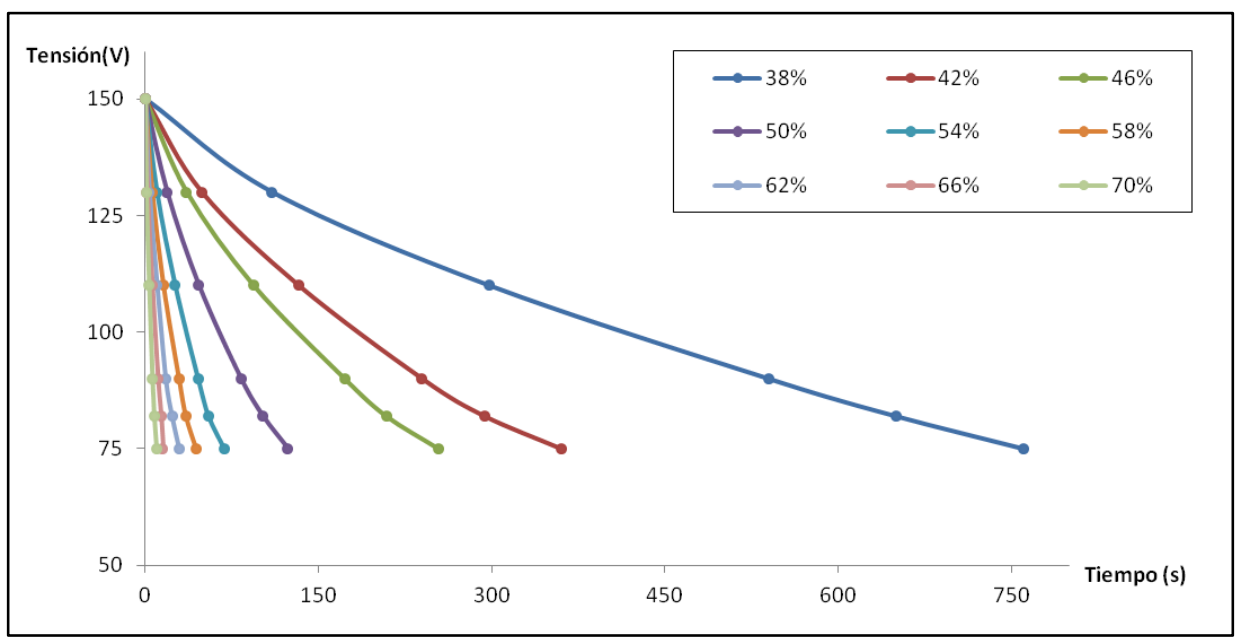

Figura 4. 24. Gráfica resumen de los resultados finales del tejido lavado de NomexKevlar-fibra antiestática, por urdimbre, a una temperatura de $19^{\circ} \mathrm{C}$ y diferentes H.R. 
En esta gráfica se muestra la evolución de la descarga para cada humedad relativa del ensayo y visualiza la dependencia de estas variables. La disminución del tiempo de semidescarga con el aumento de la humedad relativa del aire es significativa hasta llegar al 54\%. A partir de esa humedad su disminución es mucho menor debido a que la absorción de humedad de las fibras que componen el tejido y la depositada en la superficie e intersticios es menor.

Los tiempos de semidescarga obtenidos de cada ensayo vienen reflejados en la tabla 4.18 .

\begin{tabular}{|c|c|c|c|c|c|c|c|}
\hline \multirow{3}{*}{$\begin{array}{c}\text { H.R. } \\
(\%)\end{array}$} & \multicolumn{7}{|c|}{$\mathbf{t}_{50}(s)$} \\
\hline & \multicolumn{5}{|c|}{ Ensayo } & \multirow{2}{*}{ Media } & \multirow{2}{*}{$\begin{array}{l}\text { C.V. } \\
(\%)\end{array}$} \\
\hline & 1 & 2 & 3 & 4 & 5 & & \\
\hline 38 & 737,97 & 777,05 & 721,06 & 790,19 & 776,67 & 760,59 & 3,88 \\
\hline 42 & 358,98 & 375,06 & 347,38 & 353,61 & 367,59 & 360,53 & 3,05 \\
\hline 46 & 249,08 & 254,30 & 255,55 & 260,69 & 252,47 & 254,42 & 1,68 \\
\hline 50 & 121,92 & 129,13 & 128,42 & 119,14 & 120,66 & 123,85 & 3,72 \\
\hline 54 & 68,67 & 69,17 & 71,19 & 66,08 & 69,06 & 68,83 & 2,65 \\
\hline 58 & 42,13 & 47,92 & 43,80 & 43,83 & 44,41 & 44,42 & 4,81 \\
\hline 62 & 29,48 & 31,13 & 30,50 & 30,03 & 28,94 & 30,02 & 2,84 \\
\hline 66 & 19,06 & 18,98 & 16,83 & 16,88 & 17,92 & 17,93 & 6,06 \\
\hline 70 & 9,83 & 9,78 & 10,91 & 10,34 & 10,88 & 10,35 & 5,25 \\
\hline
\end{tabular}

Tabla 4. 24. Resultados y desviación típica del tejido lavado Nomex-Kevlar-fibra antiestática, por urdimbre, a una temperatura de $19{ }^{\circ} \mathrm{C}$ y diferentes H.R. 
Para el cálculo de las características eléctricas se utiliza las ecuaciones 3.11, 4.3 y 4.6. En la ecuación 4.1 el valor del espesor del tejido compuesto $(0,51 \mathrm{~mm})$ varía con respecto al de algodón $(0,70 \mathrm{~mm})$, por lo que la fórmula que relaciona la resistividad del tejido de lana con la resistencia de la muestra es:

$$
\rho=\frac{E}{L} \cdot R \cdot A=0,0051 \cdot R
$$

Los resultados obtenidos se muestran en la tabla 4.19.

\begin{tabular}{|c|c|c|c|c|}
\hline H.R. (\%) & $\mathrm{t}_{50}(\mathrm{~s})$ & $\mathrm{R}(\boldsymbol{\Omega})$ & $\rho(\Omega \cdot \mathrm{cm})$ & $\sigma(\mathrm{S} / \mathrm{cm})$ \\
\hline $\mathbf{3 8}$ & 760,59 & $659,00 \cdot 10^{11}$ & $33,61 \cdot 10^{10}$ & $0,03 \cdot 10^{-10}$ \\
\hline $\mathbf{4 2}$ & 360,53 & $312,37 \cdot 10^{11}$ & $15,93 \cdot 10^{10}$ & $0,06 \cdot 10^{-10}$ \\
\hline $\mathbf{4 6}$ & 254,42 & $220,43 \cdot 10^{11}$ & $11,24 \cdot 10^{10}$ & $0,09 \cdot 10^{-10}$ \\
\hline $\mathbf{5 0}$ & 123,85 & $107,31 \cdot 10^{11}$ & $5,47 \cdot 10^{10}$ & $0,18 \cdot 10^{-10}$ \\
\hline $\mathbf{5 4}$ & 68,83 & $59,64 \cdot 10^{11}$ & $3,04 \cdot 10^{10}$ & $0,33 \cdot 10^{-10}$ \\
\hline $\mathbf{5 8}$ & 44,42 & $38,48 \cdot 10^{11}$ & $1,96 \cdot 10^{10}$ & $0,51 \cdot 10^{-10}$ \\
\hline $\mathbf{6 2}$ & 30,02 & $26,01 \cdot 10^{11}$ & $1,33 \cdot 10^{10}$ & $0,75 \cdot 10^{-10}$ \\
\hline $\mathbf{6 6}$ & 17,93 & $15,54 \cdot 10^{11}$ & $0,79 \cdot 10^{10}$ & $1,26 \cdot 10^{-10}$ \\
\hline $\mathbf{7 0}$ & 10,35 & $8,96 \cdot 10^{11}$ & $0,46 \cdot 10^{10}$ & $2,19 \cdot 10^{-10}$ \\
\hline
\end{tabular}

Tabla 4. 25. Resultados de los parámetros eléctricos del tejido lavado de Nomex-Kevlar-fibra antiestática, por urdimbre, a una temperatura de $19^{\circ} \mathrm{C}$ y diferentes H.R.

La curva que refleja la evolución de la resistividad frente a la humedad relativa del ensayo se muestra en la figura 4.25. En esta gráfica se muestra la 
evolución de la resistividad eléctrica para cada humedad relativa del ensayo y visualiza la dependencia de estas variables.

\section{$\rho(\Omega \cdot \mathrm{cm})$}

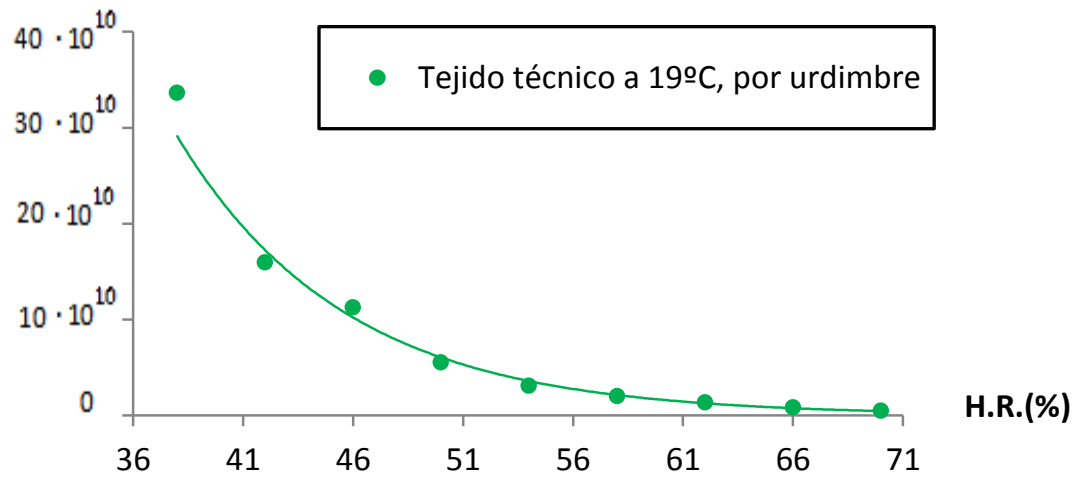

Figura 4. 25. Ajuste gráfico de la resistividad en función de la H.R. tejido lavado de Nomex-Kevlar-fibra antiestática, por urdimbre, a una temperatura de $19^{\circ} \mathrm{C}$ y diferentes H.R.

La ecuación que las relaciona es:

$$
\rho=4 \cdot 10^{13} \cdot \mathrm{e}^{-0,1311 \cdot \mathrm{H} \cdot \mathrm{R}}
$$

El coeficiente de determinación es del $99,47 \%$, es decir, muy significativo e indica que los resultados obtenidos en este estudio permiten predecir la resistividad eléctrica de cualquier muestra de este tejido a cualquier humedad relativa ambiental.

Los resultados gráficos de los ensayos en la dirección de trama son los representados en el anexo 4.

A través de los resultados obtenidos en cada ensayo se obtiene la figura 4.26, que muestra gráficamente, para cada humedad relativa, estudiada la tensión media en los extremos de la muestra del tejido en función del tiempo. 


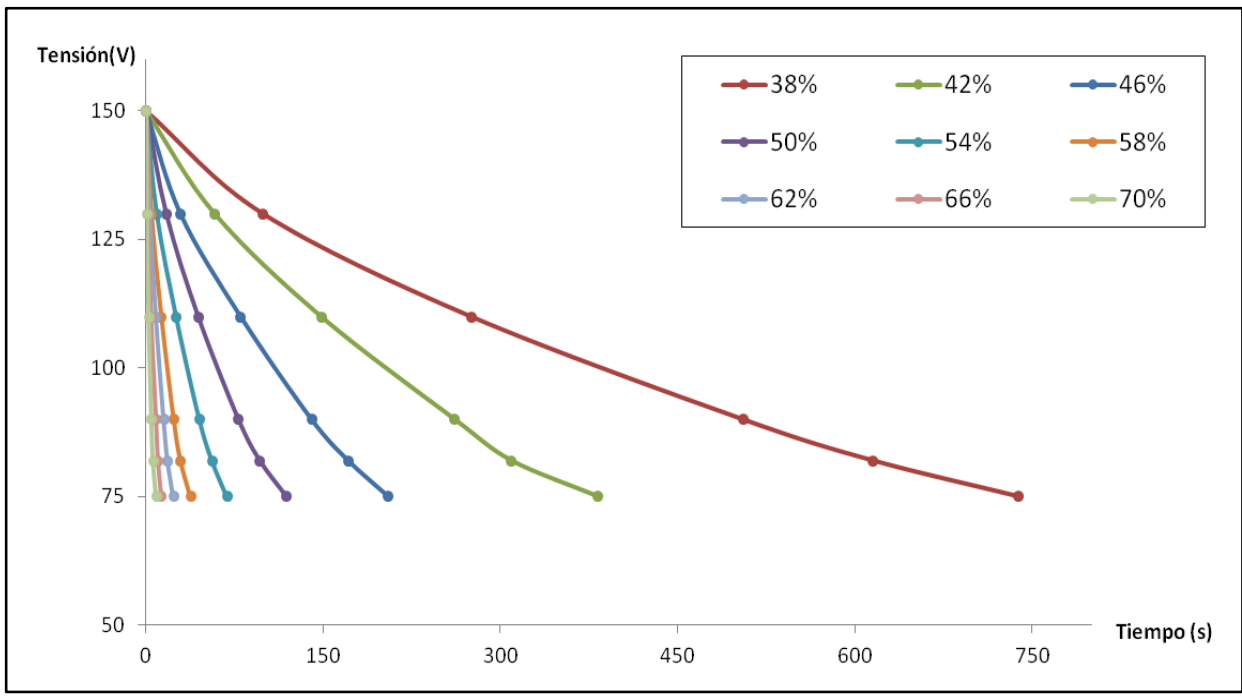

Figura 4. 26. Gráfica de los resultados finales del tejido lavado de Nomex-Kevlar-fibra antiestática, por trama, a una temperatura de $19^{\circ} \mathrm{C}$ y diferentes H.R.

La disminución del tiempo de semidescarga con el aumento de la humedad relativa del aire es significativa hasta llegar al 58\%. A partir de esa humedad su disminución es mucho menor.

Para obtener la resistencia eléctrica del tejido se debe obtener el tiempo de semidescarga. Para ello se agruparon los valores en la tabla 4.20, indicando los valores de cada serie, la media y su coeficiente de variación. 


\begin{tabular}{|c|c|c|c|c|c|c|c|}
\hline \multirow{3}{*}{$\begin{array}{c}\text { H.R. } \\
(\%)\end{array}$} & \multicolumn{7}{|c|}{$\mathbf{t}_{50}(\mathbf{s})$} \\
\hline & \multicolumn{5}{|c|}{ Ensayo } & \multirow{2}{*}{ Media } & \multirow{2}{*}{$\begin{array}{l}\text { C.V } \\
(\%)\end{array}$} \\
\hline & 1 & 2 & 3 & 4 & 5 & & \\
\hline 38 & 736,37 & 724,44 & 750,31 & 743,42 & 736,77 & 738,26 & 1,30 \\
\hline 42 & 375,45 & 380,30 & 393,95 & 389,92 & 371,02 & 382,13 & 2,52 \\
\hline 46 & 213,91 & 213,83 & 202,86 & 194,16 & 200,13 & 204,98 & 4,25 \\
\hline 50 & 115,42 & 117,52 & 116,80 & 125,19 & 118,20 & 118,63 & 3,21 \\
\hline 54 & 72,23 & 75,23 & 68,20 & 63,61 & 64,34 & 68,72 & 7,29 \\
\hline 58 & 40,77 & 35,61 & 36,23 & 40,88 & 34,58 & 37,61 & 7,94 \\
\hline 62 & 22,70 & 22,31 & 23,89 & 23,55 & 24,02 & 23,29 & 3,22 \\
\hline 66 & 12,92 & 12,94 & 12,89 & 12,92 & 12,39 & 12,81 & 1,84 \\
\hline 70 & 9,25 & 9,27 & 8,69 & 8,70 & 8,72 & 8,93 & 3,41 \\
\hline
\end{tabular}

Tabla 4. 26. Resultados y desviación típica del tejido lavado de Nomex-Kevlar-fibra antiestática, por trama, a una temperatura de $19^{\circ} \mathrm{C}$ y diferentes H.R.

Los valores de tiempo de semidescarga obtenidos en cada ensayo muestran un coeficiente de variación pequeño.

El valor de los parámetros eléctricos se calcula a través de las ecuaciones $3.11,4.3$ y 4.6. y se muestran en la tabla 4.21, obteniéndose a continuación la curva representativa de la resistividad en la figura 4.27. 


\begin{tabular}{|c|c|c|c|c|}
\hline H.R. $(\%)$ & $\mathrm{t}_{50}(\mathrm{~s})$ & $\mathrm{R}(\Omega)$ & $\rho(\Omega \cdot \mathrm{cm})$ & $\sigma(\mathrm{S} / \mathrm{cm})$ \\
\hline $\mathbf{3 8}$ & 738,26 & $639,65 \cdot 10^{11}$ & $32,62 \cdot 10^{10}$ & $0,03 \cdot 10^{-10}$ \\
\hline $\mathbf{4 2}$ & 382,13 & $331,09 \cdot 10^{11}$ & $16,89 \cdot 10^{10}$ & $0,06 \cdot 10^{-10}$ \\
\hline $\mathbf{4 6}$ & 204,98 & $177,60 \cdot 10^{11}$ & $9,06 \cdot 10^{10}$ & $0,11 \cdot 10^{-10}$ \\
\hline $\mathbf{5 0}$ & 118,63 & $102,78 \cdot 10^{11}$ & $5,24 \cdot 10^{10}$ & $0,19 \cdot 10^{-10}$ \\
\hline $\mathbf{5 4}$ & 68,72 & $59,55 \cdot 10^{11}$ & $3,04 \cdot 10^{10}$ & $0,33 \cdot 10^{-10}$ \\
\hline $\mathbf{5 8}$ & 37,61 & $32,59 \cdot 10^{11}$ & $1,66 \cdot 10^{10}$ & $0,60 \cdot 10^{-10}$ \\
\hline $\mathbf{6 2}$ & 23,29 & $20,18 \cdot 10^{11}$ & $1,03 \cdot 10^{10}$ & $0,97 \cdot 10^{-10}$ \\
\hline $\mathbf{6 6}$ & 12,81 & $11,10 \cdot 10^{11}$ & $0,57 \cdot 10^{10}$ & $1,77 \cdot 10^{-10}$ \\
\hline $\mathbf{7 0}$ & 8,93 & $7,73 \cdot 10^{11}$ & $0,39 \cdot 10^{10}$ & $2,54 \cdot 10^{-10}$ \\
\hline
\end{tabular}

Tabla 4. 27. Valores de los parámetros eléctricos del tejido lavado de NomexKevlar-fibra antiestática, por trama, a una temperatura de $19^{\circ} \mathrm{C}$ y diferentes H.R.

$\rho(\Omega \cdot \mathrm{cm})$

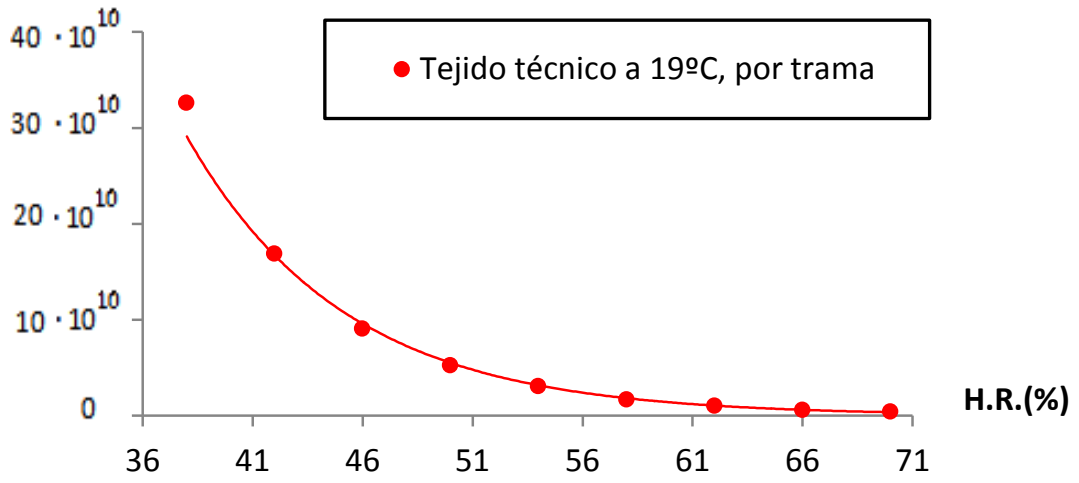

Figura 4. 27. Ajuste gráfico de la resistividad en función de la H.R. del tejido compuesto lavado en trama a una temperatura de $19^{\circ} \mathrm{C}$. 
En esta gráfica se muestra la evolución de la resistividad eléctrica para cada humedad relativa del ensayo y visualiza la dependencia de estas variables. La ecuación que las relaciona es:

$$
\rho=6 \cdot 10^{13} \cdot e^{-0,139 \cdot H \cdot R}
$$

El coeficiente de determinación es del $99,75 \%$, es decir, muy significativo e indica que los resultados obtenidos en este estudio permiten predecir la resistividad eléctrica de cualquier muestra de este tejido a cualquier humedad relativa ambiental.

Una vez obtenidos los resultados en ambas direcciones se va a realizar una comparación de ellos para exponer las diferencias existentes. La característica que más interesa en este estudio es la resistividad, que se expone la tabla 4.22 .

\begin{tabular}{|c|c|c|c|}
\hline \multirow{2}{*}{ H.R. (\%) } & \multicolumn{2}{|c|}{$\boldsymbol{\rho}(\mathbf{\Omega} \cdot \mathbf{c m})$} & \multirow{2}{*}{$\begin{array}{c}\text { Diferencia } \\
\text { Urd.-Tram. }\end{array}$} \\
\cline { 2 - 3 } & Urdimbre & Trama & $0,99 \cdot 10^{10}$ \\
\hline $\mathbf{3 8}$ & $33,61 \cdot 10^{10}$ & $32,62 \cdot 10^{10}$ & $-0,96 \cdot 10^{10}$ \\
\hline $\mathbf{4 2}$ & $15,93 \cdot 10^{10}$ & $16,89 \cdot 10^{10}$ & $2,18 \cdot 10^{10}$ \\
\hline $\mathbf{4 6}$ & $11,24 \cdot 10^{10}$ & $9,06 \cdot 10^{10}$ & $0,23 \cdot 10^{10}$ \\
\hline $\mathbf{5 0}$ & $5,47 \cdot 10^{10}$ & $5,24 \cdot 10^{10}$ & $0,00 \cdot 10^{10}$ \\
\hline $\mathbf{5 4}$ & $3,04 \cdot 10^{10}$ & $3,04 \cdot 10^{10}$ & $0,30 \cdot 10^{10}$ \\
\hline $\mathbf{5 8}$ & $1,96 \cdot 10^{10}$ & $1,66 \cdot 10^{10}$ & $0,30 \cdot 10^{10}$ \\
\hline $\mathbf{6 2}$ & $1,33 \cdot 10^{10}$ & $1,03 \cdot 10^{10}$ & $0,22 \cdot 10^{10}$ \\
\hline $\mathbf{6 6}$ & $0,79 \cdot 10^{10}$ & $0,57 \cdot 10^{10}$ & $0,07 \cdot 10^{10}$ \\
\hline $\mathbf{7 0}$ & $0,46 \cdot 10^{10}$ & $0,39 \cdot 10^{10}$ & \\
\hline
\end{tabular}

Tabla 4. 28. Comparativa de la resistividad del tejido lavado de NomexKevlar-fibra antiestática, por urdimbre y trama, a una temperatura de $19^{\circ} \mathrm{C}$ y diferentes H.R. 


\section{$\rho(\Omega \cdot \mathrm{cm})$}

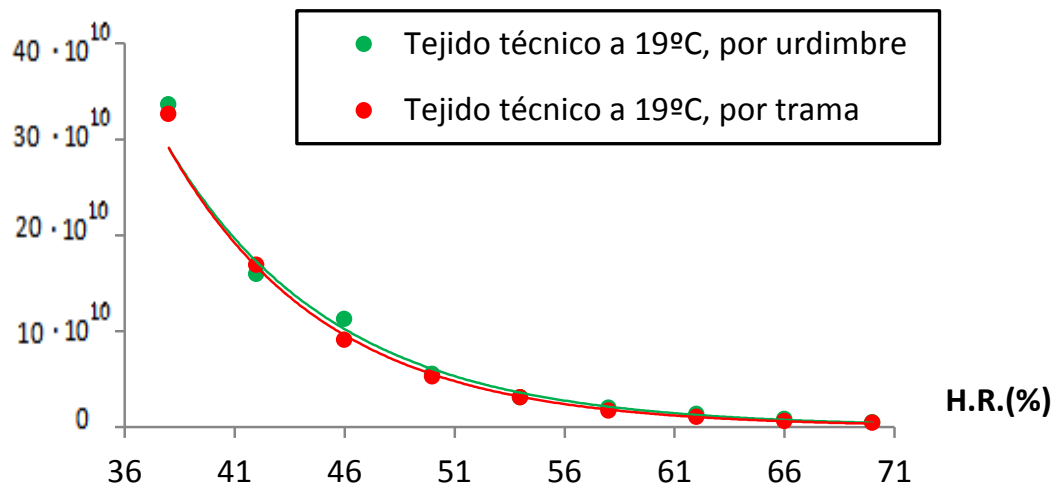

Figura 4. 28. Evolución de la resistividad eléctrica en función de la humedad relativa del tejido lavado de Nomex-Kevlar-fibra antiestática, por urdimbre y trama, a una temperatura de $19^{\circ} \mathrm{C}$.

Se comprueba como la resistividad es parecida si la carga acumulada se disipa en la dirección de trama o de urdimbre, Es decir, las características eléctricas del tejido en trama y en urdimbre se equilibran y por ello la resistividad no depende de la dirección. Pero este parámetro sí depende de la humedad relativa del aire como se ha indicado anteriormente.

En la siguiente tabla se muestra los valores de los distintos parámetros referidos a los ajustes.

\begin{tabular}{||c|c|c|c|c||}
\cline { 2 - 5 } \multicolumn{1}{c||}{} & \multicolumn{4}{c||}{ Ajuste lineal } \\
\hline \hline Tejido & $\mathrm{a}$ & $\mathrm{b}$ & $\mathrm{r}$ & $\mathrm{R}^{2}$ \\
\hline Urdimbre & $-0,1311$ & 31,381 & $-0,9973$ & 0,9947 \\
\hline Trama & $-0,1391$ & 31,682 & $-0,9987$ & 0,9975 \\
\hline
\end{tabular}

Tabla 4. 29. Coeficientes del ajuste lineal y coeficiente de determinación del tejido lavado de Nomex-Kevlar-fibra antiestática, por urdimbre y trama, a una temperatura de $19^{\circ} \mathrm{C}$. 
Se pone de manifiesto la lógica disminución de la resistividad al aumentar la humedad a través del signo negativo de la pendiente, a. Con los coeficientes de correlación obtenidos, estos ajustes son significativos al 99\%.

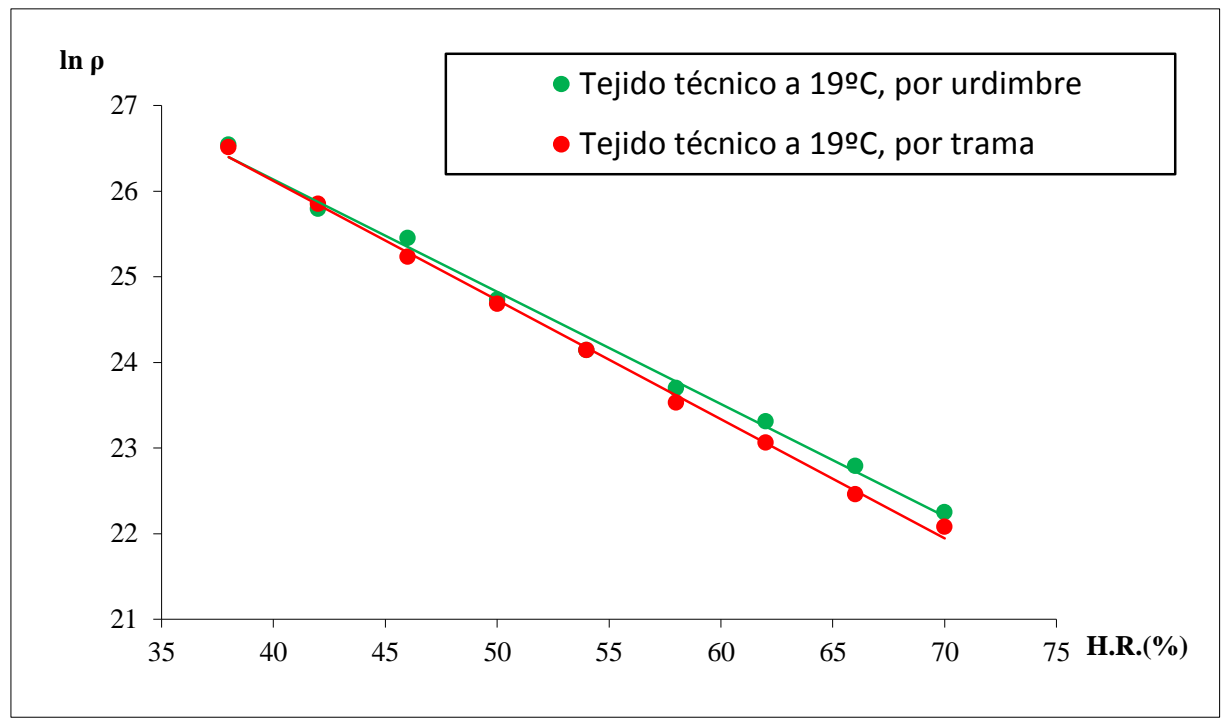

Figura 4. 29. Recta del ajuste lineal del tejido compuesto en trama y en urdimbre a una temperatura de $19^{\circ} \mathrm{C}$ en función de la H.R.

En esta gráfica se observa como prácticamente tienen la misma tendencia eléctrica en ambas direcciones, con una gran dependencia de las dos variables a estudiar, ya que las pendientes están en torno al $13 \%$.

Este tejido técnico no es el que menos resistividad posee, sin embargo, desde el punto de vista de la electricidad estática se comprueba que este tejido técnico es más equilibrado que los otros tejidos estudiados, ya que siguen la misma tendencia en ambas direcciones (urdimbre y trama). 


\subsubsection{Comparativa según su composición.}

A pesar de ser difíciles de comparar debido a las diferentes características estructurales que tienen los tejidos estudiados, ya que poseen distinta composición y grosor, diferentes densidades de urdimbre y trama, así como de los títulos de los hilos, entre otros parámetros, ha parecido interesante incorporar este punto para ver si es posible extraer alguna conclusión, ya que por la bibliografía revisada [135], la composición de los tejidos textiles es un factor importante en el valor de la resistividad de los tejidos.

Para ello se realiza la recopilación de los datos obtenidos en los apartados anteriores para analizarlos en función de la distinta composición del tejido. En la figura 4.30 se muestra los valores obtenidos de la resistividad eléctrica en función de la humedad relativa de los tres tejidos estudiados (algodón, lana y Nomex-Kevlar-fibra antiestática), tanto en la dirección de urdimbre y de trama. En ellas, se pone de manifiesto lo comentado anteriormente en los tres tejidos, es decir, la gran dependencia de la resistividad frente a la humedad relativa del aire y esta disminución se produce de forma exponencial. 


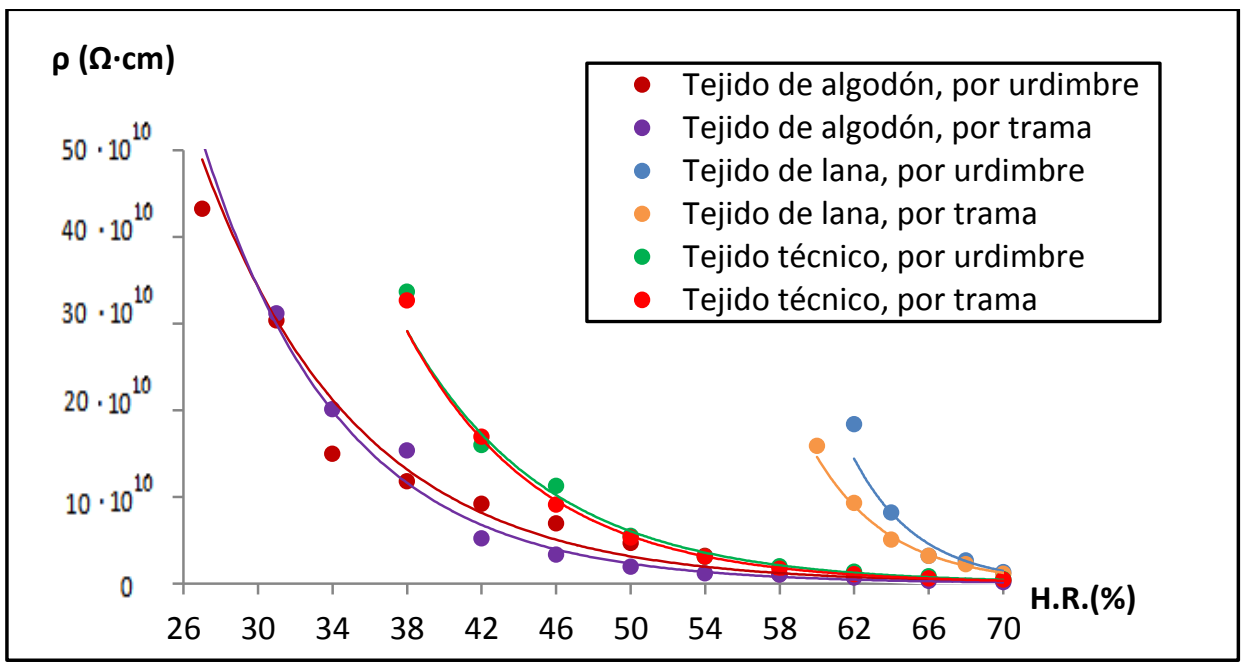

Figura 4. 30. Evolución de la resistividad eléctrica de los tejidos de algodón, lana y Nomex-Kevlar-fibra antiestática, por urdimbre, a $19^{\circ} \mathrm{C}$.

Las grandes diferencias de valores de resistividad que se han obtenido entre los distintos tejidos estudiados (en las mismas condiciones de ensayo), pueden decirse que, de algún modo, han de estar relacionadas con la composición del tejido.

Se comprueba que, a pesar de las diferencias entre los tejidos, la variable fundamental que determina el comportamiento de la electricidad estática es la naturaleza del tejido utilizado, observando también que existen diferencias si el análisis se realiza en las direcciones de trama y de urdimbre, salvo en el caso del tejido técnico. Como se ha indicado anteriormente la otra variable que determina el comportamiento es la humedad relativa del aire, ya que a humedades relativas bajas la resistividad del tejido viene determinada fundamentalmente por su composición, existiendo mayores diferencias entre los valores de los tejidos. A humedades relativas altas la resistividad viene determinada principalmente por el contenido de agua que es capaz de absorber el tejido a través de sus fibras, así como por la que se deposita en la superficie y 
en los intersticios del tejido, existiendo menores diferencias entre los valores de los diferentes tejidos.

De los tres tejidos estudiados el que posee menor resistividad es el de algodón y el que más el de lana, siendo más apreciables las diferencias a menores humedades relativas del aire. Son particularmente curiosos los resultados del tejido técnico, ya que se comprueba que aún teniendo un $2 \%$ de un material considerado antiestático, posee mayor resistividad que el algodón. Aunque no son valores tan elevados como los de fibra de Nomex, que dan valores que se sitúan en torno a $10^{16} \Omega \cdot \mathrm{cm}$ a una humedad relativa del $50 \%$ [136]. Desde el punto de vista de la electricidad estática se comprueba que este tejido técnico es más equilibrado, dado que los resultados obtenidos en ambas direcciones son muy similares independientemente de la H.R. existente en el aire. Por el contrario, el tejido de lana muestra un comportamiento muy diferente en función de la dirección, ya que la urdimbre presenta valores muy superiores al de la trama; son mayores a menores H.R. del aire.

Dada la clasificación de los tejidos desde el punto de vista eléctrico [93], se observa como los tejidos pueden dividirse en dos tipos diferentes en función de las características ambientales existentes; aislantes o antiestáticos. El tejido de algodón es el que presenta propiedades antiestáticas a lo largo de casi todo el rango de H.R., mientras que el de lana lo hace a partir de una H.R. elevada.

La tendencia del comportamiento del tejido frente a la electricidad estática a lo largo de las diversas H.R. del aire se analiza fácilmente a través de la regresión lineal. Los resultados de expresan en la tabla y las rectas representativas vienen dibujadas en la figura 4.31 . 


\begin{tabular}{||c|c|c|c|c||}
\cline { 2 - 5 } \multicolumn{1}{c|}{} & \multicolumn{4}{c||}{ Ajuste lineal } \\
\hline $\begin{array}{c}\text { Tejido } \\
\text { algodón }\end{array}$ & $\mathrm{a}$ & $\mathrm{b}$ & $\mathrm{r}$ & $\mathrm{R}^{2}$ \\
\hline Urdimbre & $-0,1193$ & 30,139 & $-0,9879$ & 0,9759 \\
\hline Trama & $-0,1348$ & 30,599 & $-0,9941$ & 0,9883 \\
\hline \hline $\begin{array}{c}\text { Tejido } \\
\text { lana }\end{array}$ & $\mathrm{a}$ & $\mathrm{b}$ & $\mathrm{r}$ & $\mathrm{R}^{2}$ \\
\hline Urdimbre & $-0,2859$ & 43,416 & $-0,9817$ & 0,9636 \\
\hline Trama & $-0,2468$ & 40,517 & $-0,9969$ & 0,9938 \\
\hline \hline $\begin{array}{c}\text { Tejido } \\
\text { técnico }\end{array}$ & $\mathrm{a}$ & $\mathrm{b}$ & $\mathrm{r}$ & $\mathrm{R}^{2}$ \\
\hline Urdimbre & $-0,1311$ & 31,381 & $-0,9973$ & 0,9947 \\
\hline Trama & $-0,1391$ & 31,682 & $-0,9987$ & 0,9975 \\
\hline \hline
\end{tabular}

Tabla 4. 30. Coeficientes del ajuste lineal y coeficiente de determinación de los tejidos estudiados, por urdimbre y trama, a una temperatura de $19^{\circ} \mathrm{C}$.

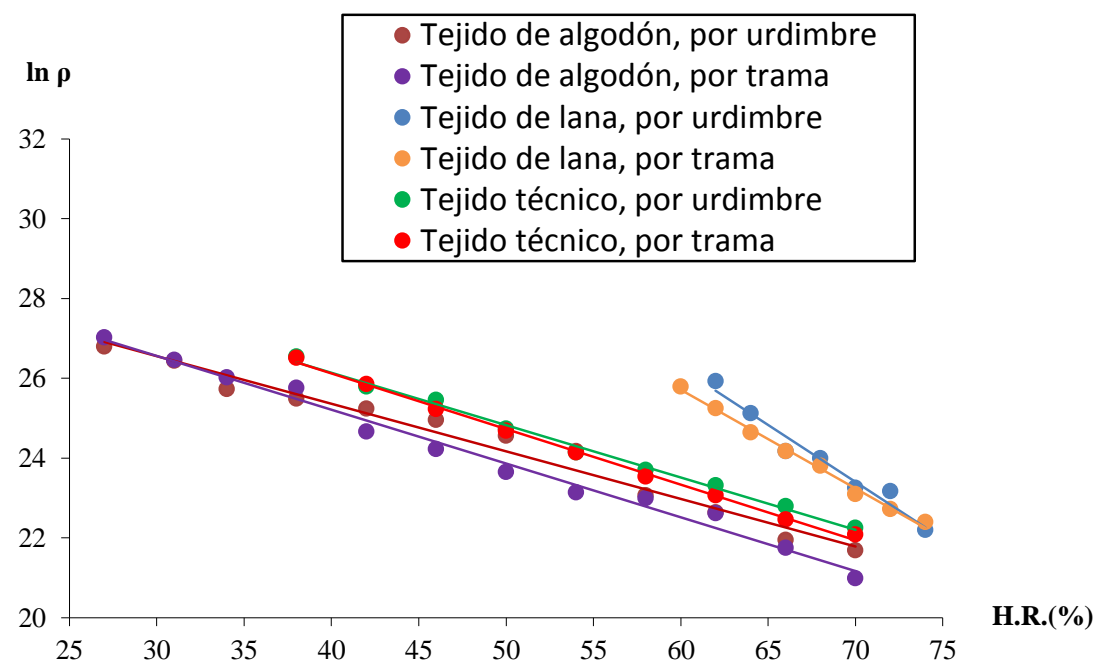

Figura 4. 31. Evolución de la resistividad eléctrica de los tejidos lavados estudiados, por urdimbre y trama, a una temperatura de $19^{\circ} \mathrm{C}$. 
La tendencia del comportamiento del tejido es la misma en todos los tejidos, a mayor H.R. menor resistividad, pero en el tejido de lana es mucho más acusada esta relación, doblando la de los otros tejidos. 


\section{CAPÍTULO 5}

\section{CONCLUSIONES GENERALES}

\section{$\underline{\mathbf{Y}}$ \\ LÍNEAS DE INVESTIGACIÓN FUTURA \\ Índice}

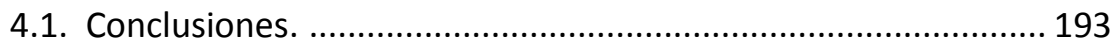

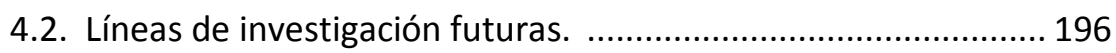




\subsection{Conclusiones.}

De los resultados obtenidos y del estudio realizado, las conclusiones que se consideran más importantes son las siguientes:

- La problemática de la electricidad estática en los materiales textiles se hace notorio tanto en los procesos de la fabricación textil como en el uso de los productos acabados y, por ello, conocer el comportamiento de este fenómeno en los materiales textiles se hace hoy en día indispensable para disminuir los trastornos ocasionados. Para un mejor estudio del fenómeno de la electricidad estática es conveniente dividirlo en tres apartados que son secuenciales: generación, acumulación y disipación de las cargas en un cuerpo. A menor generación y/o mayor disipación menores serán los efectos producidos por la electricidad estática, que generalmente suelen ser negativos o molestos para el desarrollo de cualquier actividad.

Una especial importancia tienen las consecuencias de la electricidad estática en los textiles, ya que se trata de materiales aislantes y, por tanto, más propensos a la generación de cargas electrostáticas y peores para disiparlas.

- Se ha identificado que la disipación de la electricidad estática es la etapa que más influye para que se dé este fenómeno y, por tanto, el estudio de las características eléctricas de los materiales textiles es de especial importancia para definir su magnitud. Por otra parte, el parámetro eléctrico que evalúa el comportamiento del textil en la etapa de la disipación de la electricidad estática es la "resistividad eléctrica". Este parámetro no se puede medir por procedimientos directos, ya que no existen aparatos para medir tan elevadas resistencias y por ello ha sido necesario utilizar un método indirecto. Para poder realizar una comparación entre las diferentes medidas se ha tenido que definir una metodología de cálculo, ya que existen diferentes variables que influyen en el valor de la resistividad. 
- El método indirecto utilizado es el "voltímetro estático por descarga de condensador". En él se obtienen los tiempos de semidescarga, que son el resultado necesario para el posterior cálculo de la resistencia eléctrica y, a su vez, para calcular el valor de la resistividad eléctrica. Esta sección ha sido la parte más complicada de realizar, ya que la construcción y puesta a punto del equipo ha causado múltiples dificultades debido a las diversas variables a controlar.

- En este Trabajo se ha desarrollado una adaptación propia del método indirecto anterior, ya que se ha digitalizado el proceso. Ello ha permitido el acondicionamiento de las muestras a los requisitos de los ensayos y la captación de los datos de las variables más relevantes para la obtención de la resistividad de los materiales estudiados, a través del programa LabVIEW. La información obtenida se ha procesado con diversos programas de tratamientos de datos.

- Hasta la fecha y, por lo general, el estudio de la disipación de la electricidad estática se ha limitado a la obtención del tiempo de semidescarga a unas condiciones de ensayo específicas, sin evaluar su comportamiento bajo otras condiciones. Si bien es útil para clasificar si un tejido como antiestático o no, no indica el comportamiento en situaciones diferentes.

- Se comprobó que el tratamiento que se da a los tejidos textiles para su elaboración y acabado influye en los resultados de la resistividad eléctrica. Es evidente que la incorporación de ensimajes $\mathrm{u}$ otras sustancias ajenas en su estructura modifica el comportamiento eléctrico del tejido, según pudimos determinar de forma clara. Es por ello que hubo que hacer un lavado previo de todos los tejidos, para eliminar cualquier elemento extraño a las fibras que sea modificante del comportamiento eléctrico de los tejidos. 
- Las condiciones ambientales influyen notablemente en la disipación de cargas en los tejidos. Los dos parámetros determinantes del valor de la resistividad eléctrica son la humedad relativa del aire y la temperatura. Pero de estas dos, la más relevante es la primera de ellas, pues al aumentar la humedad relativa disminuye exponencialmente el valor de la resistividad eléctrica. Y lo mismo con el aumento de la temperatura. Esto es opuesto a lo que sucede a los materiales conductores, y el comportamiento de los textiles en lo referente a la resistividad es similar al de los materiales semiconductores.

- El factor más importante en la resistividad eléctrica es sin duda el material del que esté fabricado el tejido. Por lo tanto, es función de la composición de las fibras del tejido, de la proporción de éstas y de la estructura que posea el tejido.

- De los resultados obtenidos en los tejidos estudiados, se demuestra que el tejido de algodón es el material textil con menor resistividad eléctrica para unas mismas condiciones de ensayo y, por tanto, el que más rápidamente descarga (mayor conductividad). Esta propiedad del algodón con respecto a otras fibras era conocida, ya que en trabajos realizados en atmósferas altamente inflamables o explosivas se exige utilizar prendas con altos contenidos en algodón, o bien iutilizar tejidos comercializados como antiestáticos (evitando los de fibras sintéticas, como el nylon, rayón o lycra, o naturales como la seda o la lana). Por el contrario el que menor conductividad tiene es la lana y el que más depende en este sentido de la humedad relativa del aire. Los valores de resistividad obtenidos para el tejido técnico, constituido principalmente por la mezcla de Nomex-Kevlar con un compuesto antiestático del $2 \%$, están situados entre los valores del tejido de la lana y del algodón. Todo lo expuesto en este punto se comprueba en las dos direcciones de ensayo, urdimbre y trama. 
- También se ha apreciado que, a partir de una determinada humedad, todos los tejidos tienden a una misma resistividad eléctrica, ya que ésta depende fundamentalmente del contenido de agua existente en la estructura del tejido y de la depositada en su superficie.

\subsection{Líneas de investigación futuras.}

El trabajo realizado en esta tesis está basado principalmente en la puesta en funcionamiento de un equipo que permite la medición de un parámetro para la obtención de la característica eléctrica fundamental de tejidos textiles, la resistividad, bajo condiciones de funcionamiento diferentes y controladas por este equipo. Sin embargo, las posibilidades que ofrece el aparato son mucho mayores. Se describen a continuación algunas propuestas de investigación para abordar en el futuro.

- Estudio más amplio de la relación entre la resistividad y la temperatura.

- Estudio del comportamiento de los hilos que forman el tejido, obteniendo la relación entre ambos.

- Estudio de un número mayor de tejidos para obtener relaciones entre la estructura y la resistividad eléctrica.

- Estudio del comportamiento de tejidos con mayor y menor resistividad eléctrica que la estudiada.

- Mejora de los programas para el tratamiento de datos con la incorporación de más variables que determinan la resistividad eléctrica. 


\section{CAPÍTULO 6}

BIBLIOGRAFÍA 
[1] http://en.wikipedia.org/wiki/Static_electricity. Consultado 2/2012.

[2] Dhogal, P.S. (1986). Ingeniería Eléctrica Básica, Volumen 1. Tata McGraw-Hill, 41.

[3] Información técnica CIBA. Fibras químicas GEN 050, 1.

[4] Seyam, A.F., Oxenham, W., Castle, P. (2004). Static Generation and Control in Textile Systems. National Textile Center Annual Report, 2-4.

[5] Minyoung, Suh. (2009).Generation and Dissipation in Textiles. Static Generation and dissipation in Textiles, 1-2.

[6] http://es.wikipedia.org/wiki/Generador_electrost\%C3\%A1tico. Consultado 2/2012.

[7] Benda, H. (1987). Fundamentos de los semiconductores, ep 13. Ed.MARCOMBO,S.A., 13.

[8] Sobrevila Marcelo, A. (1999). Teoría básica de la electrotecnia. Valencia: Librería y editorial Alsina, 89.

[9] Mirón, J.L. (1991). La electricidad estática y sus consecuencias. Mapfre Seguridad, TECNASA, 15.

[10] Harper, W.R. (1967). Contact and Frictional Electrification. Oxford University Express, London.

[11] mhttp://www.siafa.com.ar/notas/nota63/proteccion.htm. Consultado 2/2012.

[12] Bailey, A. (2001). The Charging of Insulators, Journal of Electrostatics, 82-90.

[13] Slade, Philip E. (1998). Antistats (in Handbook of Fiber Finish Technology), New York, USA: Marcel Dekker, 273-274.

[14] Smith, P.A., East, G.C., Brown, R.C. \& Wake D., D.J., (1988). Generation of triboelectric charge in textile fibre mixtures, and their use as air filters. J. Electrostat, 21.

[15] Tsuji, W. \& Okada, N., (1985).Vinyl Fibers (in Handbook of Fiber Science and Technology: Ed. Marcel Dekker, Vol. 4, 580.

[16] Hersh, S.P. \& Montgomery, D.J., (1955). Static Electrification of Filaments: Experimental Techniques and Results, 295.

[17] Turmo Sierra, E. (2008). Jornada Técnica Evaluación y Prevención de los Riesgos Derivados de Atmósferas Explosivas. Presentación de la Guía Técnica del RD 681/2003. CNTC Barcelona. 
[18] http://www.siafa.com.ar/notas/nota63/proteccion.htm

Consultado 2/2012.

[19] García Arévalo, M. y Redondo Quintela, (1994). Prácticas de circuitos eléctricos, Ed. Universidad de Salamanca, 28.

[20] Hambley, A.R. (2001). Electrónica. $2^{\mathrm{a}}$ edición. Michigan Technological University. Ed. Prentice Hall, 146.

[21] Redondo Quintela, F. (1992). Redes Eléctricas de Kirchoff. Ed. Revide, Béjar, 92.

[22] Gualda, J.A., Martínez, S. y Martínez, P.M.( 1992). Electrónica Industrial: Técnicas de Potencia. $2^{\mathrm{a}}$ Edición. Ed., Barcelona, 132.

[23] Descarga Electrostática. "Procedimientos para aumentar la seguridad del personal e instalaciones de las Distribuidoras de Gas Natural de la República Argentina, en las tareas de operación, reparación y mantenimiento de tuberías de polietileno (PE) en servicio". www.biel.com.ar/PDF/a4_paper_a_presentar.pdf. Consultado 5/2013.

[24] Redondo Quintela, F. (1992). Rectificadores con diodos. Ed. Revide, Béjar, 13-14.

[25] Redondo Quintela, F. (1999) Redes eléctricas de Kirchhoff. Ed Revide S.L. Béjar, 11

[26] Redondo Quintela, F. y Redondo Melchor, Roberto C. Dieléctricos. http://electricidad.usal.es/Principal/Fenomenos/Publicaciones/Descarga s/02_Dielectricos.pdf. Consultado en 12/2011.

[27] Turmo Sierra, E. (2013). NTP 567: Protección frente a cargas electrostáticas, 2-3.

[28] Nicosia, D. (2007). Lightning Safety. National Weather Service, New York.

[29] Detrell, J. (1992), Textiles Técnicos. Conferencia en Congreso Tecnitex'92, Libro de Actas. Barcelona, 36-37.

[30] Ferrandis, F. Fuster, V., Marín, J., Romualdo, F. (2000). Las perturbaciones eléctricas y la industria textil. Origen, consecuencias y soluciones. Iberdrola, 55.

[31] Soldevilla, F. (2006). Tejidos Electrotérmicos. Congreso Aplimatec I. Valencia. Libro de Actas. 18-19.

[32] Sánchez Martín, J. R., (2007). Los tejidos inteligentes y el desarrollo tecnológico de la industria textil. Técnica Industrial, $\mathrm{n}^{\circ}$ 268, 38-45.

[33] Tao, X. (2005). Smart Fibres, Fabrics and Clothing. Woodhead Publishing Limited \& The Textile Institute. England. 
[34] Shmeer-Liae, G., Stegmaier, T., Scherieble, G. \& Planck, H.(2004). El comportamiento electrostático de los tejidos para la vestimenta. International Textile Bulletin, 57.

[35] Sánchez Martín, J. R., (2007). Prendas inteligentes. Mundo Textil, vol. 90, 24-32.

[36] Redondo Quintela, F. y Redondo Melchor, Roberto C. Campo electrostático.

http://electricidad.usal.es/Principal/Fenomenos/Publicaciones/Descarga s/01_Campo_electrost.pdf. Consultado en 2/2012.

[37] http://es.wikipedia.org/wiki/William_Gilbert. Consultado 3/2012.

[38] http://magnetismoyelectricidad.wikispaces.com/Electrost\%C3\%A1tica. Consultado 3/2012.

[39] http://es.wikipedia.org/wiki/Generador_electrost\%C3\%A1tico. Consultado 5/2013.

[40] Priestley, J. (1767). The History and Present State of Electricity, with original experiments. Print. J. Dodsley, J. Johnson and T. Cadell. London.

[41] http://ideasecundaria.blogspot.com.es/2011/03/el-primer-condensadorde-la-historia.html. Consultado 5/2013.

[42] Redondo Quintela, F. y Redondo Melchor, Roberto C. Energía electrostática.http://electricidad.usal.es/Principal/Fenomenos/Publicaci ones/Descargas/07_Energia_electrostatica.pdf. . Consultado 3/2012.

[43] http://www.nndb.com/people/571/000024499/. Consultado 5/2013.

[44] Campbell, L. \& Garnett, W. (1882). The life of James Clerk Maxwell. MacMillan. Macmillan and Co: Edinburgh.

[45] Levine, Ira N. (2004). Fisicoquímica II. MacGraw-Hill, $5^{\text {a }}$ Edición, 8085.

[46] http://ttemsa.mx/SIMCOTextil.html. Consultado 9/2013.

[47] Aitex (2006), Textiles inteligentes para alfombras. Proyecto Aladin AITEX, 11.

[48] Malik, N.R. (1996). Circuitos electrónicos: Análisis, simulación y diseño. Universidad de Iowa. Ed. Prentice Hall, 129-132.

[49] Redondo Quintela, F. (1999). Redes eléctricas de Kirchhoff. Ed Revide S.L. Béjar, 20-24.

[50] Hansjochen, B. (1987). Fundamentos de los semiconductores, ep 13. Siemens Aktiengesellschaft. MARCOMBO, S.A., 27.

[51] Hearle, J.W., (1953). Journal of the Textile Institute, Vol. 44, 117-143. 
[52] Ramer, E.M., Richards, H.R., (1968). Textile Research Journal, Vol.38, $\mathrm{N}^{\circ} 1,28-35$.

[53] Hersh, S.P. \& Montgomery, D.J., (1952). Electrical Resistence Measurements on fibers and fiber assemblies. Textile Research Journal, Vol. 25, No $4,805-818$.

[54] Shinohara, I., Yamamoto F., Anzai,H. \& Endo, S.J. (1976). S. Chemical Structure and Electrostatic Properties of Polymers. Journal of Electrostatics, 99-110.

[55] Gay, L. (2012). Trabajo de Grado: Influencia de las características de los tejidos en sus propiedades electrostáticas, 16.

[56] Slater, K. (1977). Comfort Properties of Textiles. Textiles Progress, 48.

[57] Mulero, A. (2009).Termodinámica y Termotecnia. Psicrometría.

[58] Du, Y., Zahn, M., Lesieutre, B. C., Mamishev, A. V., Lindgren, S.R. (1999). Moisture Equilibrium in Transformer Paper-Oil Systems. IEEE Electrical Insulation Magazine, Vol.15.

[59] Ovejero Escudero, J. (2003). Fibras químicas (Apuntes de clase, inéditos), 89.

[60] Redondo Quintela, F. (1992). Rectificadores con diodos, Ed Revide S.L. Béjar, 20.

[61] Información técnica CIBA. Fibras químicas GEN 050, 13-14.

[62] Daimiel Mora, C. (2006). Electricidad estática: ¿un simple susto o peligro real? Gestión práctica de riesgos laborales $\mathrm{N}^{\circ} 32,22$.

[63] Sáez, V. (2010). Descarga electrostáticas en edificios. Publirreportaje Electrostatex. AENOR.

[64] http://riesgoslaborales.wke.es/articulos/electricidad-est\%C3\%Altica-unsimple-susto-o-peligro-real.Consultado 5/2013.

[65] Mirón, J. L. (1991). La electricidad estática y sus consecuencias. Mapfre Seguridad No 43, TECNASA., 16.

[66] http://fisicauniversitaria1.blogspot.com.es/2011/12/electricidadestatica-cargas-potencial.html. Consultado 5/2013.

[67] Ferrandis, F, Fustre, V., Marín, J. y Romualdo F. (2000). Las perturbaciones eléctricas y la industria textil. ITE Iberdrola, 56.

[68] Normativa NTP 567: Protección frente a cargas electrostáticas, 3-4.

[69] http://eed.gsfc.nasa.gov/562/ESD_Terms.htm. Términos ESD. Consultado 5/2013.

[70] Gualda, J.A., Martinez, S. y Martinez, P.M. (1992). Electrónica industrial: Técnicas de potencia. $2^{\mathrm{a}}$ Edición. Thomson Ed., Madrid, 132. 
[71] Thomas B. Jones, Universidad de Rochester, Rochester, Nueva York (EE.UU.) http://www.ece.rochester.edu/ jones/demos/nomo.html. Consultado en 5/2013.

[72] Kelly, M.A. (1993). An Investigation of Human Body Electrostatic Discharge. ISTFA '93: The 19th International Symposium for Testing \& Failure Analysis, Los Angeles, California, USA.

[73] Detrell, J. (1997). Introducción a las telas no tejidas. Ed.: El Autor. Publica: Tecnitex Documentación. Tarrasa.

[74] Gacén Guillén, J. (1991). Fibras textiles: Propiedades y descripción Universidad Politécnica de Cataluña. Tarrasa.

[75] Ibídem.

[76] Ibídem.

[77] Joyce, M.A. (1993). High-performance Fibres. Ed. The Textile Institute, Manchester, GB.

[78] Gacén Guillén, J. (2001) Fibras de prestaciones específicas. Boletín Intexter (U.P.C.), $\mathrm{n}^{\mathrm{o}} 119$, 59-65.

[79] http://www.ivt.ntnu.no/ipd/fag/PD9/2003/artikkel/.Consultado 5/2013.

[80] Perry, J. \& Aguilar, C. (Carolina Silver Tech.). (2006). Ventajas de la aplicación textil de la plata. Ponencia al Congreso ApliMatec'06, Valencia, ESP.

[81] Galcerán Escobet, V. (1960). Tecnología del tejido, tomo I, Tarrasa.

[82] García Obando, L. (2011). Introducción a la Tecnología Textil. Instituto Nacional Tecnológico. Nicaragua, 4.

[83] Mauri, Luis (1997). Una aportación a la tecnología del ensimaje. Ed. Revitex, Barcelona.

[84] Gonzalez, J. A., Islas, A.M., Guillen, G. (2003). Identificación cualitativa de las fibras textiles usando propiedades electrostáticas. Revista de Química Textil, $\mathrm{N}^{\circ} 165,68$.

[85] Galcerán Escobet, V. (1961). Tecnología del Tejido, tomo II, 11-47. Depósito legal: 9891-1960 (II).

[86] INDA, Association of the Nonwoven Fabrics Industry. About Nonwovens http://www.inda.org/about-nonwovens/ Consultado 6/2014.

[87] Detrell, J. (1997). Introducción a las telas no tejidas. Edita: el autor. Publica: Tecnitex Documentación. Tarrasa.

[88] Shmeer-Liae, G., Stegmaier, T., Scherieble, G. \& Planck, H.(2004). El comportamiento electrostático de los tejidos para la vestimenta. International Textile Bulletin, 56.

[89] Ibídem, 57. 
[90] Corcoran, G. F. (1949). Fundamentos de Ingeniería Eléctrica. Ed. Interciencia. Madrid, 103-112.

[91] Kasap, S.O. (2000). Principles of Electrical Engineering Materials and Devices. Ed. McGraw-Hill, Canada, 111-113.

[92] Fouille, A. (1977). Electrotecnia para Ingenieros. Ed. Aguilar, 178.

[93] Soldevilla, F. (2006). Textiles multifuncionales a partir de la conductividad eléctrica. En Congreso: $2^{\circ}$ Encuentro de Expertos en Textiles Técnicos: ASINTEC, Talavera de la Reina.

[94] Soldevilla, F. (2007). Tejidos electrotérmicos. Técnica Textil Internacional, 19.

[95] Redondo Quintela, F. (1999). Redes eléctricas de Kirchhoff. Ed Revide S.L. Béjar, 29.

[96] Adler, R.B., Smith, A.C. and Longini, R.L. (1970). Introducción a la física de los semiconductores. Ed. Reverte, 4-6.

[97] Floyd, T. L. (2010). Principles of Electric Circuits. Ed. Pearson Education, 9th Ed. New Yersey, 971.

[98] Ibídem, 971.

[99] Ramírez Vázquez, J. (1977). Materiales Electrotécnicos. Ed. Ceac., Barcelona, 81.

[100] Dawes, C. L. (1979). Tratado de Electricidad. Tomo I. Corriente Continua. Ed. Gili, S.A., México D.F., 14-15.

[101] Chacón De Antonio, F.J. (2000). Medidas Eléctricas para Ingenieros, R.B. Servicios Editoriales, 331-347.

[102] Ramírez Vázquez, J. (1989). Medidas Eléctricas, Ed. CEAC, 424-432.

[103] Ibídem, 424-437.

[104] UNE-EN 1149-1 (2007). Ropas de protección. Propiedades electrostáticas. Parte 1: Método de ensayo para la medición de la resistividad de la superficie. AENOR.

[105] UNE-EN 1149-2 (1998). Ropas de protección. Propiedades electrostáticas. Parte 2: Método de ensayo para medir la resistencia eléctrica a través de un material (resistencia vertical). AENOR.

[106] UNE-EN 1149-3 (2004). Ropas de protección. Propiedades electrostáticas. Parte 3 Métodos de ensayo para determinar la disipación de la carga. AENOR. 
[107] UNE-EN 1149-2 (2008). Ropas de protección. Propiedades electrostáticas. Parte 5: Requisitos de comportamiento de material y diseño. AENOR.

[108] Símbolo de identificación de tejido antiestático.

[109] Roberjot, P. (1939). Electricidad Industrial, Gustavo Gili Editor. Barcelona, 32.

[110] Redondo Quintela, F. y García Arévalo, J.M. (1994). Prácticas de teoría de circuitos. Ed. Universidad de Salamanca, 25-34.

[111] Ekhtiyari, E., Johari, M y Abedi M. (2002).The effect of percentage of remaining hair, breed and ambient relative humidity on electrical resistance of cashmere. IJE Transactions B: Applications, Vol.15, $\mathrm{N}^{\circ} 2$, 205-210.

[112] Neri Guerrero, K.A. (2005). Tesis: Valoración objetiva del pilling en tejidos de calada por análisis de imagen. México D.F.

[113] Barella Miró, A. (1969). Estadística Aplicada. AITA, Barcelona, 35-40.

[114] Zaragoza Velázquez, J. (2004). Tesis: Influencia de la estructura de las telas no tejidas sobre las propiedades de barrera de los componentes termofijados de confección. México D.F., 35

[115] Galindo Villardón, M.P. (1984). Exposición Intuitiva de Métodos Estadísticos, 203-231.

[116] Zaragoza Velázquez, J. (2004). Tesis: Influencia de la estructura..., Op. Cit., 35.

[117] Manrique, E, Gómez, N., Molleda, M.C. y Rey, J (2008). Estudio de la resistividad eléctrica de distintos papeles de impresión y escritura. Actas del V Congreso Iberoamericano de Investigación en Celulosa y Papel. Madrid

[118] Galindo Villardón, M.P. (1984). Exposición intuitiva de métodos estadísticos. Universidad de Salamanca, 283-287.

[119] Ibídem, 287-289.

[120] Galcerán Escobet, V. (1960). Tecnología del tejido, tomo I, Tarrasa, 9. Depósito legal: 9891-1960 (I) ,169-170.

[121] Galcerán Escobet, V. (1961). Tecnología del tejido, tomo II, 11-47. Depósito legal: 9891-1960 (II). Galcerán Escobet, V. (1960), 41-43.

[122] Instruction Manual for the Rothschild Static-Volmeter R-4021. Switzerland. 
[123] Instruction Manual for the NI-USB6008, National Instruments, USA.

[124] Pons Martín, M. y Redondo Melchor, R.C. (2001). Trabajo Fin de Carrera: Diseño y construcción de un prototipo de captación de datos de ensayos de máquinas eléctricas con LabVIEW. Béjar.

[125] Instruction Manual for the LabVIEW, National Instrument Corporation. USA.

[126] Redondo Melchor, R.C. (2008). Tesis doctoral: Estudio de las pérdidas en el suministro trifásico de energía eléctrica. Determinación de factores de pérdidas aplicables a las tarifas eléctricas, y su medida. Universidad de Salamanca, Béjar, 71-83.

[127] Morales Antigüedad, G. (2009). Tesis doctoral: Procesado y caracterización de materiales compuestos de matriz polimérica reforzados con nanofibras de carbono para aplicaciones tecnológicas. Universidad Complutense de Madrid, 89-90 .

[128] Gacén, J. y Caro, H. (1992). Comportamiento de determinados disolventes en la extracción de oligómeros del poliéster. Técnica Textil Internacional 1, 37-38.

[129] Otero, M. y Jorge, A. (1999). Trabajo Fin de Carrera. Tintura en medio alcalino del poliéster: comparación con la tintura en medio ácido. E.T.S. de I.I., Béjar, 48.

[130] García Ovejero, R. (2004). Tesina: Comportamiento tintóreo de nuevas fibras textiles. E.T.S. de I.I., Béjar, 48-49.

[131] Seyam, A.F., Oxenham, W., Castle, P. (2006). Static Generation and Control in Textile Systems (1). National Textile Center Annual Report, 2.

[132] I. Holme, J.E. McIntyre and Z.J. Shen. (1998). Electrostatic charging of textiles, Vol.28, Textil Progress. USA, 28-33.

[133] Ferrandis, F. Fuster, V., Marín, J., Romualdo, F. (2000). Las perturbaciones eléctricas y la industria textil. Origen, consecuencias y soluciones. Iberdrola, 77.

[134] Redondo Quintela, F. (1992). Rectificadores con diodos, Ed. 13-14.

[135] Martín Molina, A. (2000). Control electrostático, IEC, 6-10.

[136] Technical Data Sheet of Nomex Type 410. 


\section{ANEXOS}




\section{ANEXO 1}

\section{Resumen de la normativa vigente para el estudio de la electricidad estática en los materiales textiles.}

- EN 1149-1:2006- Ropa de protección. Propiedades electrostáticas. Parte 1: método de ensayo para la medición de la resistividad de la superficie. Este apartado nos describe el método de ensayo para determinar la resistividad superficial de un tejido bajo unas condiciones concretas, que se puede resumir en:

- En primer lugar se pre-trata la muestra, con el número de ciclos de limpieza de acuerdo con las instrucciones del fabricante del tejido. A continuación se cortan cinco muestras de un tamaño comprendido entre las dimensiones de los electrodos y las de la placa base, ya sea de la pieza del material o de la prenda. Las muestras han de ser acondicionadas al menos durante 24 horas antes del ensayo.

- El ensayo se debe realizar en las siguientes condiciones:

a) Temperatura del aire: $(23 \pm 1)^{\circ} \mathrm{C}$

b) Humedad relativa: $(25 \pm 5) \%$

- Se coloca la muestra de ensayo en la base con la superficie a ensayar hacia arriba y se apoyan el conjunto de electrodos sobre ella; los electrodos son uno cilíndrico y el otro anular, colocados concéntricamente entre ellos. A

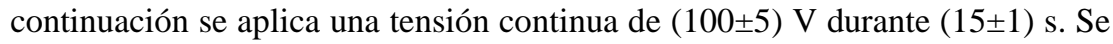
mide la resistencia utilizando un ohmímetro que mide en un rango de $10^{5} \Omega$ a $10^{14} \Omega$ con una precisión de $\pm 5 \%$ para valores $\leq 10^{12} \Omega$ y de $\pm 20 \%$ para valores $>10^{12} \Omega$. La figura 3.1. muestra el esquema de este procedimiento.

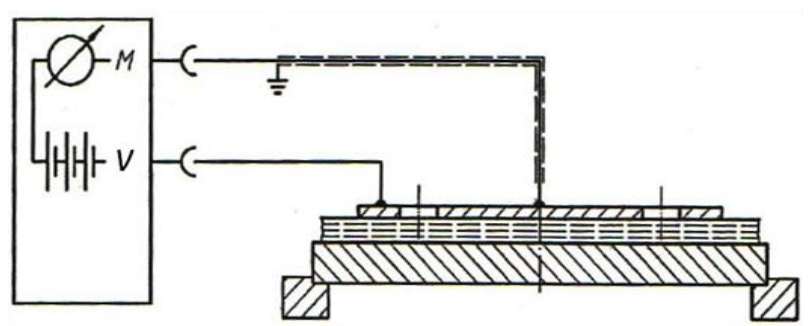

Figura Anexo1. 1. Esquema del método de ensayo para la medición de la resistividad de la superficie. 
- Se calcula la resistividad superficial $(\rho)$ para cada uno de los cinco valores a través de la fórmula:

$$
\rho=k \cdot R
$$

Donde:

$R$ es la resistencia medida $(\Omega)$.

$k$ es el factor geométrico del electrodo, determinado por la fórmula

$$
k=\frac{2 \pi}{\log _{e}\left(r_{2} / r_{1}\right)}
$$

Donde:

$r_{l}$ es el radio del electrodo interior $(\mathrm{mm})$.

$r_{2}$ es el radio interno del electrodo exterior $(\mathrm{mm})$.

- Se determina la media geométrica de estos cinco valores, que es la raíz quinta del producto de los cinco valores medidos.

- El informe del ensayo ha de incluir al menos, la siguiente información:

a) Referencia de esta Norma Europea, EN 1149-1;

b) Fecha de ensayo;

c) Atmósfera para el acondicionamiento y ensayo;

d) Descripción y número de muestras de ensayo y probetas;

e) Valores individuales de la resistividad superficial de cada muestra ensayada y media geométrica de la resistencia superficial;

f) Cualquier observación o desviación de esta norma europea.

Sustituye a la antigua EN 1149-1:1995 que, además de un método de ensayo, contenía requisitos de resistividad y diseño para la ropa de protección antiestática. 
- EN 1149-2:1997- Ropas de protección. Propiedades electrostáticas. Parte 2: Método de ensayo para medir la resistencia eléctrica a través de un material (resistencia vertical). Este apartado describe el método de ensayo para determinar la resistencia vertical, $R_{v}$, de un tejido bajo unas condiciones concretas, que se puede resumir en:

- El procedimiento de ensayo es idéntico al del primer apartado, procediendo de la misma forma en la limpieza, en el acondicionamiento y en la atmósfera de ensayo, aplicando la misma tensión y esperando el mismo tiempo. Se mide con un ohmímetro de las mismas características. Lo que cambia es el conjunto de electrodos de ensayo, representado en la figura 3.2. y está formado por:

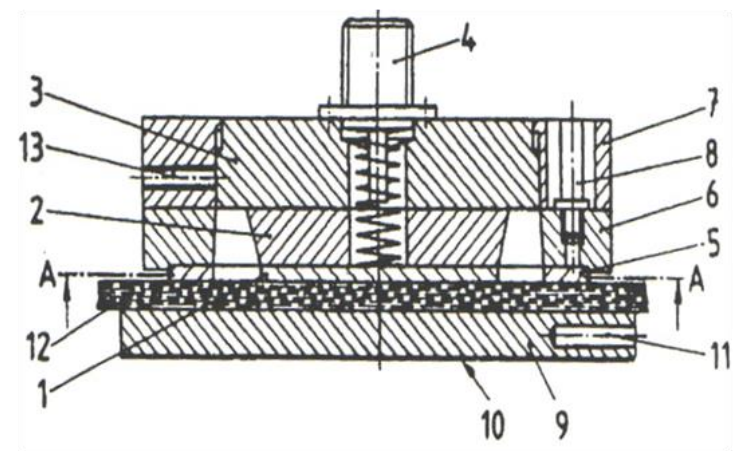

Figura Anexo1. 2. Constitución del electrodo para la medición de la resistencia vertical.

a) Electrodo de ensayo: consiste en un disco metálico (1) de unas medidas de $3 \mathrm{~mm}$ de espesor y con un diámetro $\mathrm{d}_{1}=50,4 \mathrm{~mm}$, fijado al centro de una chapa protectora metálica (3), bajo un disco de separación (2) de material altamente aislante. Un enchufe de conexión coaxial (4), asegura el contacto eléctrico entre el disco metálico y la placa de guarda.

b) Electrodo anular: consiste en un anillo protector metálico (5) de 3 $\mathrm{mm}$ de espesor aproximadamente, con un diámetro interior, $\mathrm{d}_{2}$, de $69,2 \mathrm{~mm}$ y un exterior, $\mathrm{d}_{3}$, de $89 \mathrm{~mm}$, que se van a colocar concéntricamente, bajo un anillo de separación, de material altamente aislante (6), a un anillo de apantallamiento (7), con un diámetro exterior, $\mathrm{d}_{4}$, de $100 \mathrm{~mm}$. La inserción de un conector (8) aislado del 
anillo de apantallamiento (7), asegura el contacto eléctrico con el anillo protector metálico (5).

c) Electrodo de la placa base: consiste en un disco metálico (9) de $(110 \pm 0,2) \mathrm{mm}$ de diámetro y de un espesor aproximadamente de 12 $\mathrm{mm}$, cuya cara inferior está recubierta de una capa aislante (10) de un espesor máximo de $1 \mathrm{~mm}$ y un aislamiento no inferior a $10^{14} \Omega$. El contacto eléctrico se consigue mediante una clavija (11).

- El informe del ensayo ha de incluir al menos, la siguiente información:
a) Referencia de esta Norma Europea, EN 1149-2;
b) Descripción del material ensayado;
c) Atmósfera de ensayo;
d) Tensión de ensayo, en voltios;
e) Las cinco medidas individuales;
f) Resistencia vertical media $R_{v}$, en ohmios;
g) Cualquier variación con respecto a esta norma;
h) Fecha del ensayo.

- EN 1149-3:2004- Ropas de protección. Propiedades electrostáticas. Parte 3: Métodos de ensayo para determinar la disipación de la carga.

- Hay dos métodos de ensayo para medir la tasa de disipación de la carga electrostática de los materiales de las ropas: para carga triboeléctrica y carga por inducción. El pretratamiento y la atmósfera de acondicionamiento se desarrollan de la misma manera que en la anterior metodología.

- Método de ensayo 1 (Carga triboeléctrica): Las muestras de ensayo se cargan por frotamiento contra unas barras cilíndricas montadas sobre un dispositivo deslizante vertical. La intensidad de campo eléctrico generado por la carga en el material se mide y se registra utilizando un medidor de campo electrostático conectado a un registrador gráfico.

- Método de ensayo 2 (Carga por inducción): la carga de la muestra de ensayo se realiza por efecto inductivo. El electrodo de campo, que se coloca de forma 
horizontal y debajo de la muestra, se somete bruscamente a una tensión alta. El campo que incide sobre los elementos conductores no atraviesa la muestra, y el campo resultante se reduce de una forma que es característica del material sometido al ensayo. Este campo es medido por la sonda. Esta reducción de campo se utiliza para determinar el tiempo de semidisipación, $t_{50}$, que es el tiempo que tarda la intensidad de campo medida en alcanzar la mitad del valor de $E_{\text {máx }}$ ( $E_{\text {máx }}$ es la intensidad de campo eléctrico indicada por el aparato de medida, sin muestra de ensayo presente). Además se calcula el factor de protección (S) a través de la fórmula:

$$
S=1-\frac{E_{R}}{E_{m a ́ x}}
$$

Donde $\mathrm{E}_{\mathrm{R}}$ es la intensidad de campo eléctrico indicada por el aparato de medida con la muestra de ensayo presente. Si se trata de un material que no presentan ningún efecto protector, entonces $\mathrm{E}_{\text {máx }}=\mathrm{E}_{\mathrm{R}}$, si no $\mathrm{E}_{\text {máx }}>\mathrm{E}_{\mathrm{R}}$.

- El informe del ensayo ha de incluir al menos, la siguiente información:

a) Referencia de esta Norma Europea, EN 1149-3;

b) Fecha del ensayo;

c) Atmósfera de acondicionamiento y de ensayo;

d) Descripción y número de las muestras de ensayo;

e) Método de ensayo utilizado;

f) Para el método de carga triboeléctrico, los valores individuales y medios de todos los parámetros.

g) Para el método de carga por inducción, los valores individuales de los tiempos de semi-disipación de la carga (precisión 0,01 s) y el factor de protección (precisión 0,01 unidades) para todas las muestras de ensayo y el valor medio para la muestra.

h) Cualquier observación o desviación respecto de esta norma.

- EN 1149-4: Ropas de protección. Propiedades electrostáticas. Parte 4: Requisitos, incluyendo los requisitos de prestación y diseño. Esta norma no está en vigor. 
- EN 1149-5:2008 [102]- Ropas de protección. Propiedades electrostáticas. Parte 5: Requisitos de comportamiento de material y diseño. Esta norma contiene los requisitos de resistividad y de diseño para las prendas de protección antiestática.

- Esta norma especifica los requisitos electroestáticos y de diseño que debe tener la ropa de protección antiestática para evitar la formación de chispas que puedan provocar un incendio. Los requisitos exigidos pueden no ser suficientes en atmósferas enriquecidas con oxígeno. No es aplicable frente a tensiones eléctricas.

- Los materiales de la ropa de protección antiestática deben cumplir, al menos, uno de estos dos requisitos:

a) $t_{50}<4$ s ó $S>0,2$; se determina como indica la parte tercera de la norma.

b) $\mathrm{R} \leq 2,5 \cdot 10^{9} \Omega$; se determina como indica la parte primera de la norma. 


\section{ANEXO 2}

Programa LabVIEW para la captación de datos del equipo de ensayo

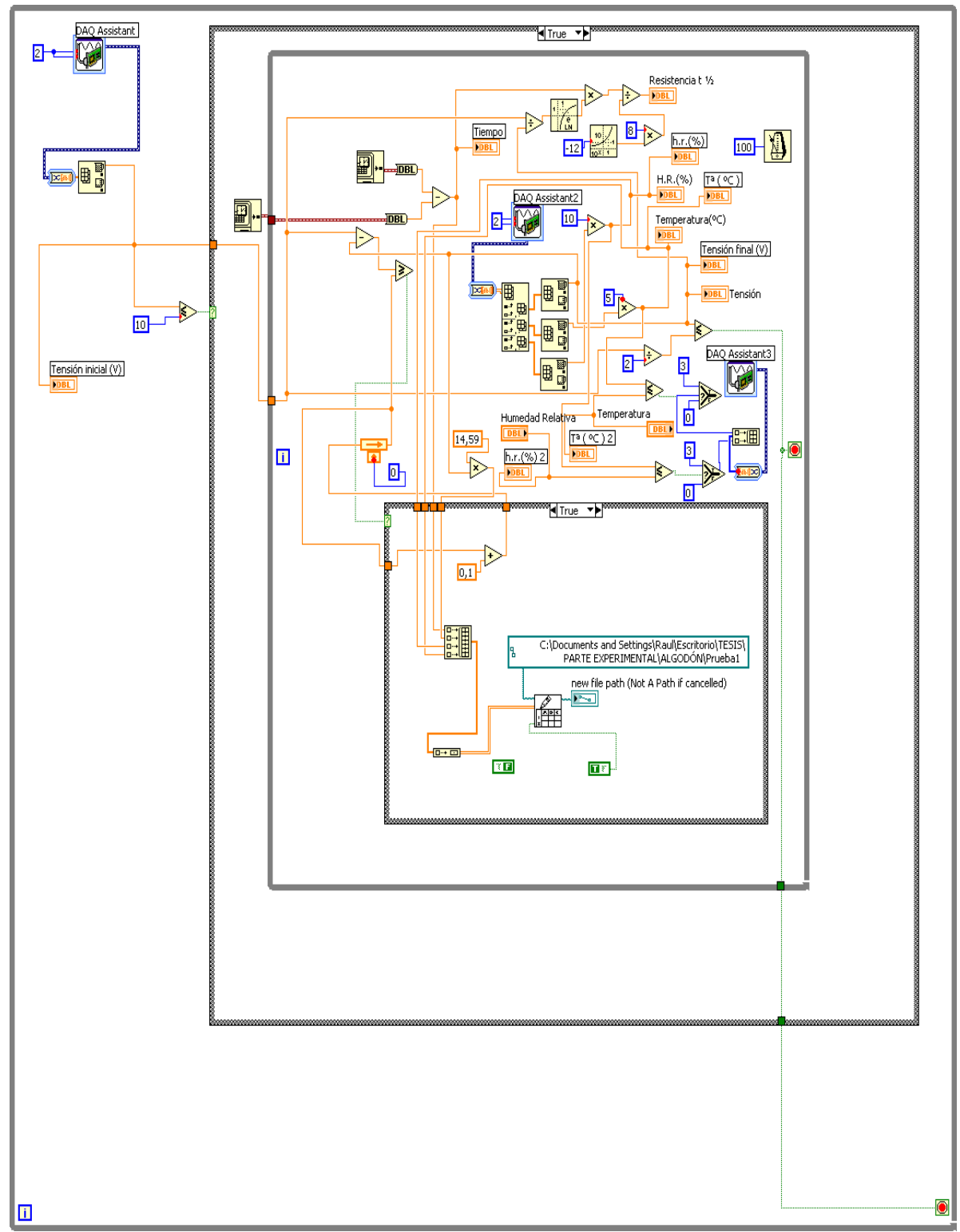




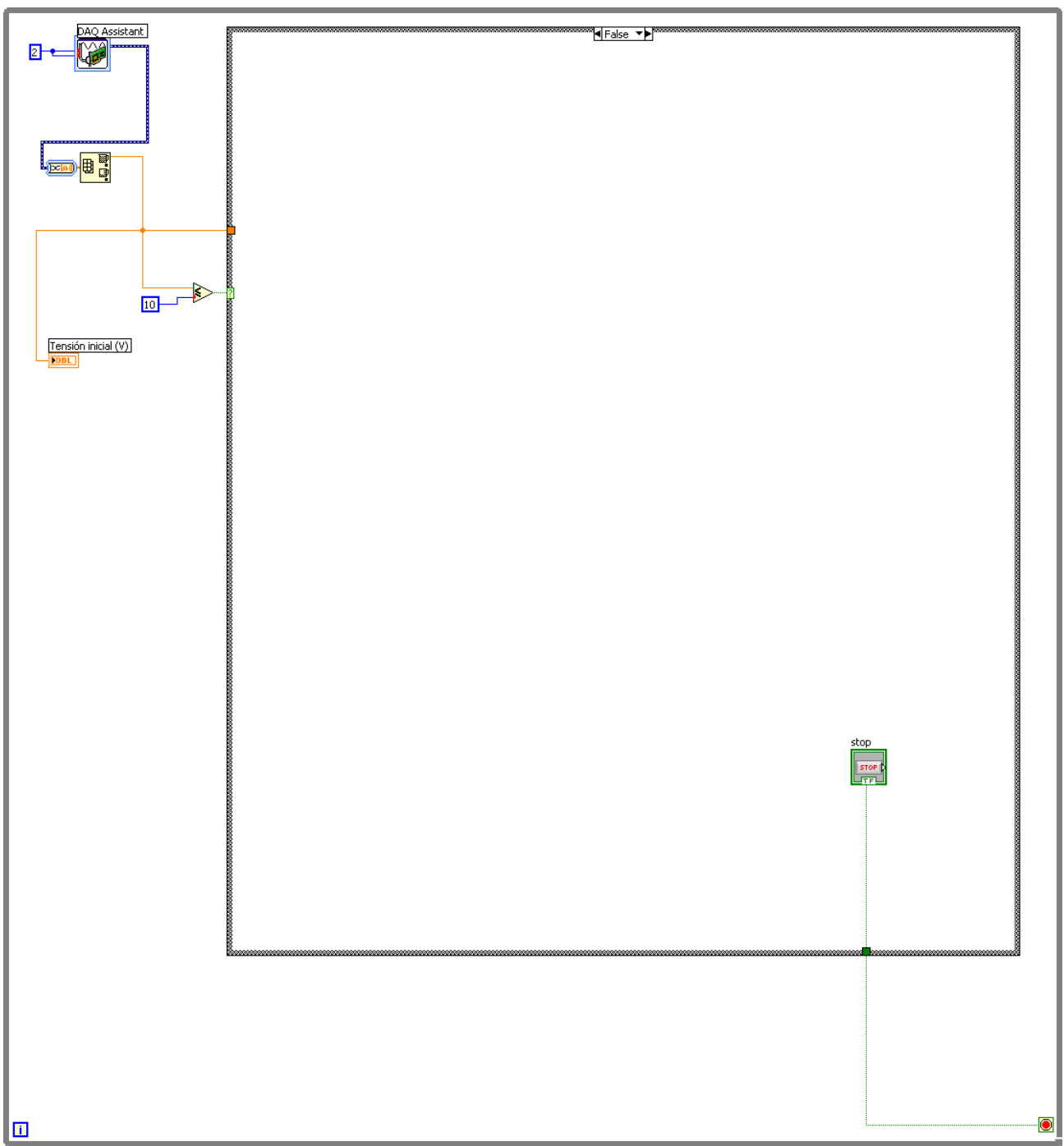




\section{ANEXO 3 \\ Programa Java para el procesamiento de datos recopilados por el programa LabVIEW}

ALGORITMO leerFichero

ENTRADA:

SALIDA: la ruta completa del fichero seleccionado o VACIO si no se seleccionara ninguno VARIABLES: selector:Selector de Fichero

INICIO

ESCRIBE: "Selecciona el fichero a procesar"

LEER selector

FIN

ALGORITMO ejecuta

ENTRADA:

SALIDA: el fichero Excel generado o el error que se ha producido

VARIABLES:

INICIO

INTENTA

SI ComprobarSeleccionFicheros ENTONCES

LLAMAR GenerarCarpetaGenerados

LLAMAR GestionarFichero

ESCRIBE "Fichero generado correctamente"

SINO SI

ESCRIBE "Seleccione un fichero"

FINSI

SI ERROR

ESCRIBE "Se ha producido un error de generación"

FIN

ALGORITMO comprobarSeleccionFichero

ENTRADA: la ruta del fichero

SALIDA: verdadero si el fichero existe o falso si no existe

VARIABLES: dir: fichero

INICIO 
SI dir $==$ VACIO O dir NO ES FICHERO ENTONCES

DEVOLVER FALSO

SINO

DEVOLVER VERDADERO

FINSI

FIN

ALGORITMO generarCarpetaGenerados

ENTRADA: la ruta del fichero

SALIDA:

VARIABLES: dir: fichero

INICIO

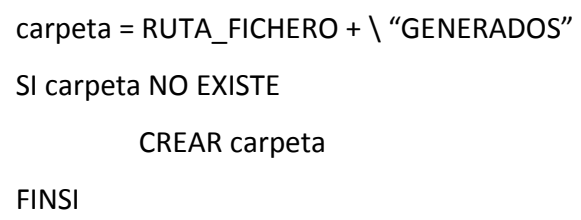


FIN

ALGORITMO obtenerValoresMayorMenor

ENTRADA: el listado de datos

SALIDA: los valores mayores y menores

VARIABLES:

datos: listado de datos

tMayor: real

tMenor: real

hMayor: real

hMenor: real

INICIO

$$
\begin{aligned}
& \text { tMayor }= \text { datos }[0] . \text { temperatura } \\
& \text { tMenor }= \text { datos[0].temperatura } \\
& \text { hMayor }= \text { datos[0].humedad } \\
& \text { hMenor }= \text { datos[0].humedad } \\
& \text { PARA i=1 HASTA tamaño (datos) CON INCREMENTO +1 } \\
& \text { temperatura }=\text { datos[i].temperatura } \\
& \text { humedad }=\text { datos[i].humedad } \\
& \text { SI temperatura }>\text { tMayor } \\
& \text { tMayor }=\text { temperatura } \\
& \text { SINSI temperatura }<\text { tMenor } \\
& \text { FINSI } \quad
\end{aligned}
$$

SI humedad < hMenor

$$
\text { hMenor }=\text { humedad }
$$

FINSI

SI humedad > hMayor

$$
\text { hMayor }=\text { humedad }
$$

FINSI

FINPARA

DEVOLVER tMayor

DEVOLVER tMenor

DEVOLVER hMayor 
DEVOLVER hMenor

FIN

ALGORITMO escribirExcel

ENTRADA: listado de datos

SALIDA: el fichero Excel generado e impreso con el listado de datos

VARIABLES:

al: listado de datos

fichero: fichero Excel

INICIO

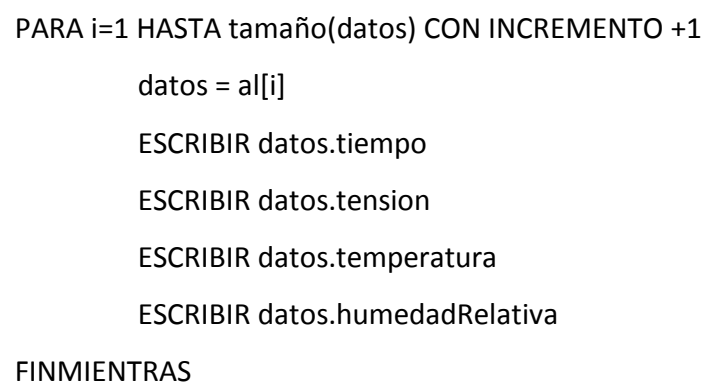

FIN

ALGORITMO gestionarFichero

ENTRADA: el fichero de datos

SALIDA: el fichero Excel generado e impreso con el listado de datos VARIABLES:

al: listado de datos

parte1: listado de datos

parte2: listado de datos

fichero: fichero Excel

tMayor: real

tMenor: real

hMayor: real

hMenor: real

INICIO

al = obtenerValoresFichero

CREAR fichero

escribirExcel (datos_originales)

tMayor $=$ obtenerValoresMayorMenor 
tMenor = obtenerValoresMayorMenor

hMayor = obtenerValoresMayorMenor

hMenor = obtenerValoresMayorMenor

CREAR parte1

CREAR parte2

PARA i=1 HASTA tamaño(al) CON INCREMENTO +1

$\mathrm{d}=\mathrm{al}[\mathrm{i}]$

SI i $<$ tamaño(al)/2

$$
\text { parte } 1=\mathrm{d}
$$

SINO SI

$$
\text { parte } 2=d
$$

FINSI

FINPARA

escribirExcel (parte1)

escribirExcel (parte2)

escribirExcel (tMayor)

escribirExcel (tManor)

escribirExcel (hMayor)

escribirExcel (hMenor)

FIN 



\section{ANEXO 4}

\section{Resultados gráficos de las pruebas.}
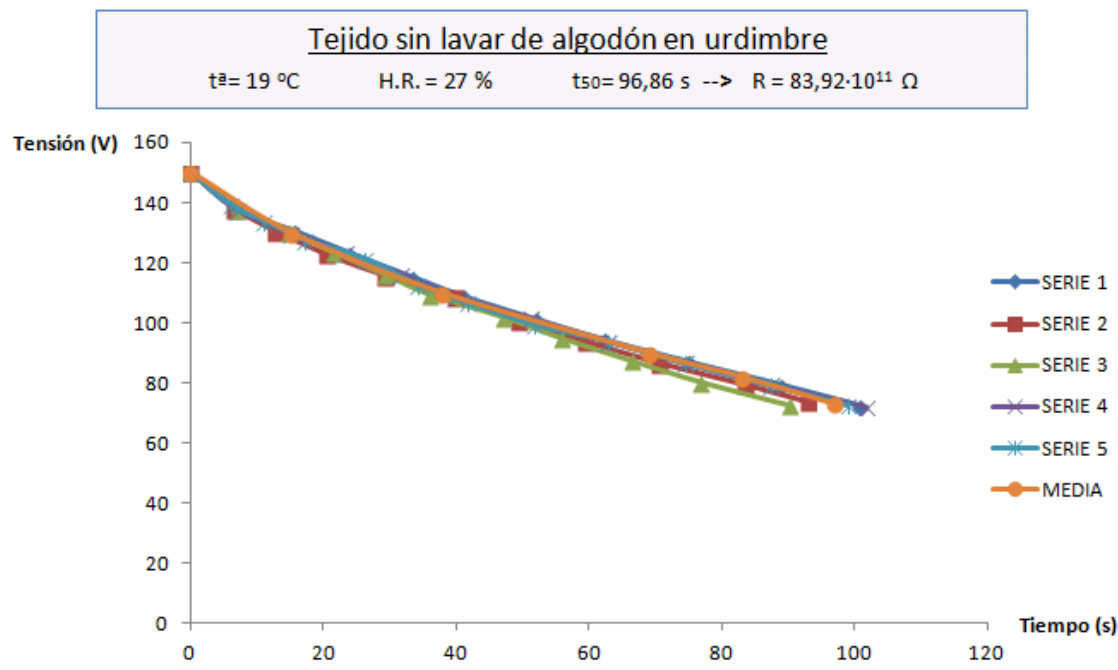

Figura Anexo 4. 1. Resultados finales del tejido de algodón sin lavar, por urdimbre, a una temperatura de $19^{\circ} \mathrm{C}$ y a $27 \%$ de H.R.

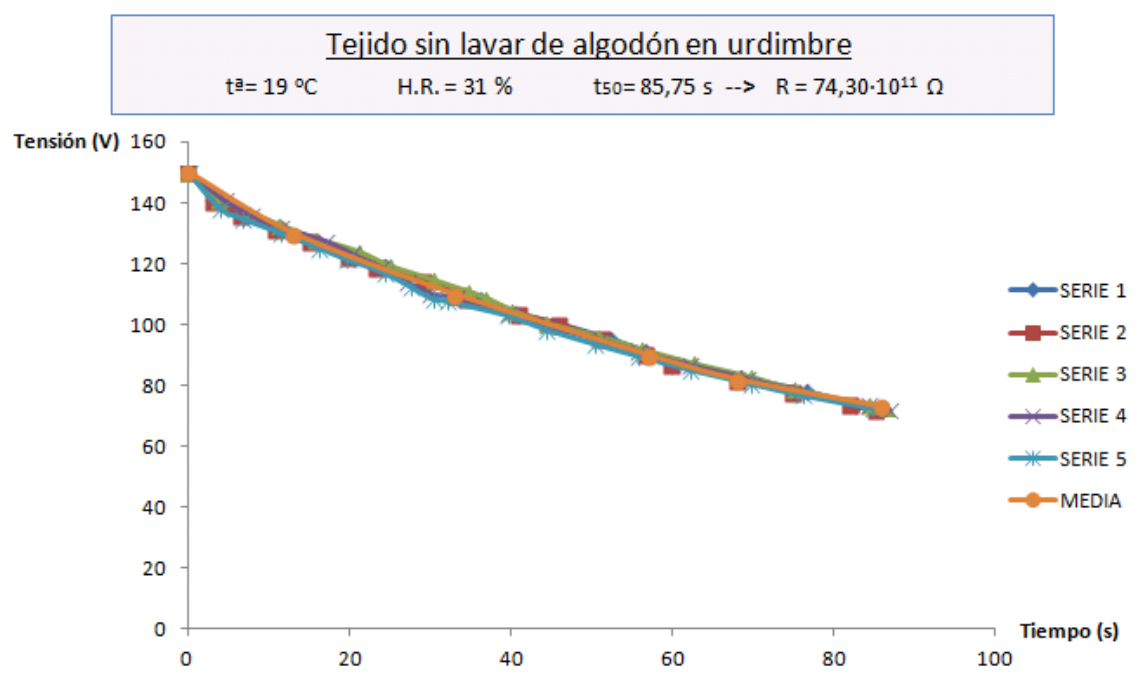

Figura Anexo 4. 2. Resultados finales del tejido de algodón sin lavar, por urdimbre, a una temperatura de $19^{\circ} \mathrm{C}$ y a $31 \%$ de H.R. 


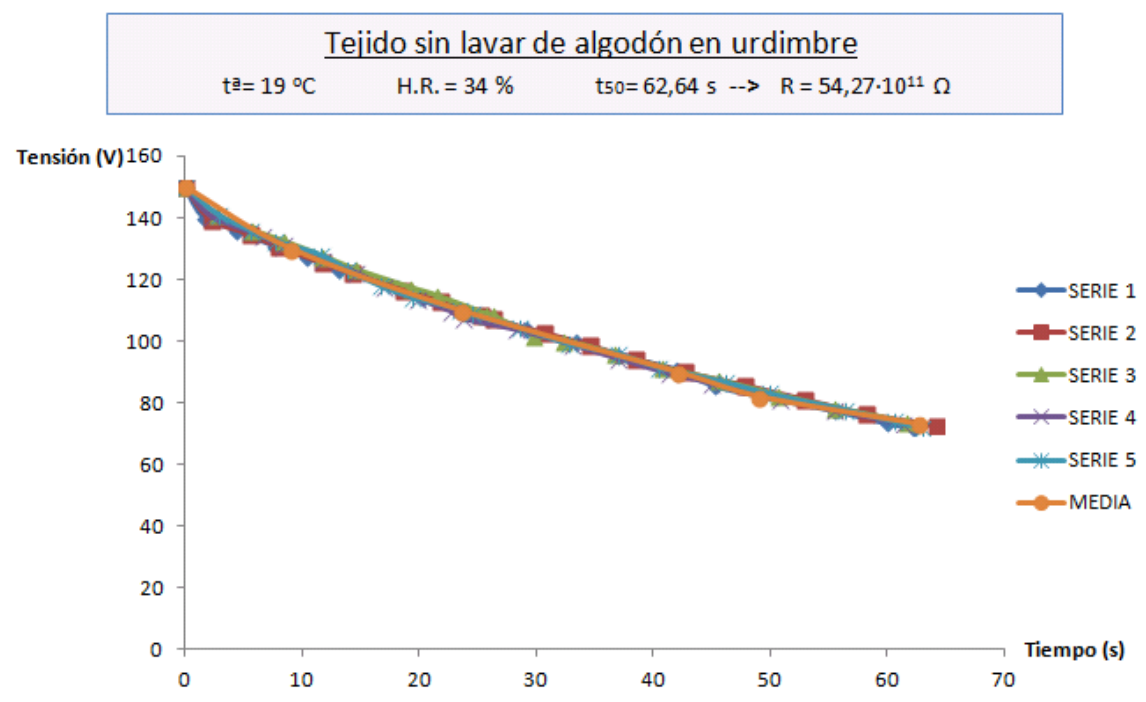

Figura Anexo 4. 3. Resultados finales del tejido de algodón sin lavar, por urdimbre, a una temperatura de $19^{\circ} \mathrm{C}$ y a $34 \%$ de H.R.

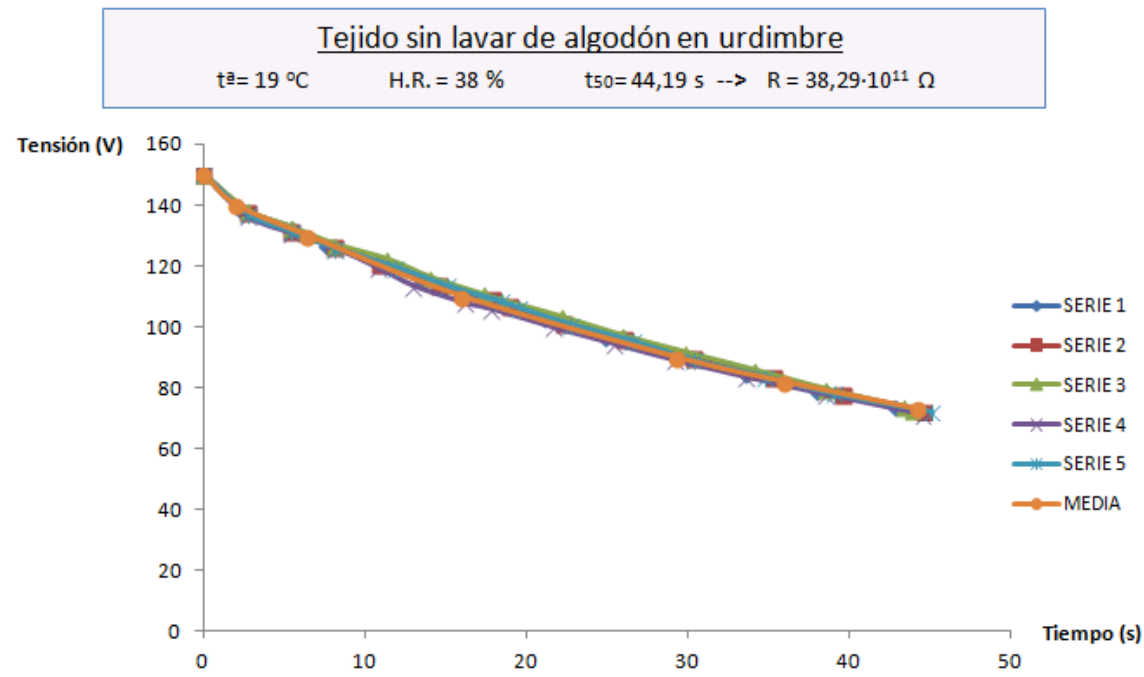

Figura Anexo 4. 4. Resultados finales del tejido de algodón sin lavar, por urdimbre, a una temperatura de $19^{\circ} \mathrm{C}$ y a $38 \%$ de H.R. 


\section{Tejido sin lavar de algodón en urdimbre}

$\mathrm{t}^{\mathrm{a}}=19^{\circ} \mathrm{C} \quad \mathrm{H} . \mathrm{R} .=42 \% \quad \mathrm{t} 50=37,68 \mathrm{~s} \rightarrow \mathrm{R}=32,65 \cdot 10^{11} \Omega$

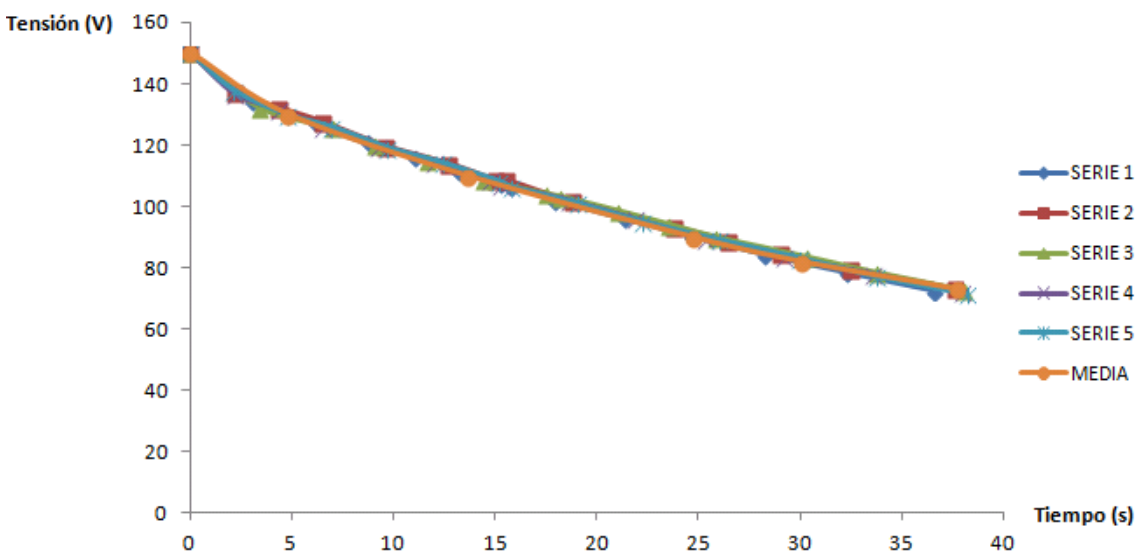

Figura Anexo 4. 5. Resultados finales del tejido de algodón sin lavar, por urdimbre, a una temperatura de $19^{\circ} \mathrm{C}$ y a $42 \%$ de H.R.

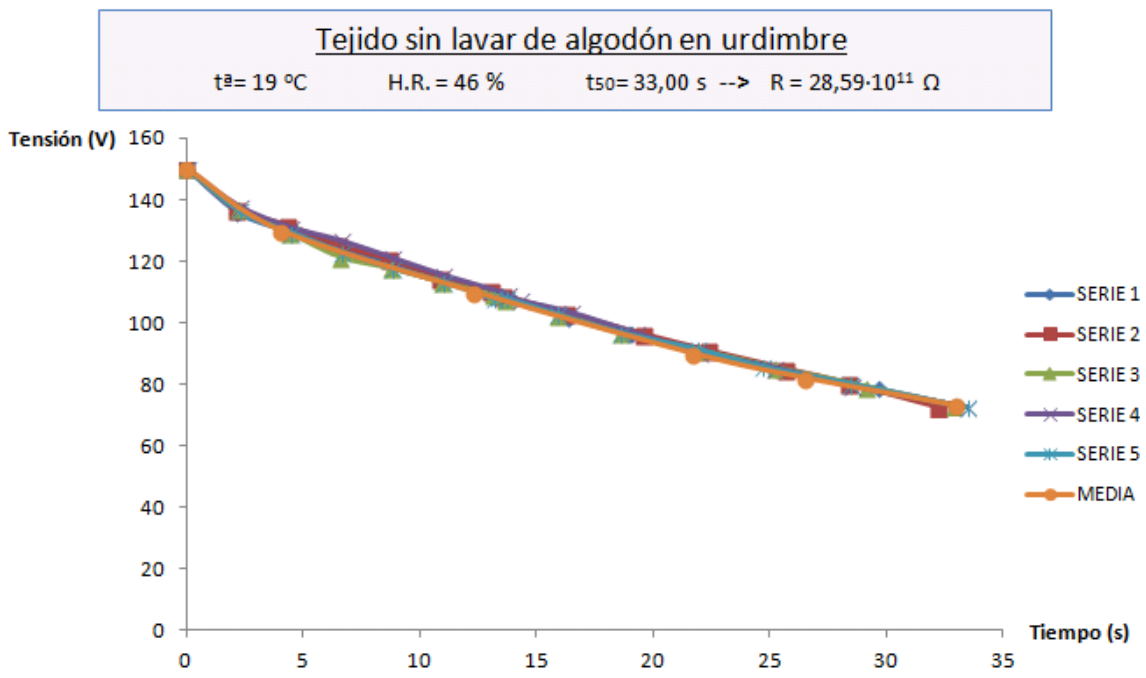

Figura Anexo 4. 6. Resultados finales del tejido de algodón sin lavar, por urdimbre, a una temperatura de $19^{\circ} \mathrm{C}$ y a $46 \%$ de H.R. 


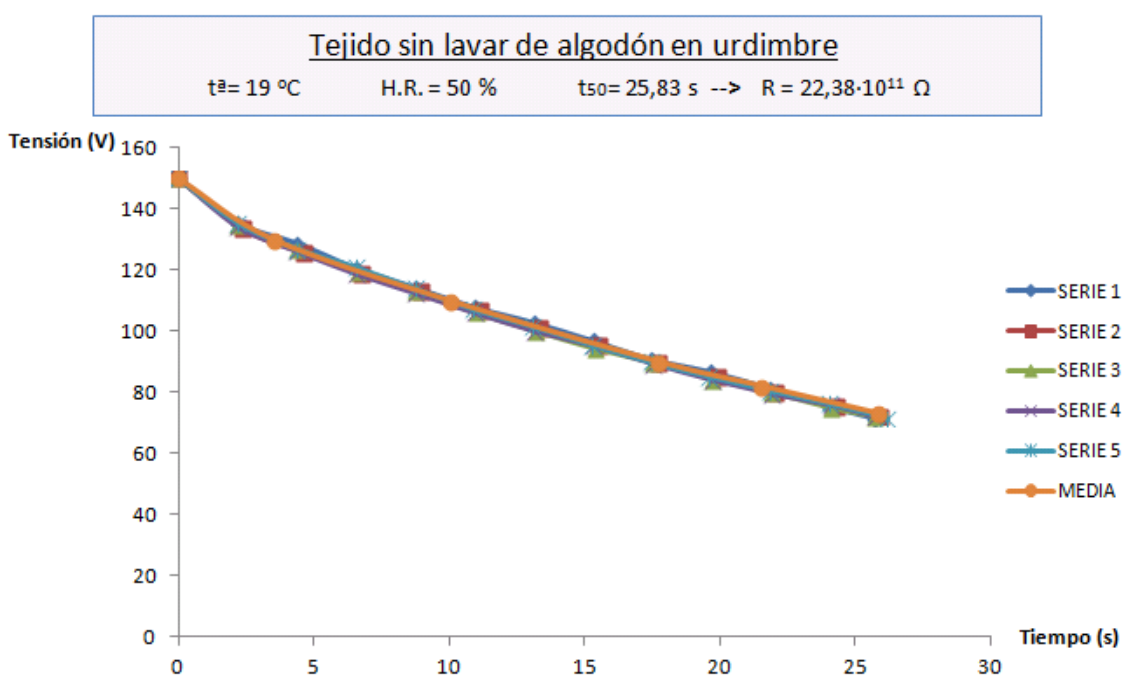

Figura Anexo 4. 7. Resultados finales del tejido de algodón sin lavar, por urdimbre, a una temperatura de $19^{\circ} \mathrm{C}$ y a $50 \%$ de H.R.

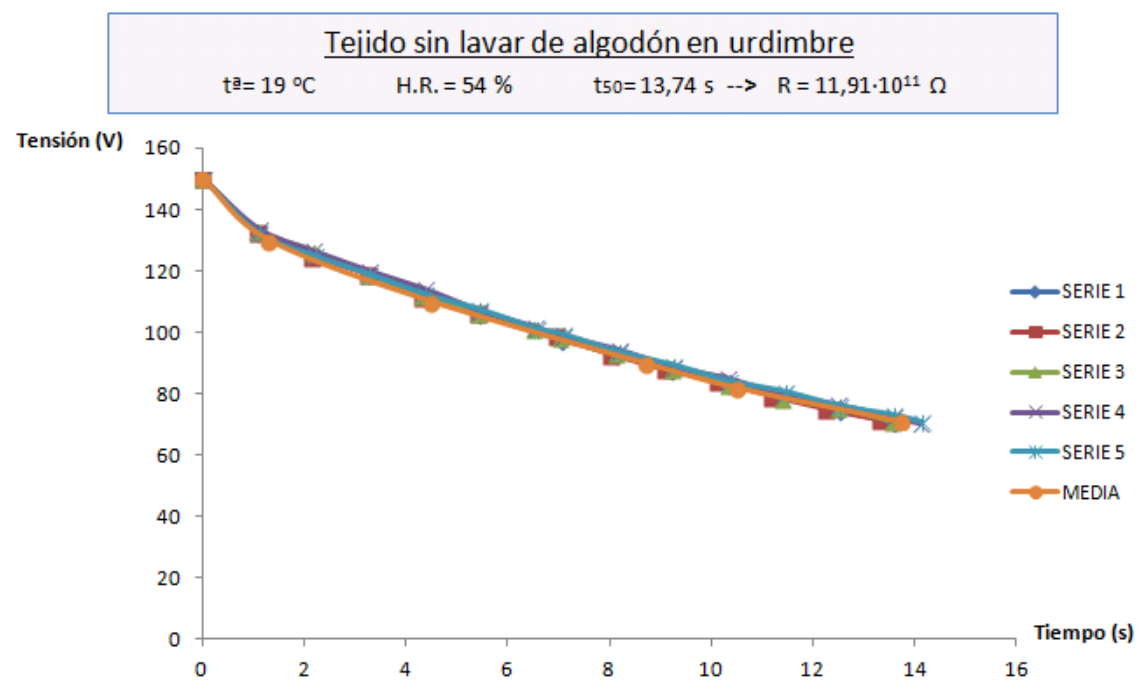

Figura Anexo 4. 8. Resultados finales del tejido de algodón sin lavar, por urdimbre, a una temperatura de $19^{\circ} \mathrm{C}$ y a $54 \%$ de H.R. 


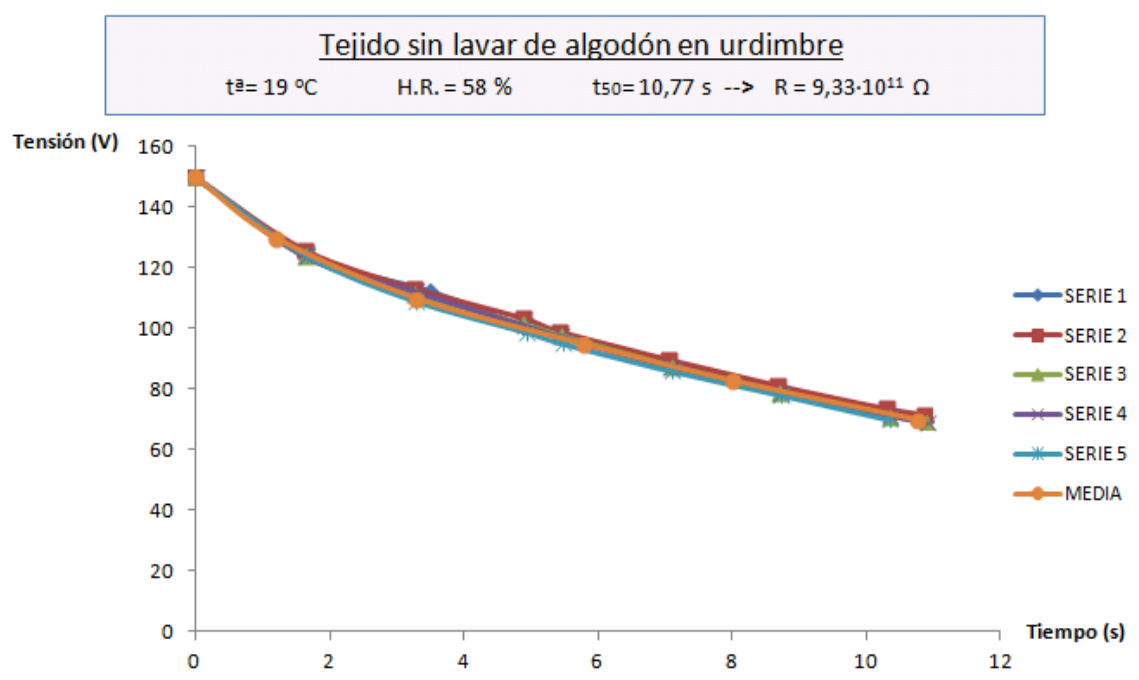

Figura Anexo 4. 9. Resultados finales del tejido de algodón sin lavar, por urdimbre, a una temperatura de $19^{\circ} \mathrm{C}$ y a $58 \%$ de H.R.

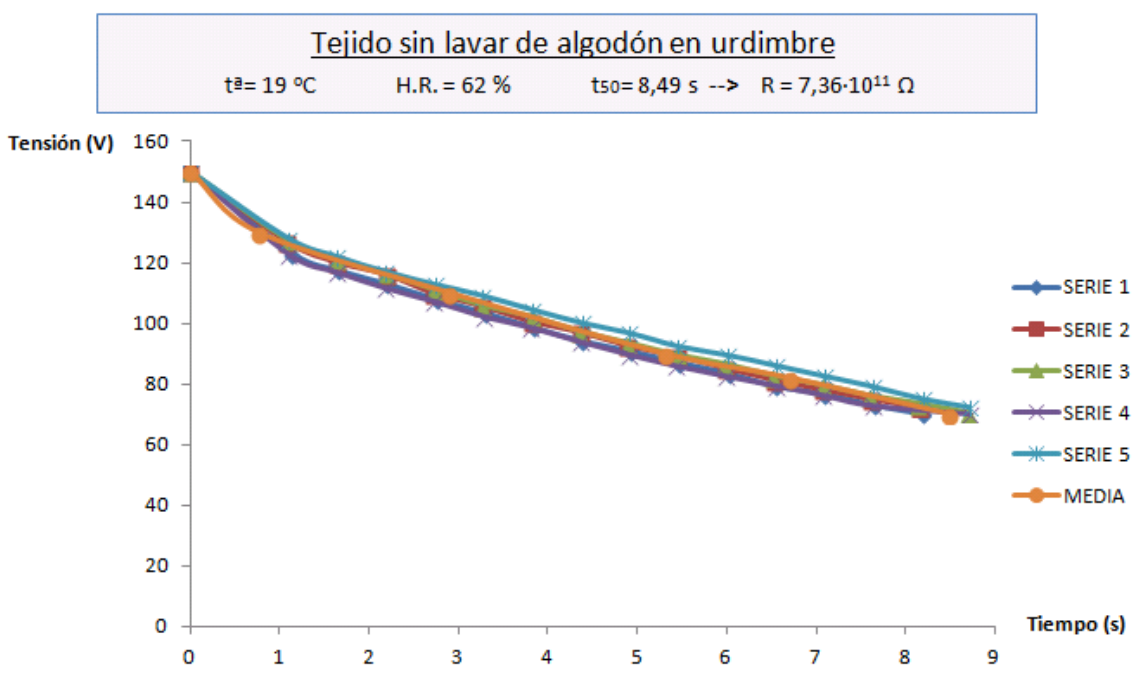

Figura Anexo 4. 10. Resultados finales del tejido de algodón sin lavar, por urdimbre, a una temperatura de $19^{\circ} \mathrm{C}$ y a $62 \%$ de H.R. 


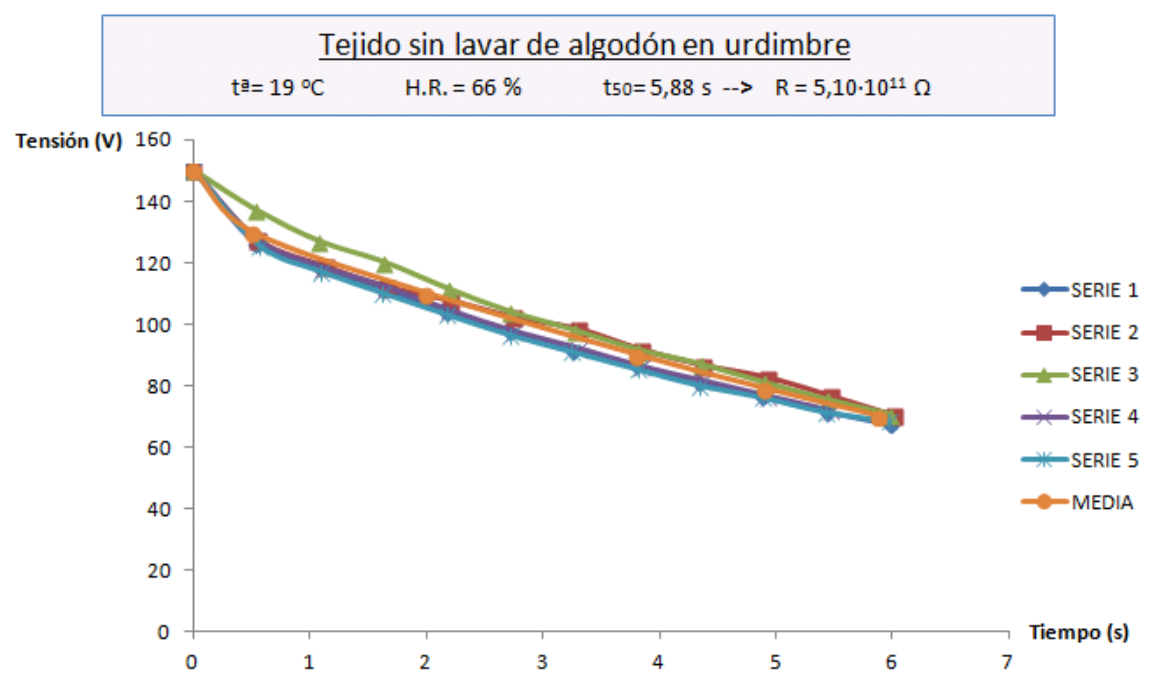

Figura Anexo 4. 11. Resultados finales del tejido de algodón sin lavar, por urdimbre, a una temperatura de $19^{\circ} \mathrm{C}$ y a $66 \%$ de H.R.

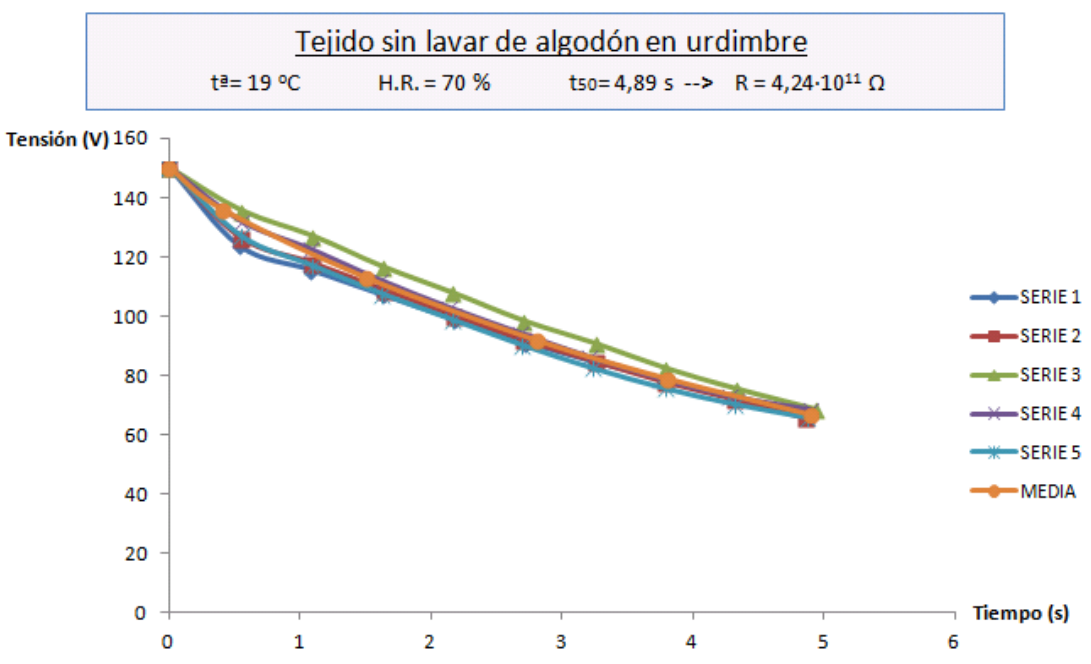

Figura Anexo 4. 12. Resultados finales del tejido de algodón sin lavar, por urdimbre, a una temperatura de $19^{\circ} \mathrm{C}$ y a $70 \%$ de H.R. 


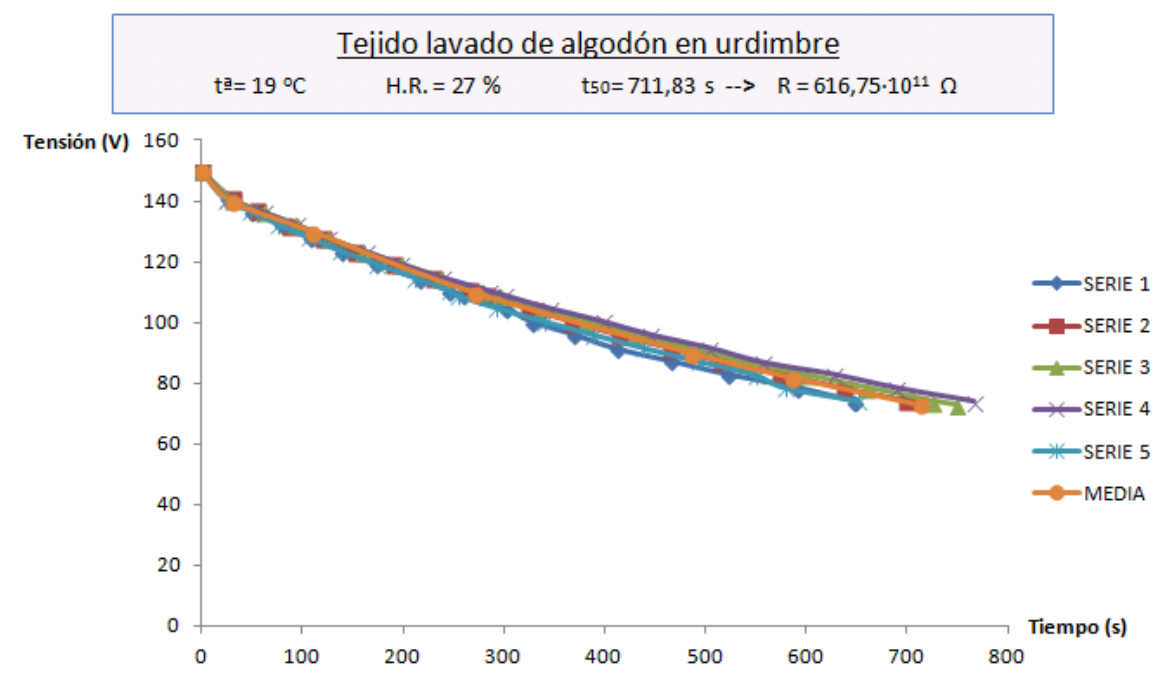

Figura Anexo 4. 13. Resultados finales del tejido de algodón lavado, por urdimbre, a una temperatura de $19^{\circ} \mathrm{C}$ y a $27 \%$ de H.R.

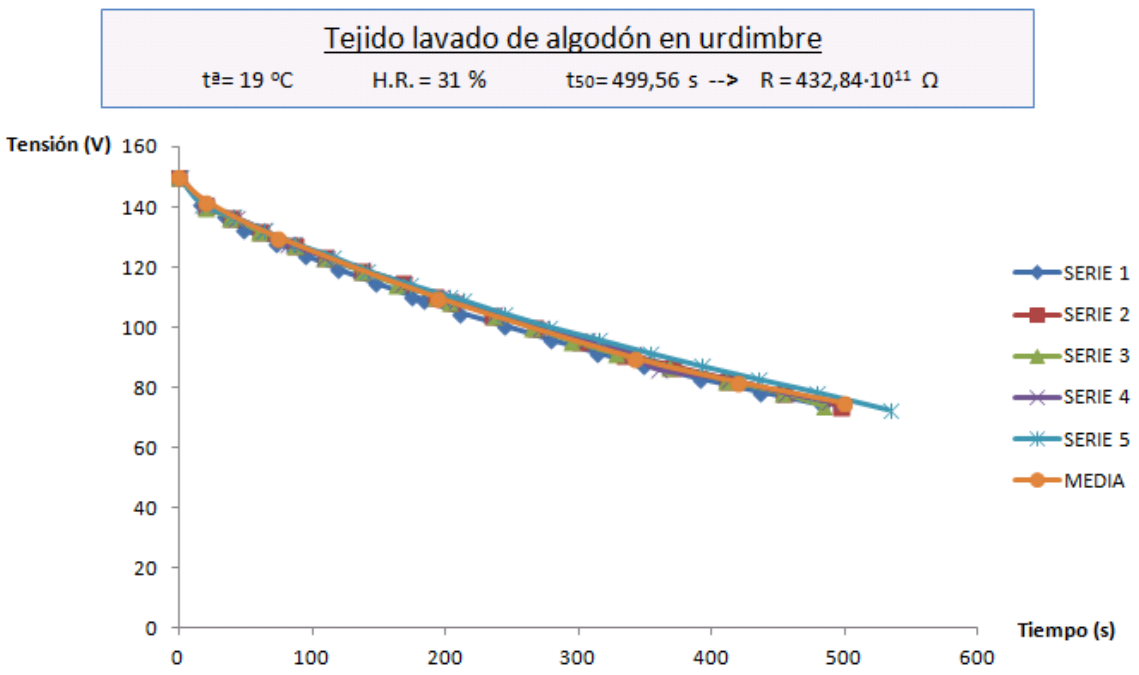

Figura Anexo 4. 14. Resultados finales del tejido de algodón lavado, por urdimbre, a una temperatura de $19^{\circ} \mathrm{C}$ y a $31 \%$ de H.R. 


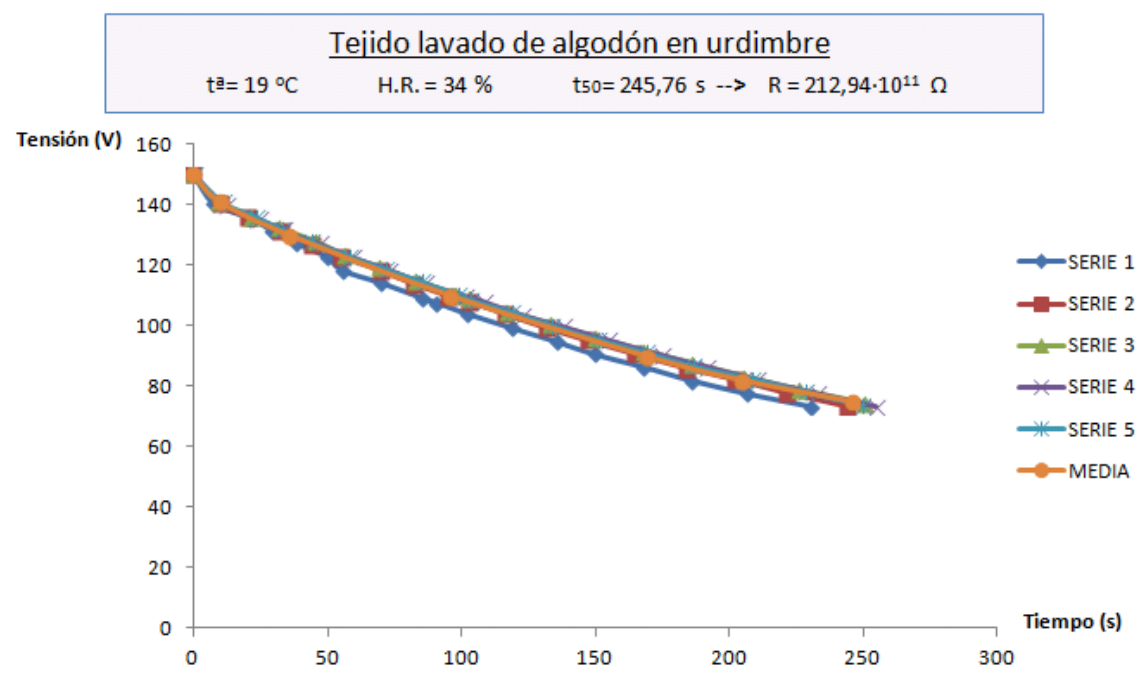

Figura Anexo 4. 15. Resultados finales del tejido de algodón lavado, por urdimbre, a una temperatura de $19^{\circ} \mathrm{C}$ y a $34 \%$ de H.R.

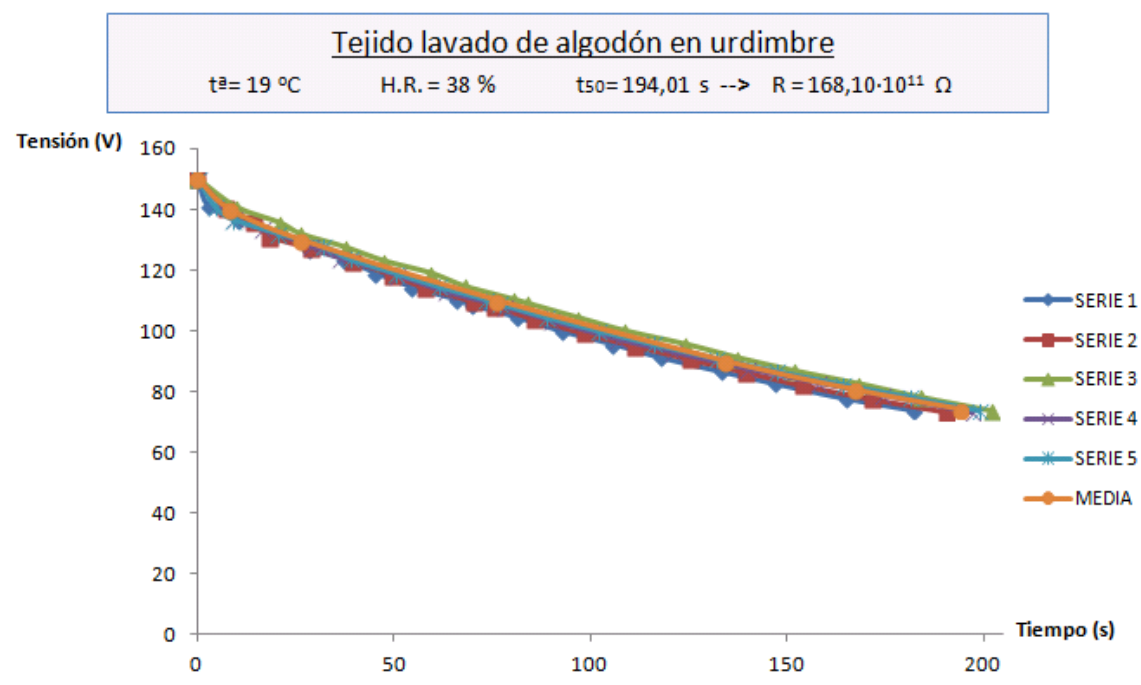

Figura Anexo 4. 16. Resultados finales del tejido de algodón lavado, por urdimbre, a una temperatura de $19^{\circ} \mathrm{C}$ y a $38 \%$ de H.R. 


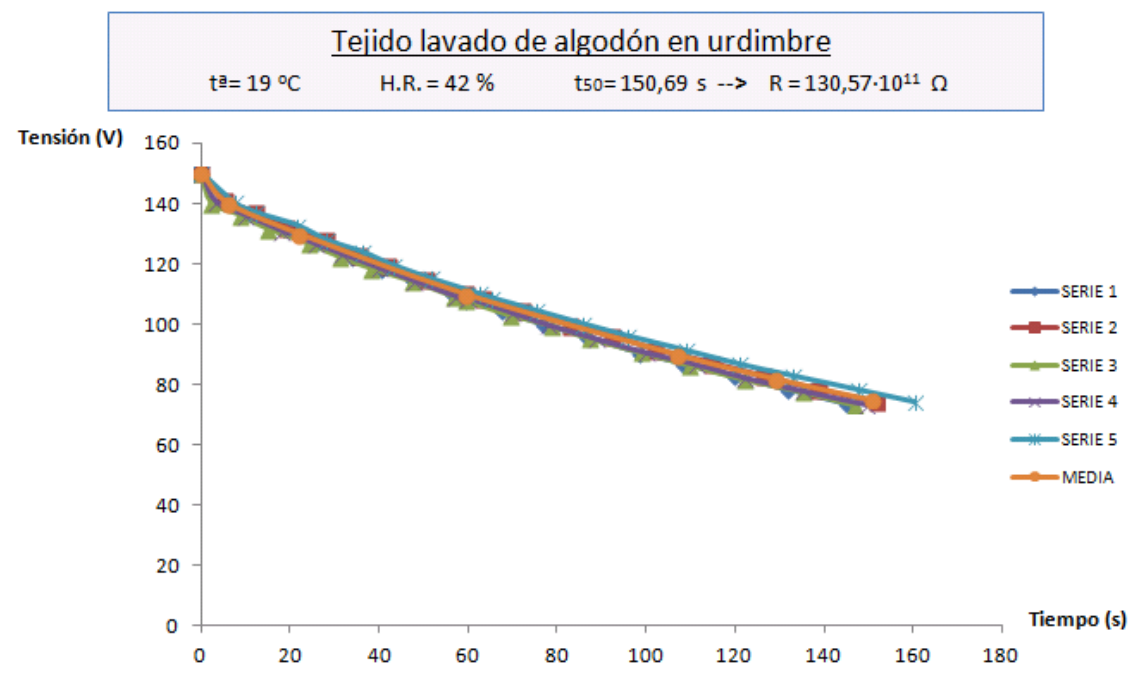

Figura Anexo 4. 17. Resultados finales del tejido de algodón lavado, por urdimbre, a una temperatura de $19^{\circ} \mathrm{C}$ y a $42 \%$ de H.R.

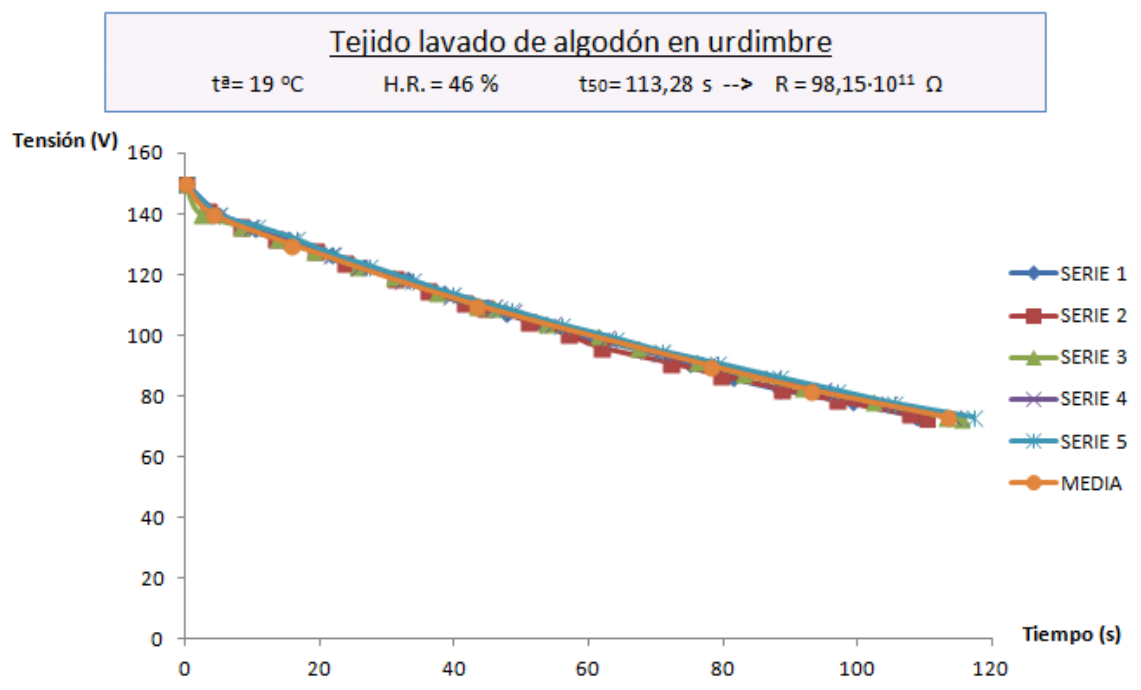

Figura Anexo 4. 18. Resultados finales del tejido de algodón lavado, por urdimbre, a una temperatura de $19^{\circ} \mathrm{C}$ y a $46 \%$ de H.R. 


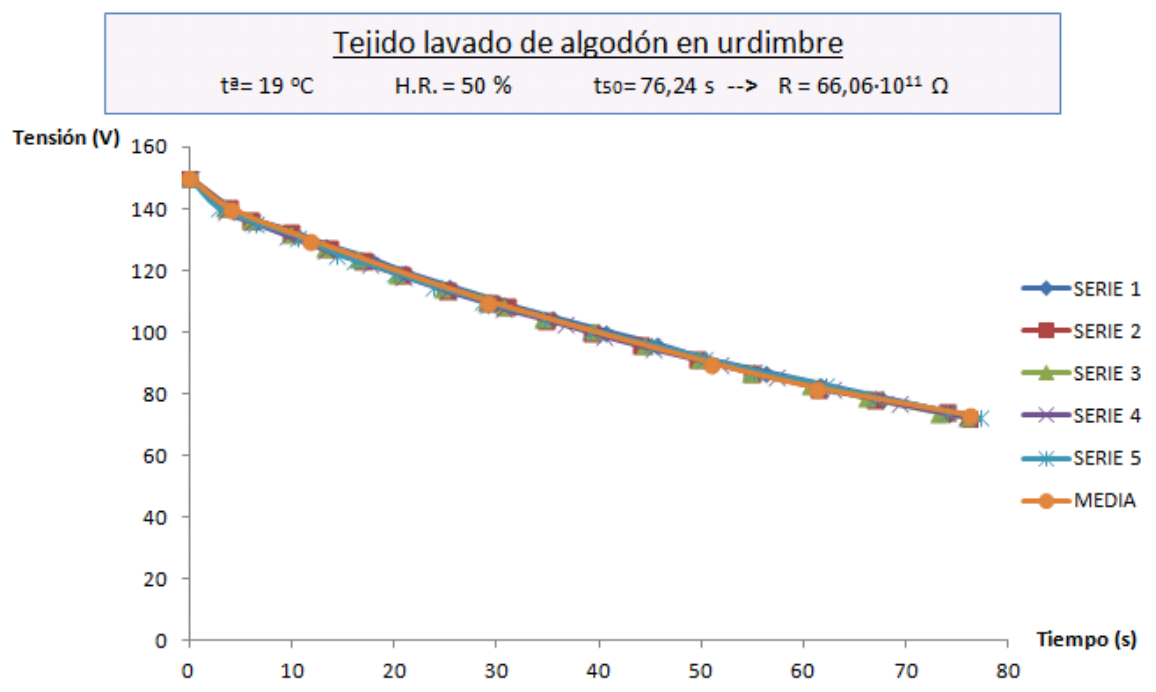

Figura Anexo 4. 19. Resultados finales del tejido de algodón lavado, por urdimbre, a una temperatura de $19^{\circ} \mathrm{C}$ y a $50 \%$ de H.R.

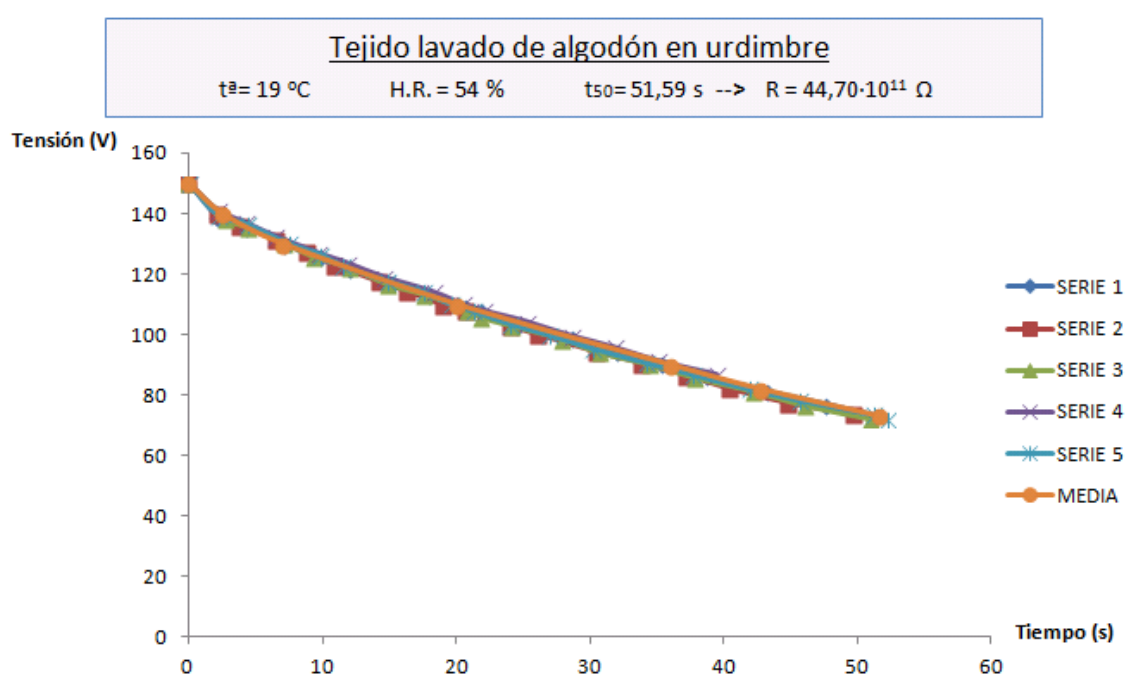

Figura Anexo 4. 20. Resultados finales del tejido de algodón lavado, por urdimbre, a una temperatura de $19^{\circ} \mathrm{C}$ y a $54 \%$ de H.R. 


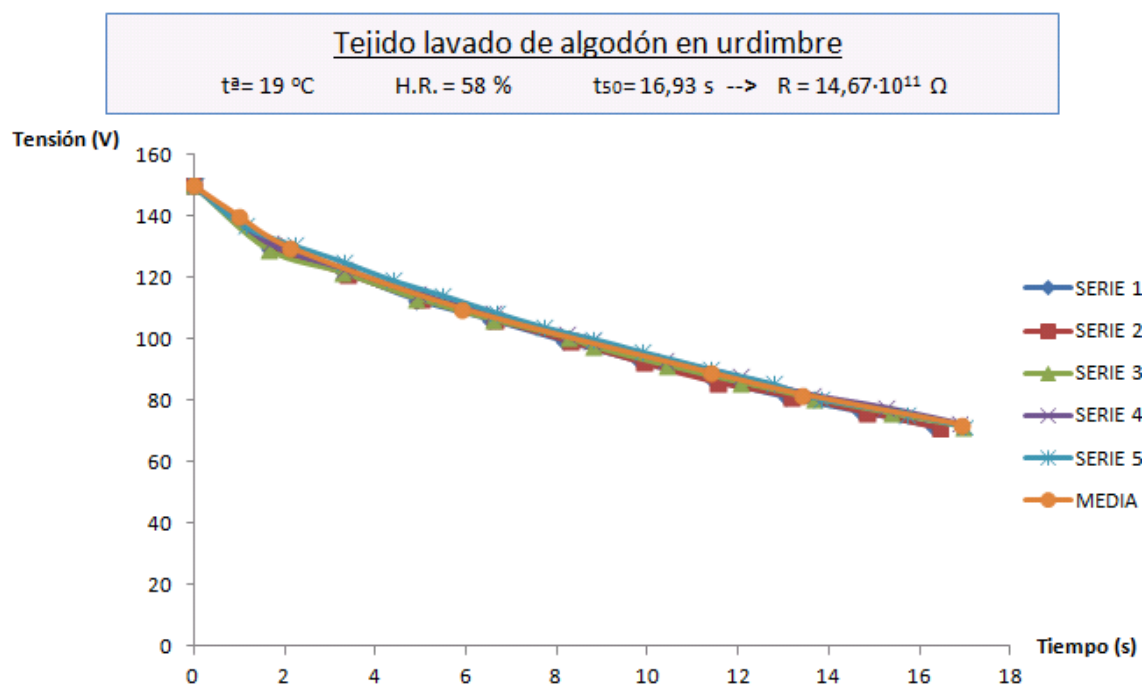

Figura Anexo 4. 21. Resultados finales del tejido de algodón lavado, por urdimbre, a una temperatura de $19^{\circ} \mathrm{C}$ y a $58 \%$ de H.R.

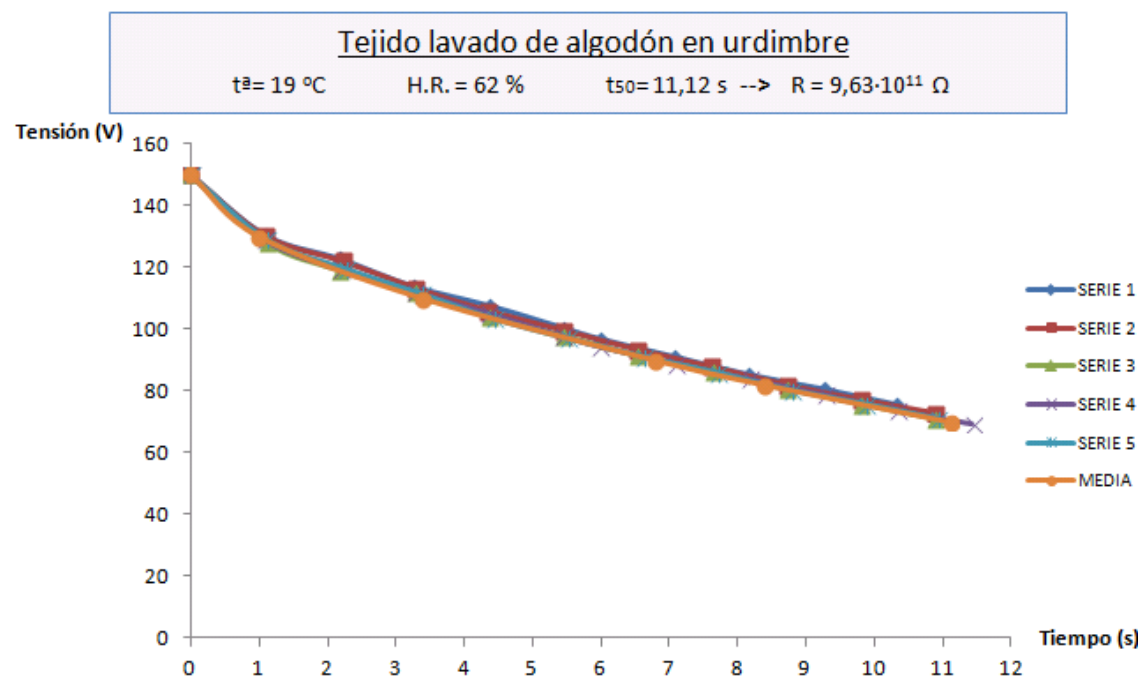

Figura Anexo 4. 22. Resultados finales del tejido de algodón lavado, por urdimbre, a una temperatura de $19^{\circ} \mathrm{C}$ y a $62 \%$ de H.R. 


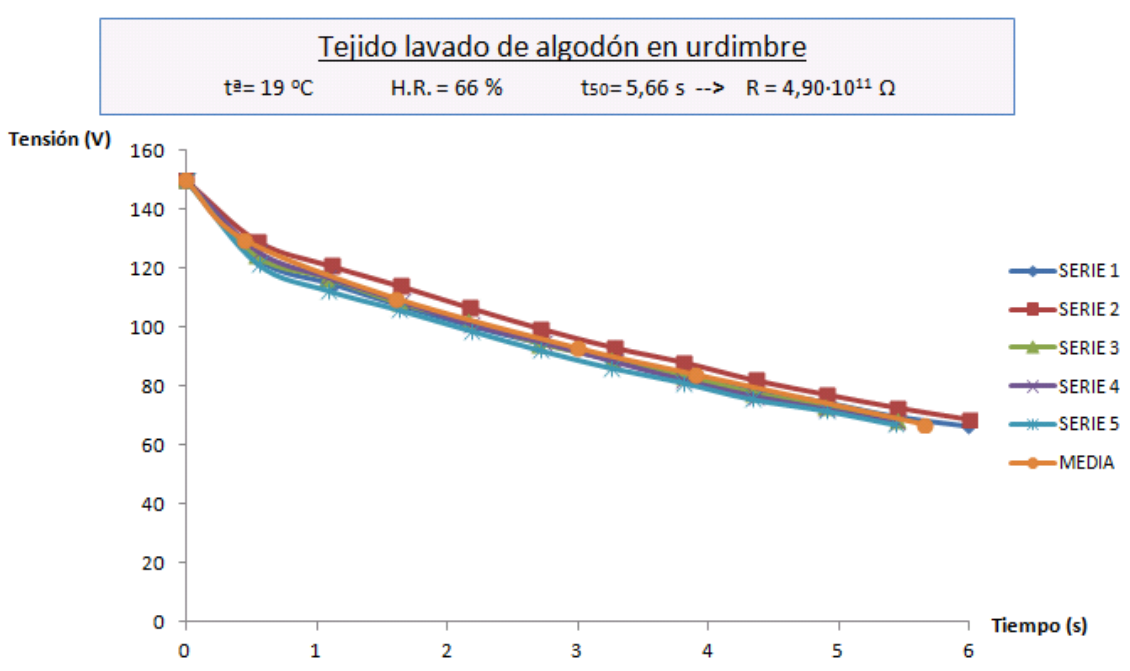

Figura Anexo 4. 23. Resultados finales del tejido de algodón lavado, por urdimbre, a una temperatura de $19^{\circ} \mathrm{C}$ y a $66 \%$ de H.R.

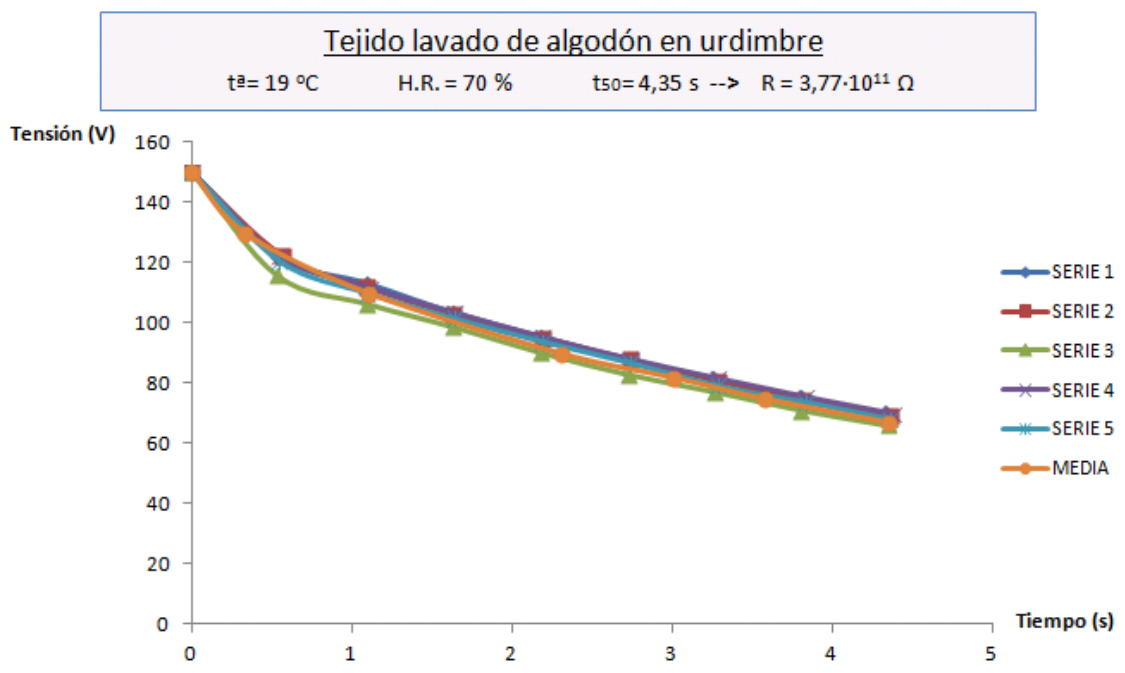

Figura Anexo 4. 24. Resultados finales del tejido de algodón lavado, por urdimbre, a una temperatura de $19^{\circ} \mathrm{C}$ y a $70 \%$ de H.R. 


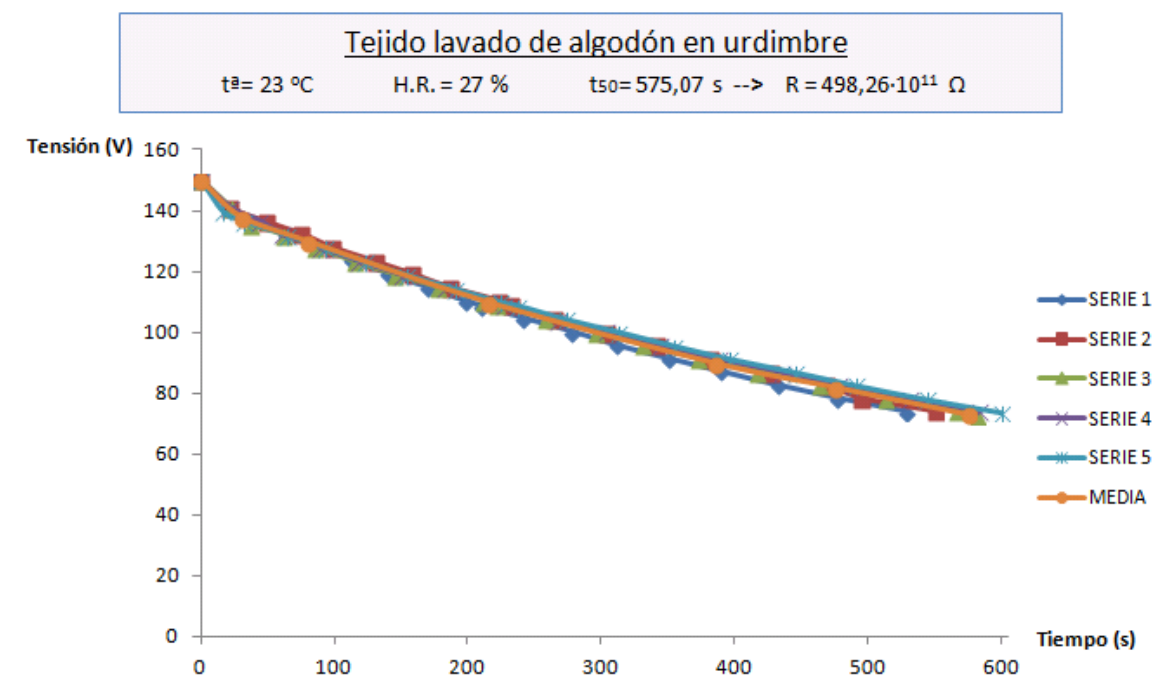

Figura Anexo 4. 25. Resultados finales del tejido de algodón lavado, por urdimbre, a una temperatura de $23{ }^{\circ} \mathrm{C}$ y a $27 \%$ de H.R.

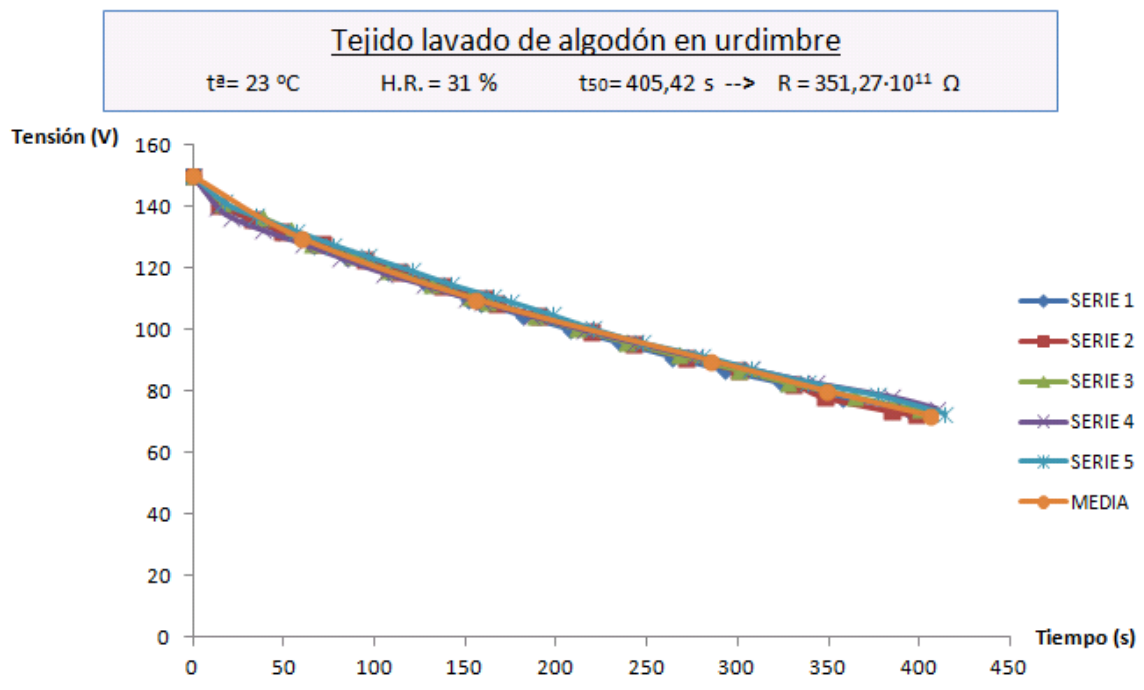

Figura Anexo 4. 26. Resultados finales del tejido de algodón lavado, por urdimbre, a una temperatura de $23{ }^{\circ} \mathrm{C}$ y a $31 \%$ de H.R. 


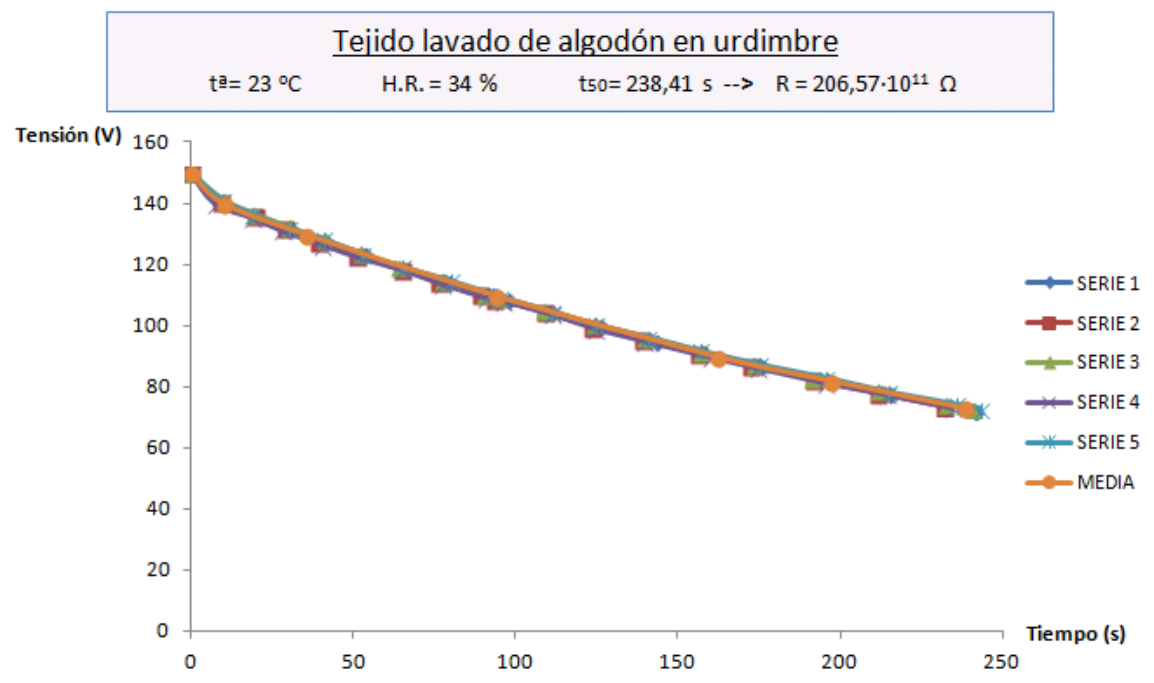

Figura Anexo 4. 27. Resultados finales del tejido de algodón lavado, por urdimbre, a una temperatura de $23{ }^{\circ} \mathrm{C}$ y a $34 \%$ de H.R.

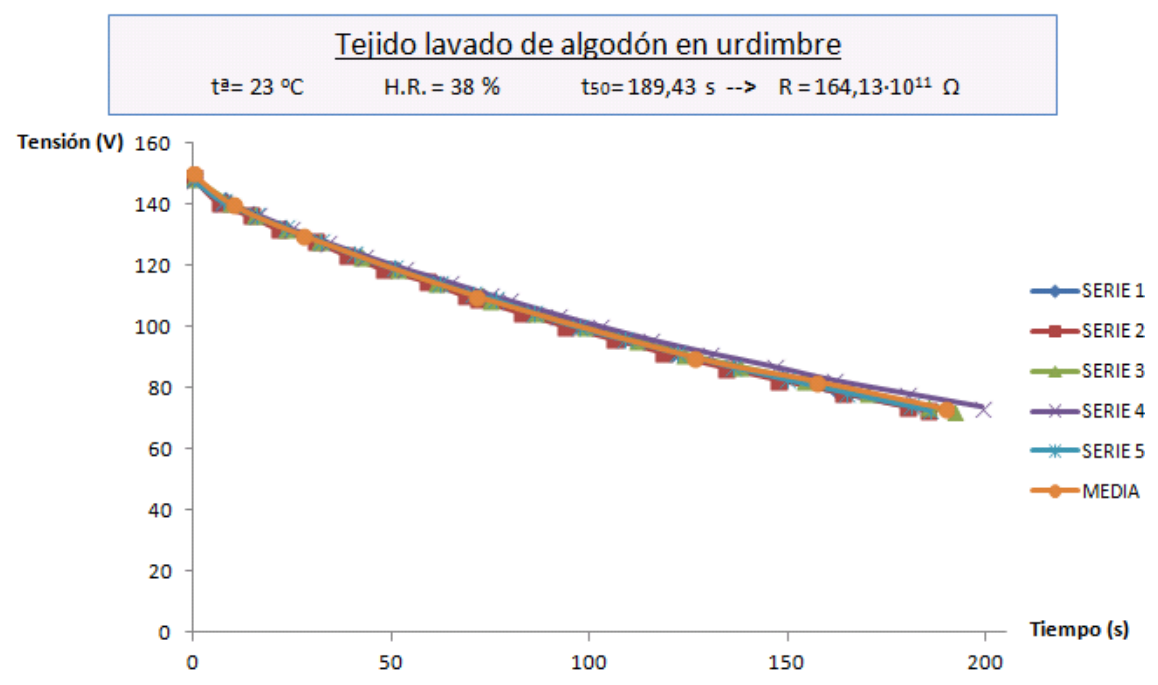

Figura Anexo 4. 28. Resultados finales del tejido de algodón lavado, por urdimbre, a una temperatura de $23{ }^{\circ} \mathrm{C}$ y a $38 \%$ de H.R. 


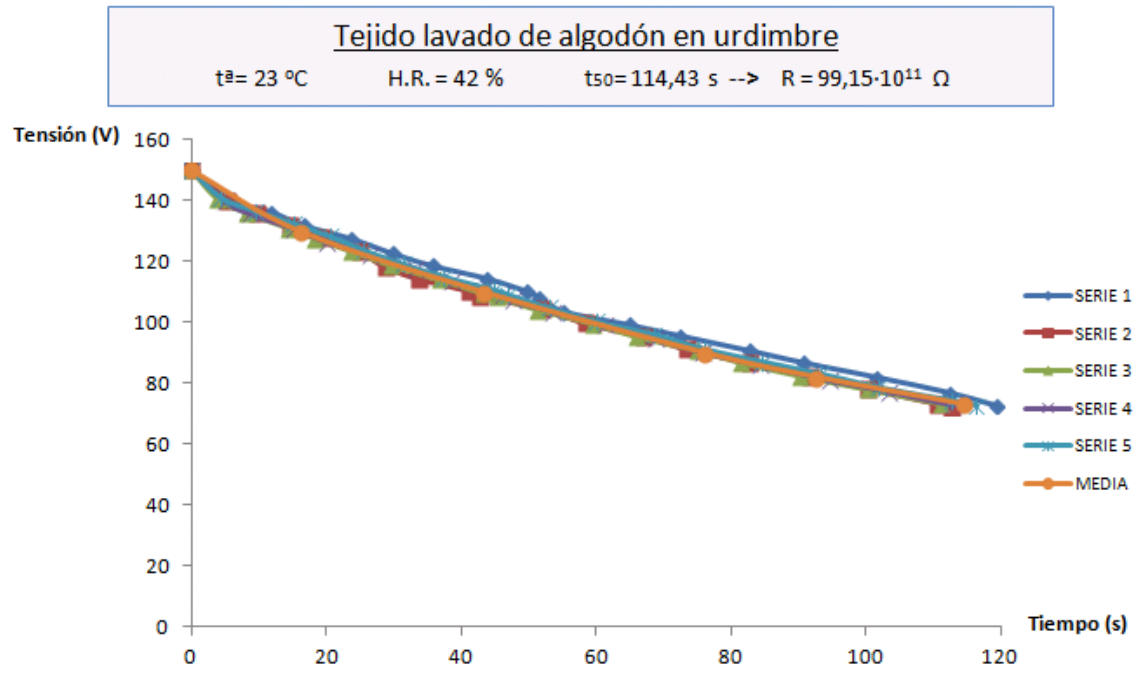

Figura Anexo 4. 29. Resultados finales del tejido de algodón lavado, por urdimbre, a una temperatura de $23{ }^{\circ} \mathrm{C}$ y a $42 \%$ de H.R.

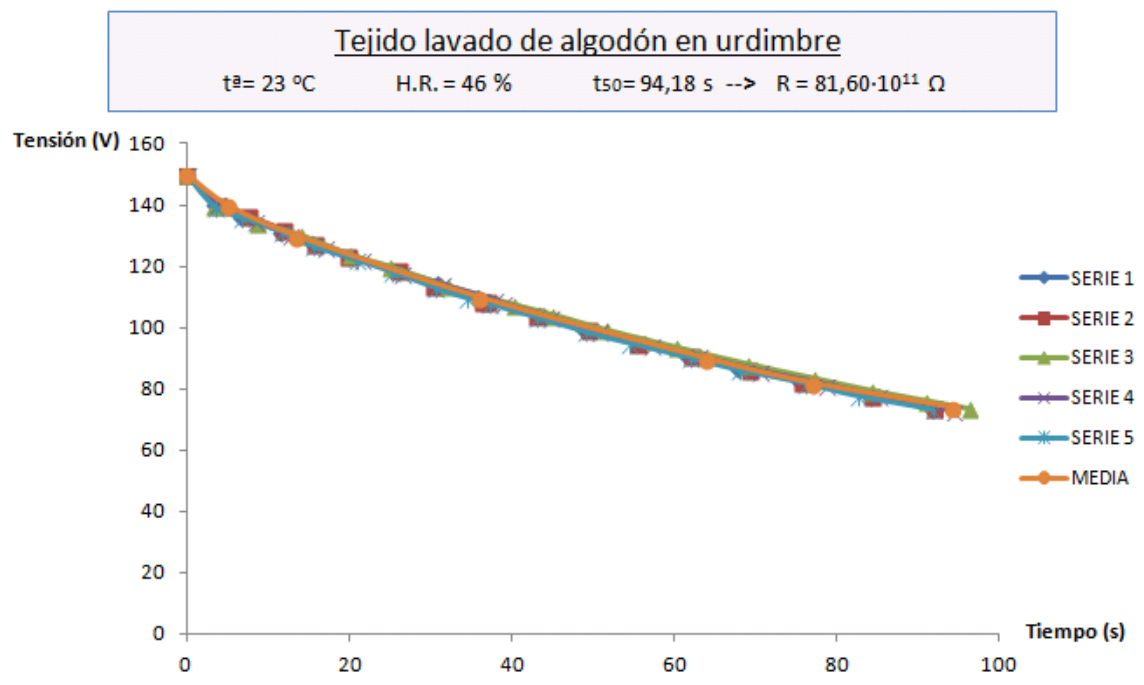

Figura Anexo 4. 30. Resultados finales del tejido de algodón lavado, por urdimbre, a una temperatura de $23{ }^{\circ} \mathrm{C}$ y a $46 \%$ de H.R. 


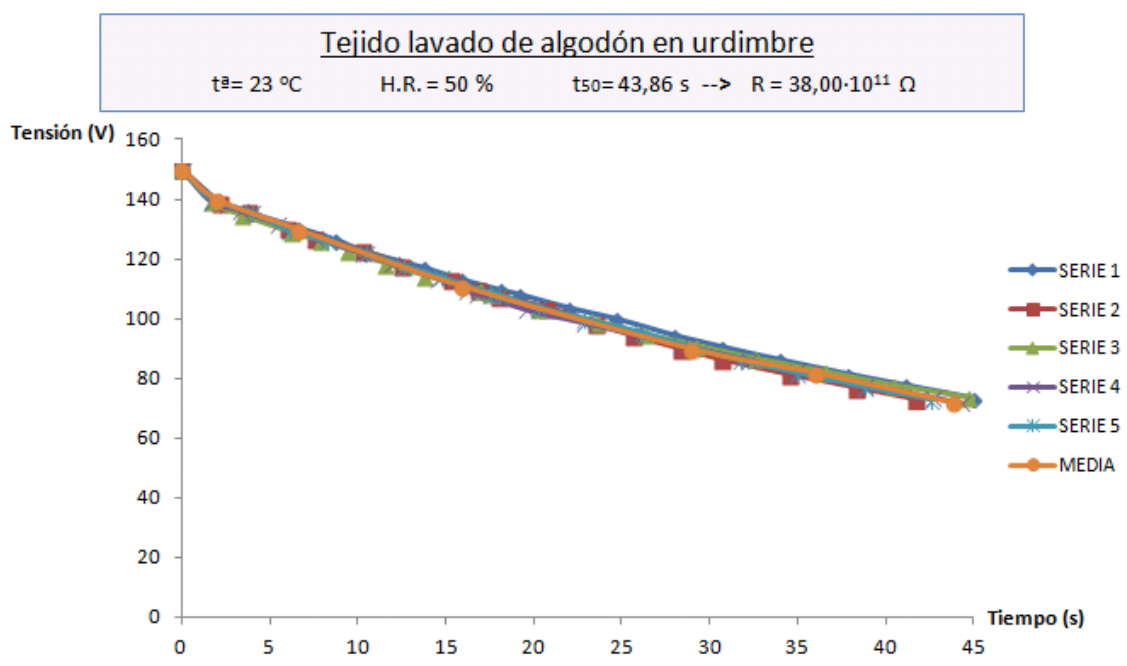

Figura Anexo 4. 31. Resultados finales del tejido de algodón lavado, por urdimbre, a una temperatura de $23{ }^{\circ} \mathrm{C}$ y a $50 \%$ de H.R.

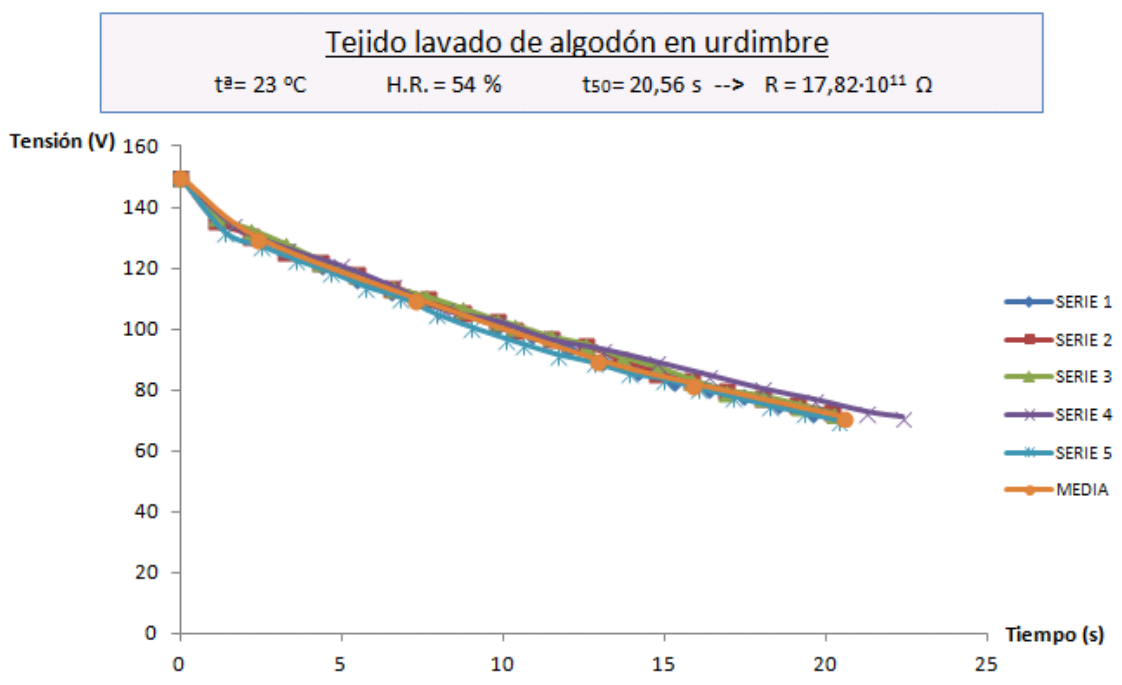

Figura Anexo 4. 32. Resultados finales del tejido de algodón lavado, por urdimbre, a una temperatura de $23{ }^{\circ} \mathrm{C}$ y a $54 \%$ de H.R. 


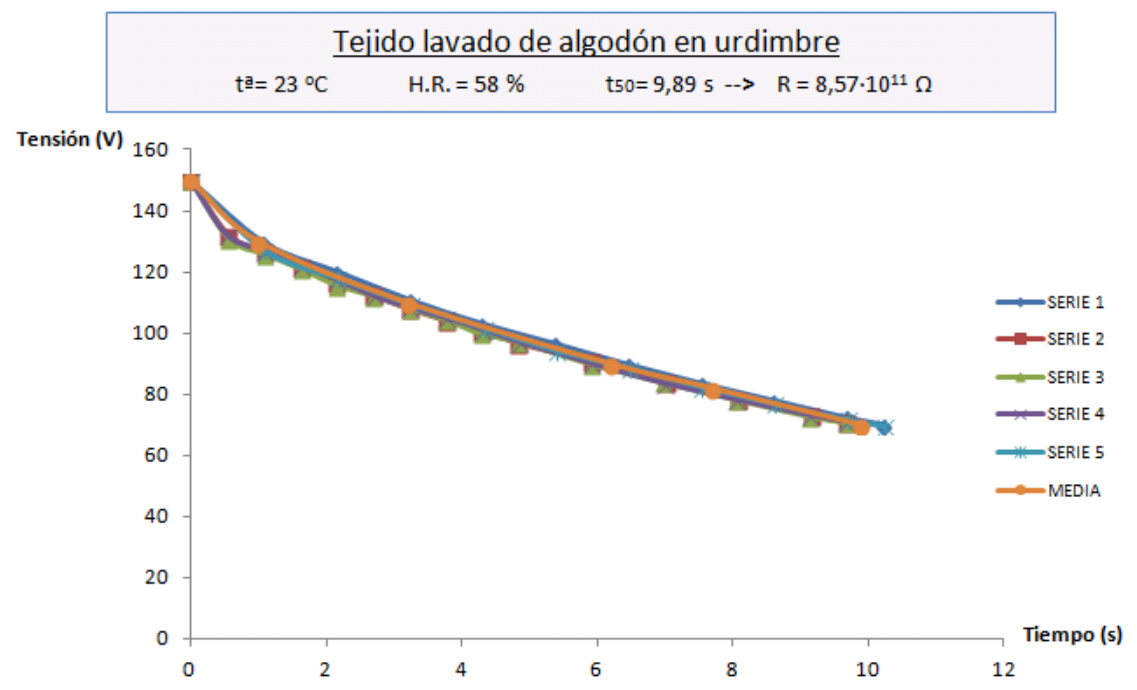

Figura Anexo 4. 33. Resultados finales del tejido de algodón lavado, por urdimbre, a una temperatura de $23{ }^{\circ} \mathrm{C}$ y a $58 \%$ de H.R.

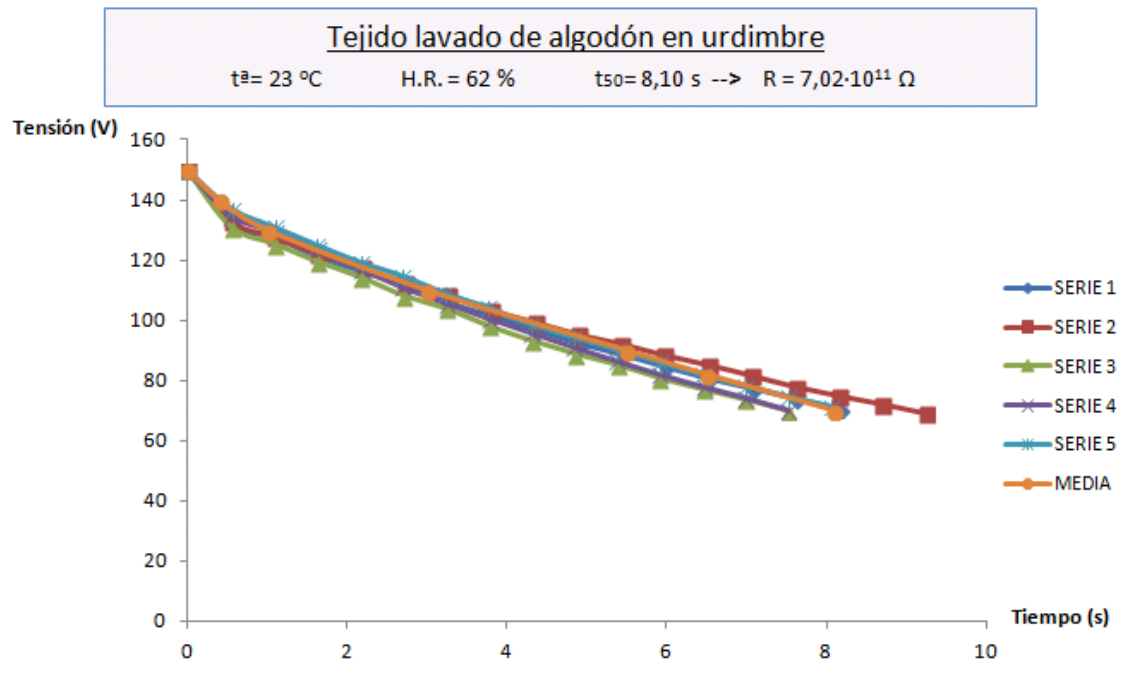

Figura Anexo 4. 34. Resultados finales del tejido de algodón lavado, por urdimbre, a una temperatura de $23{ }^{\circ} \mathrm{C}$ y a $62 \%$ de H.R. 


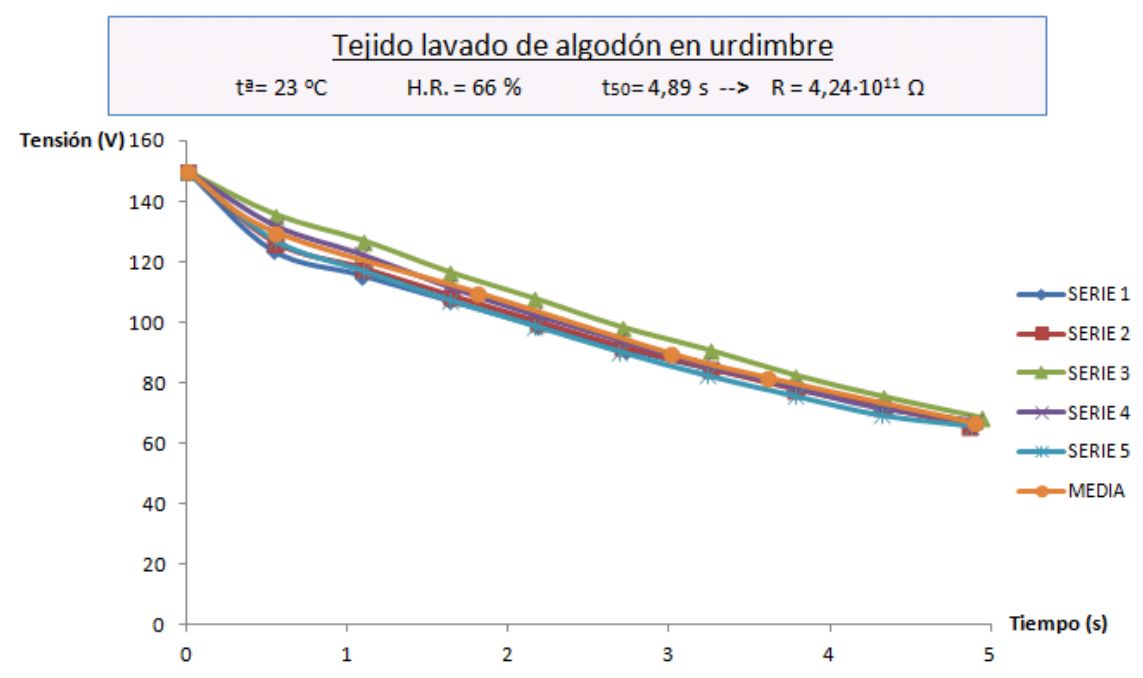

Figura Anexo 4. 35. Resultados finales del tejido de algodón lavado, por urdimbre, a una temperatura de $23{ }^{\circ} \mathrm{C}$ y a $66 \%$ de H.R.

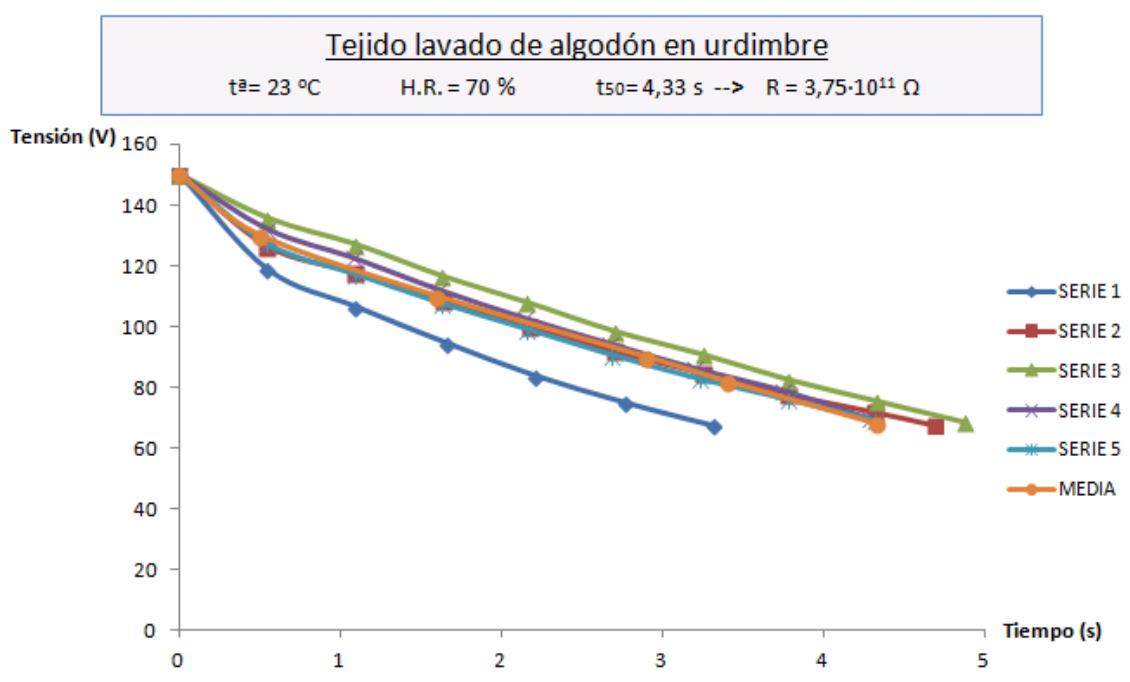

Figura Anexo 4. 36. Resultados finales del tejido de algodón lavado, por urdimbre, a una temperatura de $23{ }^{\circ} \mathrm{C}$ y a $70 \%$ de H.R. 


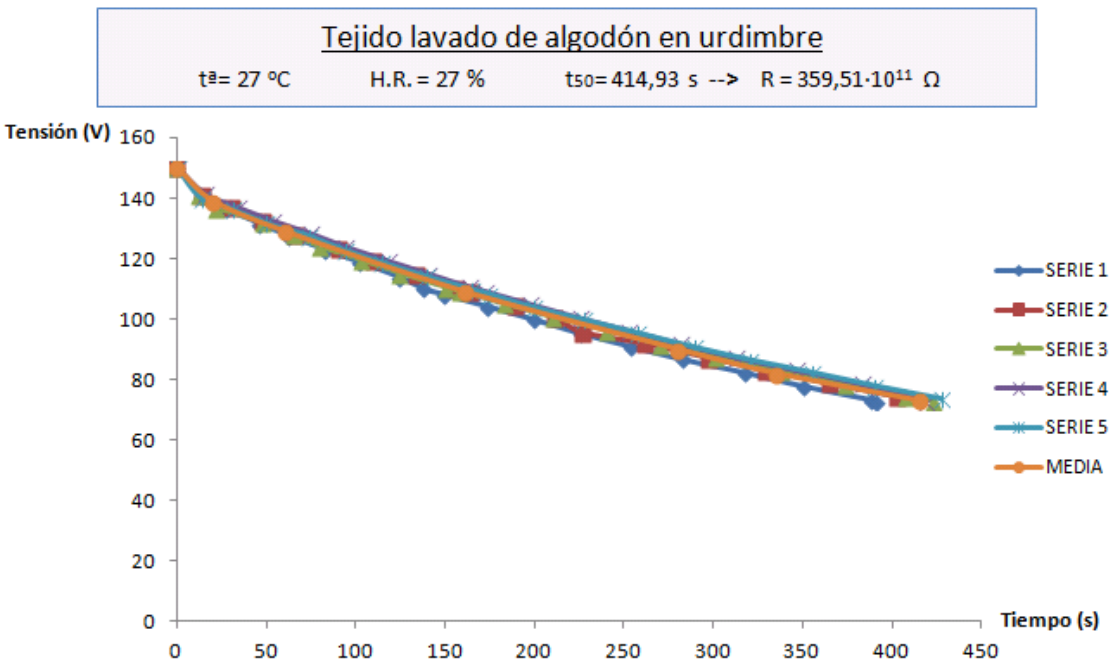

Figura Anexo 4. 37. Resultados finales del tejido de algodón lavado, por urdimbre, a una temperatura de $27^{\circ} \mathrm{C}$ y a $27 \%$ de H.R.

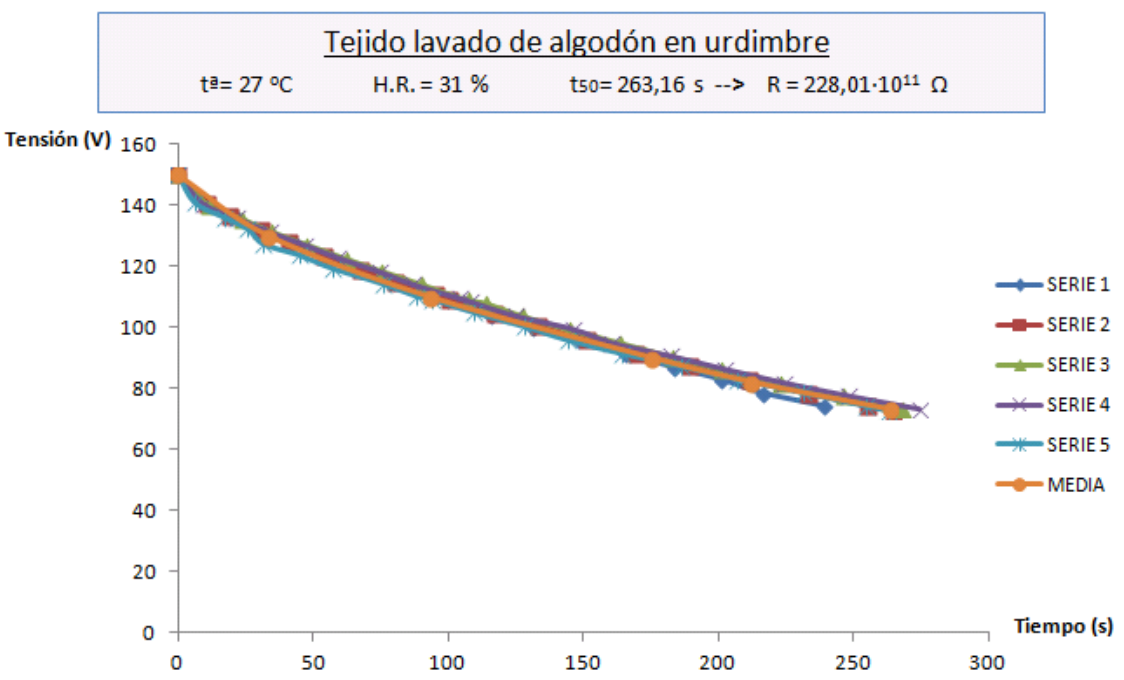

Figura Anexo 4. 38. Resultados finales del tejido de algodón lavado, por urdimbre, a una temperatura de $27^{\circ} \mathrm{C}$ y a $31 \%$ de H.R. 


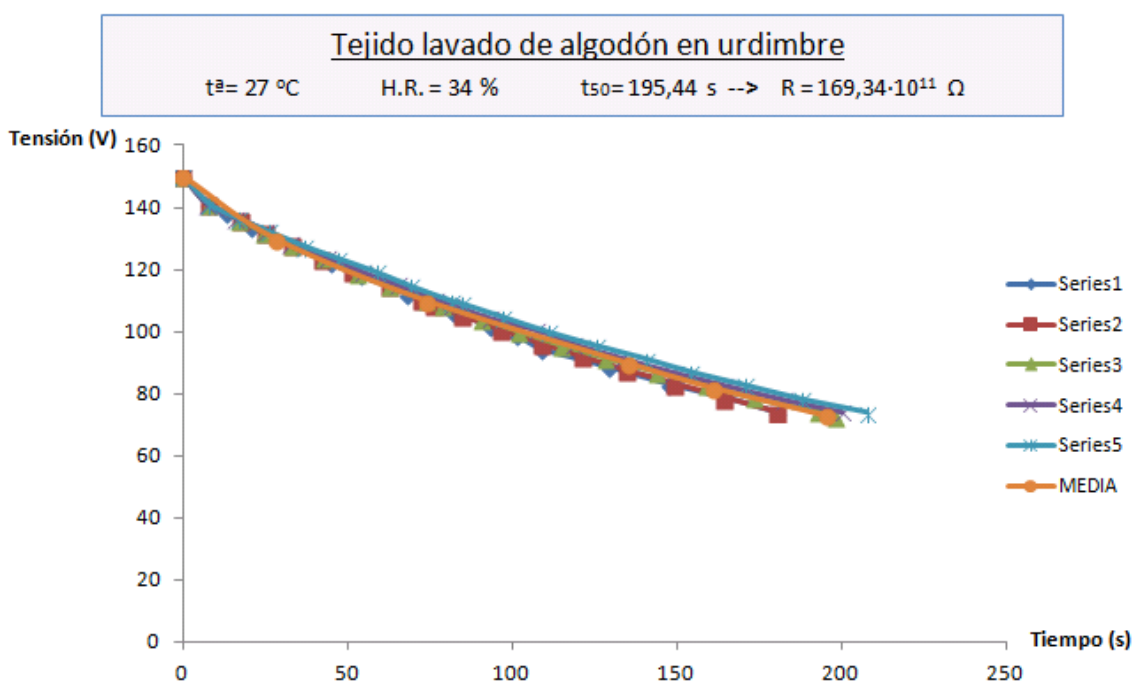

Figura Anexo 4. 39. Resultados finales del tejido de algodón lavado, por urdimbre, a una temperatura de $27^{\circ} \mathrm{C}$ y a $34 \%$ de H.R.

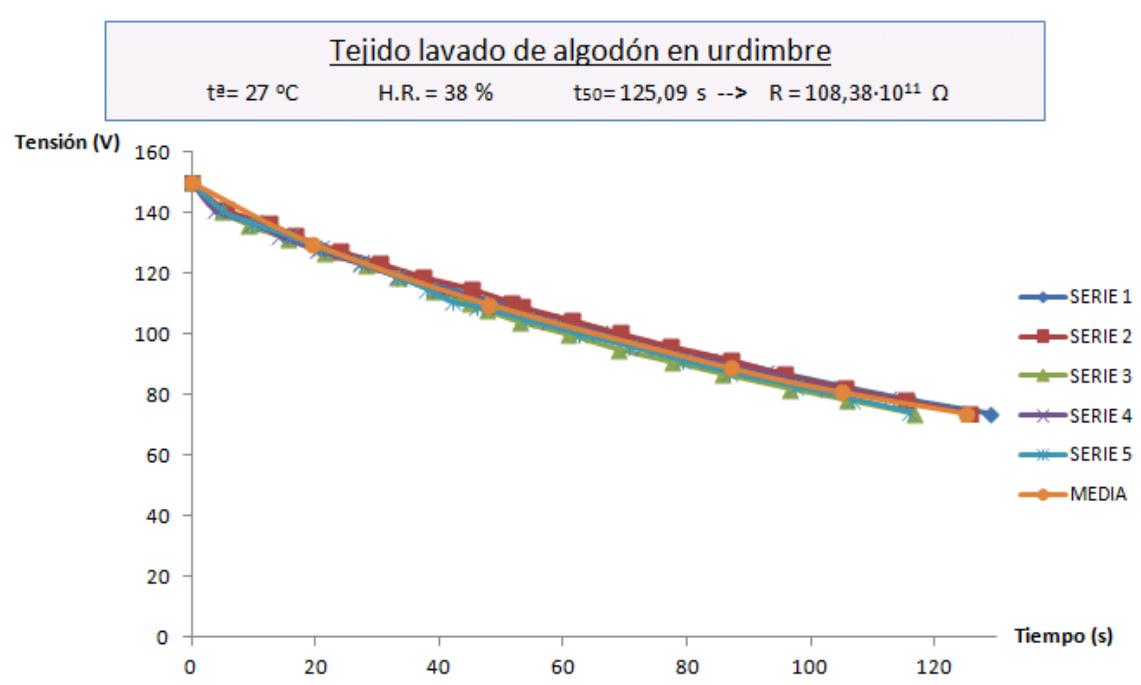

Figura Anexo 4. 40. Resultados finales del tejido de algodón lavado, por urdimbre, a una temperatura de $27^{\circ} \mathrm{C}$ y a $38 \%$ de H.R. 


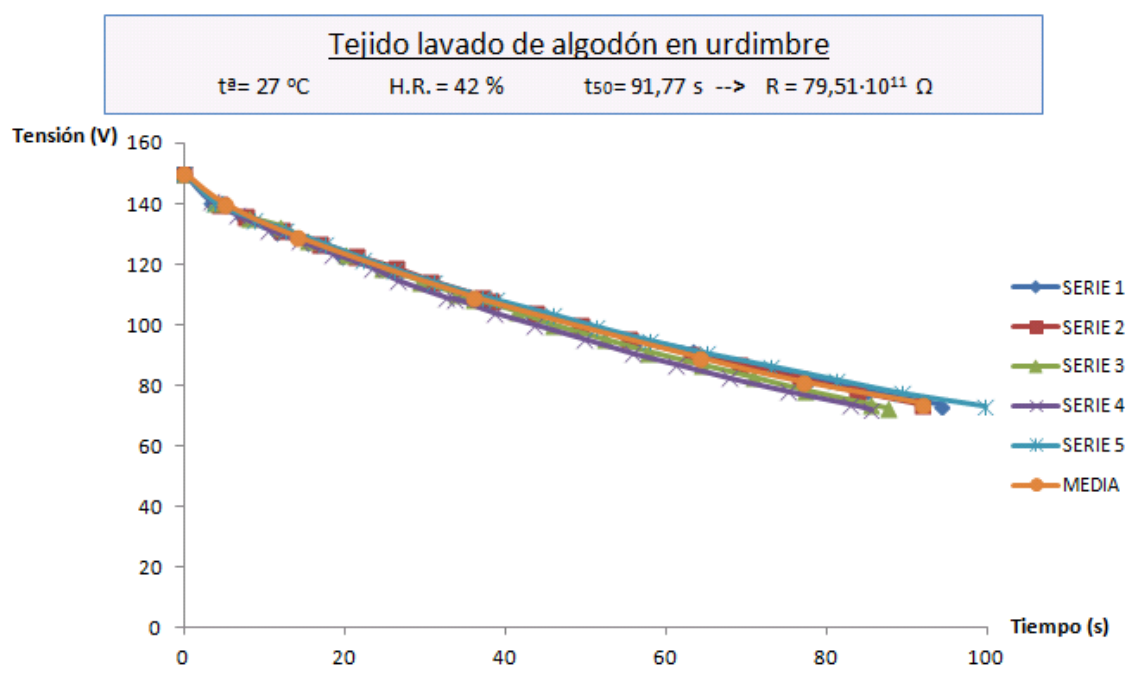

Figura Anexo 4. 41. Resultados finales del tejido de algodón lavado, por urdimbre, a una temperatura de $27^{\circ} \mathrm{C}$ y a $42 \%$ de H.R.

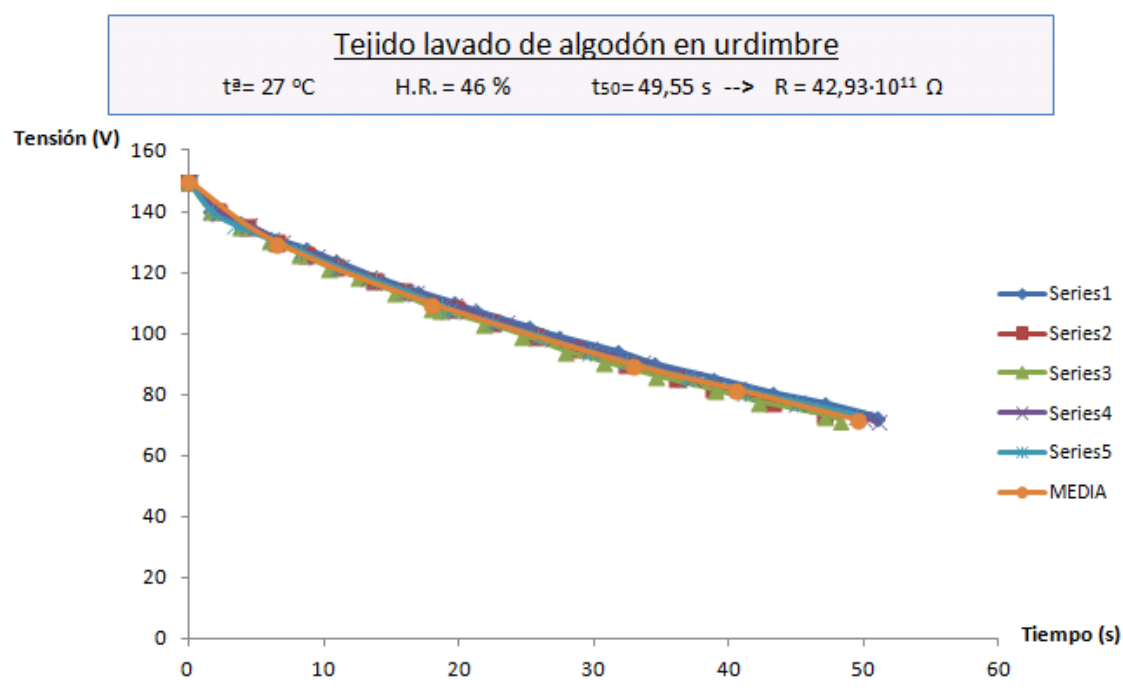

Figura Anexo 4. 42. Resultados finales del tejido de algodón lavado, por urdimbre, a una temperatura de $27^{\circ} \mathrm{C}$ y a $46 \%$ de H.R. 


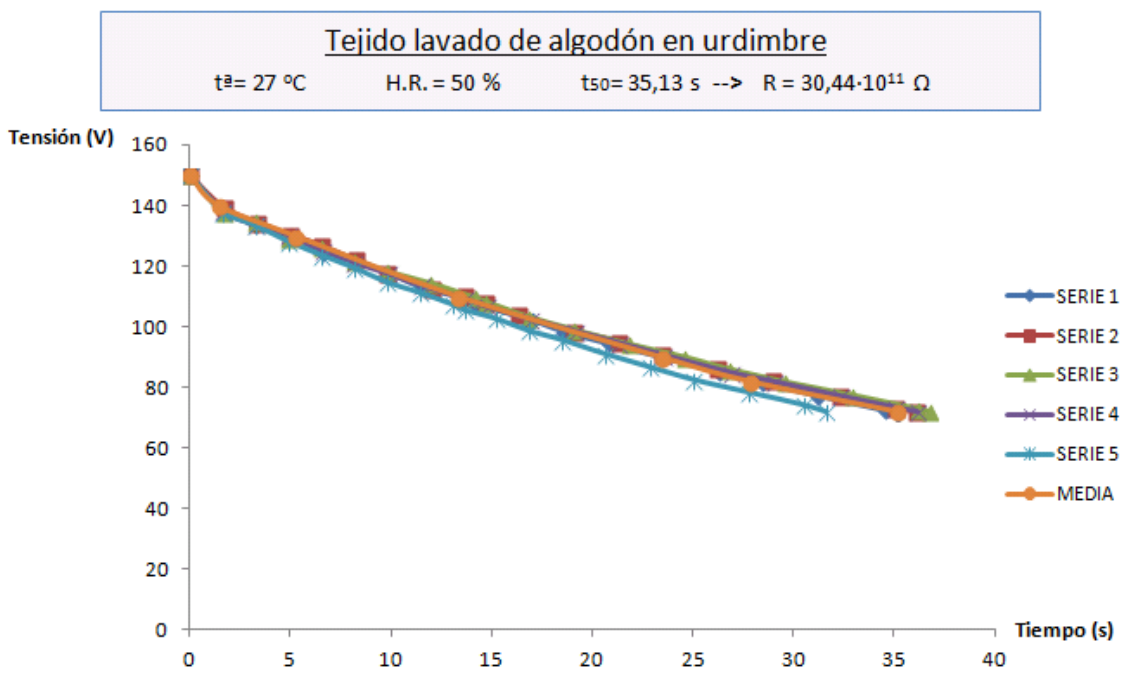

Figura Anexo 4. 43. Resultados finales del tejido de algodón lavado, por urdimbre, a una temperatura de $27^{\circ} \mathrm{C}$ y a $50 \%$ de H.R.

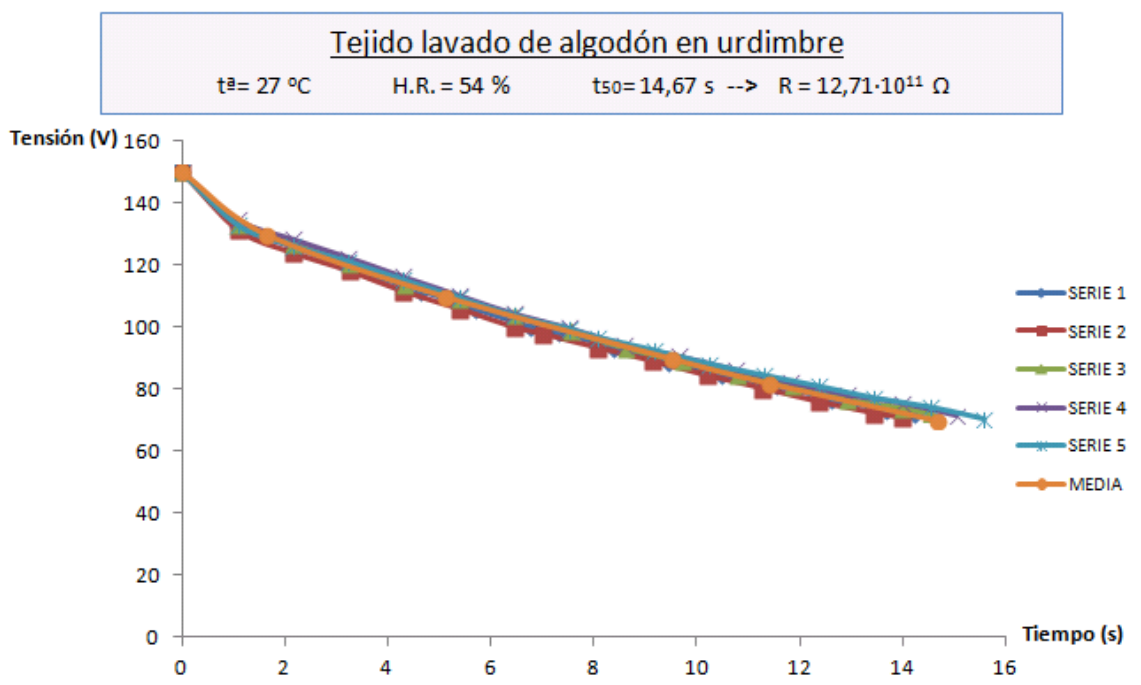

Figura Anexo 4. 44. Resultados finales del tejido de algodón lavado, por urdimbre, a una temperatura de $27^{\circ} \mathrm{C}$ y a $54 \%$ de H.R. 


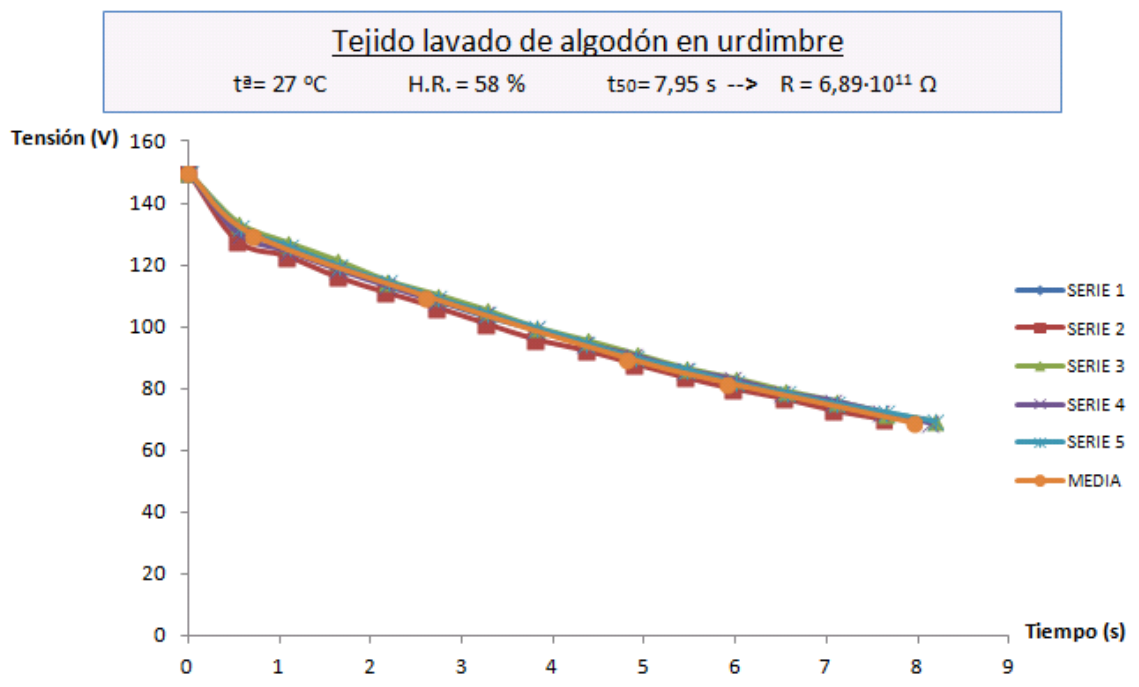

Figura Anexo 4. 45. Resultados finales del tejido de algodón lavado, por urdimbre, a una temperatura de $27^{\circ} \mathrm{C}$ y a $58 \%$ de H.R.

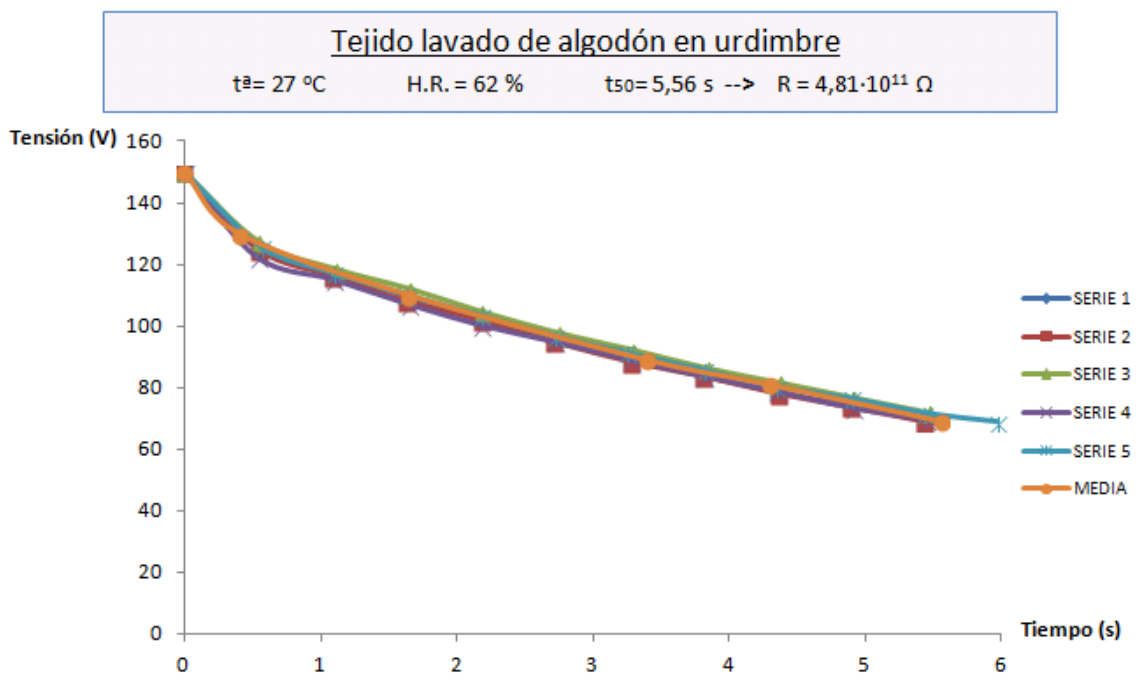

Figura Anexo 4. 46. Resultados finales del tejido de algodón lavado, por urdimbre, a una temperatura de $27^{\circ} \mathrm{C}$ y a $62 \%$ de H.R. 


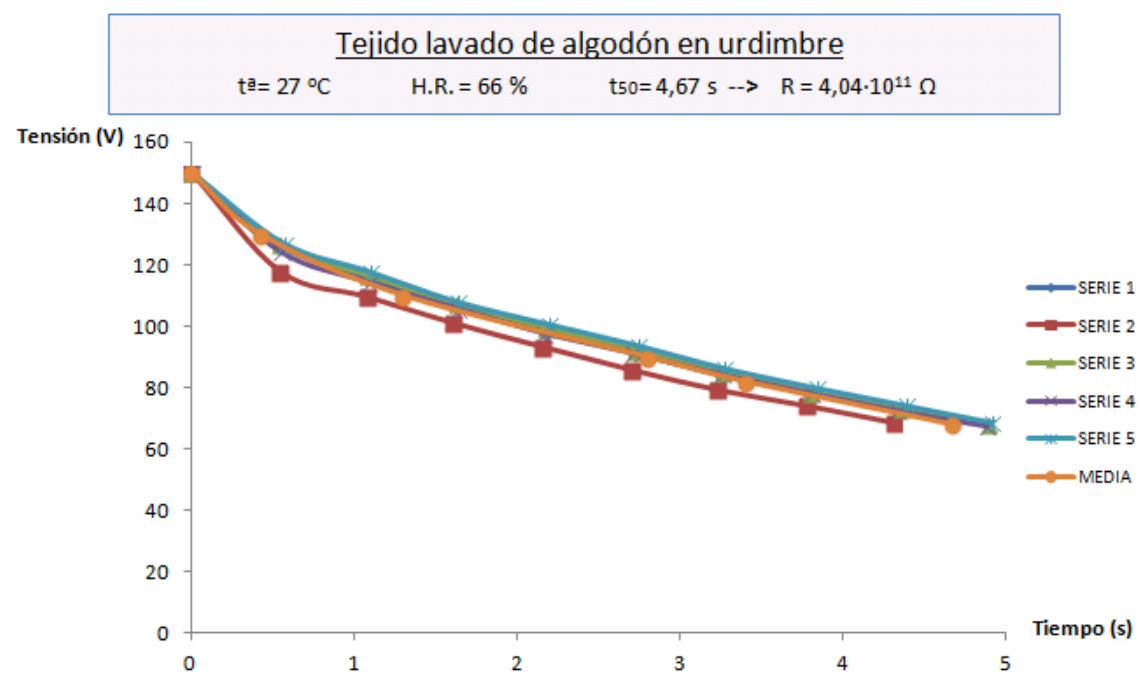

Figura Anexo 4. 47. Resultados finales del tejido de algodón lavado, por urdimbre, a una temperatura de $27^{\circ} \mathrm{C}$ y a $66 \%$ de H.R.

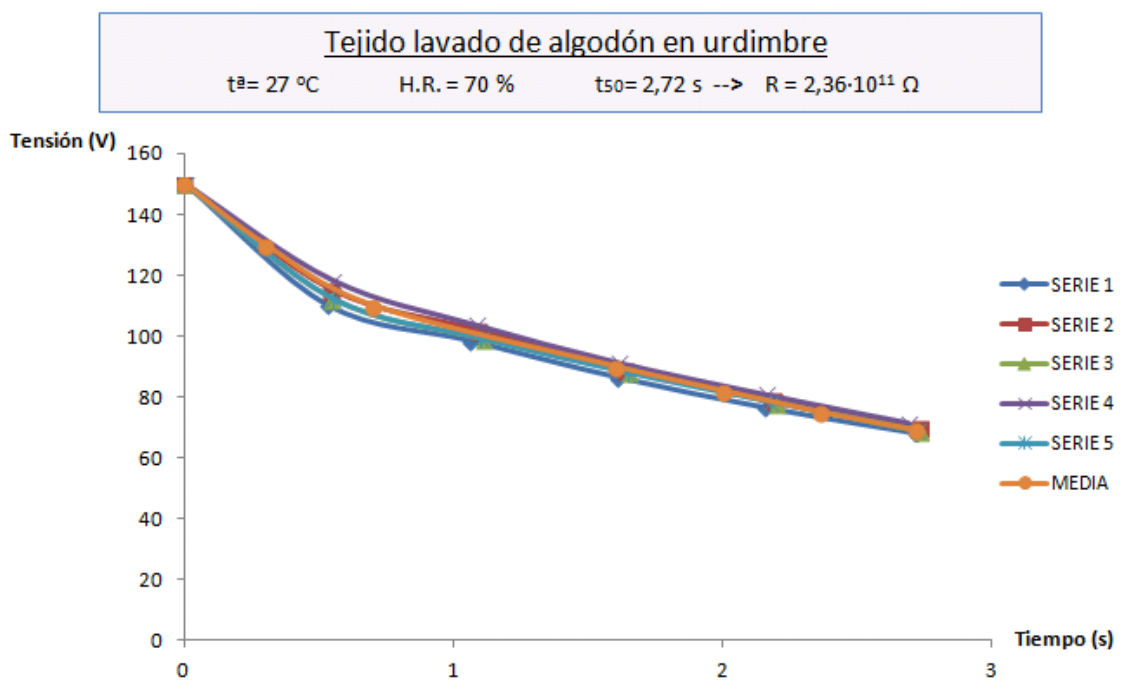

Figura Anexo 4. 48. Resultados finales del tejido de algodón lavado, por urdimbre, a una temperatura de $27^{\circ} \mathrm{C}$ y a $70 \%$ de H.R. 


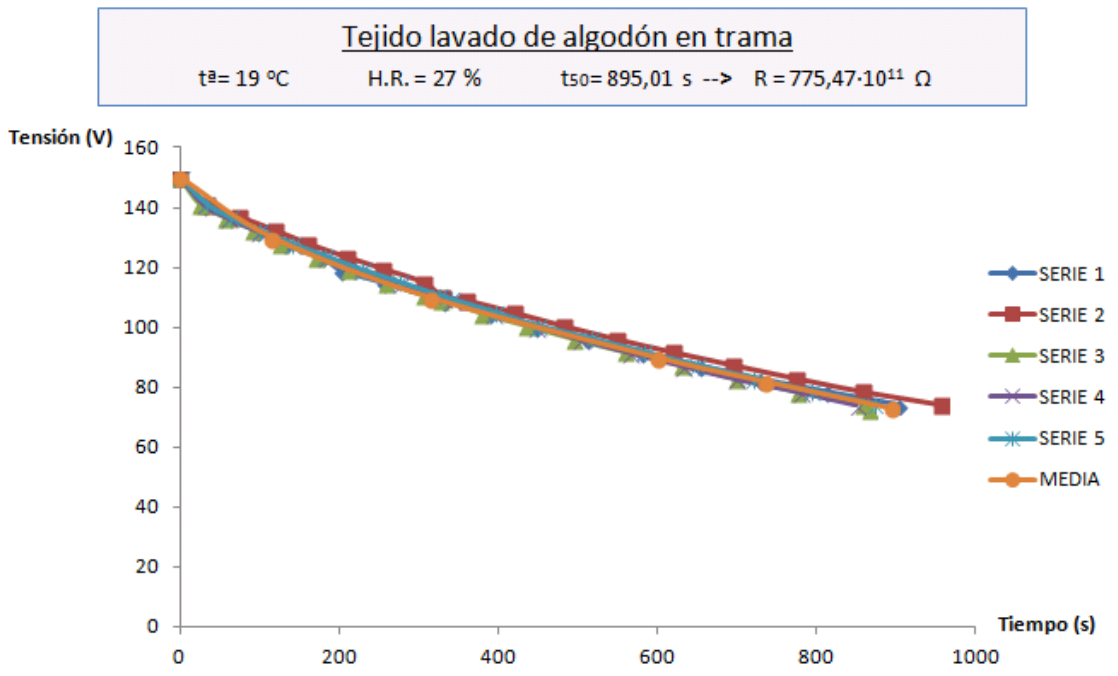

Figura Anexo 4. 49. Resultados finales del tejido de algodón lavado, por trama, a una temperatura de $19^{\circ} \mathrm{C}$ y a $27 \%$ de H.R.

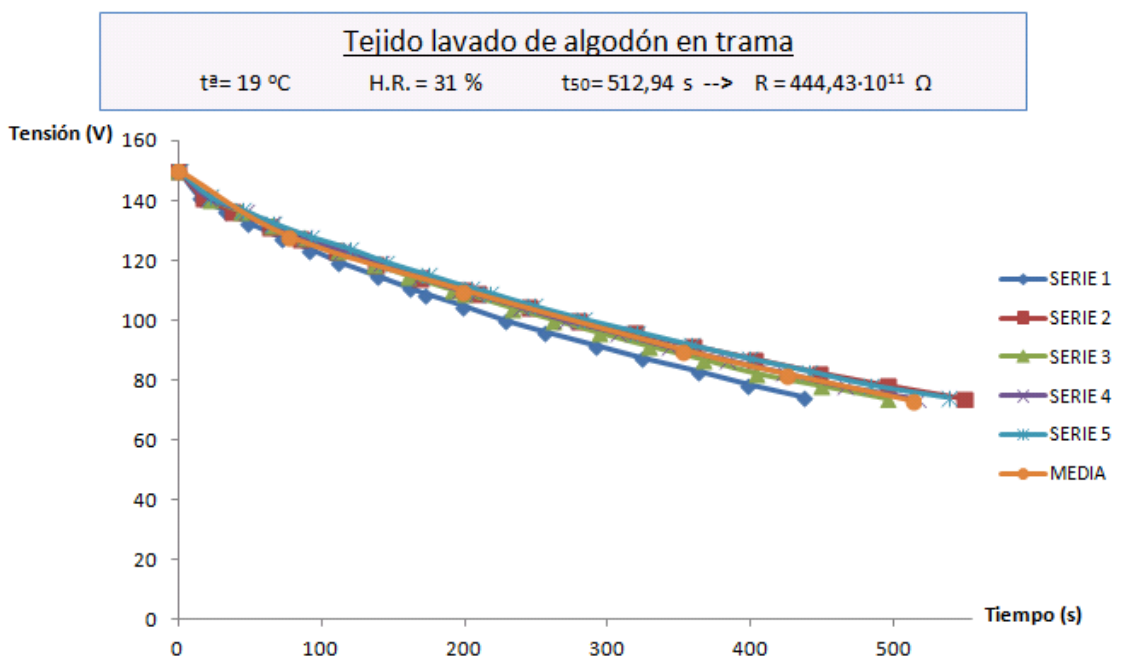

Figura Anexo 4. 50. Resultados finales del tejido de algodón lavado, por trama, a una temperatura de $19^{\circ} \mathrm{C}$ y a $31 \%$ de H.R. 


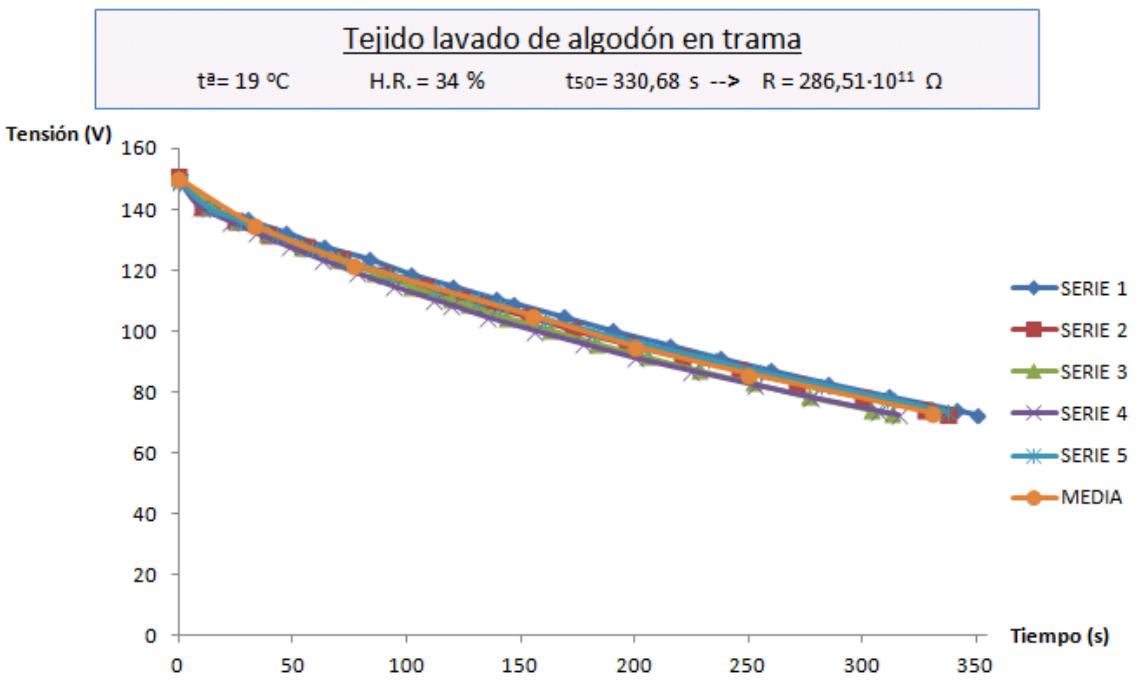

Figura Anexo 4. 51. Resultados finales del tejido de algodón lavado, por trama, a una temperatura de $19^{\circ} \mathrm{C}$ y a $34 \%$ de H.R.

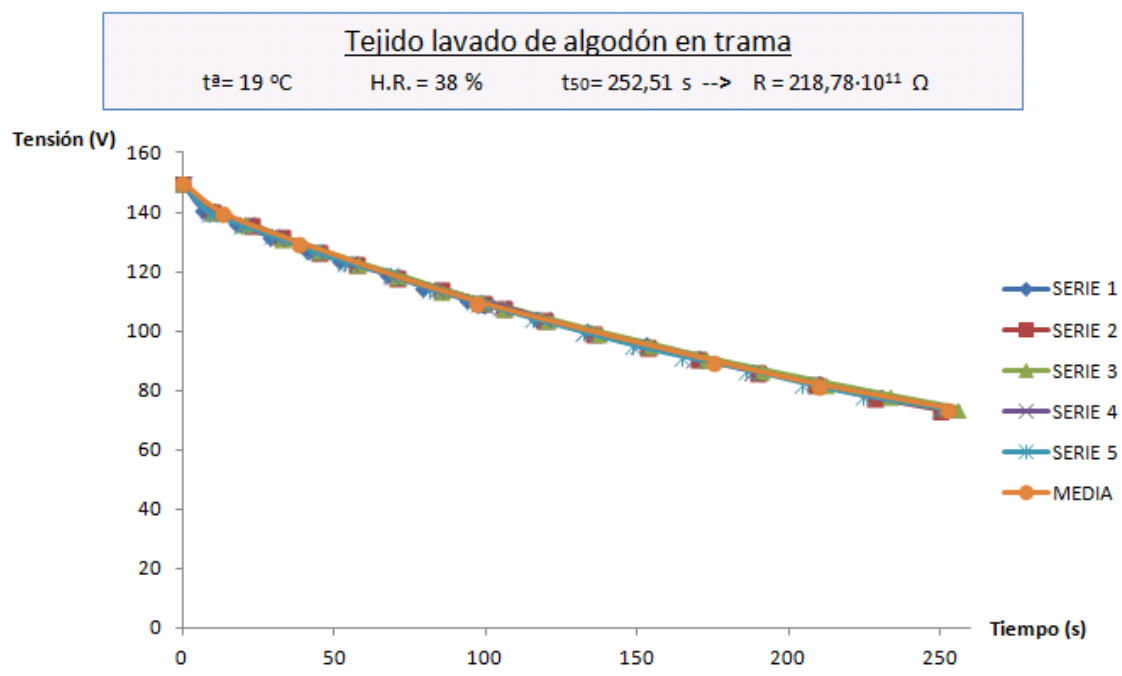

Figura Anexo 4. 52. Resultados finales del tejido de algodón lavado, por trama, a una temperatura de $19^{\circ} \mathrm{C}$ y a $38 \%$ de H.R. 


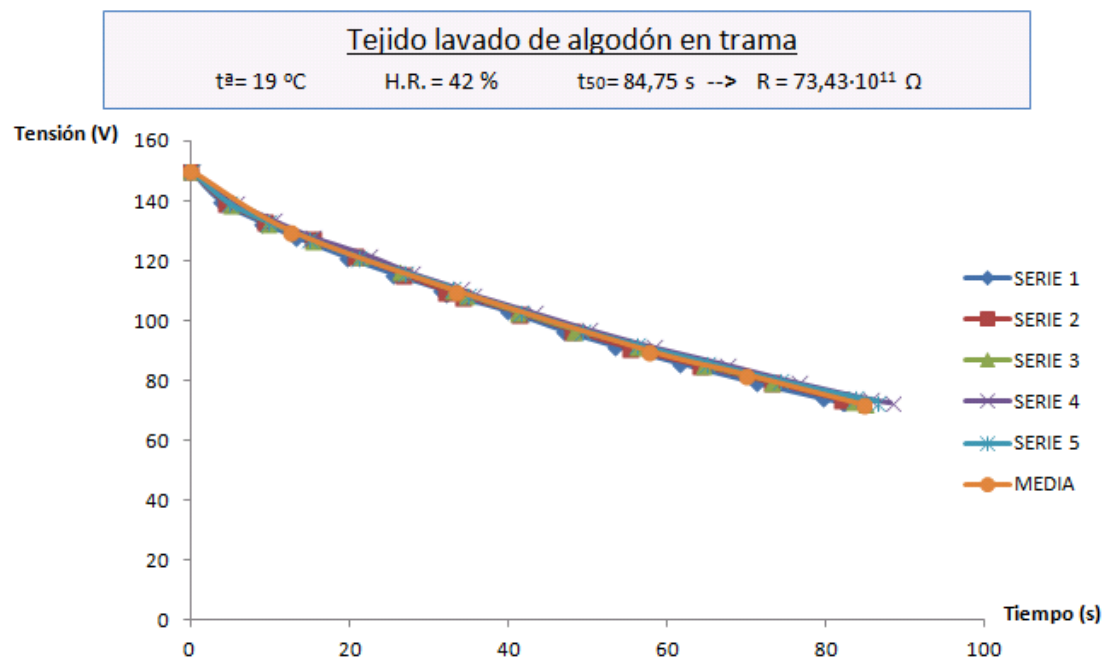

Figura Anexo 4. 53. Resultados finales del tejido de algodón lavado, por trama, a una temperatura de $19^{\circ} \mathrm{C}$ y a $42 \%$ de H.R.

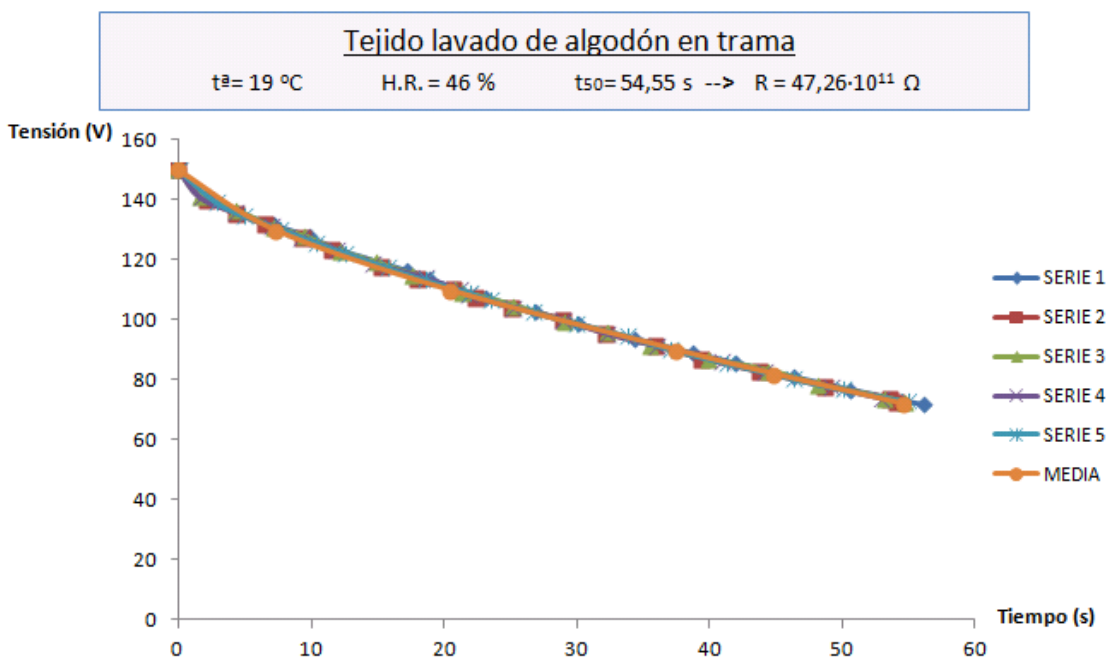

Figura Anexo 4. 54. Resultados finales del tejido de algodón lavado, por trama, a una temperatura de $19^{\circ} \mathrm{C}$ y a $46 \%$ de H.R. 


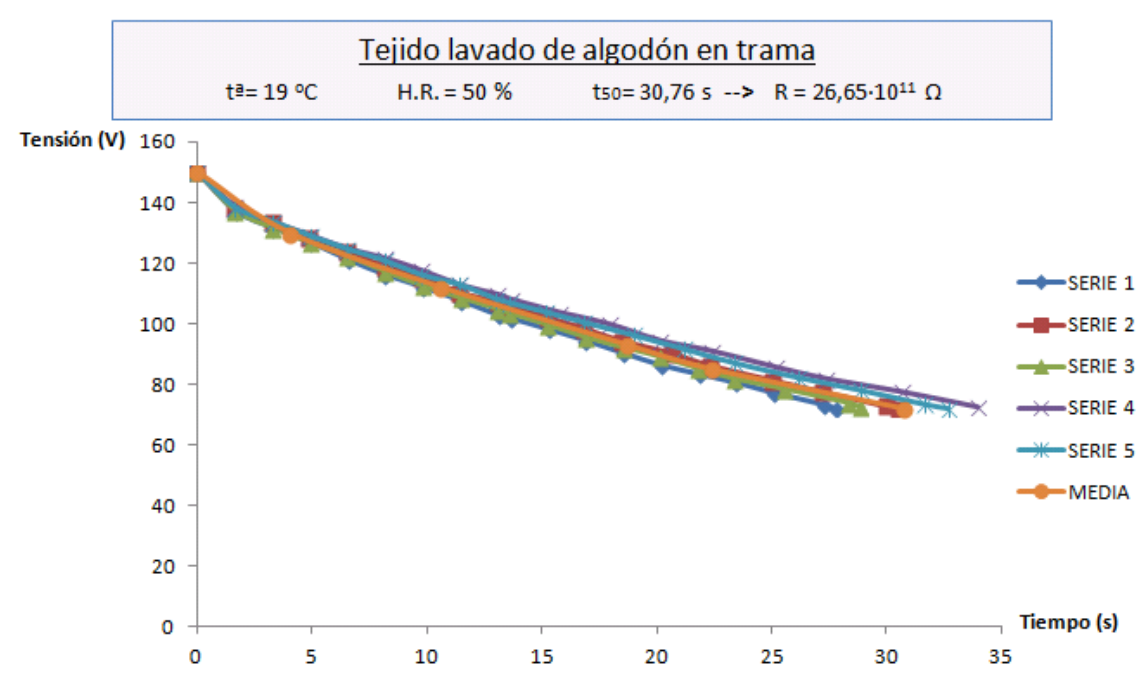

Figura Anexo 4. 55. Resultados finales del tejido de algodón lavado, por trama, a una temperatura de $19^{\circ} \mathrm{C}$ y a $50 \%$ de H.R.

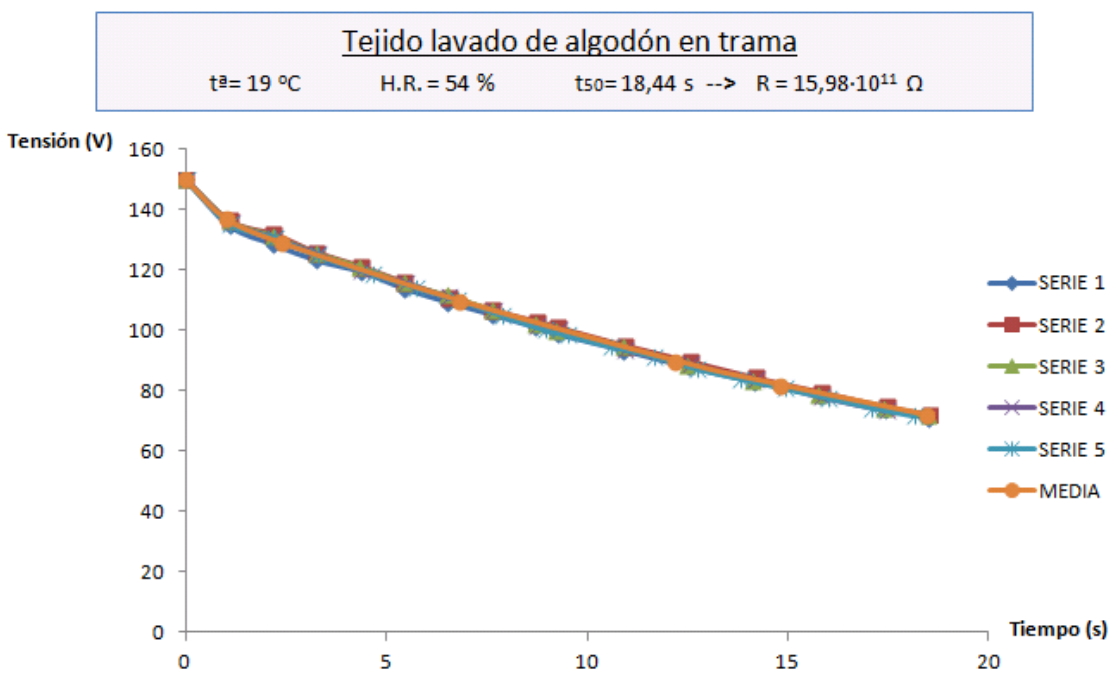

Figura Anexo 4. 56. Resultados finales del tejido de algodón lavado, por trama, a una temperatura de $19^{\circ} \mathrm{C}$ y a $54 \%$ de H.R. 


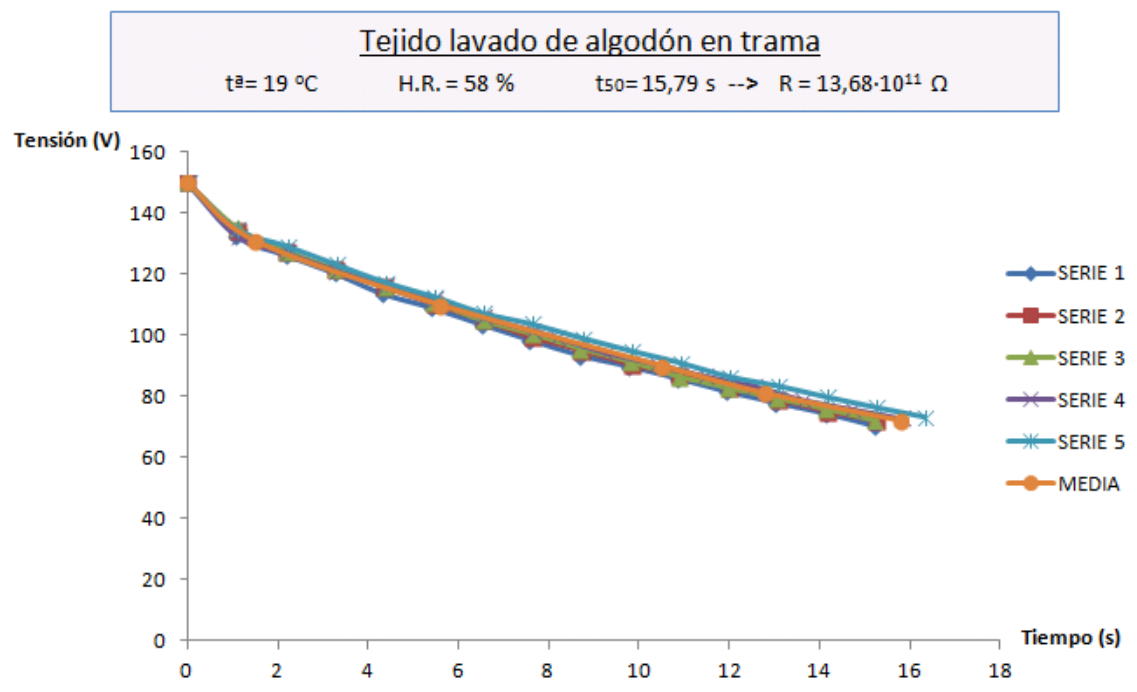

Figura Anexo 4. 57. Resultados finales del tejido de algodón lavado, por trama, a una temperatura de $19^{\circ} \mathrm{C}$ y a $58 \%$ de H.R.

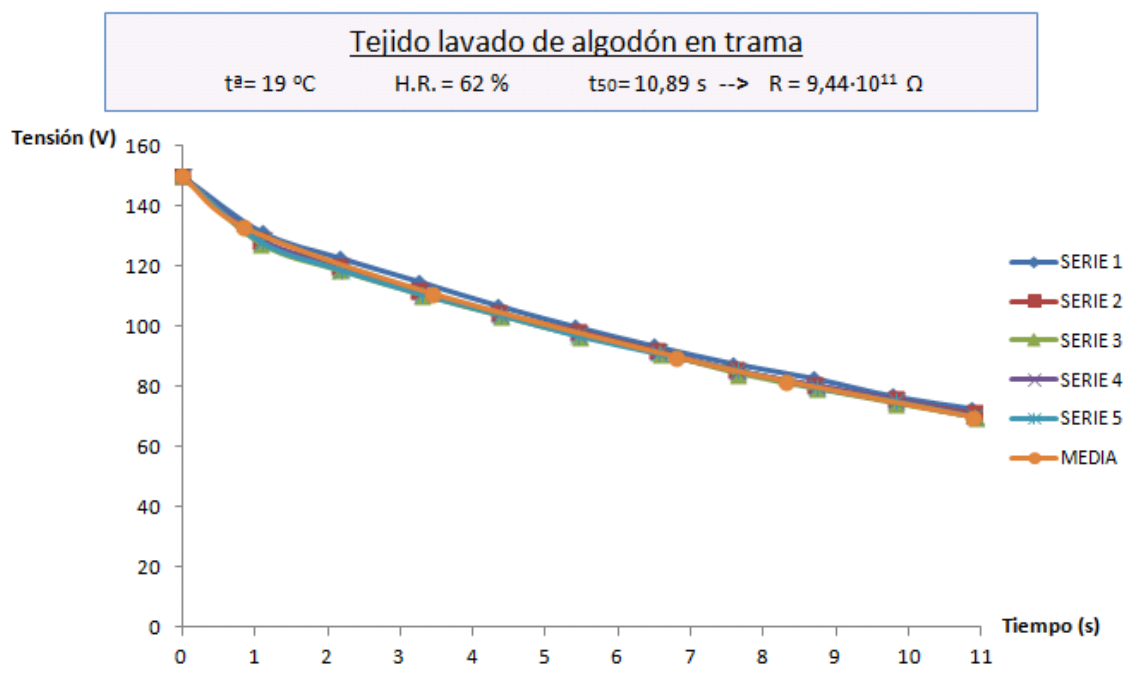

Figura Anexo 4. 58. Resultados finales del tejido de algodón lavado, por trama, a una temperatura de $19^{\circ} \mathrm{C}$ y a $62 \%$ de H.R. 


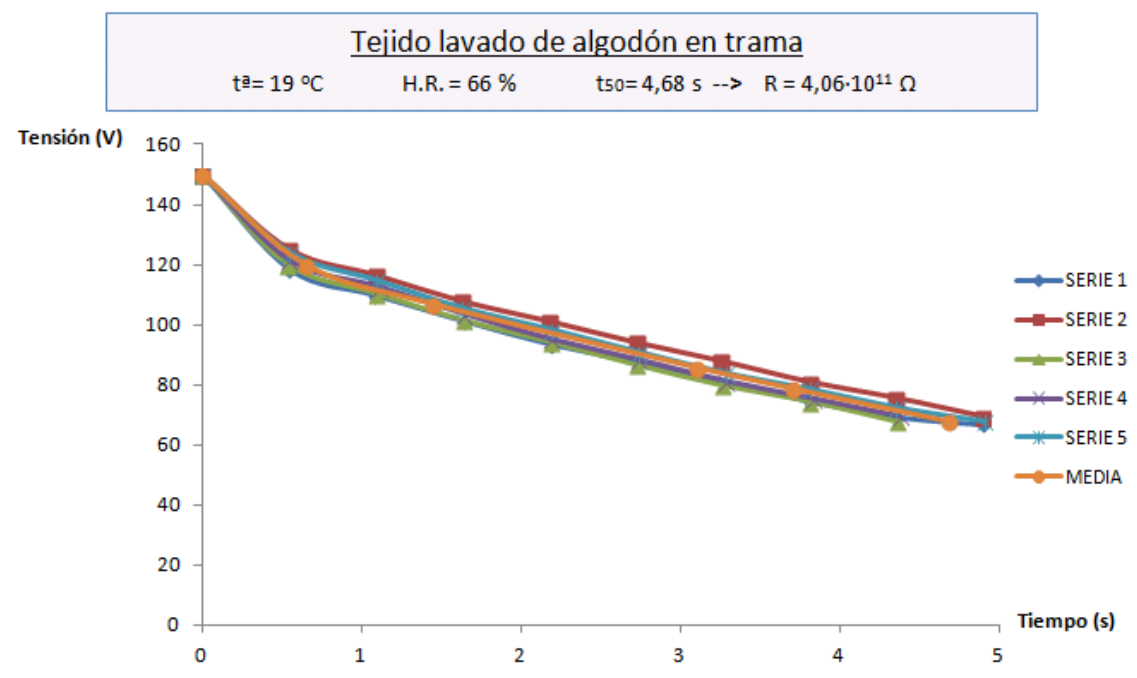

Figura Anexo 4. 59. Resultados finales del tejido de algodón lavado, por trama, a una temperatura de $19^{\circ} \mathrm{C}$ y a $66 \%$ de H.R.

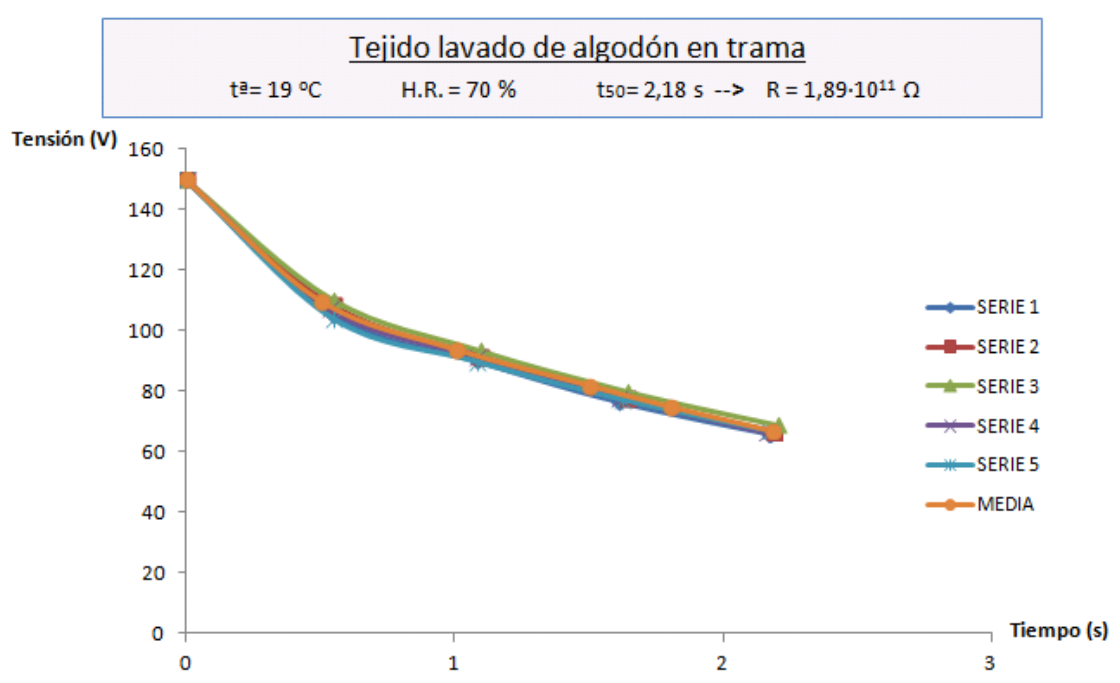

Figura Anexo 4. 60. Resultados finales del tejido de algodón lavado, por trama, a una temperatura de $19^{\circ} \mathrm{C}$ y a $70 \%$ de H.R. 


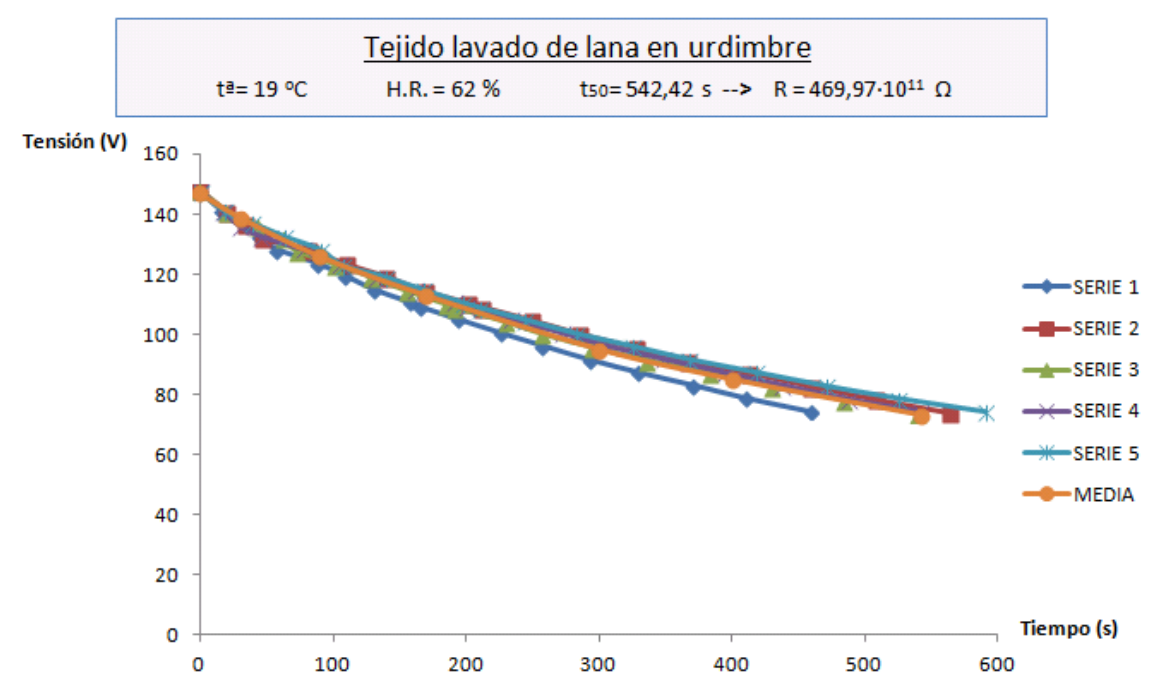

Figura Anexo 4. 61. Resultados finales del tejido de lana lavado, por urdimbre, a una temperatura de $19^{\circ} \mathrm{C}$ y a $62 \%$ de H.R.

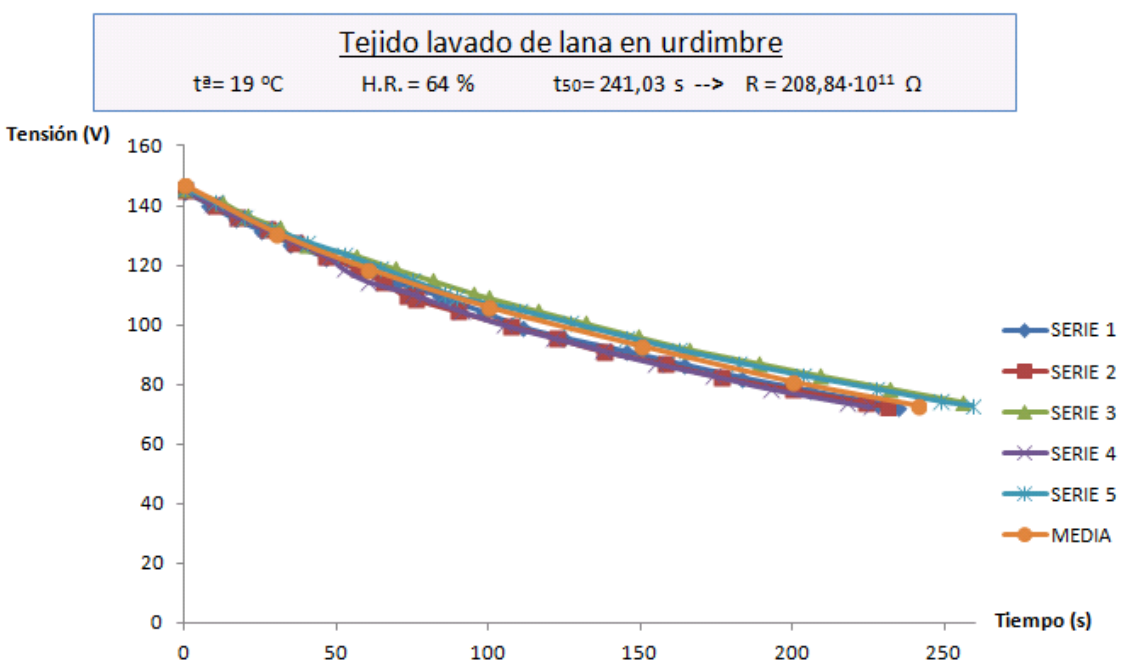

Figura Anexo 4. 62. Resultados finales del tejido de lana lavado, por urdimbre, a una temperatura de $19^{\circ} \mathrm{C}$ y a $64 \%$ de H.R. 


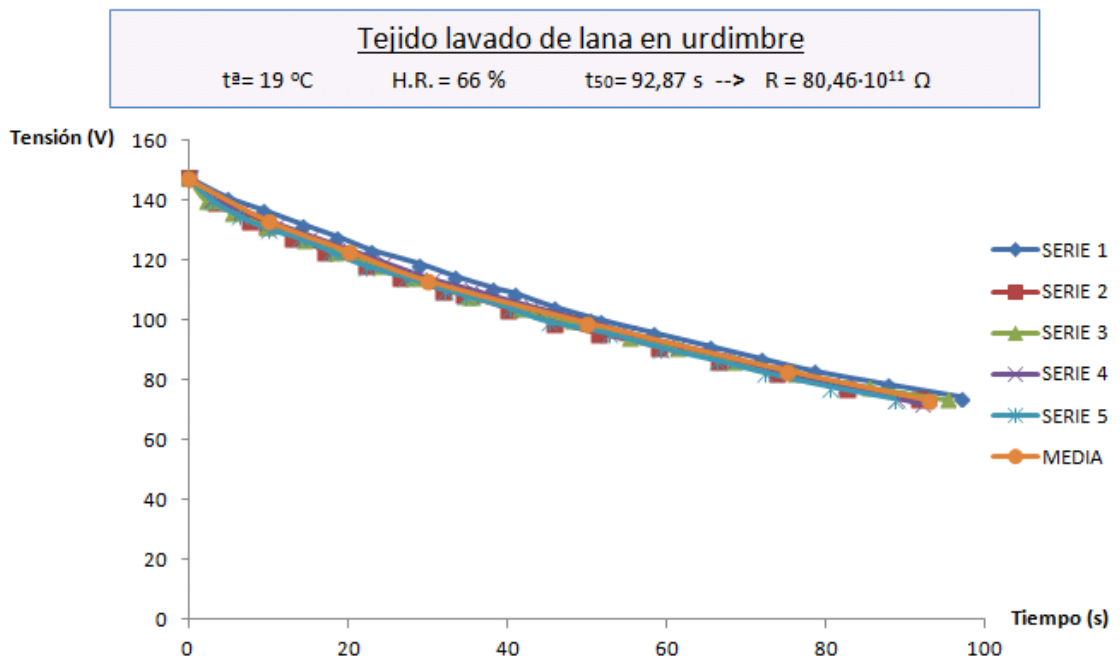

Figura Anexo 4. 63. Resultados finales del tejido de lana lavado, por urdimbre, a una temperatura de $19^{\circ} \mathrm{C}$ y a $66 \%$ de H.R.

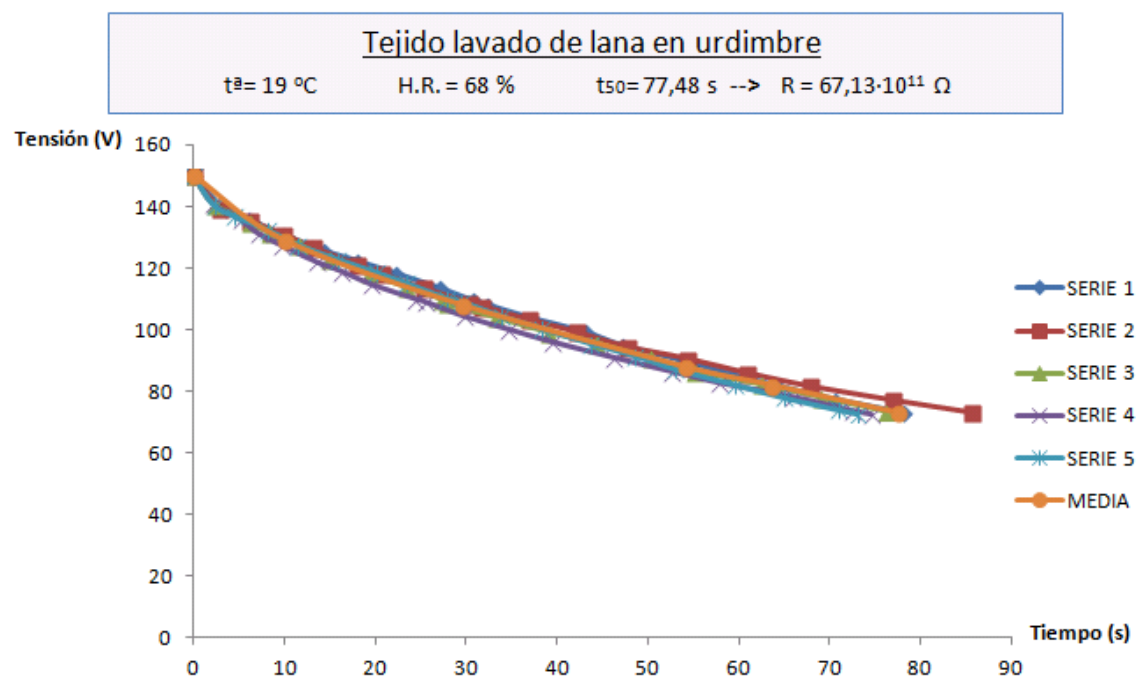

Figura Anexo 4. 64. Resultados finales del tejido de lana lavado, por urdimbre, a una temperatura de $19{ }^{\circ} \mathrm{C}$ y a $68 \%$ de H.R. 


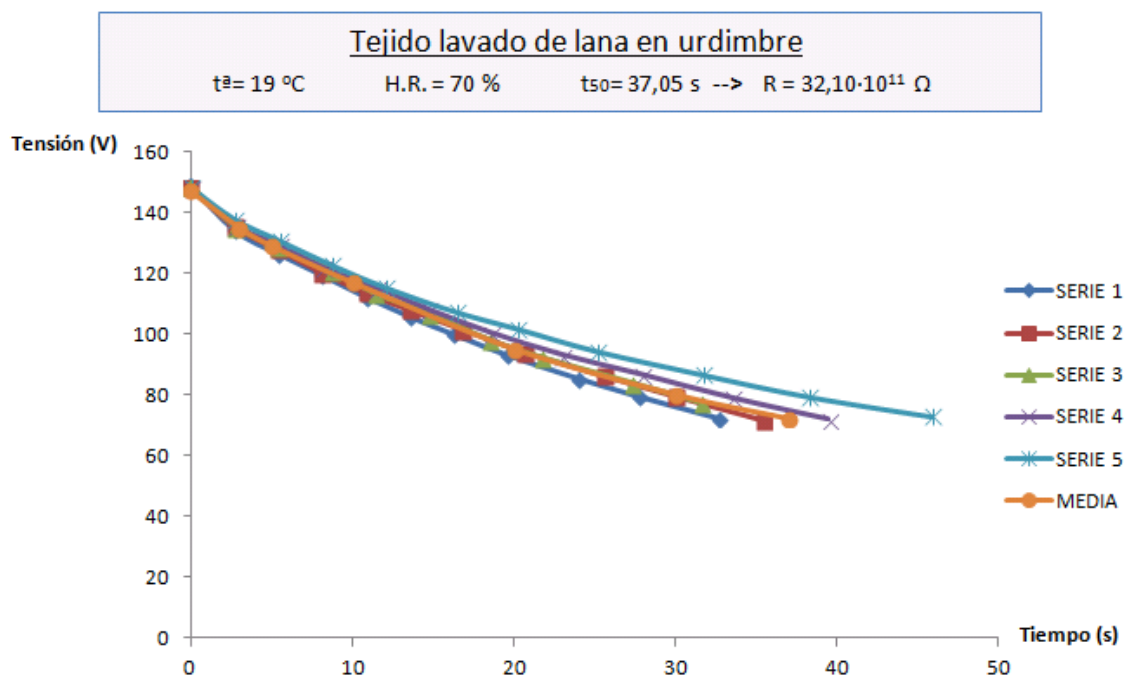

Figura Anexo 4. 65. Resultados finales del tejido de lana lavado, por urdimbre, a una temperatura de $19^{\circ} \mathrm{C}$ y a $70 \%$ de H.R.

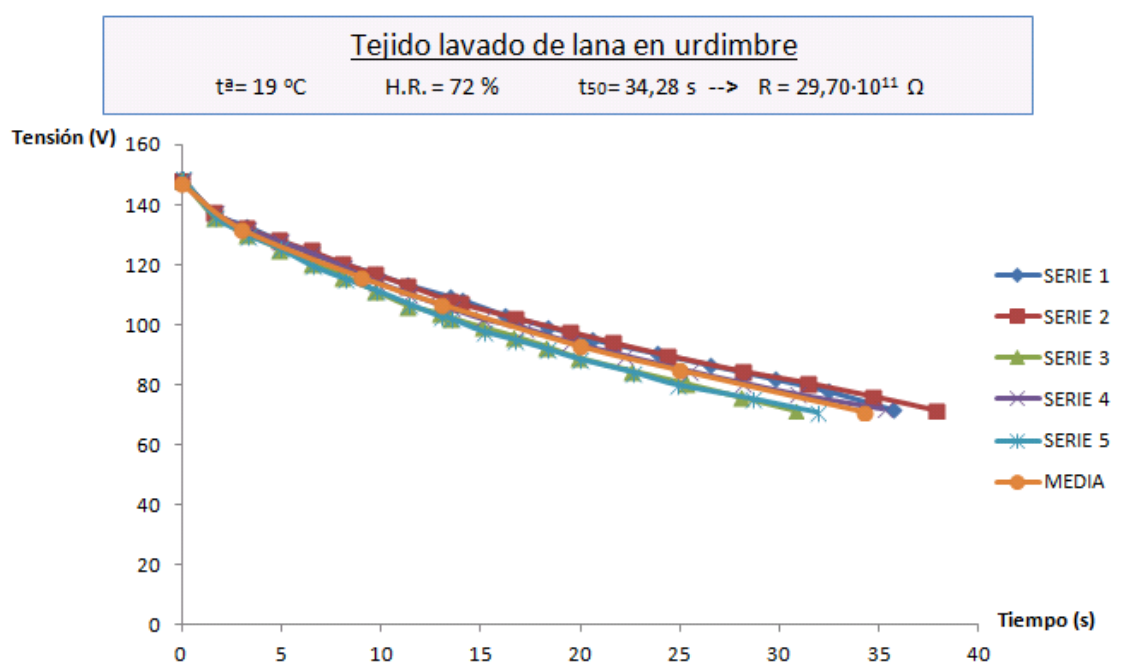

Figura Anexo 4. 66. Resultados finales del tejido de lana lavado, por urdimbre, a una temperatura de $19^{\circ} \mathrm{C}$ y a $72 \%$ de H.R. 


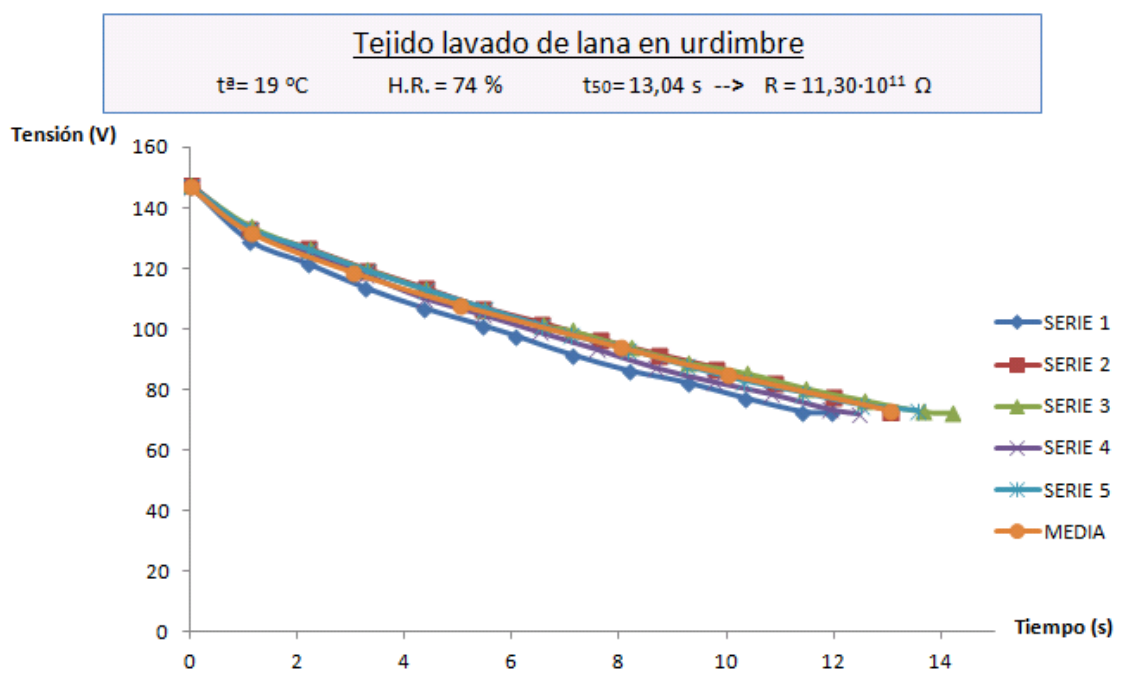

Figura Anexo 4. 67. Resultados finales del tejido de lana lavado, por urdimbre, a una temperatura de $19^{\circ} \mathrm{C}$ y a $74 \%$ de H.R.

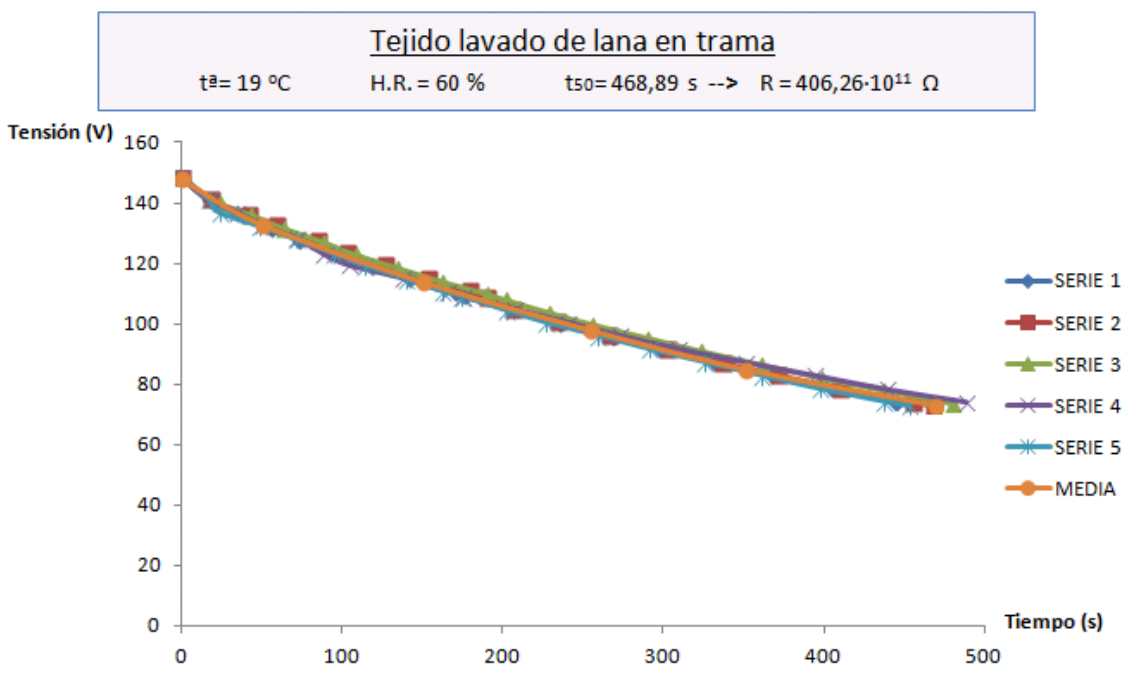

Figura Anexo 4. 68. Resultados finales del tejido de lana lavado, por trama, a una temperatura de $19^{\circ} \mathrm{C}$ y a $60 \%$ de H.R. 


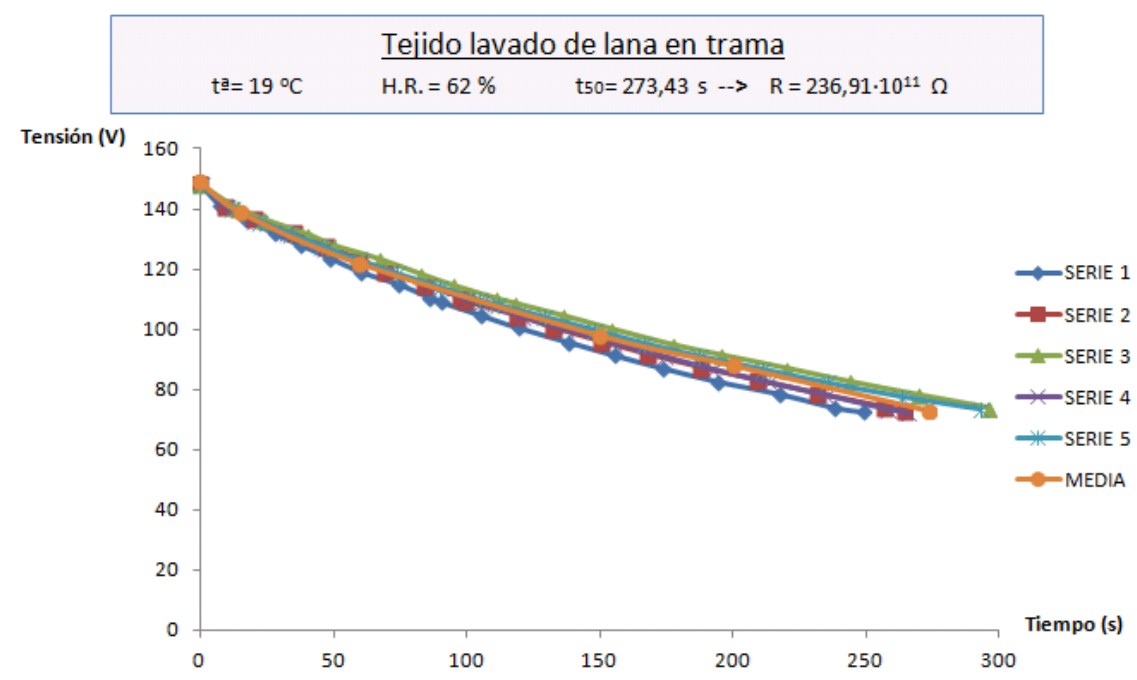

Figura Anexo 4. 69. Resultados finales del tejido de lana lavado, por trama, a una temperatura de $19^{\circ} \mathrm{C}$ y a $62 \%$ de H.R.

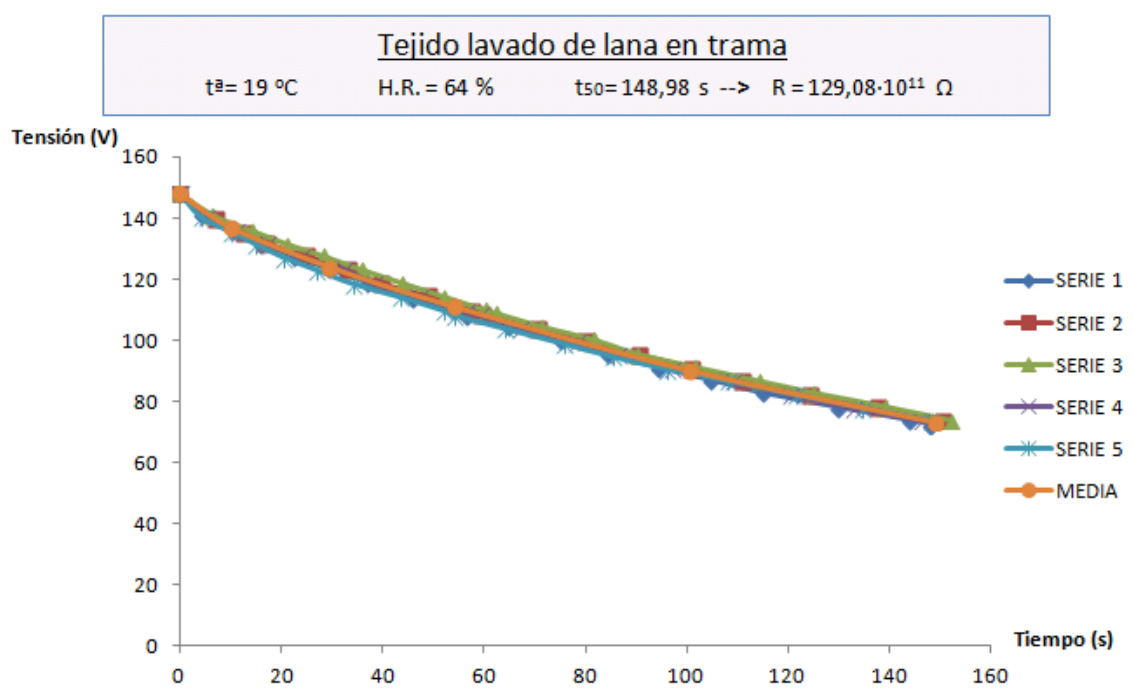

Figura Anexo 4. 70. Resultados finales del tejido de lana lavado, por trama, a una temperatura de $19^{\circ} \mathrm{C}$ y a $64 \%$ de H.R. 


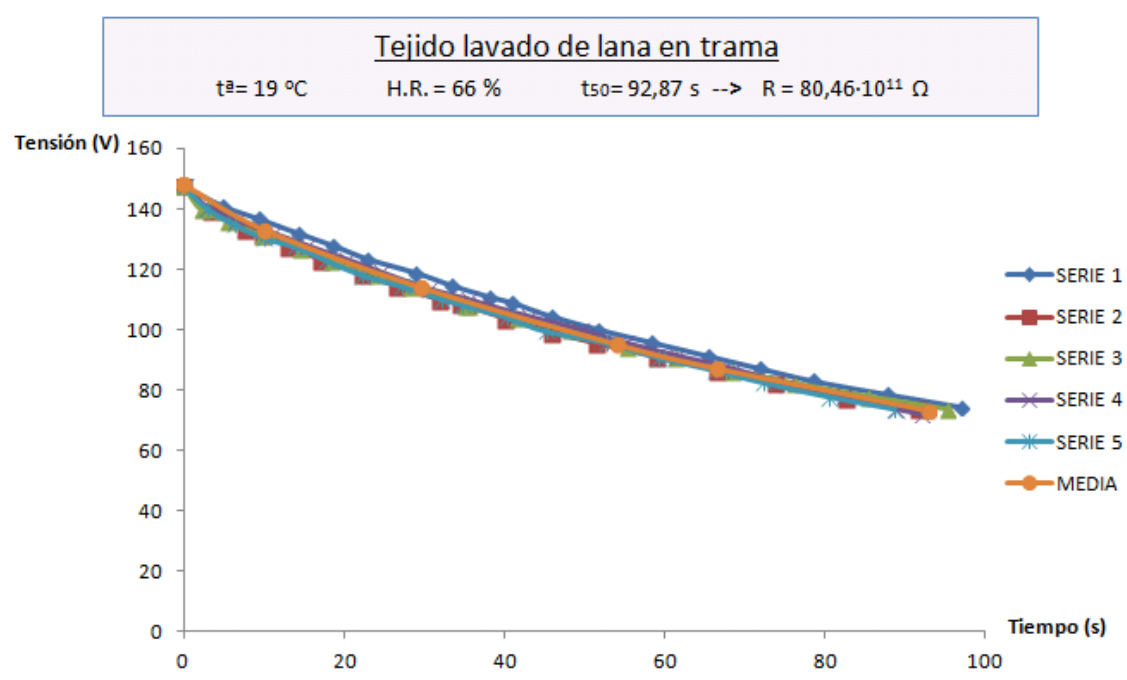

Figura Anexo 4. 71. Resultados finales del tejido de lana lavado, por trama, a una temperatura de $19^{\circ} \mathrm{C}$ y a $66 \%$ de H.R.

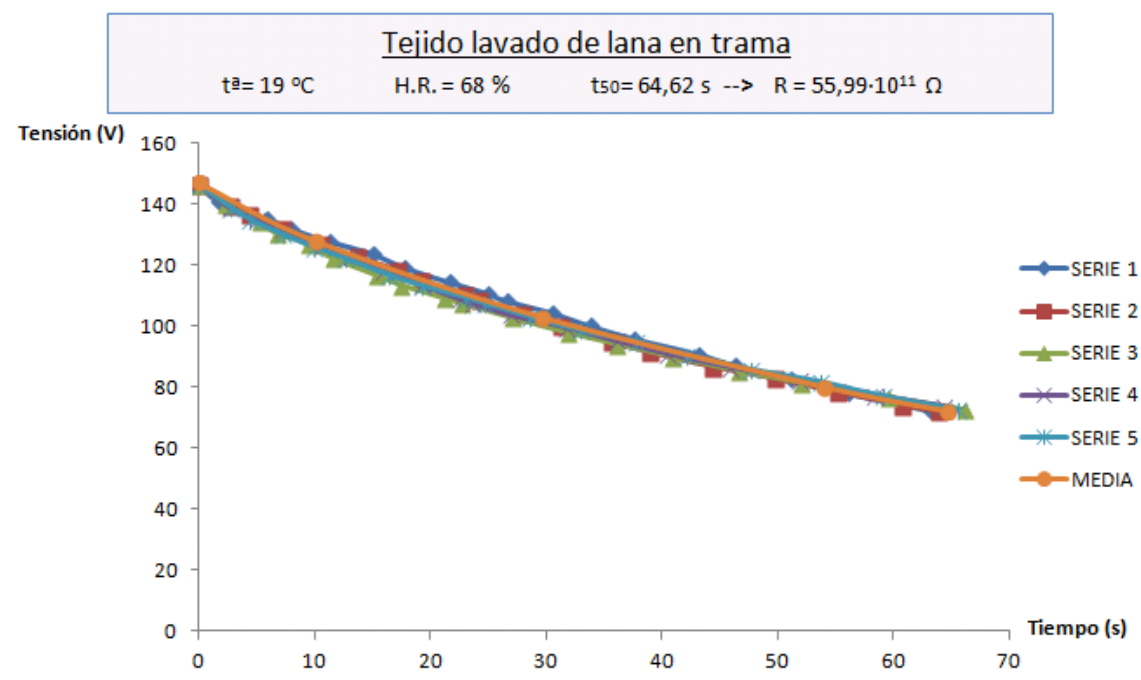

Figura Anexo 4. 72. Resultados finales del tejido de lana lavado, por trama, a una temperatura de $19^{\circ} \mathrm{C}$ y a $68 \%$ de H.R. 


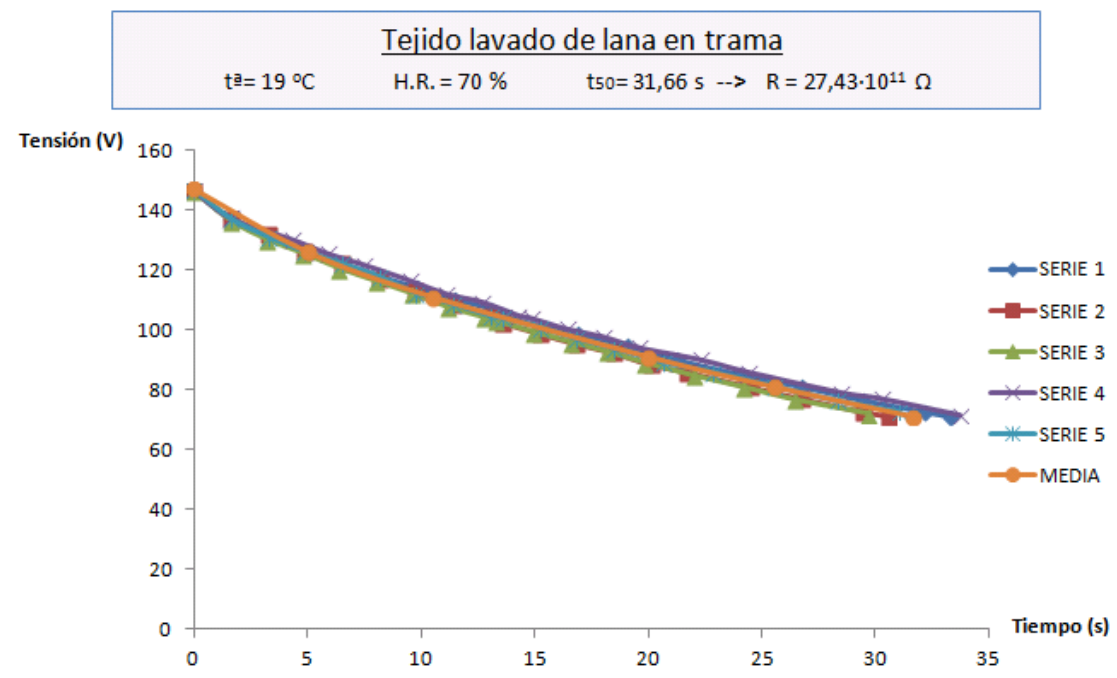

Figura Anexo 4. 73. Resultados finales del tejido de lana lavado, por trama, a una temperatura de $19^{\circ} \mathrm{C}$ y a $70 \%$ de H.R.

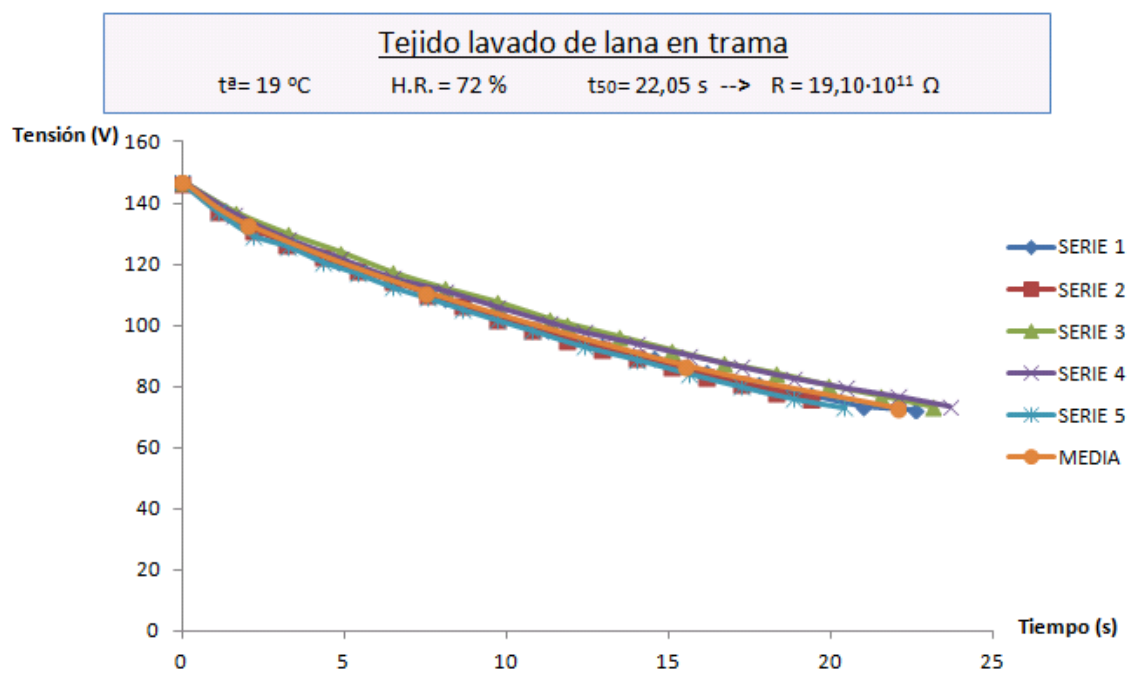

Figura Anexo 4. 74. Resultados finales del tejido de lana lavado, por trama, a una temperatura de $19^{\circ} \mathrm{C}$ y a $72 \%$ de H.R. 


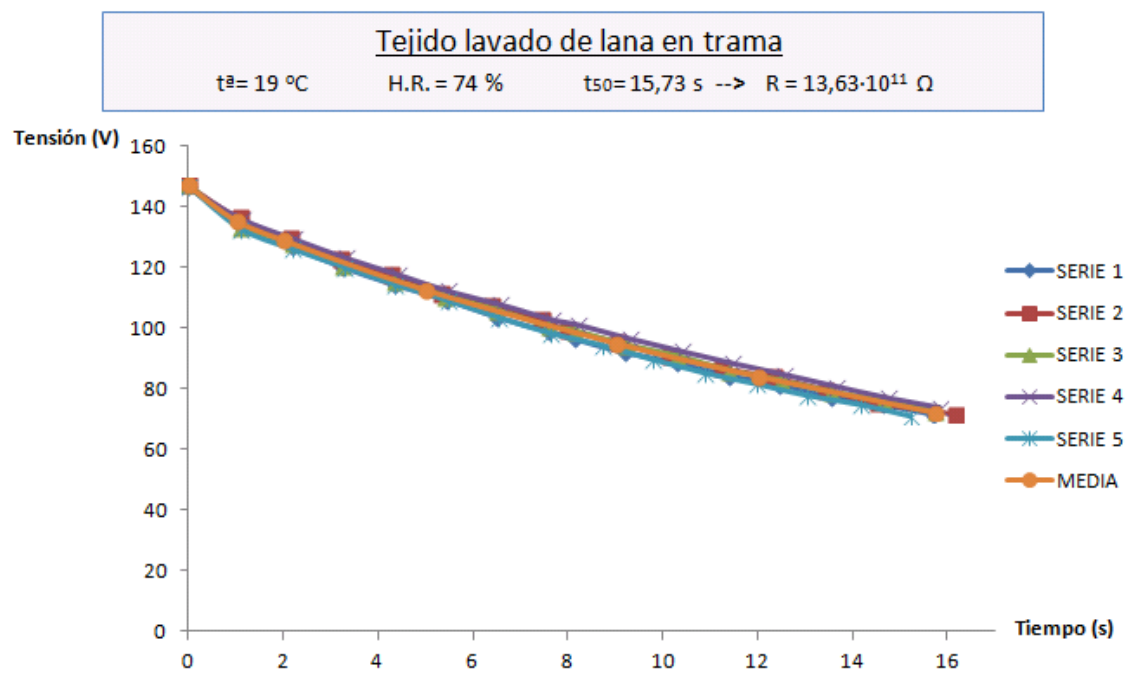

Figura Anexo 4. 75. Resultados finales del tejido de lana lavado, por trama, a una temperatura de $19^{\circ} \mathrm{C}$ y a $74 \%$ de H.R.

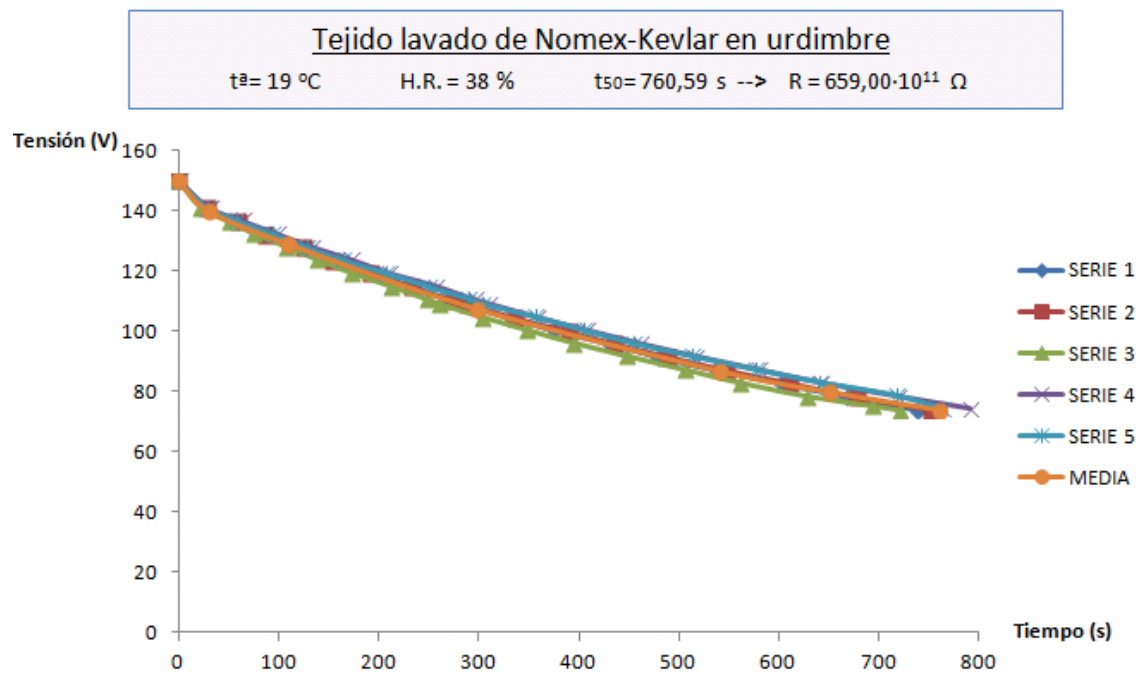

Figura Anexo 4. 76. Resultados finales del tejido de Nomex-Kevlar-fibra antiestática lavado, por urdimbre, a una temperatura de $19{ }^{\circ} \mathrm{C}$ y a $38 \%$ de H.R. 


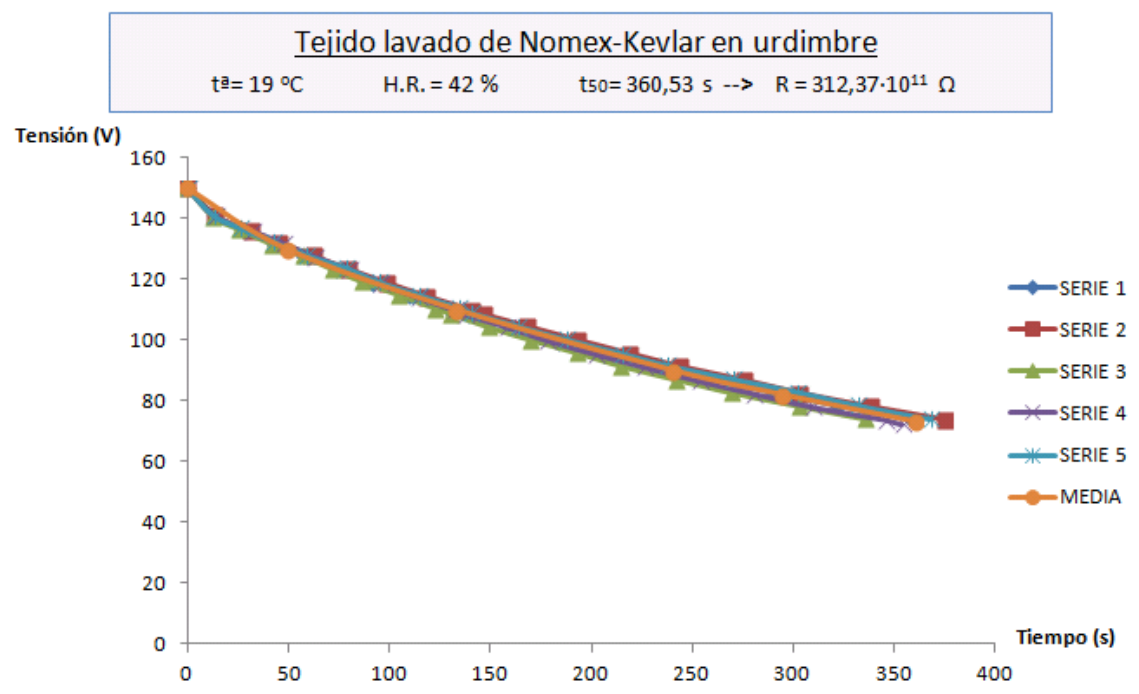

Figura Anexo 4. 77. Resultados finales del tejido de Nomex-Kevlar-fibra antiestática lavado, por urdimbre, a una temperatura de $19^{\circ} \mathrm{C}$ y a $42 \%$ de H.R

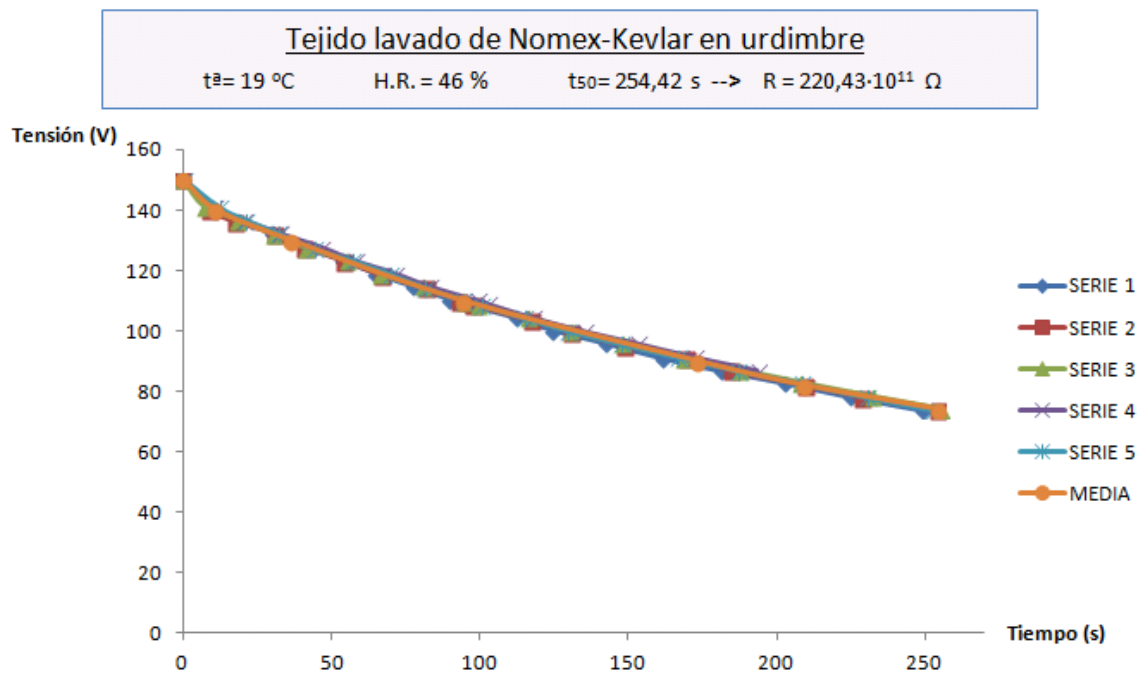

Figura Anexo 4. 78. Resultados finales del tejido de Nomex-Kevlar-fibra antiestática lavado, por urdimbre, a una temperatura de $19^{\circ} \mathrm{C}$ y a $46 \%$ de H.R 


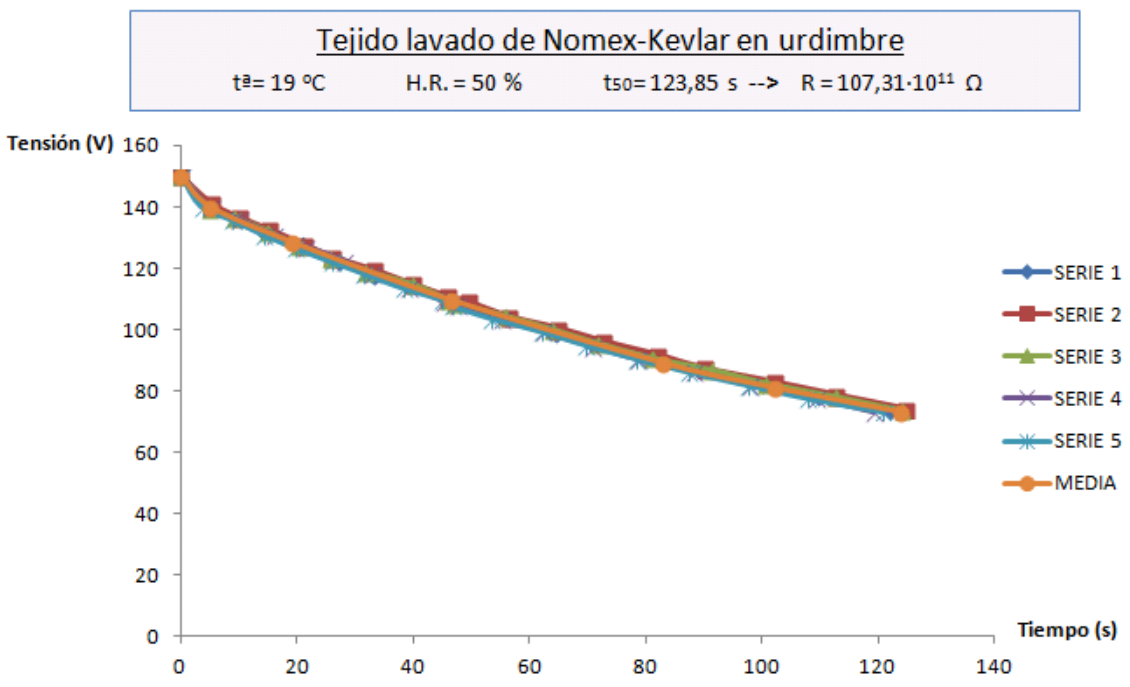

Figura Anexo 4. 79. Resultados finales del tejido de Nomex-Kevlar-fibra antiestática lavado, por urdimbre, a una temperatura de $19^{\circ} \mathrm{C}$ y a $50 \%$ de H.R

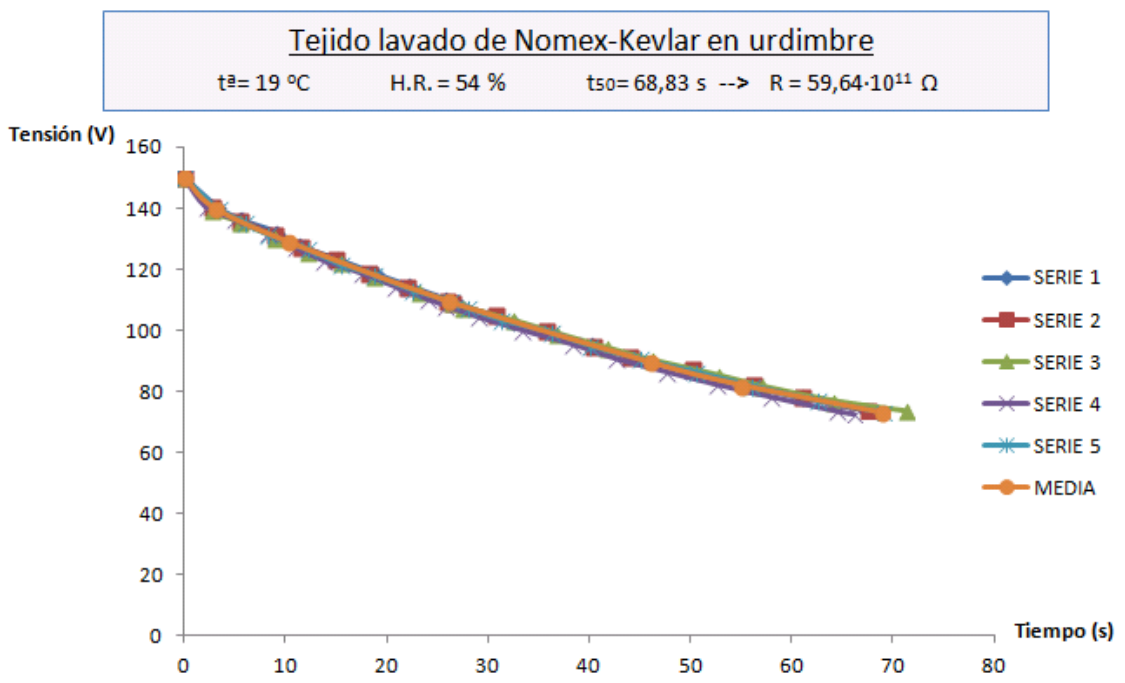

Figura Anexo 4. 80. Resultados finales del tejido de Nomex-Kevlar-fibra antiestática lavado, por urdimbre, a una temperatura de $19^{\circ} \mathrm{C}$ y a $54 \%$ de H.R 


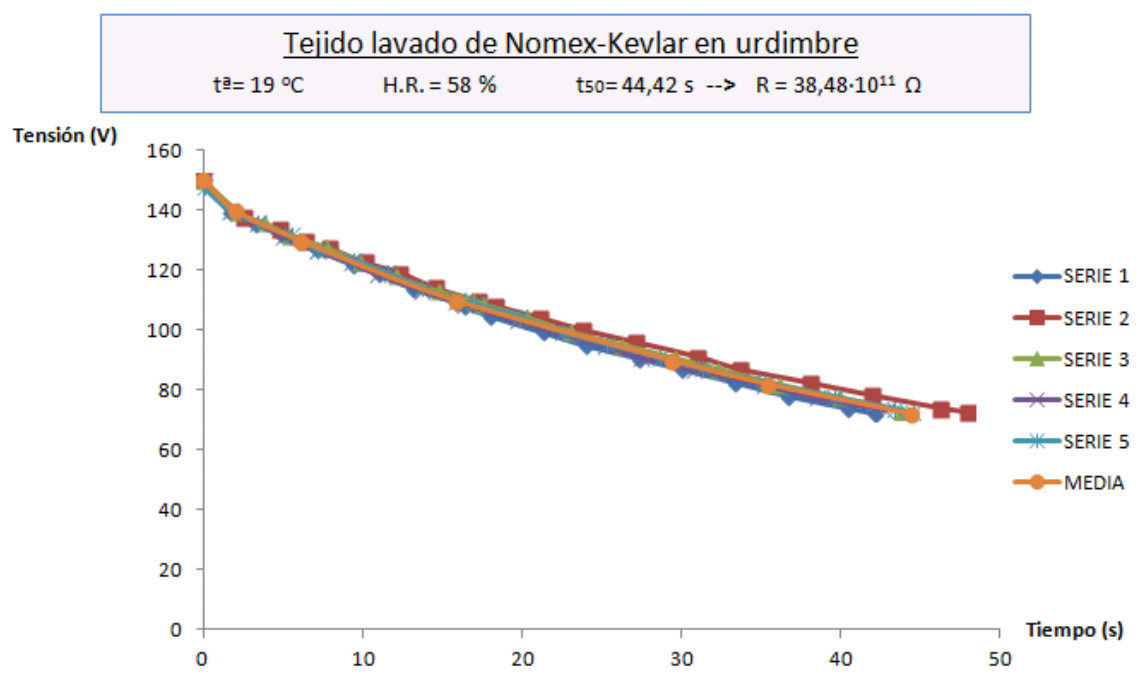

Figura Anexo 4. 81. Resultados finales del tejido de Nomex-Kevlar-fibra antiestática lavado, por urdimbre, a una temperatura de $19^{\circ} \mathrm{C}$ y a $58 \%$ de H.R
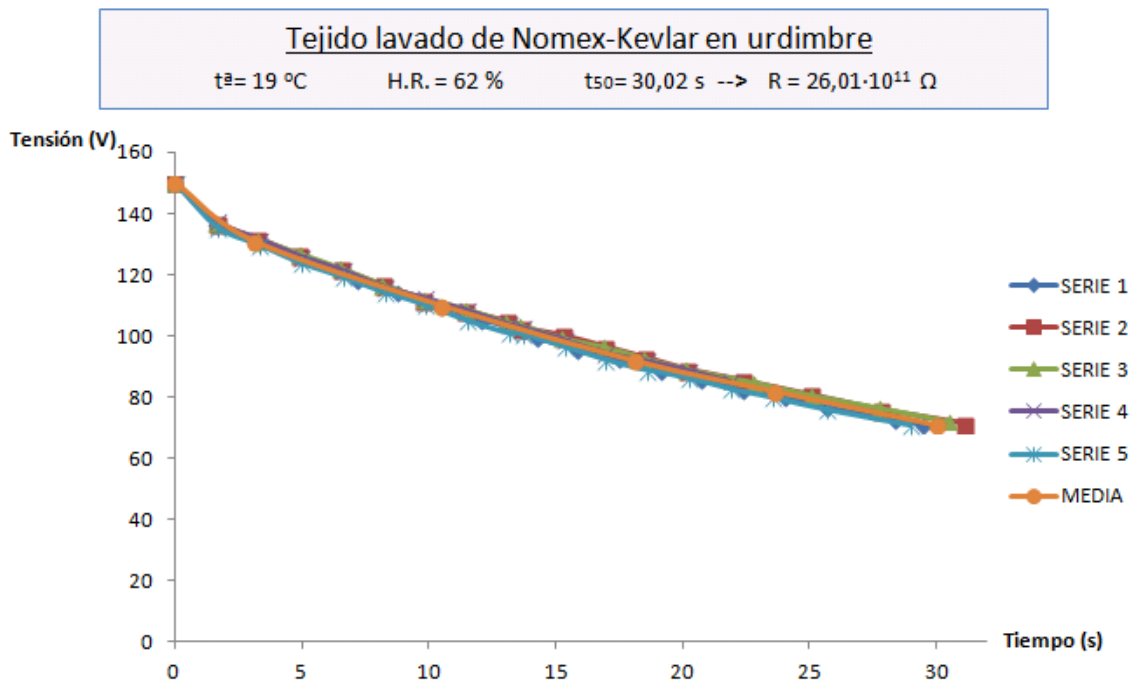

Figura Anexo 4. 82. Resultados finales del tejido de Nomex-Kevlar-fibra antiestática lavado, por urdimbre, a una temperatura de $19{ }^{\circ} \mathrm{C}$ y a $62 \%$ de H.R 


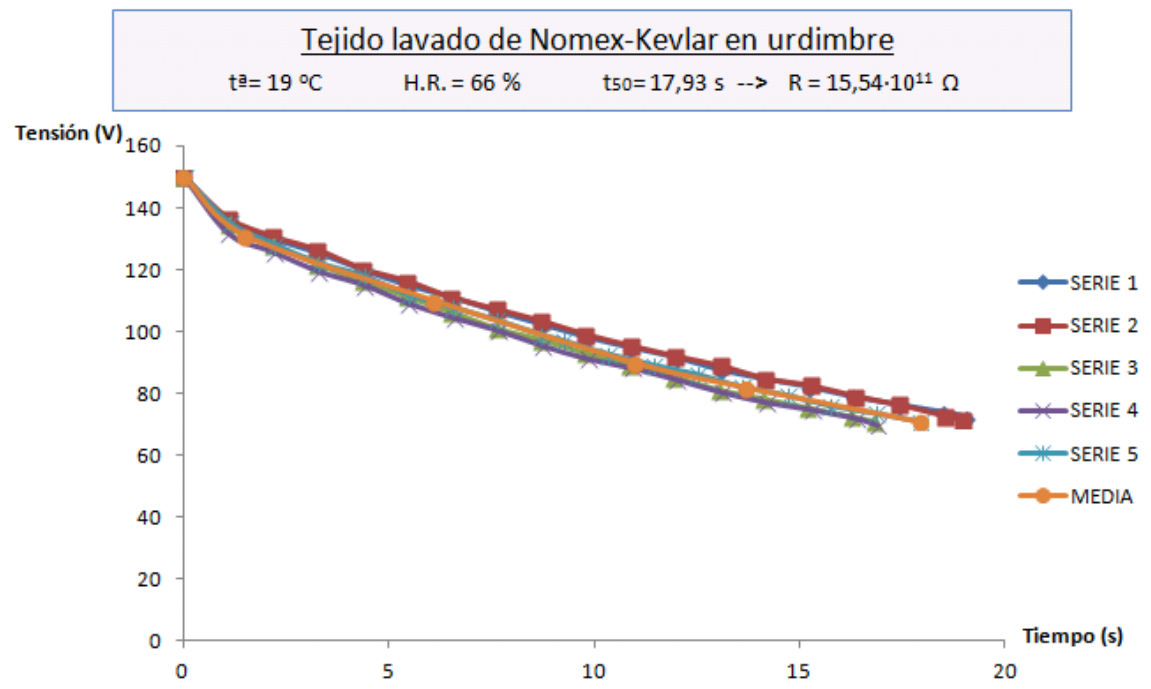

Figura Anexo 4. 83. Resultados finales del tejido de Nomex-Kevlar-fibra antiestática lavado, por urdimbre, a una temperatura de $19{ }^{\circ} \mathrm{C}$ y a $66 \%$ de H.R

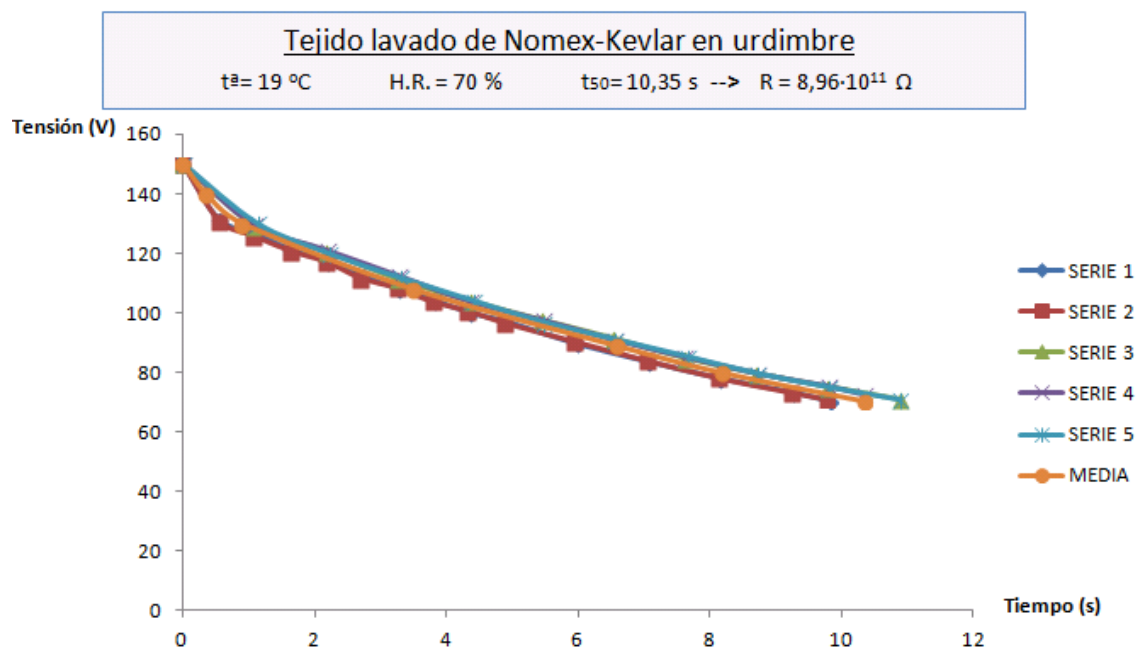

Figura Anexo 4. 84. Resultados finales del tejido de Nomex-Kevlar-fibra antiestática lavado, por urdimbre, a una temperatura de $19^{\circ} \mathrm{C}$ y a $70 \%$ de H.R 


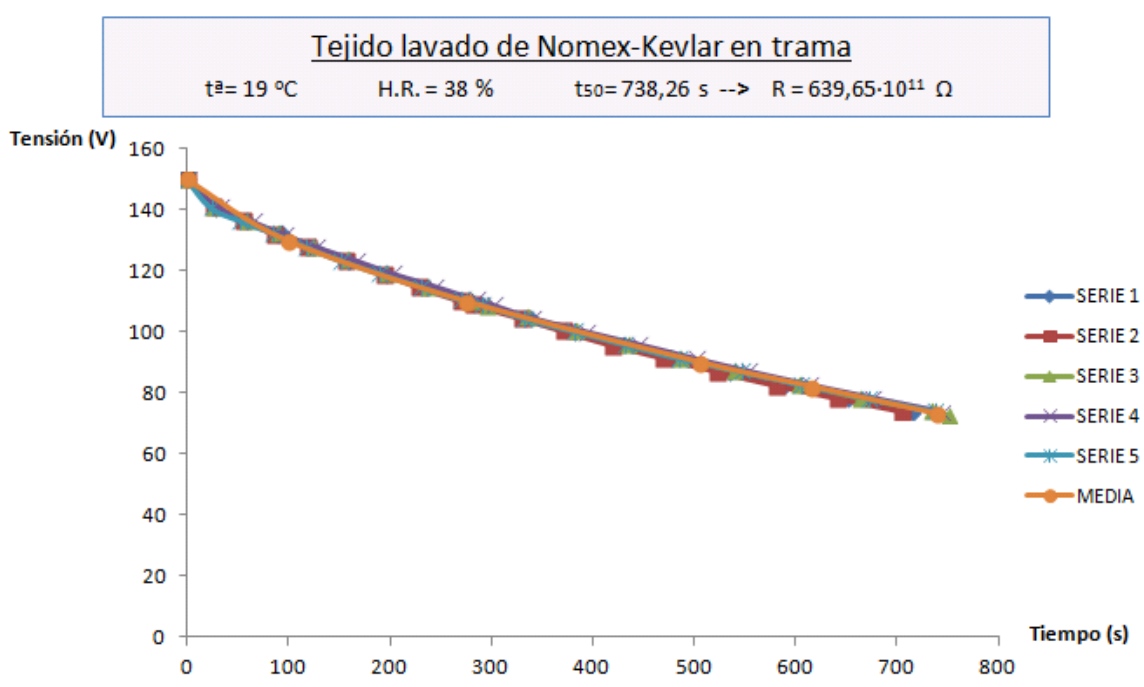

Figura Anexo 4. 85. Resultados finales del tejido de Nomex-Kevlar-fibra antiestática lavado, por trama, a una temperatura de $19{ }^{\circ} \mathrm{C}$ y a $38 \%$ de H.R

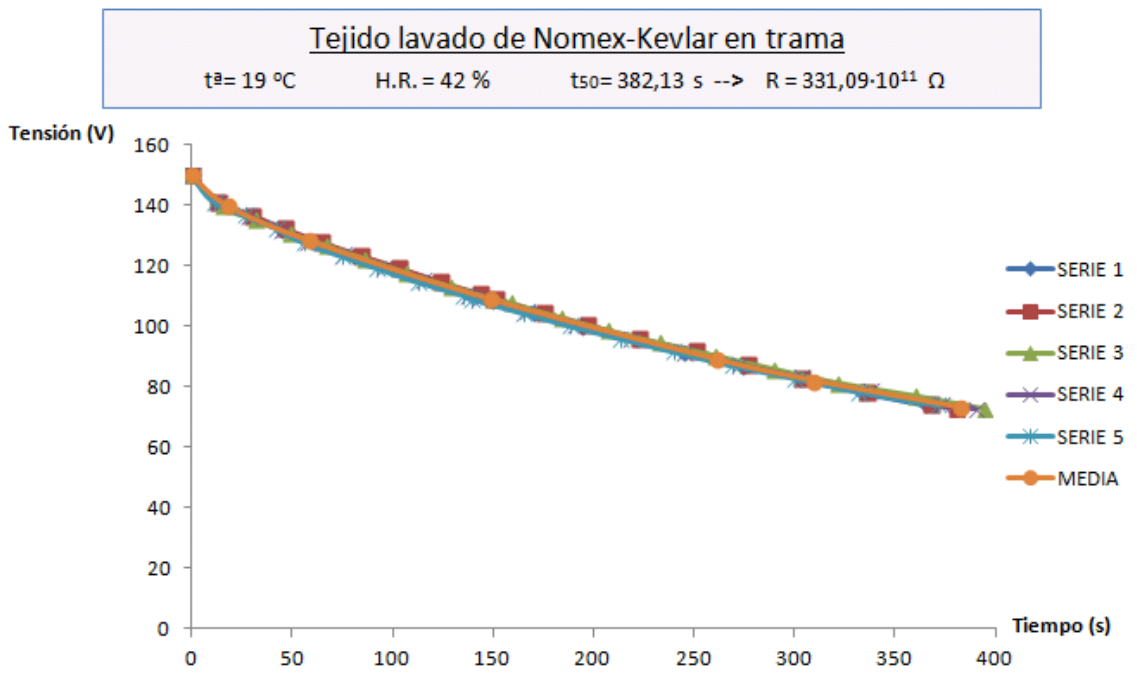

Figura Anexo 4. 86. Resultados finales del tejido de Nomex-Kevlar-fibra antiestática lavado, por trama, a una temperatura de $19{ }^{\circ} \mathrm{C}$ y a $42 \%$ de H.R. 


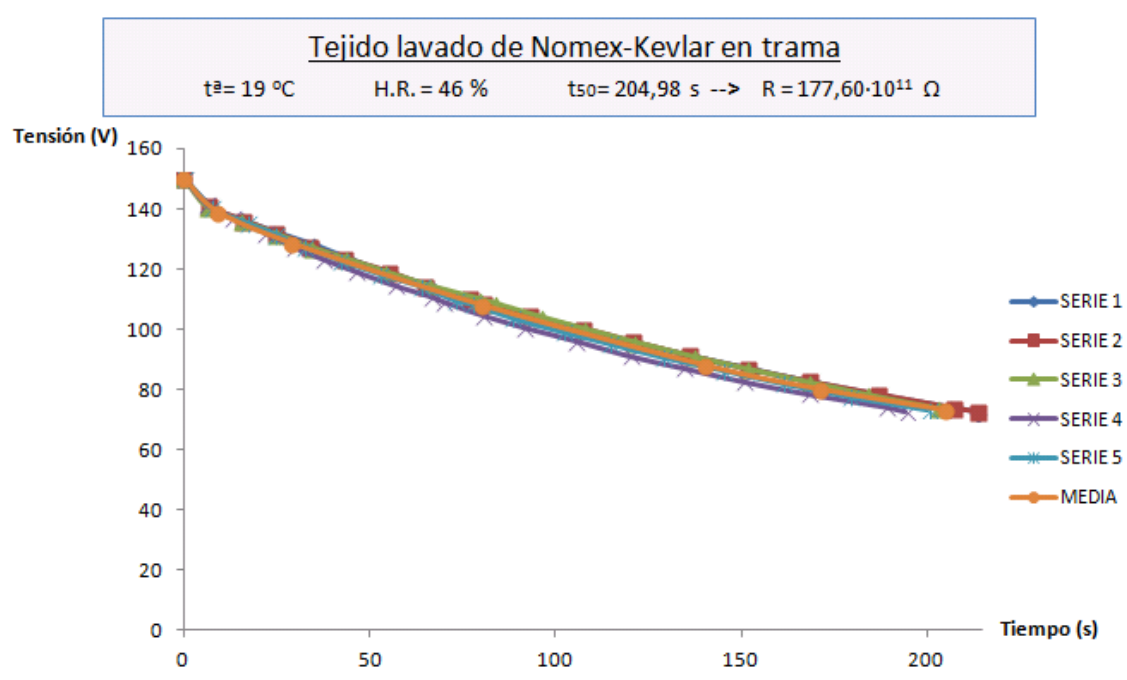

Figura Anexo 4. 87. Resultados finales del tejido de Nomex-Kevlar-fibra antiestática lavado, por trama, a una temperatura de $19{ }^{\circ} \mathrm{C}$ y a $46 \%$ de H.R

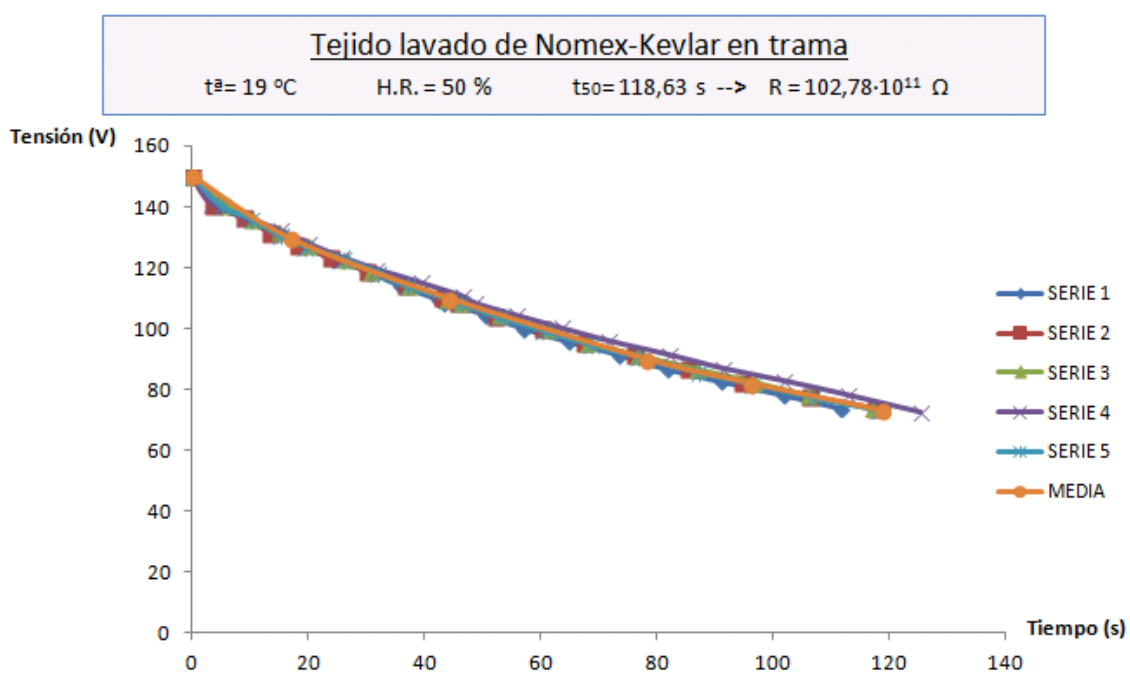

Figura Anexo 4. 88. Resultados finales del tejido de Nomex-Kevlar-fibra antiestática lavado, por trama, a una temperatura de $19^{\circ} \mathrm{C}$ y a $50 \%$ de H.R 


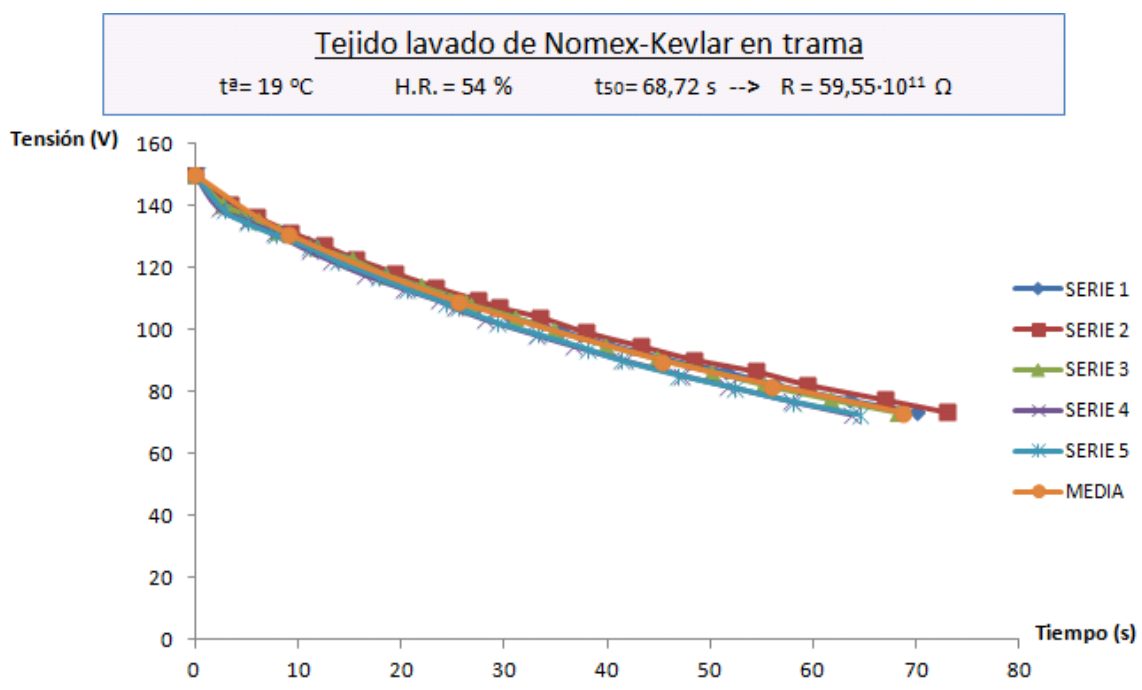

Figura Anexo 4. 89. Resultados finales del tejido de Nomex-Kevlar-fibra antiestática lavado, por trama, a una temperatura de $19^{\circ} \mathrm{C}$ y a $54 \%$ de H.R

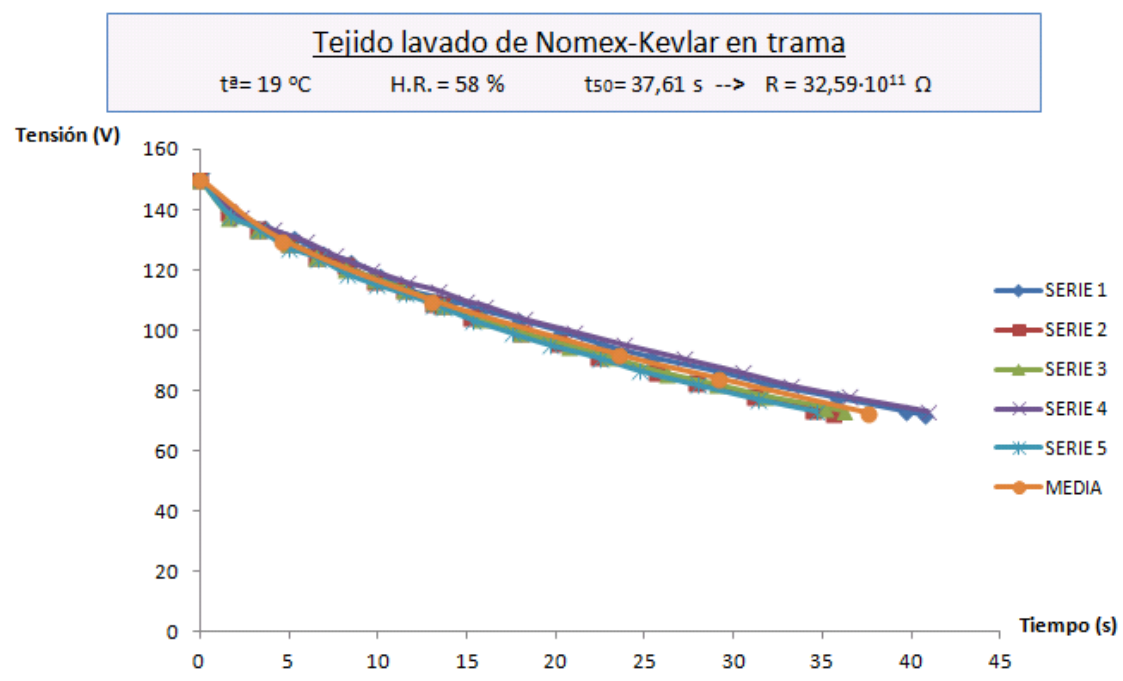

Figura Anexo 4. 90. Resultados finales del tejido de Nomex-Kevlar-fibra antiestática lavado, por trama, a una temperatura de $19^{\circ} \mathrm{C}$ y a $58 \%$ de H.R 


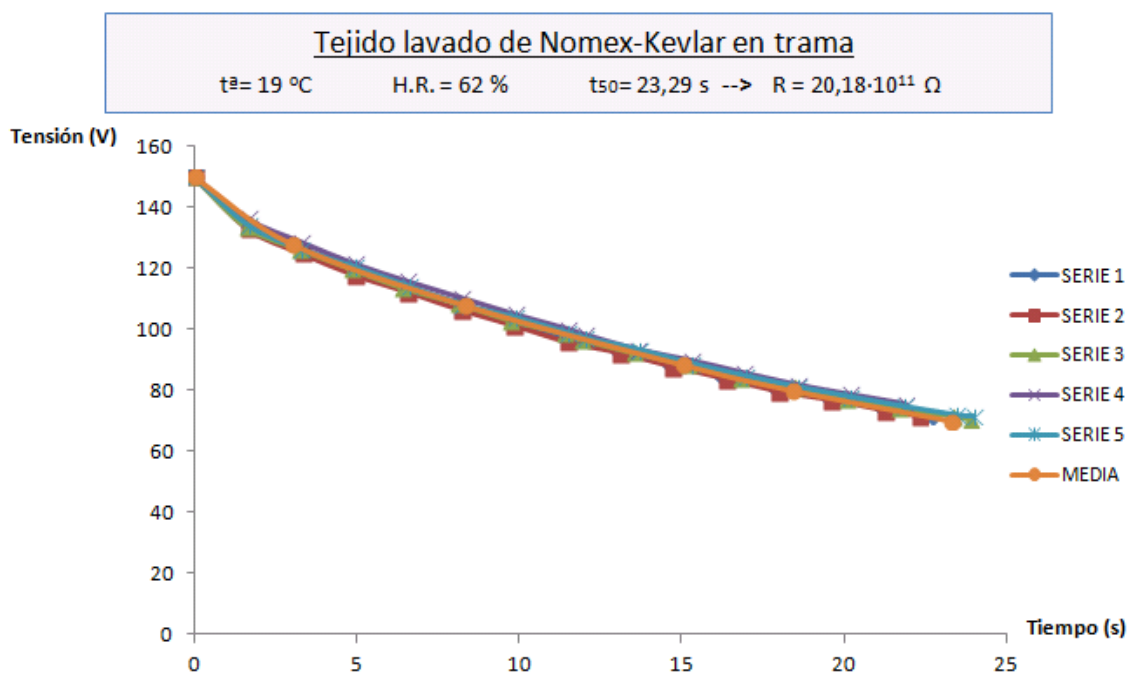

Figura Anexo 4. 91. Resultados finales del tejido de Nomex-Kevlar-fibra antiestática lavado, por trama, a una temperatura de $19^{\circ} \mathrm{C}$ y a $62 \%$ de H.R

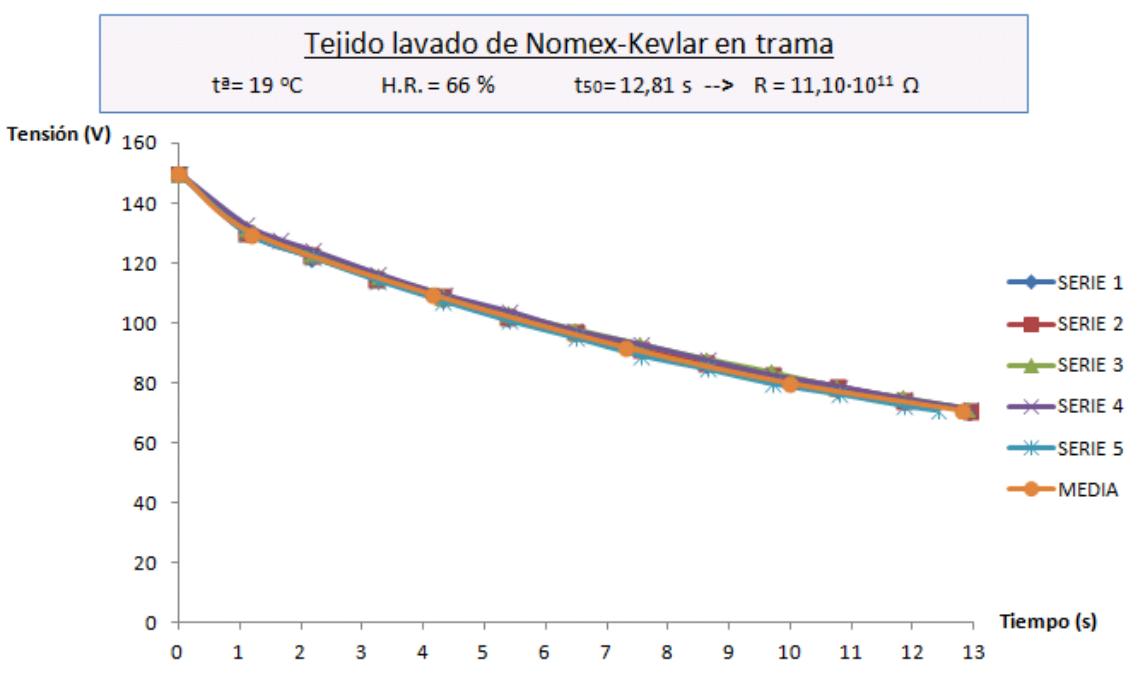

Figura Anexo 4. 92. Resultados finales del tejido de Nomex-Kevlar-fibra antiestática lavado, por trama, a una temperatura de $19{ }^{\circ} \mathrm{C}$ y a $66 \%$ de H.R 


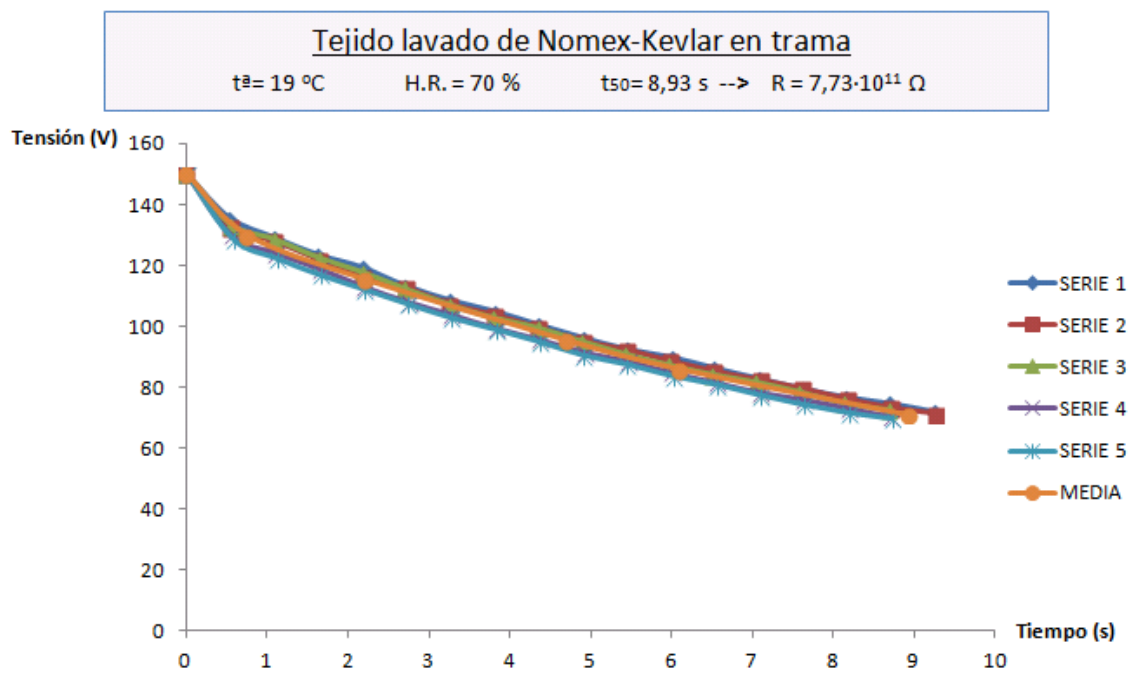

Figura Anexo 4. 93. Resultados finales del tejido de Nomex-Kevlar-fibra antiestática lavado, por trama, a una temperatura de $19^{\circ} \mathrm{C}$ y a $70 \%$ de H.R 


\section{GLOSARIO}




\section{GLOSARIO}

Debido a que el trabajo es multidisciplinar, se dedica este capítulo a definir algunos términos usados en esta memoria que pueden ser desconocidos para lectores de otro ámbito.

$\checkmark$ Aislante/Dieléctrico: Todo material que posea un número muy pequeño de cargas libres.

$\checkmark$ Conductividad eléctrica: Indica la facilidad que da un material al paso de carga eléctrica por él.

$\checkmark \quad$ Frecuencia de muestreo: Número de veces que se obtienen datos cada unidad de tiempo, habitualmente cada segundo. La frecuencia de muestreo se llama también velocidad de muestreo.

$\checkmark$ Ligamento: Disposición o regla que siguen los hilos de urdimbre al entrecruzarse con los de trama para formar un tejido de calada. Generalmente esta disposición se repite con regularidad a lo largo y a lo ancho del tejido.

$\checkmark$ Sarga: Es una clase de ligamento simple que hace el efecto de una diagonal.

$\checkmark$ Resistividad eléctrica: Oposición que ofrece un material al paso de carga eléctrica.

$\checkmark$ Raso: Es una clase de ligamento simple cuyos puntos de escalonado hacen saltos distintos a la unidad.

$\checkmark$ Tafetán: Es una clase de ligamento simple también llamado "a la plana", que caracteriza un tejido liso con ese ligamento.

Tejido de calada o convencional: Son el resultado del entrecruzamiento de una serie longitudinal de hilos paralelos entre sí (urdimbre), con otros 
hilos transversales (trama), según una disposición previamente establecida (ligamento).

$\checkmark$ Tela no tejida: También denominados fieltros o "no tejidos" a secas (nonwoven fabrics), están formados por fibras enmarañadas entre sí formando una especie de velo o manta, a la que se le da consistencia por distintos procedimientos, uno de los más corrientes es el punzonado, si bien hay otros muchos.

$\checkmark$ Tex: Unidad del sistema directo de numeración que indica el peso en gramos de mil metros de hilo o filamento. Un submúltiplo muy utilizado, especialmente en fibras muy finas, es el decitex, que sería el peso en gramos de $10000 \mathrm{~m}$ de hilo o filamento.

$\checkmark \quad$ Título o Número: Expresa la relación entre el peso y la longitud de un hilo o filamento (sistema directo de numeración), o bien al revés, la relación entre la longitud y el peso (sistema inverso).

$\checkmark$ Trama: Serie de hilos colocados transversalmente que forman parte de un tejido de calada. Estos hilos suelen denominarse "pasadas".

$\checkmark$ Urdimbre: Serie de hilos colocados longitudinalmente que forman parte de un tejido de calada. Se denominan simplemente "hilos".

$\checkmark$ Velocidad de muestreo: Número de veces que se obtienen datos cada unidad de tiempo, habitualmente cada segundo. La velocidad de muestreo se llama también frecuencia de muestreo. 


\section{NOMENCLATURA}




\section{NOMENCLATURA}
A: Anchura de la muestra de ensayo (cm).
C: Capacidad de un cuerpo (F).
D: Densidad de urdimbre-trama (hilos/cm - pasadas/cm).

d: Distancia entre las cargas (m).

E: Campo eléctrico (V/m).

E: Espesor de la muestra de ensayo $(\mathrm{cm})$.

F: Fuerza de atracción/repulsión entre las cargas (N).

$\mathrm{k}$ : Constante de Coulomb $\left(\mathrm{Nm}^{2} / \mathrm{C}^{2}\right)$.

H.R.: Humedad relativa en términos porcentuales (\%).

$\mathrm{i}(\mathrm{t})$ : Intensidad de corriente (A).

j: Densidad de corriente $\left(\mathrm{A} / \mathrm{m}^{2}\right)$.

Kd: Coeficiente de densidad de urdimbre-trama (tex).

$\mathrm{Kd}_{\max }$ (urd-tr): Coeficiente de densidad máximo urdimbre-trama (Adimensional).

K 1(urd)- K 1(tr): Coeficiente de ligadura de urdimbre y de trama(Adimensional).

1: Longitud del material (m).

$\mathrm{N}$ : Título del hilo (dtex).

n: Concentración de partículas (partículas $/ \mathrm{m}^{3}$ ).

P: Peso (g).

Q: Cantidad de carga de un cuerpo (C). 
$\mathrm{Q}_{\text {materia: }}$ Coeficiente del material para la determinación del $\mathrm{Kd}_{\max }$ (Adimensional).

q: Valor de una carga puntual (C).

R: Resistencia del material $(\Omega)$.

$\mathrm{R}^{2}$ : Coeficiente de determinación (Adimensional).

$\mathrm{R}_{\mathrm{B}}$ : Resistencia de base $(\Omega)$.

$\mathrm{R}_{\mathrm{C}}$ : Resistencia de colector $(\Omega)$.

$\mathrm{R}_{\mathrm{E}}$ : Resistencia de emisor $(\Omega)$.

r: Contenido de agua de un material $(\mathrm{kg})$.

$\mathrm{r}_{\mathrm{s}}$ : Contenido de agua de un material en condiciones de saturación $(\mathrm{kg})$.

r: Coeficiente de correlación (Adimensional).

S: Superficie de la sección del material $\left(\mathrm{m}^{2}\right)$.

T: Temperatura $(\mathrm{K})$.

$\mathrm{t}_{50}$ : Tiempo de semidescarga (s).

$\mathrm{V}$ : Diferencia de potencial entre dos puntos de un cuerpo $(\mathrm{V})$.

$\mathrm{V}_{\mathrm{BB}}$ : Tensión de la salida de la tarjeta NI USB6008 (V).

$\mathrm{V}_{\mathrm{CC}}$ : Tensión de polarización del circuito $(\mathrm{V})$.

$\mathrm{V}_{\mathrm{CE}}$ : Tensión entre colector/emisor $(\mathrm{V})$.

$\mathrm{V}_{\mathrm{BE}}$ : Tensión entre base/emisor $(\mathrm{V})$.

v: Velocidad de arrastre $(\mathrm{m} / \mathrm{s})$.

W: Energía almacenada/desprendida en un cuerpo (J). 


\section{GRIEGAS}

$\alpha$ : Coeficiente de temperatura de la resistividad del material $\left({ }^{\circ} \mathrm{C}^{-1}\right)$.

$\mu$ : Movilidad de la partícula $\left(\mathrm{m}^{2} / \mathrm{sV}\right)$.

$\rho$ : Resistividad del material a una temperatura $\mathrm{t}(\Omega \mathrm{m})$.

$\rho_{0}$ : Resistividad del material a la temperatura de $0^{\circ} \mathrm{C}(\Omega \mathrm{m})$.

$\sigma:$ Conductividad del material (S/m).

$\phi$ : Diámetro del hilo $(\mu \mathrm{m})$.

$\gamma$ : Peso específico de la fibra. 


\section{RELACIÓN DE FIGURAS}




\section{RELACIÓN DE FIGURAS}

Figura 1. 1. Generador electrostático.

Figura 1. 2. Distintas formas de formación de las cargas por triboelectricidad.

Figura 1. 3. Generación de cargas electrostáticas por inducción.

Figura 1. 4. Tejido "Smart textil".

Figura 1. 5. Descarga electrostática.

Figura 1. 6. Imagen de William Gilbert.

Figura 1. 7. Esquema de funcionamiento del electroscopio.

Figura 1. 8. Generador de electricidad electroestática.

Figura 1. 9. Botellas de Leyden.

Figura 1. 10. Imagen de Michael Faraday.

Figura 1. 11. Aplicación de circuito conductor textil.

Figura 1. 12. Tiempos de descarga de varios materiales textiles a $30^{\circ} \mathrm{C}$ de temperatura y $15 \%$ de humedad relativa.

Figura 1. 13. Proceso de obtención de las fibras químicas.

Figura 1. 14. Fibras con recubrimiento de ión Ag+ (ProTex Ag®).

Figura 1. 16. Representación de un ligamento.

Figura 1. 17. Tela no tejida punzonada.

Figura 1. 18. Generación de cargas electrostáticas en una máquina plegadora.

Figura 1. 19. Generación de cargas electrostáticas en una máquina plegadora en un mismo artículo textil con acabados diferentes. Para cada color, la columna oscura indica la carga generada, mientras que la clara a su lado, la que queda después de disiparse una parte.

Figura 1. 20. Clasificación de los materiales textiles en función de su resistividad, en $\Omega \cdot \mathrm{cm}$.

Figura 2. 1. Representación de carga que pasa a través de una superficie $\mathrm{S}$.

Figura 2. 2. Cilindro de generatriz igual a la velocidad de arrastre $\mathbf{v}$.

Figura 2. 3. a) Medio lineal b) Medio no lineal.

Figura 2. 4. Hilo conductor de sección dependiente de x.

Figura 2. 5. Ohmímetros.

Figura 2. 6. Circuito eléctrico del procedimiento voltiamperimétrico.

Figura 2.7. Circuito eléctrico del procedimiento de la desviación directa.

Figura 2.8. Circuito eléctrico del procedimiento por comparación de corriente.

Figura 2.9. Teraohmímetro.

Figura 2.10. Circuito eléctrico del procedimiento por descarga del condensador. 
Figura 3. 1. Símbolo de identificación de tejido antiestático.

Figura 3. 2. Circuito del procedimiento por descarga de condensador.

Figura 3. 3. Circuito equivalente en fase de carga del condensador.

Figura 3. 4. Constitución del electrodo para la medición de la resistencia vertical.

Figura 3. 5. Variación de la tensión en el condensador en fase de carga.

Figura 3. 6. Variación de la tensión en el condensador en fase de descarga.

Figura 3. 7. Metodología: diagrama de flujo.

Figura 3. 8. Representación de la nube de puntos.

Figura 3. 9. Representación de la regresión lineal simple.

Figura 3. 10. Muestras de fibras de algodón y lana al microscopio, así como del tejido mixto de nómex, kevlar y fibra antiestática utilizado en las pruebas.

Figura 3. 11. Ejemplo de representación gráfica del ligamento.

Figura 3. 12. Micrómetro de la casa Baxlo, modelo 40407.

Figura 3. 13. Instrumentos de medida: metro calibrado y báscula.

Figura 3. 14. Troquel o corta-probetas textil.

Figura 3. 15. Cuenta hilos.

Figura 3. 16. Voltímetro estático R-4021 (Rothschild).

Figura 3. 17. Voltímetro de control de la tensión en la muestra.

Figura 3. 18. Osciloscopio.

Figura 3. 19. Conexionado del portaprobetas en la cámara climática.

Figura 3. 20. Estufa de acondicionamiento de tejidos en su estado inicial, antes de adaptarla.

Figura 3. 21. Cámara climática ya reformada y adaptada.

Figura 3. 22. Humidificador ultrasónico utilizado.

Figura 3. 23. Sensor LCN-FTW04.

Figura 3. 24. Tarjeta de adquisición de datos NI USB6008.

Figura 3. 25. Esquema electrónico de control de los actuadores.

Figura 3. 26. Circuito electrónico utilizado.

Figura 3. 27. Sistema de instrumentación virtual.

Figura 3. 28. Panel frontal con controles (A) e indicadores (B)..

Figura 3. 29. Controles de entrada.

Figura 3. 30. Indicadores de salida.

Figura 3. 31. Ejemplo de diagrama de bloques.

Figura 3. 32. Paletas de control, de herramientas y de funciones.

Figura 3. 33. Programa de captura de datos del equipo experimental.

Figura 3. 34. Pantalla principal del programa realizado para la captura de datos en los ensayos.

Figura 3. 35. Pantalla principal del programa JAVA.

Figura 3. 36. Pantalla de datos de una de las series del programa Excel.

Figura 3. 37. Pantalla de resultados en la hoja resumen del programa Excel. 
Figura 3. 38. Esquema eléctrico del equipo experimental.

Figura 3. 39. Interior del voltímetro estático R-4021 Rothschild.

Figura 3. 40. Equipo completo para la realización de los ensayos.

Figura 3. 41. Pantalla principal del programa LabVIEW.

Figura 3. 42. Pantalla del programa Excel que muestra los resultados obtenidos de una de las pruebas realizadas.

Figura 3. 43. Pantalla del programa Excel que muestra la hoja resumen de los resultados obtenidos de un ensayo.

Figura 4.1. Gráfica resumen de los resultados finales del tejido de algodón sin lavar, por urdimbre, a una temperatura de $19^{\circ} \mathrm{C}$ y diferentes H.R.

Figura 4.2. Ajuste gráfico de la resistividad en función de la H.R. del tejido de algodón sin lavar, por urdimbre, a una temperatura de $19^{\circ} \mathrm{C}$.

Figura 4.3. Fotografía del Linitest del laboratorio Textil..

Figura 4.4. Gráfica resumen de los resultados finales del tejido lavado de algodón, por urdimbre, a una temperatura de $19^{\circ} \mathrm{C}$ y diferentes H.R.

Figura 4.5. Ajuste gráfico de la resistividad en función de la H.R. del tejido de algodón lavado, por urdimbre, a una temperatura de $19^{\circ} \mathrm{C}$ y diferentes H.R.

Figura 4.6. Ajuste gráfico de la resistividad eléctrica en función de la H.R. del tejido de algodón lavado y sin lavar, por urdimbre, a una temperatura de 19 ${ }^{\circ} \mathrm{C}$.

Figura 4.7. Recta del ajuste lineal del tejido de algodón lavado y sin lavar, por urdimbre, a una temperatura de $19^{\circ} \mathrm{C}$ y diferentes H.R.

Figura 4.8. Gráfica resumen de los resultados finales del tejido de algodón lavado, por urdimbre, a una temperatura de $23^{\circ} \mathrm{C}$ y diferentes H.R.

Figura 4. 9. Ajuste gráfico de la resistividad en función de la H.R. del tejido de algodón lavado, por urdimbre, a una temperatura de $23{ }^{\circ} \mathrm{C}$ y diferentes H.R.

Figura 4. 10. Gráfica resumen de los resultados finales del tejido lavado de algodón, por urdimbre, a una temperatura de $27^{\circ} \mathrm{C}$ y diferentes H.R.

Figura 4.11. Ajuste gráfico de la resistividad eléctrica en función de la H.R. del tejido de algodón lavado, por urdimbre, a una temperatura de $27^{\circ} \mathrm{C}$.

Figura 4.12. Ajuste gráfico de la resistividad del tejido de algodón lavado, por urdimbre, para las temperaturas $19^{\circ} \mathrm{C}, 23^{\circ} \mathrm{C}$ y $27{ }^{\circ} \mathrm{C}$ y diferentes H.R.

Figura 4.13. Recta del ajuste lineal del tejido de algodón lavado en urdimbre para unas temperaturas de $19^{\circ} \mathrm{C}, 23^{\circ} \mathrm{C}$ y $27^{\circ} \mathrm{C}$ y diferentes H.R.

Figura 4.14. Gráfica resumen de los resultados finales del tejido de algodón lavado, por trama, a una temperatura de $19{ }^{\circ} \mathrm{C}$ y diferentes H.R. 
Figura 4.15. Ajuste gráfico de la resistividad en función de la H.R. del tejido de algodón lavado, por trama, a una temperatura de $19{ }^{\circ} \mathrm{C}$ y diferentes H.R.

Figura 4.16. Evolución de la resistividad en función de la humedad relativa del tejido de algodón lavado, por udimbre y trama, a una temperatura de $19^{\circ} \mathrm{C}$.

Figura 4.17. Recta de ajuste lineal del tejido de algodón lavado, por urdimbre y trama, a una temperatura de $19^{\circ} \mathrm{C}$ y diferentes H.R.

Figura 4.18. Gráfica resumen de los resultados finales del tejido de lana lavado en urdimbre a una temperatura de $19^{\circ} \mathrm{C}$ y diferentes H.R.

Figura 4.19. Evolución de la resistividad en función de la H.R. del tejido de lana lavado, por urdimbre, a $19^{\circ} \mathrm{C}$ y diferentes H.R.

Figura 4.20. Gráfica resumen de los resultados finales del tejido de lana lavado, por trama, a una temperatura de $19{ }^{\circ} \mathrm{C}$ y diferentes H.R.

Figura 4.21. Ajuste gráfico de la resistividad en función de la H.R. del tejido de lana lavado en urdimbre a una temperatura de $19^{\circ} \mathrm{C}$.

Figura 4.22. Ajuste gráfico de la resistividad en función de la H.R. del tejido de lana lavado, por urdimbre, a una temperatura de $19^{\circ} \mathrm{C}$.

Figura 4.23. Recta de ajuste lineal del tejido de lana lavado, por urdimbre y trama, a una temperatura de $19^{\circ} \mathrm{C}$ y diferentes H.R.

Figura 4.24. Gráfica resumen de los resultados finales del tejido lavado de NomexKevlar-fibra antiestática, por urdimbre, a una temperatura de $19^{\circ} \mathrm{C}$ y diferentes H.R.

Figura 4.25. Ajuste gráfico de la resistividad en función de la H.R. tejido lavado de Nomex-Kevlar-fibra antiestática, por urdimbre, a una temperatura de $19^{\circ} \mathrm{C}$ y diferentes H.R.

Figura 4.26. Gráfica de los resultados finales del tejido lavado de Nomex-Kevlarfibra antiestática, por trama, a una temperatura de $19^{\circ} \mathrm{C}$ y diferentes H.R.

Figura 4.27. Ajuste gráfico de la resistividad en función de la H.R. del tejido compuesto lavado en trama a una temperatura de $19^{\circ} \mathrm{C}$..

Figura 4.28. Evolución de la resistividad eléctrica en función de la humedad relativa del tejido compuesto en urdimbre y en trama a una temperatura de 19 ${ }^{\circ} \mathrm{C}$.

Figura 4.29. Recta del ajuste lineal del tejido compuesto en trama y en urdimbre a una temperatura de $19^{\circ} \mathrm{C}$ en función de la H.R.

Figura 4.30. Evolución de la resistividad eléctrica de los tejidos de algodón, lana y Nomex-Kevlar-fibra antiestática, por urdimbre, a $19^{\circ} \mathrm{C}$.

Figura 4.31. Evolución de la resistividad eléctrica de los tejidos de los tejidos estudiados, por urdimbre y trama, a una temperatura de $19^{\circ} \mathrm{C}$. 


\section{RELACIÓN DE TABLAS}




\section{RELACIÓN DE TABLAS}

Tabla 1. 1. Series triboeléctricas de acuerdo con la bibliografía.

Tabla 1. 2. Tabla de valores de $\rho$ y $\alpha$ de algunos materiales conductores.

Tabla 1. 3. Porcentaje de absorción de humedad de algunas fibras en relación a su peso seco.

Tabla 1. 4. Comparación de los valores de absorción de humedad de diferentes materiales textiles.

Tabla 4. 1. Resultados y desviación típica del tiempo de semidescarga del tejido de algodón sin lavar, por urdimbre, a una temperatura de $19^{\circ} \mathrm{C}$ y diferentes H.R.

Tabla 4.2. Resultados de los parámetros eléctricos del tejido de algodón sin lavar, por urdimbre, a una temperatura de $19^{\circ} \mathrm{C}$ y diferentes H.R.

Tabla 4. 3. Resultados y desviación típica del tejido lavado de algodón, por urdimbre, a una temperatura de $19^{\circ} \mathrm{C}$ y diferentes H.R.

Tabla 4. 4. Resultados de los parámetros eléctricos del tejido lavado de algodón, por urdimbre, a una temperatura de $19^{\circ} \mathrm{C}$ y diferentes H.R.

Tabla 4. 5. Influencia del lavado en la resistividad del tejido de algodón, por urdimbre, a una temperatura de $19^{\circ} \mathrm{C}$ y diferentes H.R.

Tabla 4. 6. Coeficientes del ajuste lineal y coeficiente de determinación del tejido de algodón lavado y sin lavar, por urdimbre, a una temperatura de $19{ }^{\circ} \mathrm{C}$ y diferentes H.R.

Tabla 4. 7. Resultados y desviación típica del tejido de algodón lavado, por urdimbre, a una temperatura de $23^{\circ} \mathrm{C}$ y diferentes H.R.

Tabla 4. 8. Resultados de los parámetros eléctricos del tejido de algodón lavado, por urdimbre, a una temperatura de $23{ }^{\circ} \mathrm{C}$ y diferentes H.R.

Tabla 4. 9. Resultados y desviación típica del tejido lavado de algodón, por urdimbre, a una temperatura de $27^{\circ} \mathrm{C}$ y diferentes H.R.

Tabla 4. 10. Resultados de los parámetros eléctricos del tejido lavado de algodón en urdimbre a una temperatura de $27^{\circ} \mathrm{C}$ y diferentes H.R.

Tabla 4. 11. Resistividad del tejido lavado de algodón, por urdimbre, a cada temperatura y humedad relativa estudiada.

Tabla 4. 12. Coeficientes del ajuste lineal y coeficientes de determinación del tejido de algodón lavado, por urdimbre, a las temperaturas $19^{\circ} \mathrm{C}, 23^{\circ} \mathrm{C}$ y $27^{\circ} \mathrm{C}$ y diferentes H.R.

Tabla 4. 13. Principales características del tejido algodón.

Tabla 4. 14. Resultados y desviación típica de los tiempos de semidescarga del tejido lavado de algodón, por trama, a una temperatura de $19^{\circ} \mathrm{C}$ y diferentes H.R. 
Tabla 4. 15. Resultados de los parámetros eléctricos del tejido de algodón lavado, por trama, a una temperatura de $19^{\circ} \mathrm{C}$ y diferentes H.R.

Tabla 4. 16. Coeficientes del ajuste lineal y coeficientes de determinación del tejido de algodón lavado por urdimbre y trama, a una temperatura de $19^{\circ} \mathrm{C}$ y diferentes H.R.

Tabla 4. 17. Principales características del tejido lana.

Tabla 4. 18. Resultados y desviación típica de los tiempos de semidescarga para el tejido de lana lavado, por urdimbre, a una temperatura de $19^{\circ} \mathrm{C}$ y diferentes H.R.

Tabla 4. 19. Resultados de los parámetros eléctricos del tejido lavado de lana en urdimbre a una temperatura de $19^{\circ} \mathrm{C}$ y diferentes H.R.

Tabla 4. 20. Resultados y desviación típica de los tiempos de semidescarga para el tejido lavado de lana por trama, a una temperatura de $19^{\circ} \mathrm{C}$ y diferentes H.R.

Tabla 4. 21. Resultados de los parámetros eléctricos del tejido lavado de lana en trama a una temperatura de $19^{\circ} \mathrm{C}$ y diferentes H.R.

Tabla 4. 22. Coeficientes del ajuste lineal y coeficientes de determinación del tejido de lana lavado, por trama y urdimbre, a una temperatura de $19^{\circ} \mathrm{C}$ y diferentes H.R.

Tabla 4. 23. Características estructurales del tejido Nomex-Kevlar-fibra antiestática

Tabla 4. 24. Resultados y desviación típica del tejido lavado Nomex-Kevlar-fibra antiestática, por urdimbre, a una temperatura de $19^{\circ} \mathrm{C}$ y diferentes H.R.

Tabla 4. 25. Resultados de los parámetros eléctricos del tejido lavado de Nomex-Kevlarfibra antiestática, por urdimbre, a una temperatura de $19^{\circ} \mathrm{C}$ y diferentes H.R.

Tabla 4. 26. Resultados y desviación típica del tejido lavado de Nomex-Kevlar-fibra antiestática, por trama, a una temperatura de $19^{\circ} \mathrm{C}$ y diferentes H.R.

Tabla 4. 27. Valores de los parámetros eléctricos del tejido lavado de Nomex-Kevlar-fibra antiestática, por trama, a una temperatura de $19^{\circ} \mathrm{C}$ y diferentes H.R.

Tabla 4. 28. Comparativa de la resistividad en urdimbre y trama del tejido compuesto a $19^{\circ} \mathrm{C}$ y diferentes H.R.

Tabla 4. 29. Coeficientes del ajuste lineal y coeficiente de determinación del tejido compuesto a una temperatura de $19^{\circ} \mathrm{C}$.

Tabla 4. 30. Coeficientes del ajuste lineal y coeficiente de determinación de los tejidos estudiados, por urdimbre y trama, a una temperatura de $19^{\circ} \mathrm{C}$. 
